\title{
CLIENTS' PERCEPTIONS OF SALES FORCE EXPERT POWER
}

\author{
STEFAN FRICKE
}

A thesis submitted to The University of Gloucestershire in accordance with the requirements of the degree of Doctor of Business Administration in the School of Business and Technology

August 2019

Word Count: 61.965 


\section{Abstract}

Expert power is based on the awareness that a person in a power relationship possesses valuable knowledge, information, or skills (Raven, 1992, 2008). It builds customer trust, long-term relationships, customer satisfaction, loyalty, and exit barriers. The buyer's preferences for a product or solution are shaped by sales force expert power (Doney \& Cannon, 1997; Clauss \& Bouncken, 2018). With these preferences, the buyer participates in the decision-making process, where the mechanisms of organisational buying find application. However, what remains unclear is which attributes a buying centre specifically associates with sales force expert power, when and how the perception of sales force expert power alters in the buying process, also which factors are responsible for it are issues that have not yet been discussed in the context of group decision-making in buying centres, and finally to what extent does sales force expert power influences the decision frame of each member of the buying centre. To address these gaps, the aim of the study is to create an approach by which sales forces can consciously manage and enhance the clients' perceptions of sales force expert power.

For this purpose, Alpha Software customers from various industries were interviewed immediately after their purchase decision regarding the perception of sales force expert power and what influence this perception had on the buying centre's decision.

The findings of the study indicate an overload of sales force expert power can lead to mistrust and uncertainty. The perception of sales force expert power is important in all stages of the buying process. In early stages product knowledge is perceived more strongly while the perception of change knowledge in final stages predominates. Information exchange and recommendations lose their impact due to an unprofessional approach to change which minimises the perception of expert power significantly. Due to the intensity of change and how the change is perceived the perception of sales force expert power alters. Business customers, unlike consumers, expect a professional approach to change rather than benevolence. The interviewed clients perceive the software conversion project as a change project and expect the sales force to be approached and addressed accordingly. Change knowledge is cited as an important attribute for sales force expert power, which can advance the clients'perceptions of sales force expert power. 


\section{Author's Declaration}

I declare that the work in this thesis was carried out in accordance with the regulations of the University of Gloucestershire and is original except where indicated by specific reference in the text. No part of the thesis has been submitted as part of any other academic award. The thesis has not been presented to any other education institution in the United Kingdom or overseas.

Any views expressed in the thesis are those of the author and in no way represent those of the University.

Signed

Date 20/08/2019

doi: 10.46289/BUSM1597 
Table of Contents

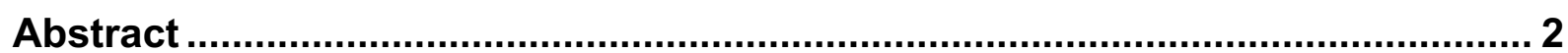

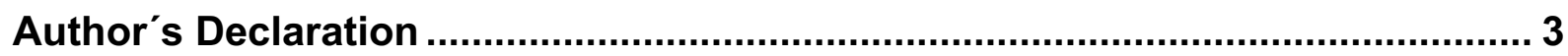

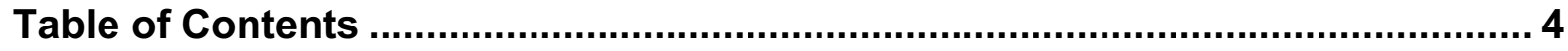

Abbreviations

List of Figures

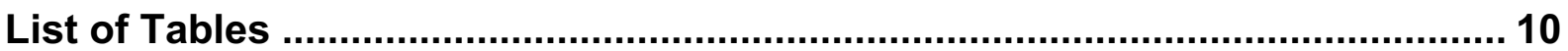

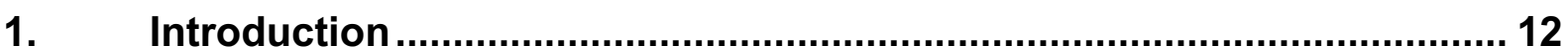

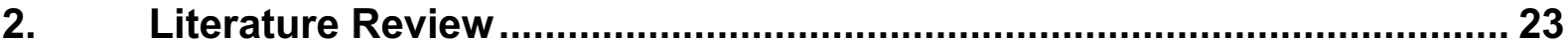

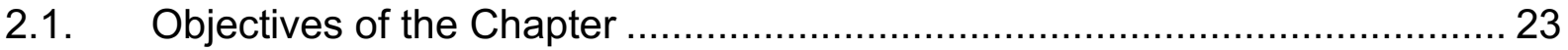

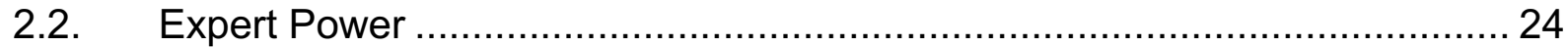

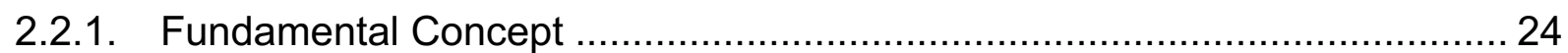

2.2.2. Expert Power in Organisational Buying and Personal Selling ..................... 34

2.3. Organisational Buying and Personal Selling......................................... 47

2.3.1. Business-to-Business Market ............................................................ 47

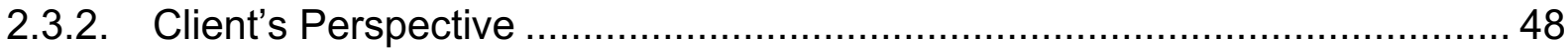

2.3.2.1. Organisational Buying Behaviour ........................................................ 48

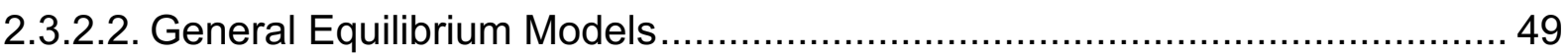

2.3.2.3. Partial Equilibrium Models ................................................................... 52

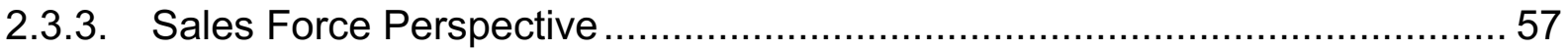

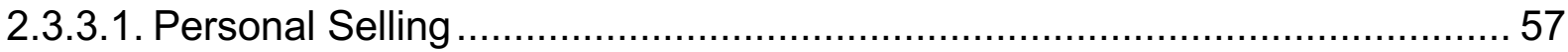

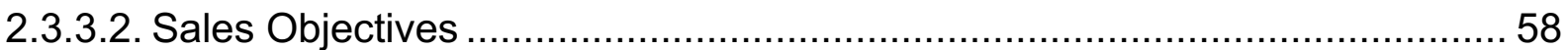

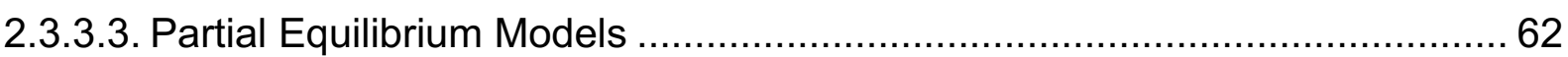

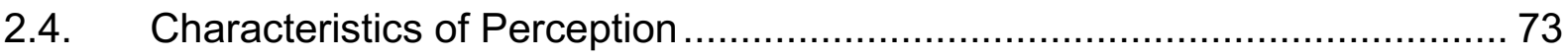

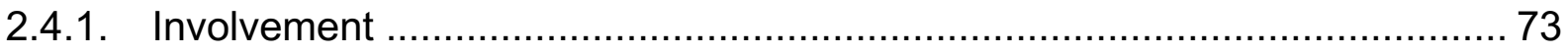

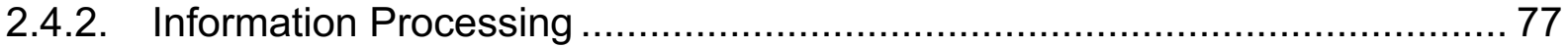

2.4.3. Expert Power and the Decision Frame .................................................. 80

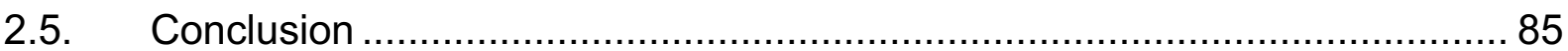

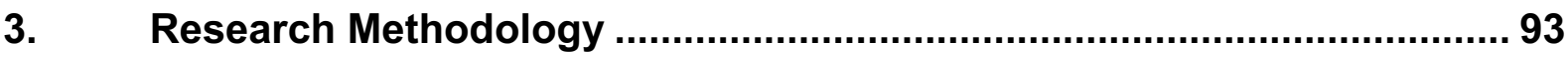

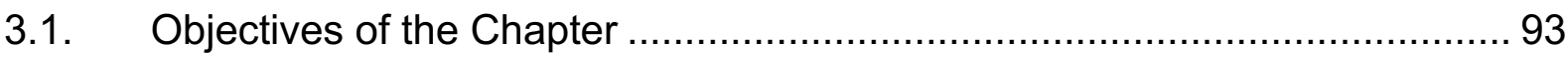

3.2. Review and Selection of Research Philosophy ......................................... 93

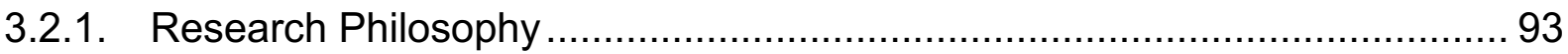

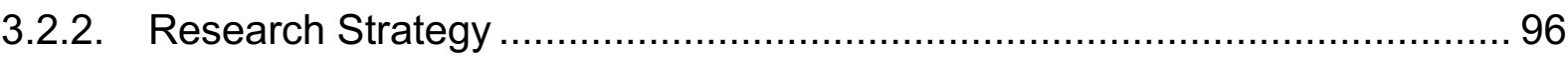




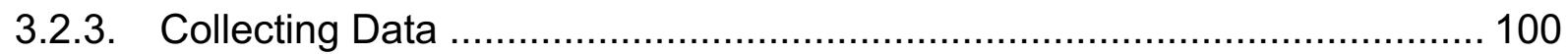

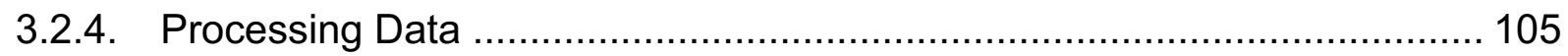

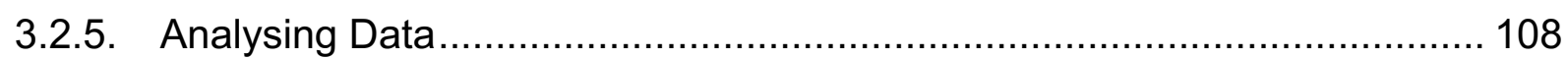

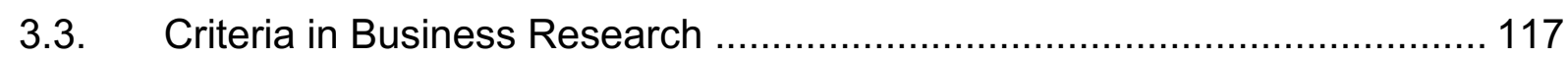

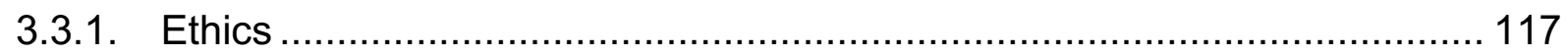

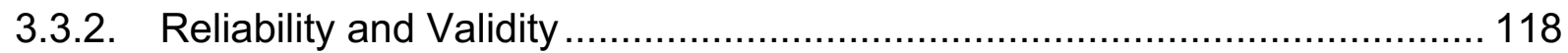

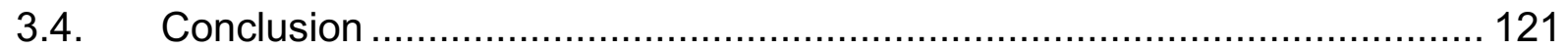

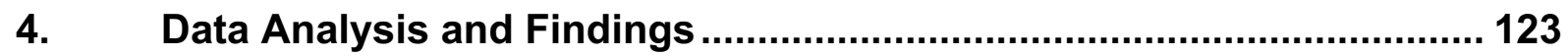

4.1. Objectives of the Chapter ................................................................. 123

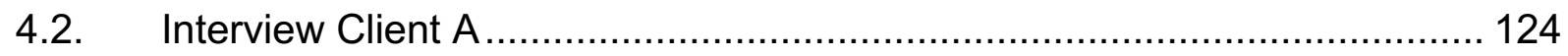

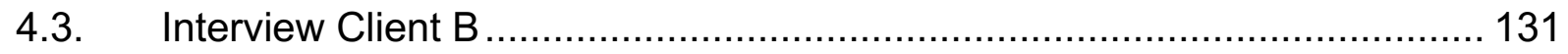

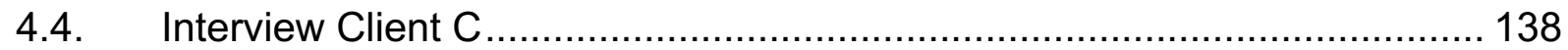

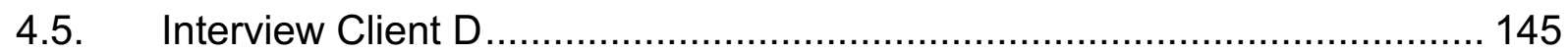

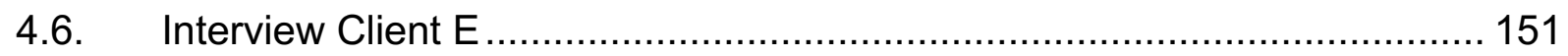

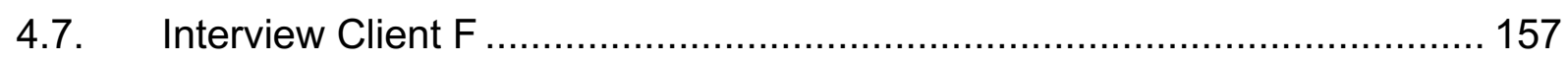

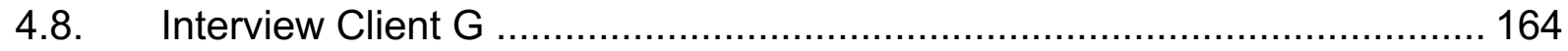

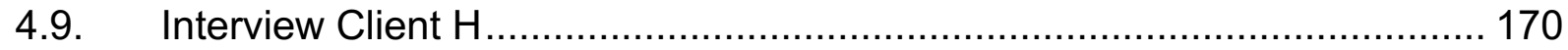

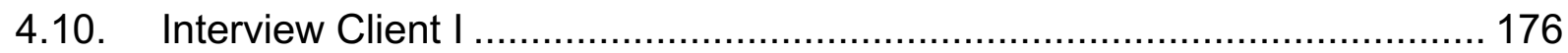

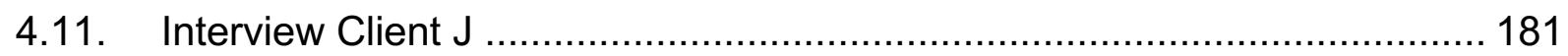

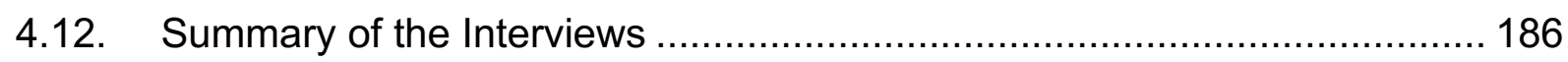

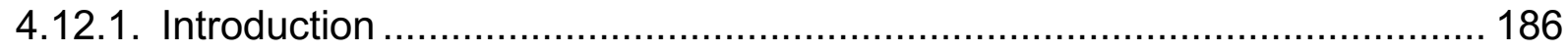

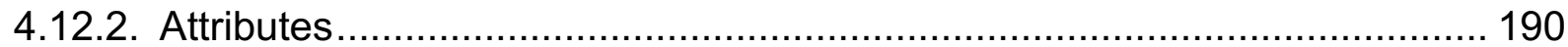

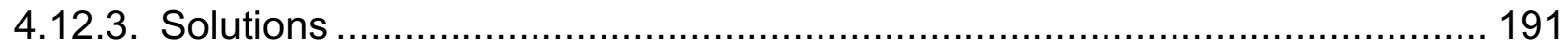

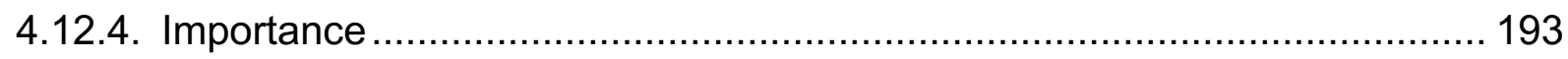

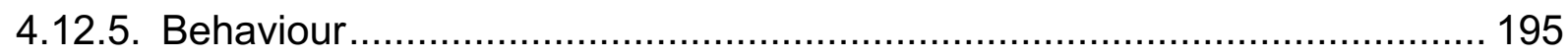

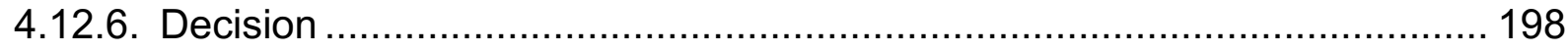

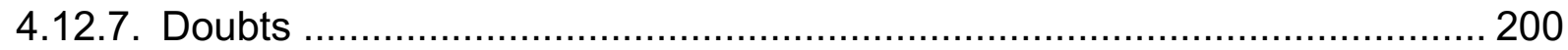

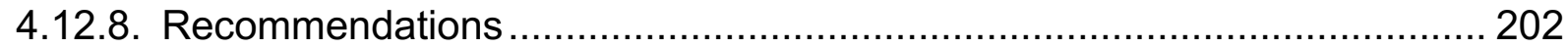

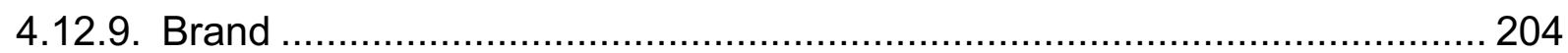

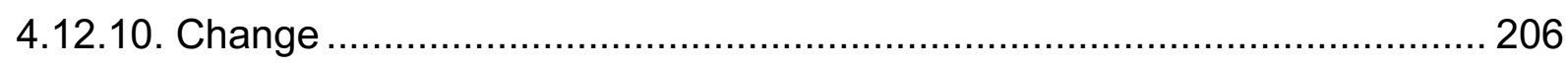

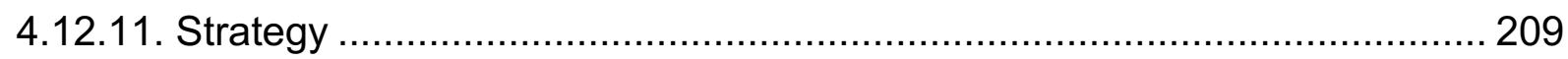

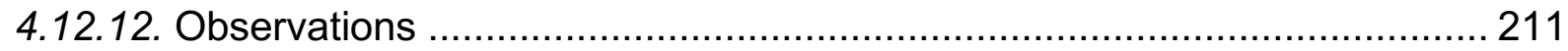

5. Conclusions and Implications ........................................................... 213 


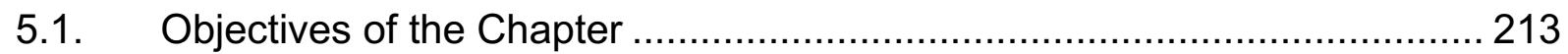

5.2. Conclusions of Research Questions ................................................ 215

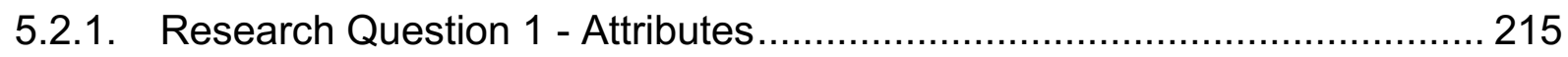

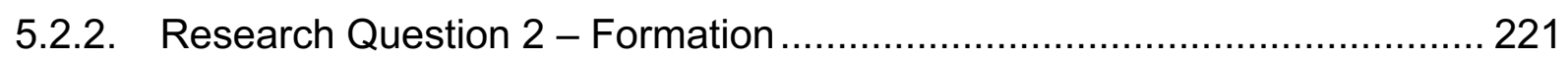

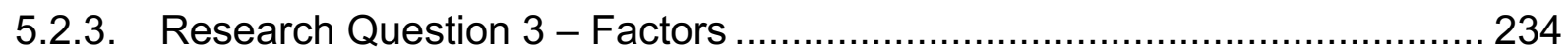

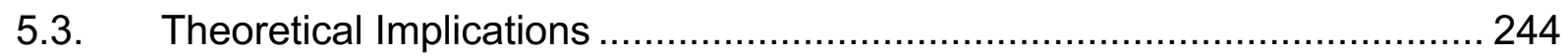

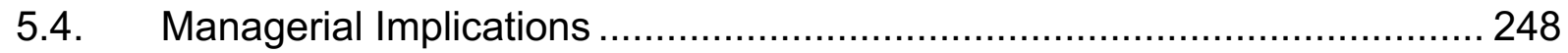

5.5. Limitations and Future Research Directions ............................................ 255

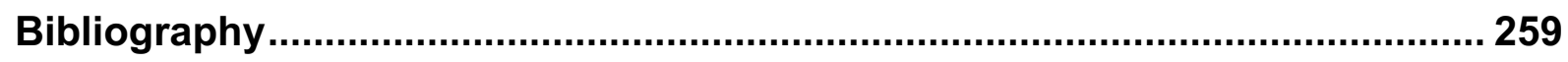

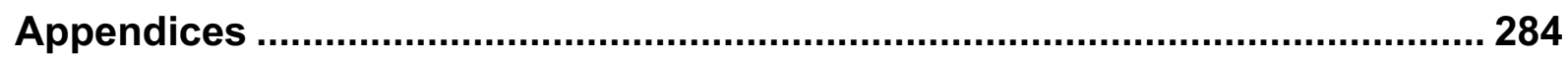

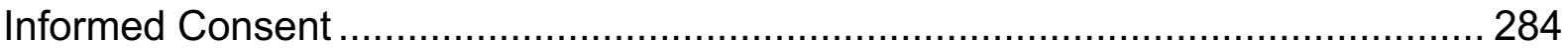

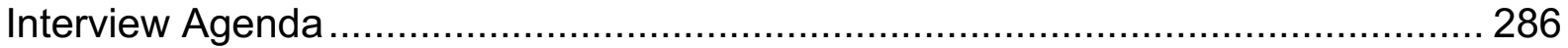

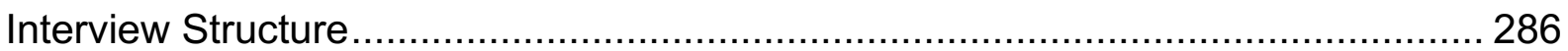

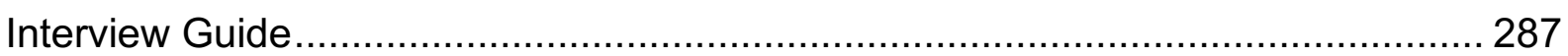

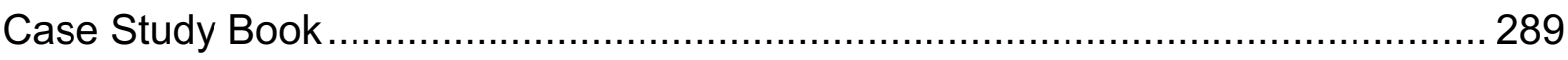


B2B market

CRM

FSD

HR

ICT

IT

RI

$\mathrm{RQ}$

URD
Business-to-business market

Customer relation mangement

Functional specification document

Human resources

Information communication technology

Information technology

Research issue

Research question

User requirement specification 


\section{List of Figures}

Figure 1: Conceptual framework of the research project................................... 16

Figure 2: Golden thread of research project ............................................... 22

Figure 3: Literature review approach .................................................. 23

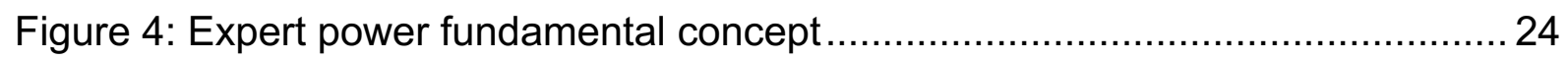

Figure 5: Interaction in business-to-business market ...................................... 47

Figure 6: Models of organisational buying behaviour ....................................... 49

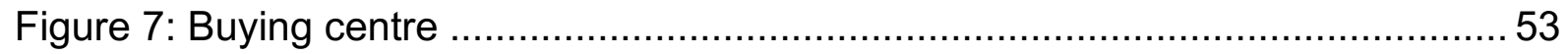

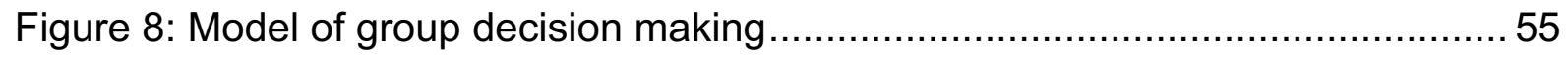

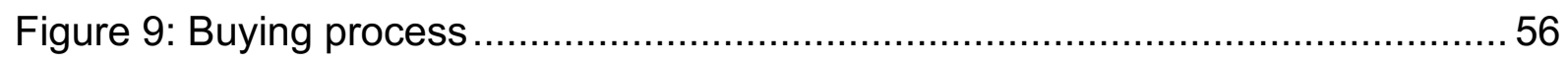

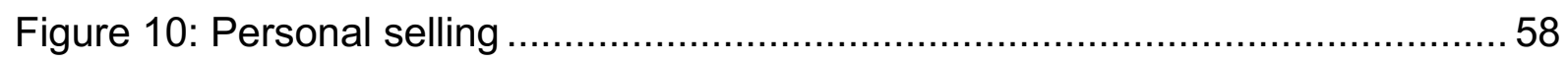

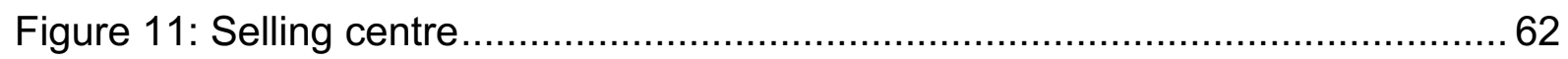

Figure 12: Interaction between buying group and selling centre .......................... 63

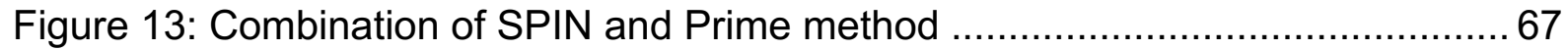

Figure 14: Influence of SPIN/Prime on the buying decision process.....................68

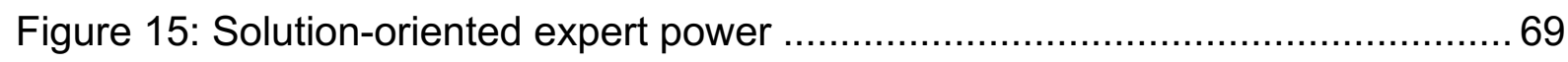

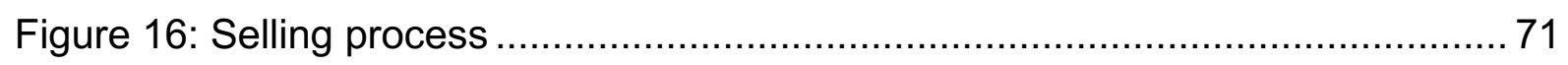

Figure 17: Synchronisation of selling and buying process ............................... 72

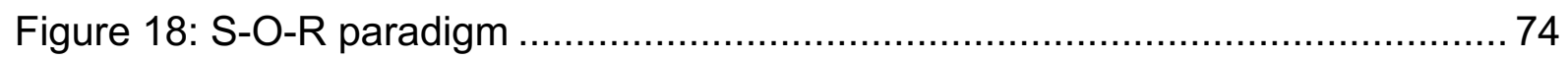

Figure 19: Systematics of the interaction approaches..................................... 75

Figure 20: Determinants of consumer behaviour ............................................. 76

Figure 21: The role of perception in consumer buying behaviour ..........................78

Figure 22: Role of the S-O-R paradigm in a group decision process ....................... 81

Figure 23: Effect of expert power as stimuli on the reference points to build a decision

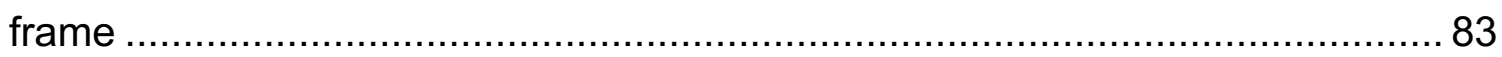

Figure 24: Attributes of sales force expert power ......................................... 86

Figure 25: Formation of expert power in the synchronised buying and selling process

Figure 26: Factors and formation of expert power perception in buying group decisions

Figure 27: Factors affecting the formation of expert power in the interaction between

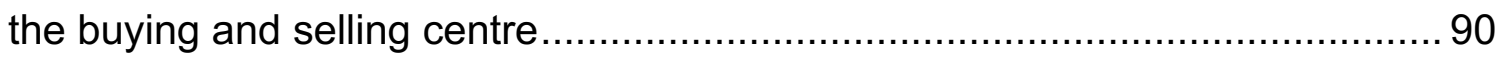

Figure 28: Conceptual framework of the research project................................ 92 
Figure 29: Analytic steps to analysing qualitative data used in this research project

Figure 30: Development of the coding frame ............................................... 113

Figure 31: Coding comparison query .................................................... 120

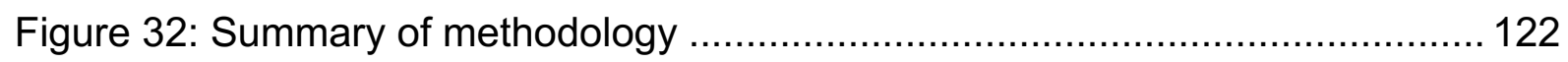

Figure 33: Attributes of sales force expert power ......................................... 191

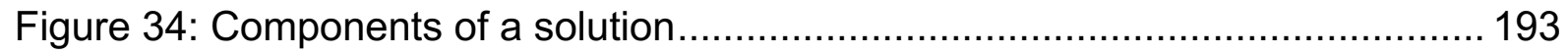

Figure 35: Change of importance in the course of the buying process .................. 195

Figure 36: Behaviour of the sales force to impart expert power and what expert power induces.

Figure 37: Simplified representation of decision-making process ....................... 199

Figure 38: Reasons for doubts ............................................................. 202

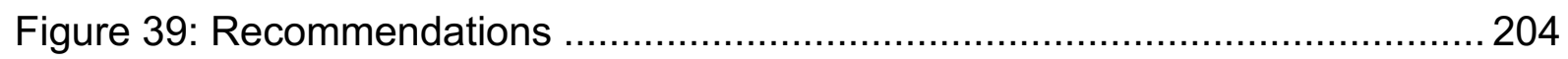

Figure 40: Components of brand awareness ................................................ 206

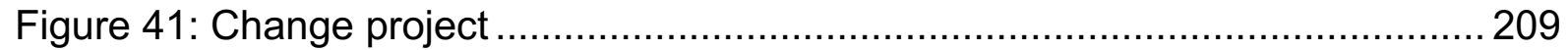

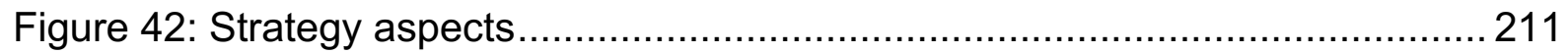

Figure 43: Conclusions and contributions to knowledge ................................. 215

Figure 44: Definition of change knowledge - Attribute (RQ1) ............................ 220

Figure 45: Expert power can lead to mustrust and uncertainty .......................... 223

Figure 46: Distribution based on the importance of expert power in a first buy....... 226

Figure 47: Predomination of change knowledge in final stages - Formation (RQ2)233

Figure 48: The intensity of change and how the change is perceived - Factors (RQ3)

Figure 49: Summary of contribution to knowledge - Advance in existing knowledge

Figure 50: Levers on the perception of sales force expert power........................ 249

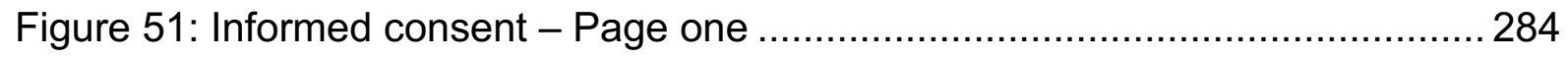

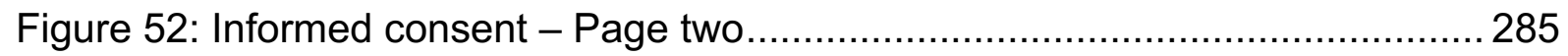

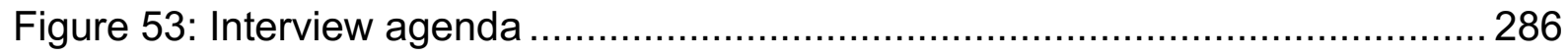

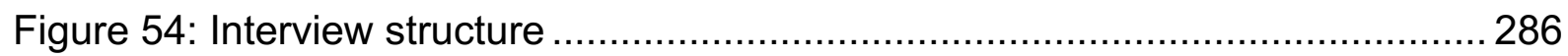




\section{List of Tables}

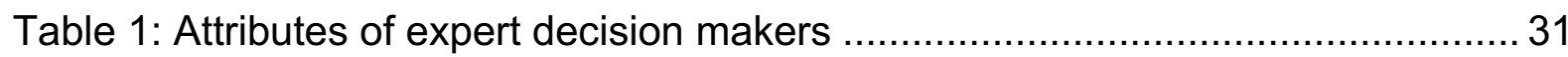

Table 2: Influential factors for the perception of expert decision makers ................. 32

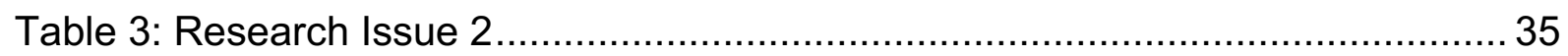

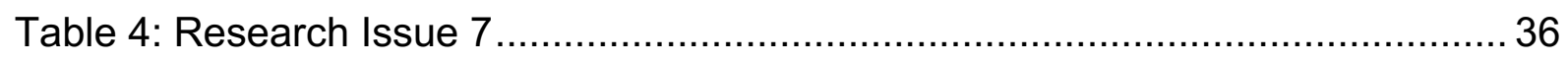

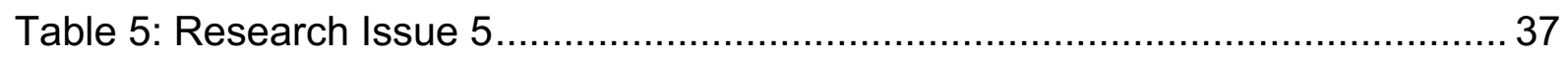

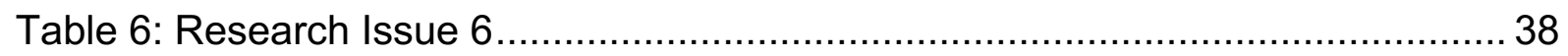

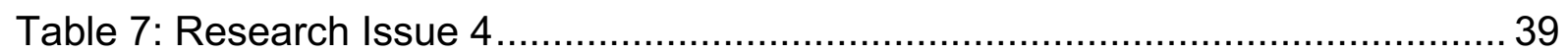

Table 8: Research Issue 8

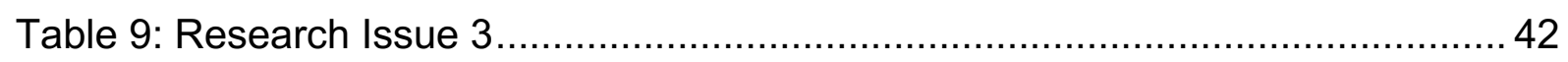

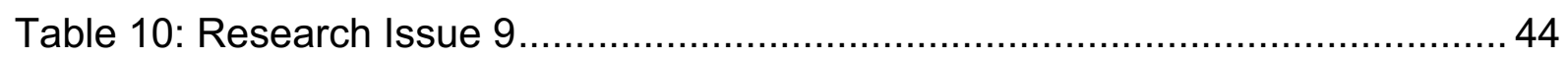

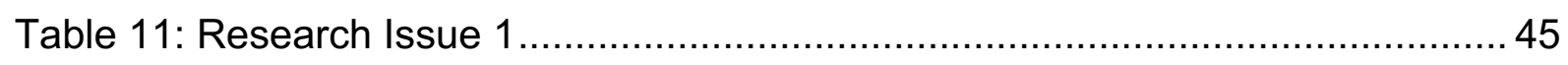

Table 12: Summary of previous research in the area of expert power .................... 46

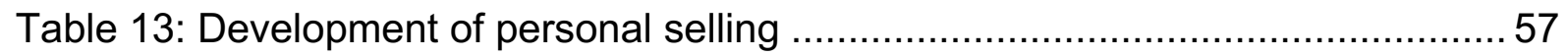

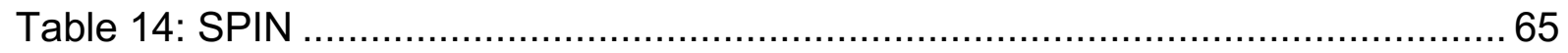

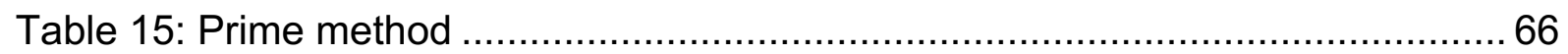

Table 16: Research Question 1 with research issue ........................................... 86

Table 17: Research Question 2 with research issues ............................................ 89

Table 18: Research Question 3 with research issues .......................................... 91

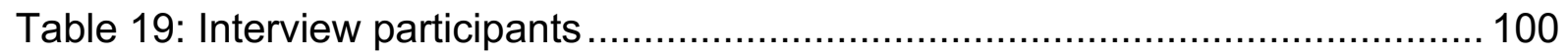

Table 20: Classic sequence of steps to analysing qualitative data ....................... 109

Table 21: Determination of the strength of the link ............................................ 116

Table 22: Categories of coding frame …………............................................. 123

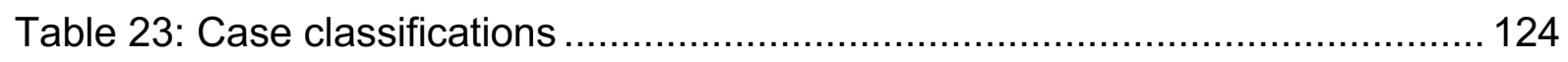

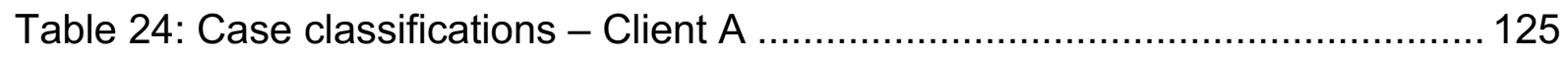

Table 25: Essentials of interview with Client A ................................................ 131

Table 26: Case classifications - Client B ....................................................... 132

Table 27: Essentials of interview with Client $B$................................................... 138

Table 28: Case classifications - Client C …………...................................... 139

Table 29: Essentials of interview with Client C ................................................. 145

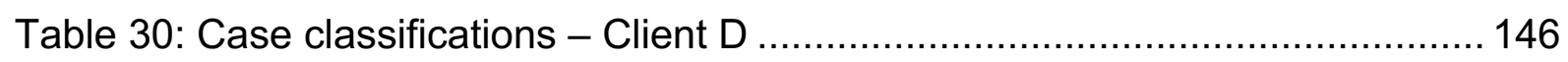

Table 31: Essentials of interview with Client $D$.................................................. 151

Table 32: Case classifications - Client E ......................................................... 152 
Table 33: Essentials of interview with Client E .............................................. 157

Table 34: Case classifications - Client F ....................................................... 158

Table 35: Essentials of interview with Client F ................................................. 164

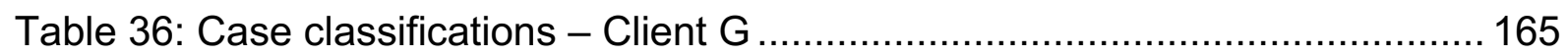

Table 37: Essentials of interview with Client G................................................ 170

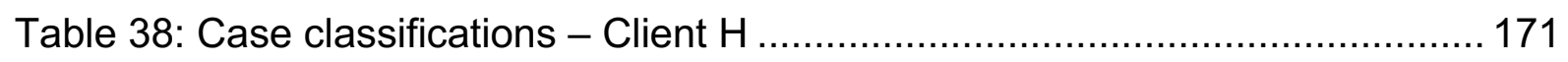

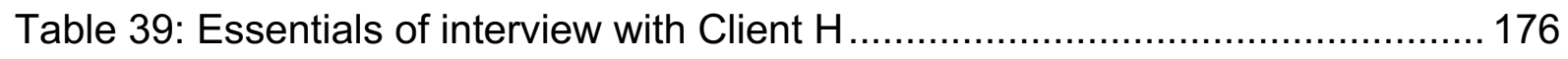

Table 40: Case classifications - Client I ......................................................... 177

Table 41: Essentials of interview with Client I ..................................................... 181

Table 42: Case classifications - Client J ..................................................... 182

Table 43: Essentials of interview with Client J............................................... 186

Table 44: Categories of coding frame summary ............................................. 187

Table 45: Case classifications summary ....................................................... 189

Table 46: Category Attributes summary ........................................................ 190

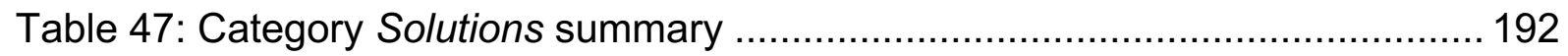

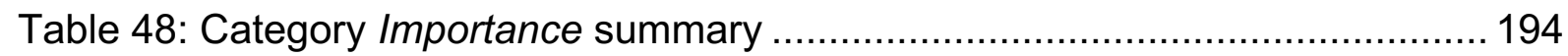

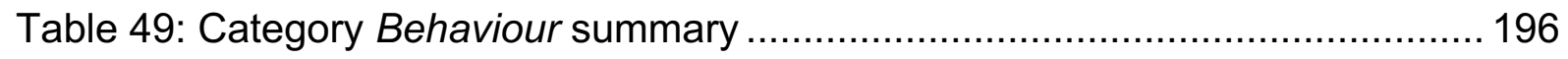

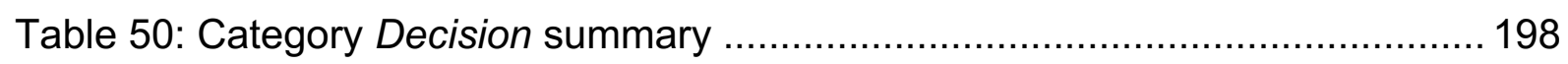

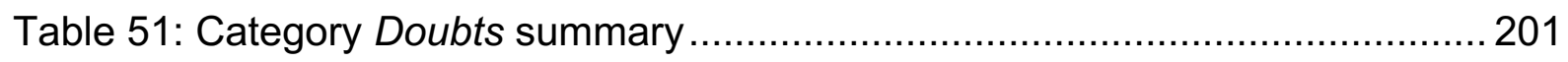

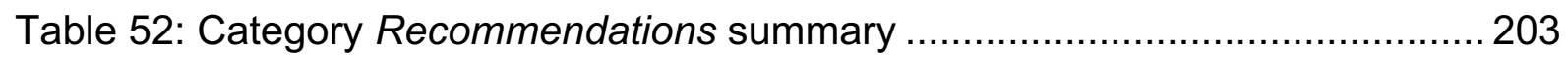

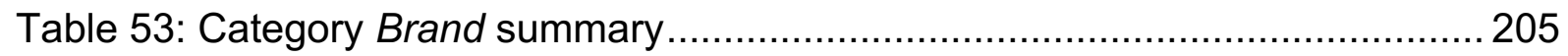

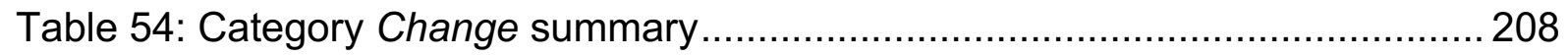

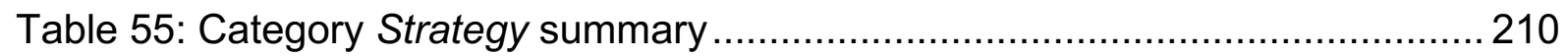

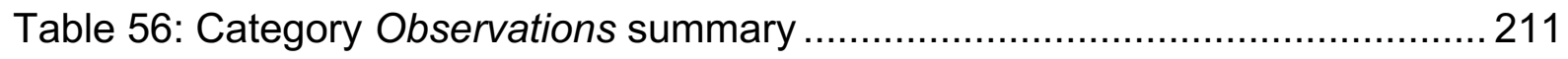

Table 57: Conclusions and contributions to knowledge - Research Question 1.... 215

Table 58: Conclusions and contributions to knowledge - Research Question 2.... 224

Table 59: Conclusions and contributions to knowledge - Research Question 3..... 236

Table 60: Contribution to knowledge - Advance in existing knowledge ................. 245

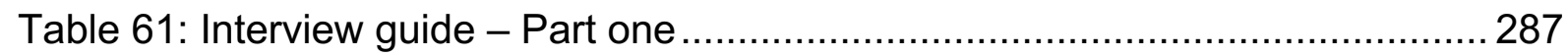

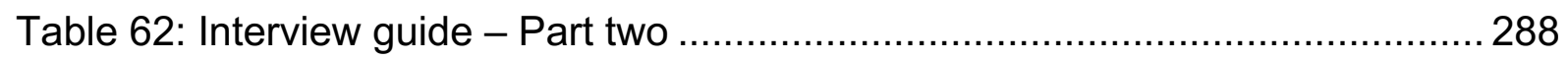

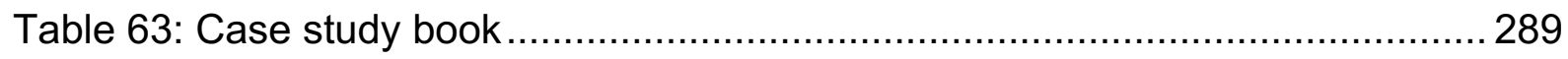




\section{Introduction}

Alpha Software (name modified) is one of Germany's leading information service providers and software companies (Lünendonk, 2018). Its key products and services are in the area of financial and payroll accounting. The company's identity, as well as the brand, specifics of internal processes, and the interviewees' identification of employees and clients, have been modified or completely anonymised. Particular attention was given to avoid undermining the competitive position of the company. In addition, it was important that the company provided access to the sales force and the decision makers within the clients' companies.

A software conversion in a financial and payroll accounting department is a tremendous challenge for each enterprise, since the clearing of invoices and salaries should not be affected and should not lead to operating delays. Furthermore, each software conversion project is simultaneously a change project in which the individual necessities of the clients' workforce must be considered. Alpha Software responds to such complexity in client projects by providing its workforce with extensive training. Each employee has an average advanced training budget of 15 days each year based on internal Alpha Software resource planning. Customer surveys have indicated that Alpha Software's workforce has an outstanding standard of education compared to its competitors. Moreover, the same surveys have revealed that Alpha Software's workforce has a level of knowledge equivalent to that of the clients' specialists.

These surveys have led to contentious ongoing internal discussions among Alpha Software managers on the appropriate state of sales force knowledge. A portion of managers claimed that more expert power indicates a better sales force. The other managers favoured the restraint of sales force expert power. Alpha Software managers have not conclusively examined how clients truly perceive sales force expert power or its effect on client software purchasing decisions. As a manager, I have observed, in various sales pitches, negative impacts of sales force expert power on buying decisions. The clients' perceptions of sales force expert power were incongruent with the sales forces' intentions. At times, these clients reconsidered conversations with competitors and a transfer of business.

In the B2B market, capital-intensive and industrial goods are marketed and sold (Backhaus \& Voeth, 2014). The buying process in this market is a multi-personal 
problem-solving process with a number of participating individuals with varying defined responsibilities and is often referred to as 'organisational buying behaviour' (Duncan, 1940). The process is characterised by active information exchange and frequent interactions within and among the participating groups (Johnston \& Lewin, 1996). Robinson, Faris, and Wind (1967) differentiated between three types of buying decisions: new task, modified rebuy, and straight rebuy. The complexity of the buying decision process declines from new task to straight rebuy as the contact person, product features, and processes are established (Robinson et al., 1967). Lewin and Donthu (2005) argued that the more expensive and complicated services or goods are, the more individuals are involved, and the more time demanding, and complex is the decision-making process, especially in a new task situation. A choice is often made via group decision (Corfman \& Lehmann, 1987). After the elimination of the alternatives, each involved individual forms personal preferences based on the decision frame (Choffray \& Lilien, 1978; Puto, 1987). Organisational preferences are deduced on the basis of these personal preferences and lead to a purchasing decision (or a decision against a purchase). Additional factors, such as environmental uncertainty, perceived risk, novelty, time pressure, formalisation, and derived demand, act on purchasing decisions (Anderson, Chu, \& Weitz, 1987; Johnston \& Bonoma, 1981b; Michael Kleinaltenkamp \& Saab, 2009; Webster \& Wind, 1972).

By means of social power and influence tactics, the sales forces' goal is to persuade clients to make the 'desired' decision (Conger, 1998; Funkhouser, 1984). The repertoire available to the individual reflects social power, while influence tactics signifies the actual utilisation of a particular behaviour in a particular situation (Schwarzwald \& Koslowsky, 1999). French and Raven (1959) and Raven (1965) presented six bases of power: information, reward, legitimacy, coercion, expertise, and reference. Expert power is based on the awareness that a person in a power relationship possesses valuable knowledge, information, or skills in a relevant area. For instance, subordinates follow superiors due to their high level of knowledge and experience. The perception of the expert power of the sales force leads to a larger proportion of purchases (Woodside \& Davenport Jr., 1974). Expert power is also based on the perception that the seller has valuable knowledge, skills, or information in relevant areas, as well as on quotas and ratings by peers, superiors, and clients (Busch \& Wilson, 1976). Applying expert power in sales situations builds customer trust (Busch 
\& Wilson, 1976; Liu \& Leach, 2001), long-term relationships (Sharma, 1990), customer satisfaction (Liu \& Leach, 2001; Mallalieu, 2006), loyalty (Liu \& Leach, 2001; Nyaga et al., 2013), and exit barriers (Clauss \& Bouncken, 2018; Liu \& Leach, 2001). In addition, selling methods are considered to be influence tactics (Bänsch, 2013; Blake \& Mouton, 1970; Rackham, 1995).

Perception is cognitive information processing whereby external stimuli and internal signals are merged into an internal image of the environment and the person him/ herself (Foscht, Swoboda, \& Schramm-Klein, 2017). The perception process is a subjective, selective, and active procedure (Kroeber-Riel, Weinberg, \& Gröppel-Klein, 2013). Its relevance in consumer behaviour, such as in the evaluation of product features, is indisputable (Foscht et al., 2017; Kroeber-Riel et al., 2013). Various theories and models have been developed to explain consumer behaviour (Meffert, Burmann, \& Kirchgeorg, 2018). They differ according to the nature and extent of the situation and condition constellations involved (Kroeber-Riel et al., 2013). In addition to observable and measurable variables, unobservable processes within the organism, which can only be detected indirectly via indicators, are taken into account to explain human behaviour (Meffert et al., 2018). Meffert et al. (2018) have described these models as genuine behavioural models. The S-O-R paradigm as a representative of a genuine behavioural model states that certain stimuli $(\mathrm{S})$ encounter an organism $(\mathrm{O})$ and together lead to a reaction $(R)$. A response does not directly follow a stimulus; rather, a number of internal events occur between a stimulus and a response (Foscht et al., 2017; Rutschmann, 2005). The S-O-R paradigm of consumer behaviour research is not generally applicable to organisational purchasing decisions, because a decision is rarely made by one person and without organisational constraints (Foscht et al., 2017; Kroeber-Riel et al., 2013). Before people can participate in a decisionmaking process, however, they must form their own opinions. In this view, expert power acts as stimuli. By perceiving and processing the expert power of the sales force and the associated information, one or more preferences for a product or a solution are formed by the buyer. With these preferences, the buyer participates in the decisionmaking process and represents it as far as possible, where the mechanisms of organisational buying find application. A buying centre who chooses between two suppliers, for whom at least one is somewhat uncertain about the performance (e.g. whether a project can be carried out successfully) would make a risk-tasking choice. 
Risk aversion is the opposite and refers to the preference for a guaranteed outcome over a probabilistic one with the same expected value (Qualls \& Puto, 1989). Puto (1987) assumed that when evaluating a supplier's offer, the buyer initially set a first point of reference (e.g. a target value for a key dimension such as the brand or buying objectives), which then changes due to environmental factors and influences of the selling centre changes continuously until the time of the decision. A reference point that results in the outcomes being classified as gains tends to promote risk-averse voting behaviour (Qualls \& Puto, 1989). That is, buying centres whose reference points have a positive (gain) decision framework tend to choose the supplier whose offer represent the least risk, while buying centres whose reference points have a negative (loss) decision framework tend to choose the riskier alternative (Qualls \& Puto, 1989).

The role of perception of sales force expert power in purchasing decisions in the business-to-business (B2B) market is undisputed. However, which attributes a buying centre specifically associates with sales force expert power, when and how the perception of sales force expert power alters in the buying process, and which factors are responsible for it are issues that have not yet been discussed in the context of group decision-making in buying centres and how sales force expert power influences the decision frame of each member of the buying centre. The aim of the present study is to answer these questions and to derive an approach by which sales forces can consciously manage and enhance the clients' perceptions of sales force expert power.

Figure 1 depicts the conceptual framework of this research project. 


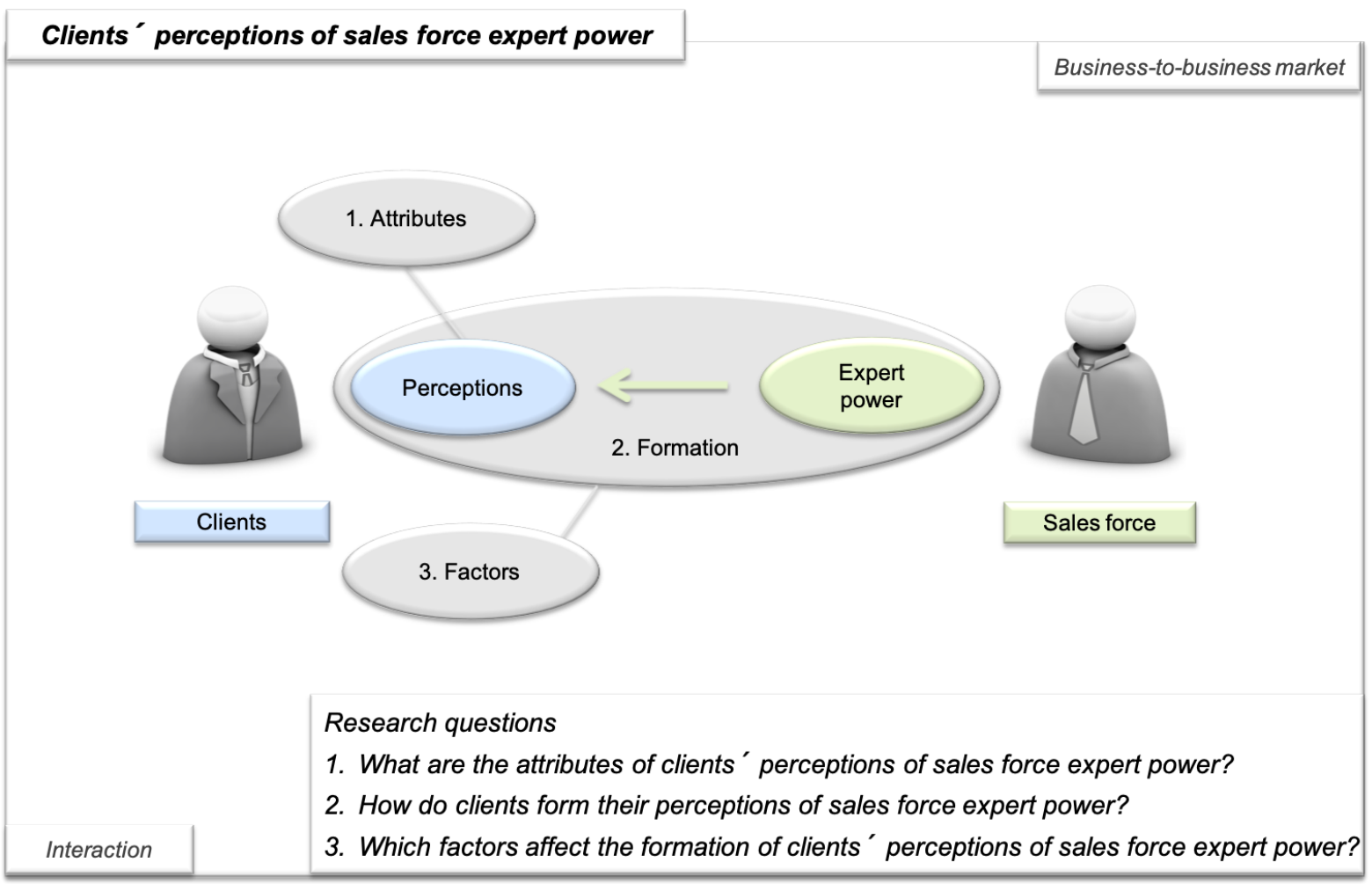

Figure 1: Conceptual framework of the research project

Source: Developed for the research project based on Busch \& Wilson, 1976; Crosby et al., 1990; Liu \& Leach, 2001; Palmatier et al., 2006; Taylor \& Woodside, 1982

In the following paragraphs, the research questions are briefly outlined.

$R Q$ 1: What are the attributes of clients' perceptions of sales force expert power?

Several attributes of expert power have been identified through scientific investigations in recent decades. Knowledge is the most widely recognised attribute of expert power (Woodside \& Davenport Jr., 1974). A distinction is made between product knowledge (Mallalieu, 2006), market knowledge (Crosby et al., 1990), process knowledge (Lines, 2007; Sahadev, 2005), and knowledge about logistics to make promised deliveries (Crosby et al., 1990; Paesbrugghe, Rangarajan, Sharma, Syam, \& Jha, 2017). Other attributes that enhance the perception of expert power include experience (Busch \& Wilson, 1976; Mallalieu, 2006; Sharma, 1990; Taylor \& Woodside, 1982), qualification/education (Belonax, Newell, \& Plank, 2007; Lines, 2007; Mallalieu, 2006; Sharma, 1990), information (McFarland, Challagalla, \& Shervani, 2006; Paesbrugghe et al., 2017), and confidence (Doney \& Cannon, 1997). Applying expert power in sales situations builds customer trust (Busch \& Wilson, 1976; Liu \& Leach, 2001), long-term relationships (Sharma, 1990), customer satisfaction (Liu \& Leach, 2001; Mallalieu, 2006), loyalty (Liu \& Leach, 2001; Nyaga et al., 2013), and exit barriers (Clauss \& 
Bouncken, 2018; Liu \& Leach, 2001). The formation of trust, however, is not clearly documented. Sahadev (2005) observed no strong effect of expert power on building trust. Moreover, the aforementioned attributes of expert power are not specified in the literature. Busch and Wilson (1976), Kohli (1989), Lines (2007), and Liu and Leach (2001), for instance, refer to differentiated attributions. For example, Lines (2007) regards knowledge as scarce and critical for the performance of organisational tasks. Kohli (1989) subdivides knowledge into knowledge about the usage of the product and expertise to make the best decision. Some other findings focus on knowledge as accurate, current, and specialised (Liu \& Leach, 2001) and on the ratings of knowledgeability made by peers, superiors, and customers (Busch \& Wilson, 1976). Which attributes and involved characteristics are relevant for the clients of Alpha Software? It is necessary to identify and understand the specific attributes that make up Alpha Software's clients' perceptions of sales force expert power.

$R Q$ 2: How do clients form their perceptions of sales force expert power?

This question focuses on the understanding of how the perceptions of sales force expert power are formed from a process perspective. Clients are forced to question each statement and every action of the sales force during the buying process. Subsequently, when and how the perception of sales force expert power initially arises, what intensifies or diminishes those perceptions, and whether expert power is equally important throughout the process deserves attention from the process perspective (Figure 25). Mallalieu (2006) suggested that expert power is more important to consumers in an early stage of the process than in a final stage. It is not entirely understood what the role of expert power is in a first buy, where decision-making processes and decision-making criteria have not yet been determined, as the products and services are being purchased for the first time. According to Crosby et al. (1990), expert power plays a crucial role in a first buy, while Doney and Cannon (1997) disagree. Taylor and Woodside (1982) argue that the frequency of attempts to establish expert power in the selling process has a positive influence on sales success. This statement is quite general; they do not clarify whether this equally applies to all stages within the selling process or whether the frequency can be overdone and cause expert power to negatively impact sales success. The way the sales force behaves and acts in the process may have a positive or negative impact on the group decision 
process. The literature refers, in this regard, to the quality of interaction (Liu \& Leach, 2001) and behaviour-based coordination strategies (Sahadev, 2005).

$R Q$ 3: Which factors affect the formation of clients' perceptions of sales force expert power?

Few studies have considered the factors that affect the formation of perceptions of expert power. For instance, Sharma (1990) suggested that low or no prior brand expectations strengthens the perception of expert power and makes its use necessary for a buyer to be certain of a decision. The importance of the purchase (Barnett White, 2005; Belonax et al., 2007) act on the decision frames of the buyers and support their perceptions of expert power. The aforementioned factors primarily affect the perception of expert power during the purchase decision. Their impact, albeit weaker, affects the composition of the buying centre as well (Figure 28). Depending on this composition, the effect of expert power varies (Kohli, 1989). Task-oriented buying centres (McFarland et al., 2006), which themselves have means of expert power (Clauss \& Bouncken, 2018) and are in a supportive or integrative stage in their purchasing evolution (Paesbrugghe et al., 2017), respond positively to and appreciate expert power more than buying centres that have few means of expert power. On the one hand, a lack of expert power can be compensated for by the expert power of the sales force (Chinomona \& Pretorius, 2011). On the other hand, it can provoke a buying centre to consciously follow the recommendations and requirements of the sales force, for example through process adjustments or process changes (Nyaga et al., 2013). According to Liu \& Leach (2001), the position and perception of the sales force or the power they have in their own company, as well as quotas and ratings (Busch \& Wilson, 1976), have a decisive effect on the formation of perceptions of sales force expert power.

The inquiries have revealed that certain factors affect the formation of perceptions of expert power. However, their modes of action have received little or no attention. It remains unclear whether there are specific factors that enhance or inhibit the formation of sales force expert power and how the sales force is able to adjust. Thus, the third research question has been derived. 
The three specified research questions guide the literature review, the design of the methodology approach, and the analysis of the data (Bryman, Bell, \& Harley, 2018).

This research follows the interpretivism tradition. As social actors play a crucial role in understanding a phenomenon, interpretivism requires the researcher to understand the subjective reality and perceptions of the participants. The research is an interpretivist inquiry which is designed to follow an inductive approach and uses qualitative methods to collect and analyse the data. The three purposes of research (exploratory, descriptive, and explanatory) are considered. Exploratory fieldwork was necessary to generate data given that the perceptions and resulting actions particularly interactions - form the basis for further examinations. Prior to data collection, it was important to have a clear understanding of the participants' situation, which is portrayed by descriptive research. The explanatory aspect of the study is the derivation of an approach by which the sales forces recognise and appraise the attributes and factors influencing the formation of clients' perceptions of sales force expert power based on causal relationships emerging from the data generation. Semistructured interviews were conducted with the clients and sales forces involved in the same interaction in one sample firm (Alpha Software). The interviews were conducted during or shortly after the completion of the sales process. As a result, the probability that the answers reflect intrinsic perceptions is higher than if a considerable time lag had occurred, which may have led to memory lapses and perceptions that had already become hazy (Foscht et al., 2017). This is what differentiates the present study from previous research, in which the data were collected via questionnaires with time lags, and the participants did not have a specific interaction to draw on (Busch \& Wilson, 1976; Doney \& Cannon, 1997; Liu \& Leach, 2001). It is striking that, in most studies, questionnaires were used, and the studies were based on quantitative results (Table 12). It can be assumed that there was no direct relation to a purchase or a sale. Participants responded on the basis of their past experiences or forward-looking assumptions. Only Liu and Leach (2001) and Paesbrugghe, Rangarajan, Sharma, Syam, and Jha (2017) have provided more insight through their rather complementary qualitative methods for a better understanding of the motives of the buyers and sellers.

Four principal objectives accompany this research:

1) To identify the attributes of sales force expert power. 
2) To explore the process by which clients form their perceptions of sales force expert power.

3) To examine the factors that affect the formation of clients' perceptions of sales force expert power.

4) To derive an approach by which sales forces can consciously manage and enhance the client's perception of sales force expert power.

The intention is that the results and findings of the inquiry will contribute to the theory of expert power studies and will enrich sophisticated sales force training, as well as enable sales forces to consciously enhance the perceptions of their expert power in distinct sales situations. The theoretical contribution of this scientific work is to supplement the previous findings and definitions of expert power to better classify and understand the mode of action in the decision-making process of buying centres.

The thesis is structured on the basis of Perry's (1998) five-chapter model.

Chapter 1, the introduction, presents the background of the research project and introduces the research questions. It not only summarises the methodology, but also provides an overview of the entire dissertation and the procedure.

The literature review in Chapter 2 is the cornerstone of the research project. The aim is to obtain a comprehensive understanding of the topic and to engage with previously published research. The interaction between the clients and the Alpha Software sales force is the core process in this study. The role and consequences of expert power in the interaction between sellers and buyers are discussed, as well as the detailed issues of expert power in organisational buying and personal selling. Finally, the focus shifts to how perceptions of expert power develop. Based on previously published research, research issues have been formulated, through which the research questions are later defined and answered in detail.

The purpose of Chapter 3 is to present the methodology used to collect, analyse, and interpret data regarding the clients' perceptions of sales force expert power. Five key methodological steps were conducted during the research process: (a) choice of research site, (b) selection of subjects, and (c) collection, (d) processing, and (e) analysis of the collected data (Bryman et al., 2018; Saunders, Lewis, \& Thornhill, 
2015). Each of these steps is further discussed in the next section, in addition to the relevant criteria in business research, such as ethics, as well as reliability and validity.

Chapter 4 succinctly presents the results of the semi-structured interviews and evaluates their relevance in regard to the research questions.

The aim of Chapter 5 is to discuss the results in relation to the literature review and the research issues. Contributions to knowledge in the form of theoretical implications are articulated. To classify the contributions to knowledge, the findings are divided into two categories. In the first category, the findings are classified as Advance in existing knowledge if there is no counterpart in the existing literature. In the second category, the findings are classified as either Addition to existing knowledge or Confirmation of existing knowledge if there are similarities with existing literature. The theoretical implications form the basis for managerial implications to derive an approach by which sales forces can consciously manage and enhance clients' perceptions of sales force expert power.

Figure 2 illustrates the golden thread of the research project. 


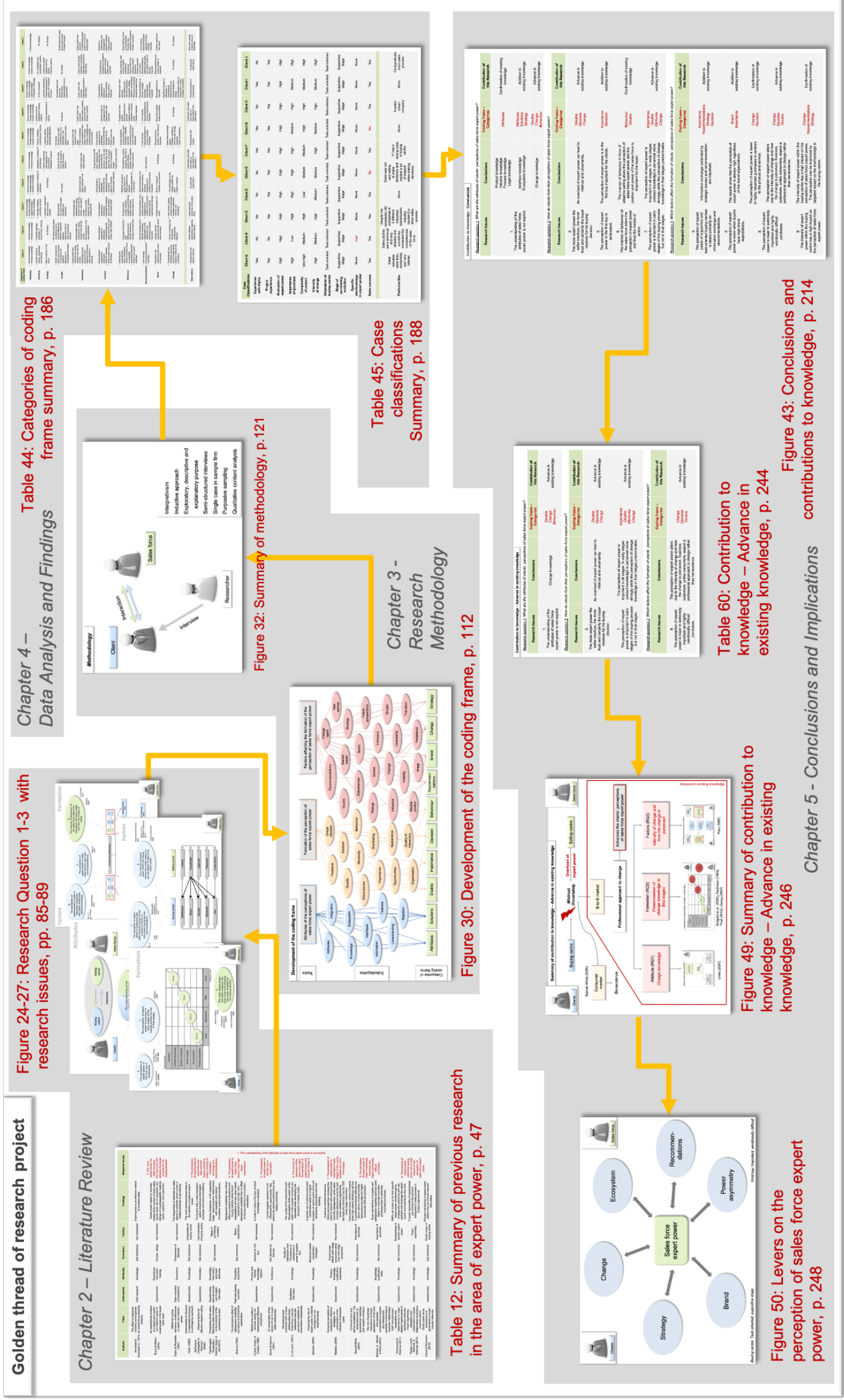

Figure 2: Golden thread of research project Source: Developed for the research project 


\section{Literature Review}

\subsection{Objectives of the Chapter}

The presented literature review is the foundation of this research project. Its aim is to obtain a profound understanding of the topic and to engage with previously published research to uncover research issues which require further investigation (Hart, 2010). The interaction between the clients and the Alpha Software sales force is the core process in this study. Therefore, the literature is based on three streams of research (Figure 3). The first stream considers the role and consequences of expert power in the interaction between sellers and buyers. The second stream of research reviews the detailed issues of expert power in organisational buying and personal selling. Emphasis is placed on the concepts and methods used by Alpha Software. Third, the focus is placed on the way perceptions of expert power develop.

Based on previously published research, research issues have been formulated, through which the research questions are defined and answered in detail.

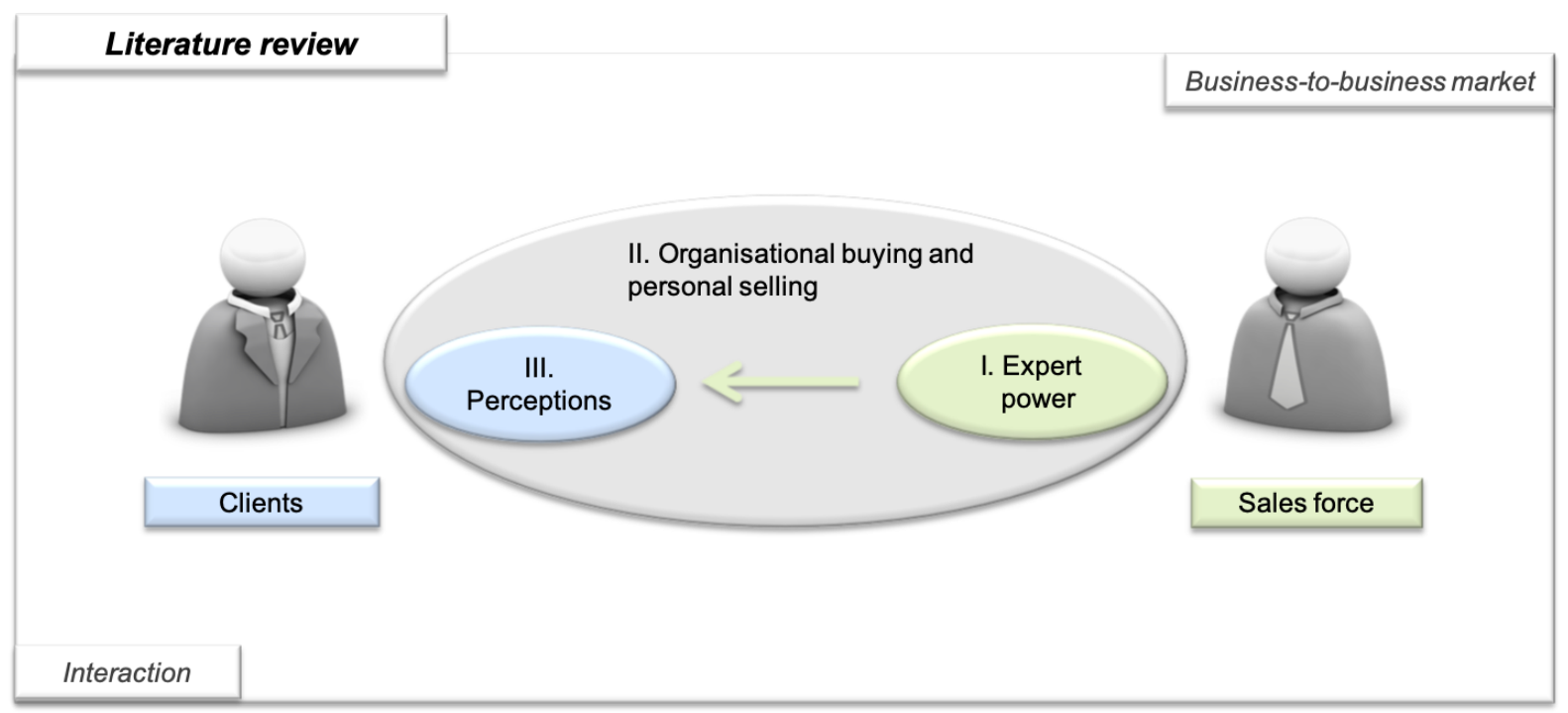

Figure 3: Literature review approach

Source: Developed for the research project

In conclusion, voids in the literature are identified and articulated, and the research questions resulting from these knowledge gaps are explicitly underpinned to form the conceptual framework for further investigation. 


\subsection{Expert Power}

\subsubsection{Fundamental Concept}

\section{Bases of social power}

The study of the foundations of social power has become a fundamental concept in social and organisational studies. One of the most influential concepts is French \& Raven's (1959) power taxonomy. By means of social influence, a person can change the belief attitude and behaviour of another person (Raven, 2008). The basis for such influence is defined as social power (Cartwright, 1959). According to Dahl (1957), "A has power over $B$ to the extent that $A$ can get $B$ to do something that $B$ would not otherwise do" (p. 202).

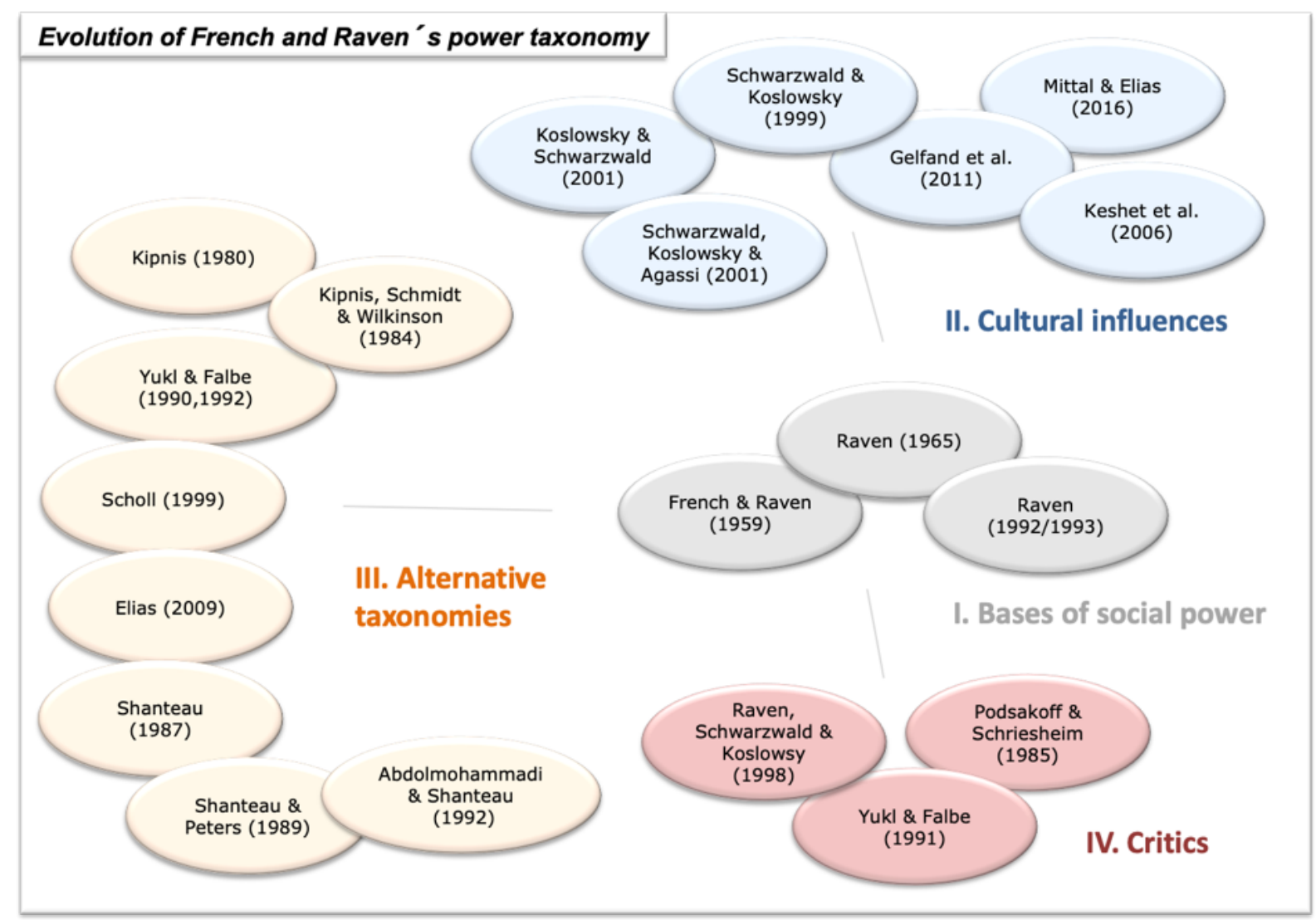

Figure 4: Expert power fundamental concept Source: Developed for the research project

Based on the research of French and Raven, Figure 4 provides an overview of related studies and discusses the concept from various critical directions. Initially, French and Raven (1959) distinguished five sources of power: reward, coercion, legitimate, expert, and referent. In a later study, Raven (1965) added information as an additional power base. Reward power is expressed when a person grants compensation to another 
person when he or she behaves in accordance with a certain behaviour. An example of this is when an employee completes a task that was not part of the original agreedupon task and receives an additional reward. Coercion power is applied by a superior when he or she, for example, threatens a subordinate with dismissal to ensure a task gets completed. Legitimate power is based on the subordinate's acceptance of the supervisor's right to demand the changed behaviour; the subordinate is obliged to comply. Expert power is based on the awareness that a person in a power relationship possesses valuable knowledge, information, or skills in a relevant area. For instance, subordinates follow superiors due to their high level of knowledge and experience. Referent power is the perceived attraction of members in a relationship to one another. For example, the subordinate may admire the superior and wish to be like him /her. Finishing tasks according to the superior's wishes, then, gives the subordinate deeper satisfaction.

Information power was not differentiated in French and Raven's (1959) initial power base taxonomy. French considered information as more of an influence than a power character (Raven, 2008). Informational influence was subcategorised into expert power (French \& Raven, 1959). Later, Raven (1965) distinguished information from expert power. A person uses information power when he or she provides information to someone that results in that person thinking or behaving in a different way. The difference between expert and information power is that, with information power, the information itself causes the change, rather than the person who provides the information.

After several years of research, Raven $(1992,1993)$ developed the power/interactive model based on the original power base taxonomy, since social power is far more complex than using only one or more bases of power through a powerholder to influence a goal. He suggested a wide-ranging taxonomy of power bases by extending the initial six power bases to 14. Following Schwarzwald, Koslowsky, \& Agassi (2001), "coercion and reward were divided into four categories: impersonal coercion (threat of punishment), personal coercion (threat of disapproval or dislike), impersonal reward (promise of monetary or non-monetary compensation), and personal reward (promise to like or approve)" (p. 275). Four types represent legitimate power: legitimate reciprocity, in which the agent does something useful to succeed; legitimate equity, based on reward for either (a) solid labour and suffering by the agent or (b) damage 
caused by the target; legitimate position, ascribes public accountability to a needy person; and legitimate position, the attributes assigned to status based on rank or position. According to Raven (1992), it became apparent that information power must be split, either directly or indirectly, while referent power and expert power are recognised as either positive or negative.

The power/interactive model offers a theoretical perspective on several factors to determine how the social power of an individual influences the actions of another. The first part of the model is the motivation to influence. This motivation can be established, for example, based on role requirements, personality, and intrinsic and extrinsic goals. The choice of influence strategies is determined by these motivational factors. The assessment of available power is the second part of the model. It deals with the particular forms of power a powerholder may have and the possible outcomes associated with each approach. The third part, preparing for influence tactics, sets the stage for the use of power. The fourth part involves choosing the power base and influence trial. It regards what power base a powerholder uses based on his decision to achieve a goal by influencing a target. The last part of the model, effects, aids as a feedback circle, which can influence the future influence attempts of a powerholder. The power interaction model is more than just an extension of possible power bases (Raven, 1992, 1993). It assumes that cultural or situational factors influence the effectiveness and acceptability of influencing behaviours. Raven (1992, 2008) stated that the selection of assured influence strategies is rational for a powerholder, but it is also influenced by situational, individual, organisational, or normative aspects.

In the power/interaction model, Raven (1992) did not only consider the powerholder perspective, but focused on the target perspective as well. The target's submission to the choice of power depends on the characteristics of the powerholder (Koslowsky, Baharav, \& Schwarzwald, 2011; Koslowsky \& Schwarzwald, 2001). A powerholder that is popular tends to achieve better compliance, even if the power strategies are unfavourable to the target. According to Aguinis, Nesler, Quigley, and Tedeschi (1994), the target's perception of the powerholder is critical to the influence of power strategies. Compliance with the objectives is influenced by the presumed or potential power decisions of the influencing powerholder, as well as the explicit use of specific influence strategies. In addition, Raven et al. (1998) discovered an underlying structure of punitive and open (harsh) power bases like impersonal and personal reward, 
impersonal and personal coercion, legitimacy of position, reciprocity, and equity, in addition to subtle and positive (soft) power bases like referent, expert, legitimacy of dependence, and information, as extracted from the 14 power bases. The harsh-soft distinction concurred with the findings of other researchers (Kipnis, 1984; Yukl \& Falbe, 1991). The findings of Hunt (1984) are correspondingly dependable. He associated the soft personal power bases (reference, expertise) with leadership and the harsh power bases (reward, coercion, legitimacy) with management.

\section{Cultural influences}

The power/interaction model is valuable for appreciating the impact of influence strategies used by powerholders to achieve agreement. According to Mittal and Elias (2016), however, the model does not sufficiently consider the cultural environment that influences the range of power bases and foundation required to perform the influence endeavour. By investigating the tolerance of different cultural manifestations to the hard/soft power bases, they offer an intercultural expansion of the power/interaction model. Culture has the potential to influence every component (i.e. the motive to influence, the employment of power bases, preparing to influence, selecting power bases, and considering the effects of the influence attempt) of the power/interaction model (Hofstede, 2011). Mittal and Elias (2016) found differences between cultures in terms of harsh and soft power bases. Soft power bases are more commonly used by powerholders in loose, collectivist cultures with low power distance, masculinity, and avoidance of insecurity, as is the case in Israel and the Netherlands (Gelfand et al., 2011). Hard power bases are chosen to influence targets in cultures that are narrow, short term, have high power removal, and avoid uncertainties (Mittal \& Elias, 2016). As Turkey and South Korea, for example, have strong cultures, a high power distance, and tend to avoid uncertainties (Gelfand et al., 2011), Mittal and Elias (2016) suggest that the implementation of harsh power bases in these countries is more dominant and more efficient.

Koslowsky \& Schwarzwald (2001) argued that the environment decisively determines the range of influence strategies. Therefore, military officers force their subordinates to appeal to reason, while the usage of coercion by relatives and friends is offensive and may not be applicable (Schwarzwald et al., 2001). The influence of gender on the use of influence strategies is an example of existing norms affecting social power 
usage (Schwarzwald, Raven, \& Bui, 1994). Although considered by some to be a personal variable, gender is actually a function of social and cultural norms (Keshet, Kark, Pomerantz-Zorin, Koslowsky, \& Schwarzwald, 2006; Schwarzwald \& Koslowsky, 1999). Men are more likely to impose their will on somebody else, while women tend to be less likely to do so, as they are less directive and more consultative. For women, the use of direct and coercive power bases is perceived as less appropriate and violates gender role expectations (Aguinis et al., 1994; Keshet et al., 2006; Mittal \& Elias, 2016). Men tend to recourse more frequently to impersonal and personal coercion and various terms of harsh bases of legitimate power when satisfaction with the relationship wanes. Woman tend to recourse to soft bases, regardless of satisfaction (Schwarzwald et al., 2001).

\section{Alternative taxonomies}

Kipnis, Schmidt, \& Wilkinson (1980) recognised eight influencing factors in the workplace: assertiveness, dissatisfaction, rationality, sanctions, exchanges, requests, blockages, and coalitions. Based on a field study conducted by Yukl and Tracey (1992), the utility of nine sources of power (rational conviction, inspirational complaint, consultation, satisfaction, exchange, personal complaint, coalition, legitimacy, and pressure) was observed. Furthermore, Yukl and colleagues distinguished three influence directions: upward (a supervisor who is influenced by a subordinate), downward (a subordinate who is influenced by a supervisor), and lateral (mutual interferences) (Yukl \& Falbe, 1990, 1991; Yukl \& Tracey, 1992). In a distinctive power study, Yukl \& Falbe (1991) identified two power sources, persuasiveness and charisma, that did not appear in the original French and Raven taxonomy. Their definition of persuasiveness (being able to convince through a person's logical argument) overlaps with Raven's (1992) definition of information. Charisma may be viewed as a projected character trait likely closely related to the use of referent power, but it may also contribute to legitimate and expert power (Raven et al., 1998).

Regarding Elias (2009) and Scholl (1999), there is an emerging tendency in management literature to examine the leading power in terms of restrictive control versus promoting control (Elias, 2008; Elias and MacDonald, 2006; Scholl, 1999). The setting in which managers rely on the power structure of the organisation to influence their subordinates is referred to as restrictive control (Elias \& Macdonald, 2006). 
According to Scholl (1999), promotive control in the interaction process involves focusing on the problem to find a better solution. Thus, the question of how enhanced ways can be found to secure the interests of both parties is at the centre of attention. During a decision process, the management respects, for example, the thoughts of subordinates and gives them the opportunity to participate (Elias, 2009). As Elias stated:

Each of these methods of influence can be implemented through the use of one or more of French and Raven's bases of power. Political power can be exerted through the use of expert and/or informational power, whereas institutionalized power and restrictive control can be implemented through the use of legitimate power and promotive control through referent and reward power (Elias, 2008, 273).

The literature additionally distinguishes non-mediated power (legitimate power, referent power, and expert power) from mediated power (coercion power and reward power). Non-mediated forces can provide the frameworks that can exacerbate or impede the impact of mediated powers on the relationship commitment of suppliers (Chae, Choi, \& Hur, 2017). Coercive and reward power are considered mediated because their use is controlled by the client, who can coerce a manufacturer with negative consequences (e.g. cancelling a demand) or reward a manufacturer by producing positive consequences, such as placing the order. The client decides, as a power source, if, when, and how he can use his power to influence the behaviour of the producer (Grant \& Preston, 2018).

In contrast, legitimate, referent, and expert power are considered non-mediated because the producer himself / herself decides whether and to what extent he is influenced by a client. The producer seeks to connect with a client because he or she assumes that the client has the natural right to influence him or her (legitimate power) or perceives the knowledge or expertise (expert power) or the reputation (referent power) of the customer. Non-mediated power is based on perceiving the power of the source, rather than on its implementation. Legitimate, referent, and expert power are expected to be strong in high-performance, distanced cultures, where perceived power differences are considered seriously (Gelfand et al., 2011; Zhao, Huo, Flynn, \& Yeung, 2008). 
Based on observations and interviews in auditing, agriculture, and management, as well as assumptions from research initially conducted for other purposes, 14 attributes of expert decision makers were identified by Shanteau (1987). The attributes include content knowledge, adaptiveness, simplification of complexity, and perceptiveness. The use of information reflects the level of expertise. Experts are able to adjust creative decision-making strategies or find new strategies. When presented with incomplete information or contradictory facts, experts can create appropriate decision rules (Shanteau \& Stewart, 1992). The initial attributes were intended as a broad description of experts of all categories. Of course, some attributes suit one profession more than another. The attributes were derived from a combination of formal expert studies and informal observations during these studies. Because there were no empirical analyses of how laypersons view these attributes, Shanteau and Peters (1989) developed a list of 13 expert attributes (Table 1) supplemented by 7 influential factors (Table 2) for experts in various professions (i.e. truck drivers, managers, nurses, personnel managers, doctors, auto mechanics, and accountants) based on the evaluation and ranking of the importance of expert attributes by numerous undergraduates. The mentioned influential factors affect the perceptions of expert decision makers. These factors are distractors that are considered to be relevant (Abdolmohammadi \& Shanteau, 1992; Shanteau \& Peters, 1989). 


\section{Attributes for expert decision makers}

Current knowledge

Creativity

Perceptive

Knows what is relevant

Simplification

Makes exceptions
Experts have an extensive knowledge base. They make a special effort to keep up with the current facts, facts, trends, and developments.

Experts can find novel or unique solutions to difficult problems. They are capable of generating new approaches to established problems as necessary.

Experts are able to extract information from a problem that others cannot see. Their decision-making ability is enhanced by insightful recognition and evaluation of confusing situations.

Experts, based on experience, can readily distinguish relevant from irrelevant information in a problem. They utilise only what is relevant; they ignore what is not.

Experts know how to use a divide-and-conquer approach with complex problems. They work on parts to get a better understanding of a complex problem.

Experts know when to follow established decision strategies and when not to. They don't have just one way to solve problems.

\section{Personality/individual-difference attributes}

Self-confidence

Experts have a strong belief in their ability to make good decisions. They are calm and self-assured while making decisions.

Adaptability

Experts adjust their decision-making strategies to fit the current situation. They are responsive to changes in conditions of the on-going problem situation.

Experience

Experts use past experience to make decisions more-or-less automatically. Their background and experience produces decisions without obvious effort.

Experts are able to make decisions under high stress situations. They continue

Stress tolerance to be effective problem solvers even as conditions progressively worsen because of high levels of pressure.

\section{Presentation / image attributes}

Communicates expertise

Problem selectivity

Assumes responsibility
Experts can convince others that they have specialized knowledge. They can effectively communicate their ability to make decisions to others.

Experts use foresight and planning in selecting which problems to work on and which not. They tackle those problems that they can effectively handle or resolve.

Experts accept responsibility for the outcomes of decisions, successful or unsuccessful. They are willing to stand behind their decisions.

Table 1: Attributes of expert decision makers

Source: Adapted from Shanteau (1987) by Shanteau \& Peters (1989) 


\begin{tabular}{|c|c|}
\hline \multicolumn{2}{|c|}{ Influential factors for the perception of expert decision makers } \\
\hline Inquisitive & $\begin{array}{l}\text { Experts exhibit a high degree of inquisitiveness in problem solving situations. } \\
\text { They have a tendency to work on problems just out of curiosity. }\end{array}$ \\
\hline Methodical & $\begin{array}{l}\text { Experts approach each new problem situation very systematically with one } \\
\text { thought-out plan of attack. They use a set way to examine problems and } \\
\text { carefully proceed step-by-step to make a decision. }\end{array}$ \\
\hline Perfectionist & $\begin{array}{l}\text { Experts attempt to achieve high levels of decision making by seeking the best of } \\
\text { all possible strategies. They keep working to find the absolute best solution for } \\
\text { the problem. }\end{array}$ \\
\hline Decisiveness & $\begin{array}{l}\text { Experts make decisions quickly, clearly, and emphatically. They do not bother } \\
\text { with a detailed analysis of the problem situation. }\end{array}$ \\
\hline Physical characteristics & $\begin{array}{l}\text { Experts present the outward image of someone who is good at solving } \\
\text { problems. They have the style and physical appearance of someone who makes } \\
\text { good decisions. }\end{array}$ \\
\hline Energetic & $\begin{array}{l}\text { Experts are capable of investing large amounts of energy into problem solving. } \\
\text { They give the appear- ance of going the extra mile when making decisions. }\end{array}$ \\
\hline Warm and friendly & $\begin{array}{l}\text { They get along well with people, even in difficult decision-making tasks. They } \\
\text { use personality to smooth things over and appear more convincing when } \\
\text { making decisions. }\end{array}$ \\
\hline
\end{tabular}

Table 2: Influential factors for the perception of expert decision makers Source: Adapted from Shanteau \& Peters (1989)

According to Shanteau, Weiss, Thomas, and Pounds (2003), an expert has many years of experience. Nobody is able to perform as an expert without any long-term competencies. Further defined competencies include creativity, self-confidence, problem-solving skills, stress tolerance, and communication skills. A common feature of experts is that they exhibit strong confidence in their decision-making abilities. When evidence is presented for inconsistent decisions, experts will usually recognise the flaw as being outside their own control. Experts believe in themselves and their ability to solve most problems in their field (Shanteau, 1992). Someone who knows nothing about a topic will not be able to make informed decisions. Consequently, a condition for expert power is knowledge of the essentials (Shanteau \& Stewart, 1992). Cognitive/thinking attributes (knowledge, knows what is relevant, and experience) are most important in expert decision making for auditors, followed by presentation/image attributes (assumes responsibility, self-confidence, communication) and strategy/problem-solving attributes (creativity, analytical skills, problem simplification) (Abdolmohammadi \& Shanteau, 1992). Personal appearance attributes (e.g. 
physically attractive, warm and friendly, methodical) seem to be less important (Abdolmohammadi \& Shanteau, 1992). No matter how good a decision maker is, the way he is perceived depends on convincing others of his expertise. An expert is one who convinces others of one's own expert force.

\section{Critics}

Despite the broad acceptance of the power bases in studies of social and organisational psychology, Podsakoff and Schriesheim (1985) identified methodological and substantive concerns. Methodological critiques regarded the use of single measurement items for each power base, along with ranking techniques which produce forced and artificial correlations. Although the results between the studies do not entirely coincide, in general, effective managers had more expert and referent power than ineffective managers (Podsakoff \& Schriesheim, 1985). The typical research design has been a field study in which questionnaire measures of each type of power were correlated with measures of subordinate satisfaction and performance (Yukl \& Falbe, 1991). A number of limitations in the power studies have biased the results (Podsakoff \& Schriesheim, 1985; Yukl \& Tracey, 1992). These include, for example, social desirability biases, as noted by Yukl and Falbe (1991). To measure power, most studies used single-item scales, for which content validity and measurement accuracy are likely to be weak. Respondents were also often asked to rank power sources in order of importance (Podsakoff \& Schriesheim, 1985). The scoring for this tends to distort the results, causing some power sources to appear more important and others to appear less important than they would be if a rating format were used (Yukl \& Falbe, 1991). Raven et al. (1998) additionally raised concerns in regard to conceptual overlaps between categories, inconsistent operational definitions, and low agreement between observations and prediction. For example, references to expertise may involve elements of referent and information power. This problem is compounded by the fact that different power bases, such as expert and information power, are often used in combination. The powerholder tends to expose power profiles with unique power base constellations rather than simple clear preferences for individual power bases (Elias, 2008; Kipnis, 1984; Raven, 2008; Yukl \& Falbe, 1990). 


\section{Summary}

In the literature, the taxonomy of French and Raven is still recognised and relevant (Elias, 2009; Hopkinson \& Blois, 2014; Koslowsky et al., 2011; Mittal \& Elias, 2016; Raven, 2008). The power bases of French and Raven essentially refer to the relationship between superiors and subordinates and have been extended in various continuing studies, for example, to the areas of cultural influences, leadership, organisational power, and academic settings, among others (Elias, 2008). As previously stated, French and Raven are the basis for various advanced studies. Although other studies have produced alternative taxonomies on power bases, they are all based on the six familiar power bases of French and Raven and can be assigned or subordinated to them (Elias, 2008; Raven, 2008). Abdolmohammadi and Shanteau (1992) and Shanteau and Peters (1989) have defined a conception of the expert and examined the attributes of expert decision makers intensively with regard to the professional group of auditors. In the following chapter, the focus is placed on to what extent the power bases, particularly expert power, as well as the aforementioned attributes, are relevant in the context of organisational buying and personal selling.

\subsubsection{Expert Power in Organisational Buying and Personal Selling}

Organisational buying plays an important role in the purchasing process of organisations (i.e. corporations, government agencies, and associations) in which buyers acquire goods for processing or long-term use in capital-intensive and industrial goods markets (Backhaus \& Voeth, 2014). When selling products in need of explanation, or when the object of purchase exceeds a certain size, the sales process is no longer disputed by the seller and the buyer alone (Winkelmann, 2012). Various interest groups collide, and distribution needs to adjust to group negotiations (Hofbauer \& Schöpfel, 2010). Informed and commercially minded sales teams (selling centres) and purchasing teams (buying centres) collide much more than in the consumer goods business (Winkelmann, 2012). Personal and business interests and requirements, including constraints, must be reconciled (Homburg, Schäfer, \& Schneider, 2016). Expert power plays a decisive role, which is discussed in the following section.

\section{Selling Centre Perspective}

The perception of the expert power of the sales force leads to a larger proportion of purchases (Woodside \& Davenport Jr., 1974). Expert power is also based on the 
perception that the seller has valuable knowledge, skills, or information in relevant areas and on quotas and ratings by peers, superiors, and clients (Busch \& Wilson, 1976). Sellers' attributes are positively associated with successful attempts to influence a particular outcome (Crosby et al., 1990). Sales success is positively related to the frequency of attempts to establish expert power (Taylor \& Woodside, 1982). The greater the perceived professional skills of the seller, the higher the likelihood of a customer purchase (Wilson, Lilien, \& Wilson, 1991; Wilson \& Woodside, 1995; Woodside \& Davenport Jr., 1974). These statements have resulted in Research Issue 2 (Table 3).

\begin{tabular}{|c|c|c|c|}
\hline Authors & Titles & Findings & Research Issues \\
\hline $\begin{array}{l}\text { Woodside \& } \\
\text { Davenport Jr. (1974) }\end{array}$ & $\begin{array}{l}\text { The effect of salesman similarity } \\
\text { and expertise on consumer } \\
\text { purchasing behavior }\end{array}$ & $\begin{array}{l}\text { Expert power is an effective method to } \\
\text { increase sales. }\end{array}$ & \multirow{3}{*}{$\begin{array}{l}\text { 2. The more expert } \\
\text { power the seller } \\
\text { employs, the more trust } \\
\text { and certainty the buyer } \\
\text { receives for his buying } \\
\text { decision. }\end{array}$} \\
\hline $\begin{array}{l}\text { Busch \& Wilson } \\
\quad(1976)\end{array}$ & $\begin{array}{c}\text { An experimental analysis of a } \\
\text { salesman's expert and referent } \\
\text { bases of social power in the buyer- } \\
\text { seller dyad }\end{array}$ & $\begin{array}{l}\text { Expert power based on success measured by } \\
\text { number of times sales quotas were met or } \\
\text { exceeded, and ratings of knowledgeability } \\
\text { made by peers, superiors, and customers. }\end{array}$ & \\
\hline $\begin{array}{l}\text { Taylor \& Woodside } \\
\text { (1982) }\end{array}$ & $\begin{array}{c}\text { Effects on buying behaviour of } \\
\text { references to expert and referent } \\
\text { power }\end{array}$ & $\begin{array}{l}\text { The frequencies of attempts by sales agents } \\
\text { to establish expert power is related positively } \\
\text { to purchasing. }\end{array}$ & \\
\hline
\end{tabular}

Table 3: Research Issue 2

Source: Developed for this research project

Sales organisations clearly view expertise as a critical factor in sales efficiency, because product knowledge is the most comprehensive asset in nearly all sales training agendas (Sahadev, 2005). It is believed that expertise as an attribute of the seller has a positive impact on sales efficiency (Giacobbe, Jackson Jr, Crosby, \& Bridges, 2006). Expert power is closely linked to the process of achieving the goals and objectives of the system, rather than the results. It is usually about having expertise in terms of market, sales processes, consumer behaviour, and product technology (Sahadev, 2005). Customer perceptions of a seller's expert power replicate the association of pertinent capabilities related to product and market knowledge, most often presented in the form of seller-provided information (Crosby et al., 1990). Because customers lack information and performance assessment expertise, they must often make assumptions about service quality (Crosby et al., 1990). The salesman's verbal instruction on how to use a product, in comparison to the customer's stated inability to operate the product, is defined as the perception of expert power (Busch \& Wilson, 1976). Product knowledge, an essential attribute for expert power, is decisive for increasing product sales (Wilson \& Woodside, 1995; Woodside \& 
Davenport Jr., 1974). Expertise is a source of influence that the participant in a buyingselling situation must assume and cannot be delegated by a third party (Busch \& Wilson, 1976). Specific influencing strategies, such as sales orientation (scarcity and social validation [the environment defines success and failure]) and customer orientation (preferences and expertise [i.e. product knowledge, skills, and experience]) influence buyers' intentions (Mallalieu, 2006). To build a solid interpersonal sales relationship, at least one threshold of expert power of the sales force must be recognisable and perceptible. Years of experience in the market and with the company, in addition to years of professional education and training and the achieved or exaggerated sales (sales awards), promotes the customer orientation and the perception of expert power by colleagues, supervisors, and customers (Busch \& Wilson, 1976). Buyers who are in an early stage of the decision-making process and already buying from and interacting with a seller are affected by the choice of the seller's influence strategy; however, customer-oriented behaviours increase the intention to contact and buy from the seller, while sales-oriented behaviours significantly reduce the intent, only among buyers in the early stages of the decisionmaking process (Mallalieu, 2006). Thus, an increased number of attempts by sales agents to display expert power is positively related to sale success (Taylor \& Woodside, 1982). Buyers who are in the final stages of the decision-making process, in contrast, are not influenced by the seller's choice of specific influencing strategies (Mallalieu, 2006). Based on Mallalieu's (2006) statements, the following research issue has been derived (Table 4).

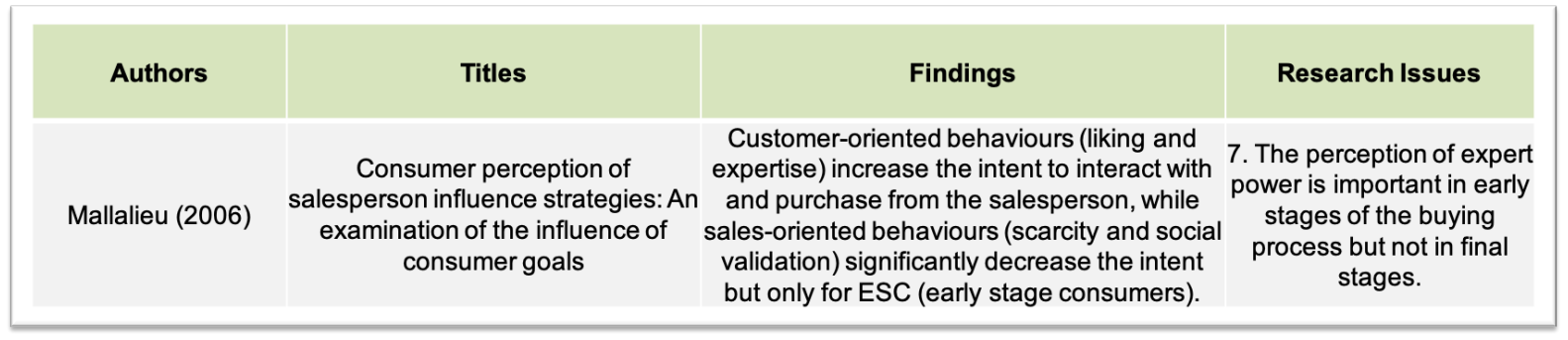

Table 4: Research Issue 7

Source: Developed for this research project

The stronger the expert base, the more trustworthy the client perceives the seller to be (Busch \& Wilson, 1976). The confidence that a seller can deliver on his promises plays an important role in building trust (Jolson, 1997). Trust is important, but trust in a current selection of suppliers, for example, has no significant impact (Doney \& Cannon, 1997). The delivery performance and the cost-benefit ratio seem to have a more 
significant impact. Doney and Cannon (1997) represent a contrasting opinion to Crosby et al. (1990). According to them, expert power is crucial in making a first sale. From these contrasting results, Research Issue 5 has been derived (Table 5 ).

\begin{tabular}{|c|c|c|c|}
\hline Authors & Titles & Findings & Research Issues \\
\hline $\begin{array}{c}\text { Crosby, Evans, \& } \\
\text { Cowles (1990) }\end{array}$ & $\begin{array}{c}\text { Relationship quality in services } \\
\text { selling: An interpersonal influence } \\
\text { perspective }\end{array}$ & $\begin{array}{c}\text { In order to make a first buy, product } \\
\text { knowledge is decisive. }\end{array}$ & $\begin{array}{c}\text { 5. The perception of } \\
\text { expert power in the first } \\
\text { buy is ambivalent. }\end{array}$ \\
\hline $\begin{array}{c}\text { Doney \& Cannon } \\
(1997)\end{array}$ & $\begin{array}{c}\text { An examination of the nature of } \\
\text { trust in buyer-seller relationships }\end{array}$ & $\begin{array}{c}\text { Current supplier selection is not influenced by } \\
\text { expert power. Key criteria are delivery } \\
\text { performance and relative price/cost. }\end{array}$ \\
\hline
\end{tabular}

Table 5: Research Issue 5

Source: Developed for this research project

Sahadev (2005) suggested that sales partners are assumed to have a high level of expert power, tend to be more communicative and collaborative, and focus on their behaviour, rather than just the results. These findings are similar to Liu and Leach (2001), who view the quality of interactions as an important factor in the formation of expert power. However, Sahadev's (2005) analysis revealed that expert power is not necessarily related to trust and the use of collaborative communication, for example, in distribution channels. In the case of collaborative communication, this may be because, due to the need to gather expertise, the flow of communication in the distribution channel is generally high, thereby reducing the level of bilateral communication (Sahadev, 2005). One reason for the lack of a positive relation between expert power and trust may be the uncertain environment. A negative correlation between environmental uncertainty and trust, suggesting that, in uncertain environments, trust between business partners is generally low despite the frequent use of expert power, was observed by Geyskens, Steenkamp, and Scheer (1996). Based on the findings of Liu and Leach (2001) and Sahadev (2005), Research Issue 6 has been derived (Table 6). 


\begin{tabular}{|c|c|c|c|}
\hline Authors & Titles & Findings & Research Issues \\
\hline Liu \& Leach (2001) & $\begin{array}{l}\text { Developing loyal customers with a } \\
\text { value-adding sales force: } \\
\text { Examining customer satisfaction } \\
\text { and the perceived credibility of } \\
\text { consultative salespeople }\end{array}$ & $\begin{array}{l}\text { The quality of the interactions and the } \\
\text { perception of the power of the seller in the } \\
\text { supplier company are important when } \\
\text { developing the perception of expert power. }\end{array}$ & \multirow{2}{*}{$\begin{array}{l}\text { 6. The manner of } \\
\text { behaviour of the sales } \\
\text { force alters the } \\
\text { perception of expert } \\
\text { power and thus the } \\
\text { modes of action. }\end{array}$} \\
\hline Sahadev(2005) & $\begin{array}{l}\text { Exploring the role of expert power in } \\
\text { channel management: An empirical } \\
\text { study }\end{array}$ & $\begin{array}{l}\text { A greater use of behavioural-based } \\
\text { coordination leads to a higher perception of } \\
\text { expert power but is not necessarily } \\
\text { associated with trust building. }\end{array}$ & \\
\hline
\end{tabular}

Table 6: Research Issue 6

Source: Developed for this research project

According to Doney and Cannon (1997), trust has a much greater impact on the formation of long-term relationships. The use of expert power is the most effective means of building and maintaining strong customer relationships (Arli, Bauer, \& Palmatier, 2018; Palmatier et al., 2006). In addition to building trust and long-term relationships, expert power increases sales, customer satisfaction, and loyalty, creates exit barriers, and protects against shifts (Liu \& Comer, 2007; Palmatier et al., 2006; Sahadev, 2005). The results regarding the seller's expert power propose that the shortand long-term efficiencies are equally affected by a sales force's expert power (Crosby et al., 1990). This influence is not surprising, as one of the key factors in defining complex services is helping buyers solve their problems. As previously mentioned, perceived expert power includes basic product knowledge, but the advisory role of the seller increases in the long term, and it is understandable that the customer's problems beyond the traditional service boundaries will need to be resolved in the future (Crosby et al., 1990; Giacobbe, Jackson Jr, Crosby, \& Bridges, 2006). While expertise is required to develop long-lasting service distribution relations, this alone does not seem to be enough. As long as the relationship exists, the expertise should reflect proven competence in the broader aspects of purchase and use by the customer - especially if the customer makes multiple purchases in one area and expects the seller to understand the interrelationships between those purchases (Crosby et al., 1990). For example, some clients are looking for an effective and efficient way to obtain information about a range of complementary services to build long-term relationships with service providers (Giacobbe et al., 2006).

The expert power of the seller affects product evaluation and purchase intent when buyers have no previous expectations of the brand (Sharma, 1990). The expert power of sales representatives has a stronger impact on purchase intentions than on the 
product ratings when brand expectations are low. If the brand expectations are high, the seller has little or no impact on buying intentions and product ratings (Sharma, 1990). The customer chooses a product even if the seller does not fulfil his expectations. The perception of the expert power of the seller and the company he represents depends not only on the expectations of the brand, but also on the importance of the purchase decision, to which Research Issue 4 refers (Table 7).

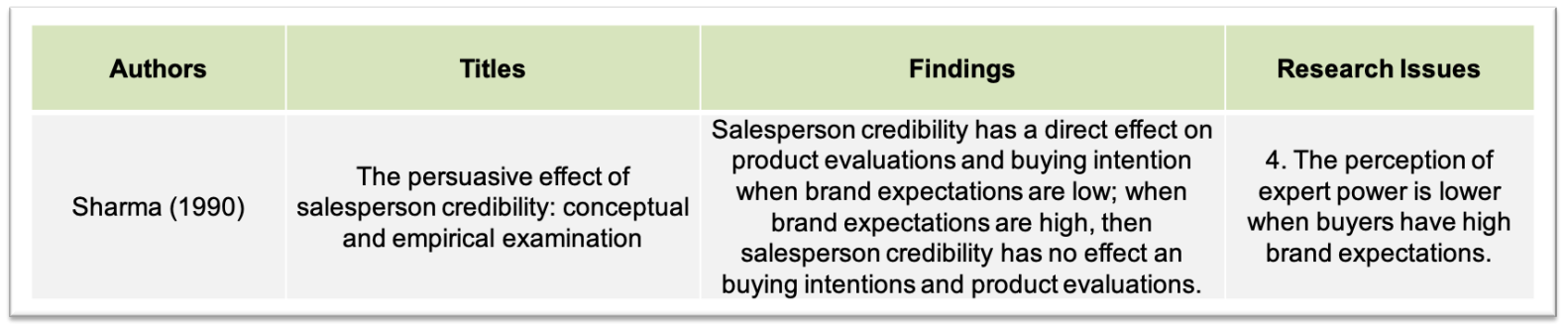

Table 7: Research Issue 4

Source: Developed for this research project

The importance of the perception of buyers in terms of expert power of suppliers and sellers is higher for minimally important purchases than for extremely important purchases (Belonax et al., 2007). Due to the uncertainty associated with major buying decisions, buyers are generally less willing to make a quick and effortless decision (Barnett White, 2005). Although recognised by the buyer, the seller's expert power plays a less prominent role, while the perceived ability of the product or service to meet the buyer's needs plays a more significant role in the buyer's buying and decision making (Belonax et al., 2007). In contrast, due to the routine, repetitive nature of a lowimportance buying decision, the buyer relies more on criteria that facilitate a quick and effortless decision in this case (Belonax et al., 2007; Sahadev, 2005). The buyer's positive assessment of the sales force's performance and the resulting confidence form the basis for a quick and easy decision (Belonax et al., 2007). Research Issue 8 has been derived based on the findings of Barnett White (2005) and Belonax et al. (2007) (Table 8). 


\begin{tabular}{|c|c|c|c|}
\hline Authors & Titles & Findings & Research Issues \\
\hline Barnett White (2005) & $\begin{array}{l}\text { Consumer trust and advice } \\
\text { acceptance: The moderating roles } \\
\text { of benevolence, expertise, and } \\
\text { negative emotions }\end{array}$ & $\begin{array}{l}\text { Consumers favour advice of experts when } \\
\text { high-stakes decisions are low in perceived } \\
\text { emotional difficulty but favour advice of } \\
\text { predominantly benevolent providers for highly } \\
\text { emotionally difficult decisions. }\end{array}$ & \multirow{2}{*}{$\begin{array}{l}\text { 8. The perception of } \\
\text { expert power is lower in } \\
\text { extremely important and } \\
\text { highly emotionally } \\
\text { difficult purchases. }\end{array}$} \\
\hline $\begin{array}{l}\text { Belonax Jr., Newell, \& } \\
\text { Plank (2007) }\end{array}$ & $\begin{array}{l}\text { The role of purchase importance on } \\
\text { buyer perceptions of the trust and } \\
\text { expertise components of supplier } \\
\text { and salesperson credibility in } \\
\text { business-to-business relationships }\end{array}$ & $\begin{array}{l}\text { Buyer perceptions of supplier and } \\
\text { salesperson expertise and trust were higher } \\
\text { in minimally important purchases than in } \\
\text { extremely important purchases. }\end{array}$ & \\
\hline
\end{tabular}

Table 8: Research Issue 8

Source: Developed for this research project

Farrell and Schroder (1999) investigated the connections between power bases and the use of various influence strategies in a company's decision, particularly the power of experts to acquire the services of an advertising agency. They discovered that the power of experts is positively correlated with influencing strategies such as consultation and rational persuasion. Expert power is a critical factor associated with effective advisory sales activities (Liu \& Leach, 2001; Liu \& Comer, 2007). The impact of benevolence versus expert power (subject-specific knowledge) in accepting counselling depends on how emotionally difficult high-engagement decisions are perceived as (Barnett White, 2005; Sirdeshmukh, Singh, \& Sabol, 2002). Barnett White (2005) discovered that consumers prefer the advice of experts when high-stakes decisions have little emotional difficulty but prefer the advice of mostly benevolent providers for extremely emotionally difficult decisions. The expertise of the seller reflects his or her knowledge, experience, and overall competence. The perception of the supplier's power in the company and of the quality of the interactions with the seller are crucial factors for the seller, which are related to value-adding, advisory sales activities (Liu \& Comer, 2007). When customers interact with a competent salesperson, they get a greater value, their relationship becomes more important, and they invest more effort into strengthening and sustaining it (Palmatier et al., 2006). The use and disclosure of current and specialised knowledge to customers through tailored solutions offer him /her decisive added value (Liu \& Comer, 2007). Nonetheless, consumers appear to be willing to trade expertly perceived knowledge for goodwill, which means they place little or no importance on the expert power of the seller in the presence of benevolence. They do not compromise as potential victims. Instead, they seem to believe that following the advice of predominantly benevolent providers, as opposed to experts, leads to better, more accurate results (Barnett White, 2005). Contrary to these findings, consumers' online buying intentions are more likely to be 
influenced by supplier characteristics (Schlosser, Barnett White, \& Lloyd, 2006). They reflect expertise (e.g. website design), rather than properties that communicate goodwill (e.g. privacy policy and security statements) (Barnett White, 2005). In other words, perceived expertise is a stronger driver of online buying intent than goodwill. According to Schlosser et al. (2006), consumers are more likely to be influenced by the provider's information, meaning that they choose the most competent supplier, rather than choosing the one with the highest perceived benevolence.

\section{Buying centre perspective}

Kohli (1989) discovered that expert power has the greatest influence on the members of a buying centre. He asserted that "expert power is related more strongly to manifest influence in committees that are large, viscid, and not under time pressure, and when it is not accompanied by very strong influence attempts" (p. 61). By viscidity, he refers to how the members of buying centres work together as a team, rather than being fragmented and hostile (Kohli, 1988, 1989). Influence attempts refer to the efforts an individual makes to influence a purchase decision (Kohli, 1989). Professional competence (e.g. knowledge of different suppliers, knowledge about the needs of the organisation in relation to the product, competence for the evaluation of different options, knowledge about the use of the product, and expertise to make the best decision) plays an important role in sales team training (Ulaga \& Kohli, 2018). Training programs, which transfer the knowledge of their best salesmen to trainees, have achieved sustainable results (Evans, McFarland, Dietz, \& Jaramillo, 2012; Kohli, 1989). Due to the utilisation of expertise, sales persons with little experience are able to react adequately in difficult situations ( $H$. Sujan, Weitz, \& Sujan, 1988). The utilisation of expert power is recommended as the appropriate approach to persuade primarily task-oriented buying centres (Evans et al., 2012; Román \& lacobucci, 2009; Sheth, 1976; Spiro \& Perreault Jr, 1979; Williams \& Spiro, 1985). McFarland et al. (2006) advised selling centres to focus on recommendations and information exchange. The sales force should make conscious efforts to influence the customer through expert power (Busch, 1980). Interaction-oriented (focus on personal connections and socialising) and self-oriented (focus on self-preservation, selfsurvival, and self-emulation) buying centres are influenced through the second most important factor, reinforcement power (Kohli, 1989; Sheth, 1976). Reinforcement power more strongly manifests influence when accompanied by strong influence 
attempts and in committees that are small, not very viscid, and under time pressure. Kohli (1989) consolidated reward and coercive power into reinforcement power. McFarland et al. (2006) view the influence as more differentiated. For interactionoriented buying centres, the selling centres should rely, in their opinion, more on kindness and inspiring appeals. For buying centres that are self-oriented, McFarland et al. (2006) recommend that selling centres rely increasingly on promises and insinuations. While McFarland et al. (2006) evaluated the buying centre based on how they behave primarily in the purchasing process, Paesbrugghe, Rangarajan, Sharma, Syam, and Jha (2017) highlighted the goals that a buying centre is focused on and differentiated four types of purchasing stages: passive (motivated by price and service level), independent (motivated by TCO), supportive (motivated by solutions and innovations), and integrative (strategy). Each buying centre is assigned to one of the four evolution stages. A buying centre which is considered to be in the solutioninnovation stage focusses on choosing the right product or service to solve current and future problems or needs. Neither the cheapest price for the product or service nor the biggest cost reduction to follow the TCO concept play an important role. The buying centre values long-term relationships with suppliers who can deliver innovative, customised solutions to support their requirements. A buying centre in the integrative stage is primarily motivated either by mass production or by the best quality on the market. Long-term and strategic relationships, in which the selling centre and the buying centre work closely together during their strategic engagement, are favoured by both orientations. To meet the requirements of the buying centre in both stages (solution-innovation and integrative), the selling centre needs to have sophisticated expert power in the products, processes, and markets. McFarland et al. (2006) would consider these buying centres to be task-oriented, rather than interaction oriented or self-oriented, which has resulted in Research Issue 3 (Table 9).

\begin{tabular}{|c|c|c|c|}
\hline Authors & Titles & Findings & Research Issues \\
\hline Kohli (1989) & $\begin{array}{c}\text { Determinants of influence in } \\
\text { organizational buying: } \mathrm{A} \\
\text { contingency approach }\end{array}$ & $\begin{array}{c}\text { The most dominant power base in the } \\
\text { decision process is expert power. }\end{array}$ & $\begin{array}{c}\text { 3. The perception of } \\
\text { expert power of }\end{array}$ \\
\hline $\begin{array}{c}\text { McFarland, } \\
\text { Challagalla, \& } \\
\text { Shervani } \\
\text { (2006) }\end{array}$ & $\begin{array}{c}\text { Influence tactics for effective } \\
\text { adaptive selling }\end{array}$ & $\begin{array}{c}\text { For buyers with a task-orientation, sellers } \\
\text { should use information exchange and } \\
\text { recommendations. }\end{array}$ & $\begin{array}{c}\text { oriented buying centres } \\
\text { is based primarily on } \\
\text { information exchange }\end{array}$ \\
\hline $\begin{array}{c}\text { Paesbrugghe, } \\
\text { Rangarajan, Sharma, } \\
\text { Syam, \& Jha (2017) }\end{array}$ & $\begin{array}{c}\text { Purchasing-driven sales: Matching } \\
\text { sales strategies to the evolution of } \\
\text { the purchasing function }\end{array}$ & $\begin{array}{c}\text { Buying companies in the supportive stage } \\
\text { value long-term relationships with suppliers } \\
\text { who deliver innovative, customised solutions. }\end{array}$ \\
\hline \hline
\end{tabular}

Table 9: Research Issue 3

Source: Developed for this research project 
From the perspective of the buyer, expert power reinforces the effects of reward and coercive power (Chae et al., 2017). A buyer with a high level of expert power should exercise caution when using coercive means and should consider the potentially limited effectiveness of his reward power when he has no or little expert power (Chae et al., 2017). The expert power of the buyer influences the perception of the expert power of the seller (Clauss \& Bouncken, 2018). If the supplier perceives the buyer as an expert in the field, he anticipates opportunities to improve his knowledge and reputation through the alliance (Clauss \& Bouncken, 2018). The expertise of experts includes the ability of the buyer to assist suppliers through guidance and information sharing to achieve their individual goals (Shanteau, 1987). Technical competence results from the expert power of the buyers in areas relevant for the partner (Clauss \& Bouncken, 2018). This implies that the supplier feels that the buyer can help him/her achieve his individual goals through guidance or information sharing (Crosby et al., 1990; Sahadev, 2005). This motivates the supplier to adopt certain behaviours and to adapt the relationship norms to the buyer. Expert power strengthens supplier collaboration (Chae et al., 2017; Gonçalves, da Silva, \& Teixeira, 2018). Sahadev (2005) stated that buyers' expertise strengthens suppliers' abilities to achieve individual goals when buyers transfer relevant knowledge and provide guidance. This increases suppliers' motivation to pursue and sustain the alliance (Clauss \& Bouncken, 2018). As the increased information exchange between buyers leads to a better relationship, more cooperation and trust develops (Doney \& Cannon, 1997; Liu \& Comer, 2007). The positive impact of procurement policy underlines the importance of expert power in increasing the likelihood of achieving shared goals and mutual benefits (Clauss \& Bouncken, 2018). If the buyer is considered to be an expert, it is reasonable and strategic to follow the guidelines, as these could provide the benefits of the alliance (Clauss \& Bouncken, 2018). A buyer's expert power is based on the perception of suppliers that the buyer knows what the end user wants and signals knowledge and expertise in the design or distribution of new products to end users (Nyaga et al., 2013; Zhao et al., 2008). If buyers lack expertise, sellers may not provide relevant information when available, or they may be opportunistic in disseminating information (Clauss \& Bouncken, 2018). Policies and relationship standards are controlled by buyer policies. Research Issue 9 has been derived from the findings of Chinomona and Pretorius (2011), Clauss \& Bouncken (2018), and Nyaga et al. (2013) (Table 10). 


\begin{tabular}{|c|c|c|c|}
\hline Authors & Titles & Findings & Research Issues \\
\hline $\begin{array}{l}\text { Chinomona \& } \\
\text { Pretorius (2011) }\end{array}$ & $\begin{array}{l}\text { SME manufacturers' cooperation } \\
\text { and dependence on major dealers' } \\
\text { expert power in distribution }\end{array}$ & $\begin{array}{l}\text { SMEs can make up for their specific expert } \\
\text { power shortcomings by strategically } \\
\text { partnering with key partners who leverage the }\end{array}$ & \multirow{3}{*}{$\begin{array}{l}\text { 9. The intensity of expert } \\
\text { power within the buying } \\
\text { centre has an high } \\
\text { impact on the perception } \\
\text { of sales force expert } \\
\text { power. }\end{array}$} \\
\hline $\begin{array}{l}\text { Nyaga, Lynch, } \\
\text { Marshall, \& Ambrose } \\
\text { (2013) }\end{array}$ & \multirow{2}{*}{$\begin{array}{c}\text { Power asymmetry, adaptation and } \\
\text { collaboration in dyadic relationships } \\
\text { involving a powerful partner } \\
\text { Social power as an antecedence of } \\
\text { governance in buyer-supplier } \\
\text { alliances }\end{array}$} & $\begin{array}{l}\text { A power asymmetry of expert power can } \\
\text { enhance the partner's willingness to make } \\
\text { process or product adjustments. }\end{array}$ & \\
\hline $\begin{array}{l}\text { Clauss \& Bouncken } \\
\qquad(2018)\end{array}$ & & $\begin{array}{l}\text { If buyers are lacking in expert power, sellers } \\
\text { may not provide relevant information. }\end{array}$ & \\
\hline
\end{tabular}

Table 10: Research Issue 9

Source: Developed for this research project

Previous analyses have revealed that, with stronger and larger suppliers or less dominant buyers, the buyers' professional competence and reputation do not affect suppliers, because they do not need to trust the buyers (Kwak, Anderson, Leigh, \& Bonifield, 2019; Lai, Pai, Yang, \& Lin, 2009). The judgment of the representative of the buyer or supplier is respected. They are industry experts, and their business knowledge and experience makes them the most likely to make the right decision. Nyaga et al. (2013) discovered that expertise has a significant impact on the willingness of buyers and suppliers to adapt and collaborate. The positive impact of expert power asymmetry on adaptive behaviour implies that using expert power increases the partner's willingness to make product or process changes. Both buyers and suppliers assume that the other party is knowledgeable, reputable, and able to provide the desired goods and/or services (Palmatier et al., 2006). In general, it is the relationship quality, expertise, and reputation of the partner that most affects operational performance, while the impact of collaborative and adaptive behaviours on performance is comparatively lower (Nyaga et al., 2013). When a company has expert power, other companies feel that it has unique skills needed to perform certain tasks and therefore has a resource advantage (Chinomona \& Pretorius, 2011). The professional competence of a buyer influences the relationship engagement of the seller more than confidence (Nyaga et al., 2013). The managers in large buying companies use expert power to get sellers to work with them in the distribution channel system (de Ruyter, Keeling, \& Cox, 2018). The seller can compensate for his shortcomings in specific skills, such as marketing skills or product promotion, through strategic networking with large buyers who have the required expertise and experience (Chinomona \& Pretorius, 2011). 
Based on these results, it is evident that the attributes of sales force expert power are not clear in the literature, which leads to Research Issue 1 (Table 11).

\begin{tabular}{|c|c|c|}
\hline Authors & Titles & $\begin{array}{l}\text { Research } \\
\text { Issue }\end{array}$ \\
\hline $\begin{array}{l}\text { Woodside \& Davenport } \\
\text { Jr. (1974) }\end{array}$ & $\begin{array}{c}\text { The effect of salesman similarity and expertise on consumer purchasing } \\
\text { behavior }\end{array}$ & \multirow{17}{*}{ 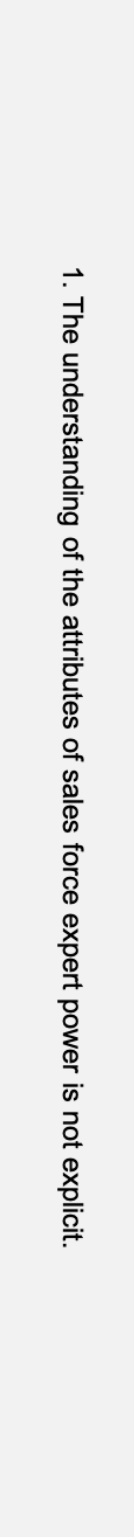 } \\
\hline Busch \& Wilson (1976) & $\begin{array}{l}\text { An experimental analysis of a salesman's expert and referent bases of social } \\
\text { power in the buyer-seller dyad }\end{array}$ & \\
\hline Taylor \& Woodside (1982) & Effects on buying behaviour of references to expert and referent power & \\
\hline Kohli (1989) & Determinants of influence in organizational buying: A contingency approach & \\
\hline $\begin{array}{l}\text { McFarland, Challagalla, \& } \\
\text { Shervani } \\
\text { (2006) }\end{array}$ & Influence tactics for effective adaptive selling & \\
\hline $\begin{array}{l}\text { Paesbrugghe, } \\
\text { Rangarajan, Sharma, } \\
\text { Syam, \& Jha (2017) }\end{array}$ & $\begin{array}{l}\text { Purchasing-driven sales: Matching sales strategies to the evolution of the } \\
\text { purchasing function }\end{array}$ & \\
\hline Sharma (1990) & $\begin{array}{l}\text { The persuasive effect of salesperson credibility: conceptual and empirical } \\
\text { examination }\end{array}$ & \\
\hline $\begin{array}{l}\text { Crosby, Evans, \& Cowles } \\
\text { (1990) }\end{array}$ & Relationship quality in services selling: An interpersonal influence perspective & \\
\hline Doney \& Cannon (1997) & An examination of the nature of trust in buyer-seller relationships & \\
\hline Liu \& Leach (2001) & $\begin{array}{l}\text { Developing loyal customers with a value-adding sales force: Examining } \\
\text { customer satisfaction and the perceived credibility of consultative salespeople }\end{array}$ & \\
\hline Sahadev (2005) & $\begin{array}{l}\text { Exploring the role of expert power in channel management: An empirical } \\
\text { study }\end{array}$ & \\
\hline Mallalieu (2006) & $\begin{array}{l}\text { Consumer perception of salesperson influence strategies: An examination of } \\
\text { the influence of consumer goals }\end{array}$ & \\
\hline Barnett White (2005) & $\begin{array}{l}\text { Consumer trust and advice acceptance: The moderating roles of } \\
\text { benevolence, expertise, and negative emotions }\end{array}$ & \\
\hline $\begin{array}{l}\text { Belonax Jr., Newell, \& } \\
\text { Plank (2007) }\end{array}$ & $\begin{array}{c}\text { The role of purchase importance on buyer perceptions of the trust and } \\
\text { expertise components of supplier and salesperson credibility in business-to- } \\
\text { business relationships }\end{array}$ & \\
\hline $\begin{array}{l}\text { Chinomona \& Pretorius } \\
\text { (2011) }\end{array}$ & $\begin{array}{l}\text { SME manufacturers' cooperation and dependence on major dealers' expert } \\
\text { power in distribution channels }\end{array}$ & \\
\hline $\begin{array}{l}\text { Nyaga, Lynch, Marshall, } \\
\text { \& Ambrose (2013) }\end{array}$ & $\begin{array}{l}\text { Power asymmetry, adaptation and collaboration in dyadic relationships } \\
\text { involving a powerful partner }\end{array}$ & \\
\hline $\begin{array}{l}\text { Clauss \& Bouncken } \\
(2018)\end{array}$ & Social power as an antecedence of governance in buyer-supplier alliances & \\
\hline
\end{tabular}

Table 11: Research Issue 1

Source: Developed for this research project

Table 12 summarises the results of previous studies regarding the role of expert power in organisational buying and personal selling. Nine research issues have been derived from the results, each of which has been assigned to one of the three research questions (see Section 2.5). The research issues form the basis for the further considerations in this research project. 


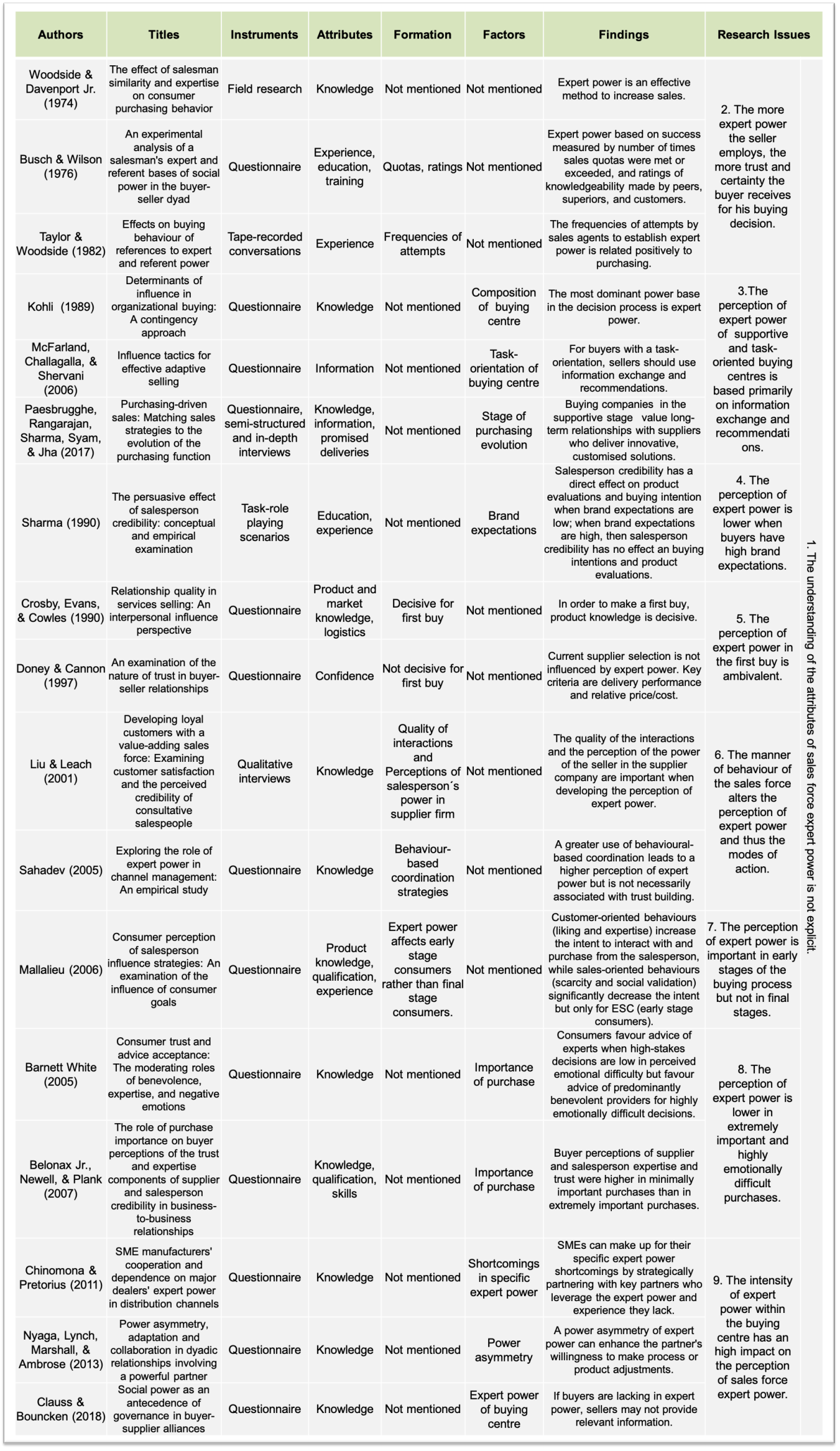

Table 12: Summary of previous research in the area of expert power Source: Developed for the research project 


\subsection{Organisational Buying and Personal Selling}

\subsubsection{Business-to-Business Market}

In the business-to-business (B2B) market (Figure 5), where capital-intensive industrial goods are marketed and sold, clients and sales forces are counterparts in the interaction (Backhaus \& Voeth, 2014; Ghingold \& Wilson, 1998; Homburg, Workman Jr, \& Jensen, 2002; Johnston \& Bonoma, 1981b; Moon \& Armstrong, 1994).

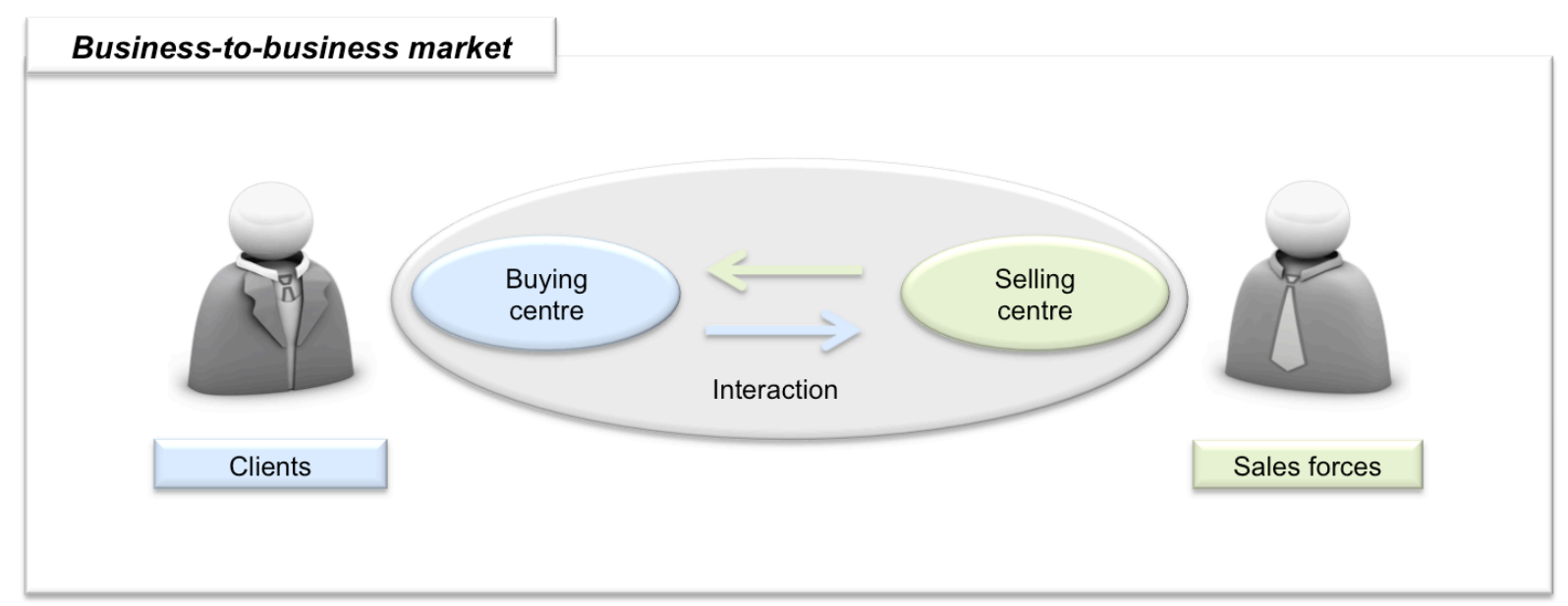

Figure 5: Interaction in business-to-business market

Source: Developed for the research project based on Backhaus \& Voeth, 2009; Ghingold \& Wilson, 1998; Homburg et al., 2002; Johnston \& Bonoma, 1981b; Moon \& Armstrong, 1994

Primarily explanation-requiring products and services are sold to business customers in the product and industrial plant business, as well as in the systems solution business (Backhaus \& Voeth, 2014; Hofbauer \& Hellwig, 2016; Winkelmann, 2012). The goal is an individual solution, custom-made for each client's problem (Ahlert, Wangenheim, \& Kawohl, 2008; Weitz, Sujan, \& Sujan, 1986). The buying decision has far-reaching consequences for the company (Doyle, Woodside, \& Michell, 1979). Therefore, the decisions are made rather cautiously (Doyle et al., 1979). A buying centre is created for this purpose (Johnston \& Bonoma, 1981b; Webster \& Wind, 1972). Its approach is influenced by the organisational buying behaviour (Johnston \& Lewin, 1996). To be able to adequately react to the demands of buying groups, selling centres are being created as counterparts (Homburg et al., 2002; Moon \& Armstrong, 1994). Explanation-requiring products and services are mainly sold via personal selling (Backhaus \& Voeth, 2014; Wotruba, 1991). E-commerce and supply chain management are additional sales channels in the B2B market (Hofbauer \& Hellwig, 2016; Homburg et al., 2016), though they are not considered further in this research. 


\subsubsection{Client's Perspective}

\subsubsection{Organisational Buying Behaviour}

Organisational buying decisions represent an important part of the purchasing process of organisations (i.e. enterprises, authorities, and associations), as buyers in the capital-intensive and industrial goods market, to purchase goods for processing or long-term utilisation (Backhaus \& Voeth, 2014). Kleinaltenkamp and Saab (2009) defined particular inherent characteristics of organisational buying:

- Derived demand: The demand for industrial goods is derived from the demand in the consumer market. Tangible and intangible goods are likewise demanded.

- Market transparency: Individual problem solutions imply an intensive decision process. Copious interactions between the buying and selling group lead to an almost virtual market.

- Sustainability of business relationships: Investment security, service, and support for durable goods necessitate a long-term relationship and entail profitability.

- Degree of formalisation: Defined processes, procedural rules, and competences impair the purchasing process. Depending on the structure of the company and the organisation in terms of specialisation, centralisation, and standardisation, the impact varies. Garrido-Samaniego \& Gutiérrez-Cillán (2004) added that the more marked the aforementioned structures are, the greater the participation and influence of each individual involved in the decision process.

- Heteronomy: Contractual links and internal company instructions constrain buying decisions.

Organisational buying behaviour is a multi-personal problem-solving process with several participating individuals and varying defined responsibilities (Duncan, 1940). This process is characterised by active information behaviour and frequent interactions within and among the participating groups (Johnston \& Lewin, 1996). A survey of medium-sized and large-scale enterprises by Spiegel-Verlag (1982) revealed that, on average, at least four individuals are involved in each phase of the goods and services buying process. In particular circumstances, up to 34 participants can influence the buying decision. The presence of more participants increases the complexity, which 
can prolong the decision-making process, particularly when there are poorly defined or varying goals and motives within the group.

To illustrate and characterise the interaction of influential factors of organisational buying behaviour, various general equilibrium models were conceptualised (Foscht \& Swoboda, 2007; Figure 6). General equilibrium models attempt to define all main dominant factors for collective purchasing decisions and highlight correlations, in contrast to partial equilibrium models, in which the main determining factors are contemplated in isolation from each other (Backhaus \& Voeth, 2009). General equilibrium models are subdivided into structure models, discussion of the relation of the main factors, and process models, with emphasis on the flow (Backhaus \& Voeth, 2014; Foscht et al., 2017). The joint model is a consolidation of decades of research efforts (Backhaus \& Voeth, 2009).

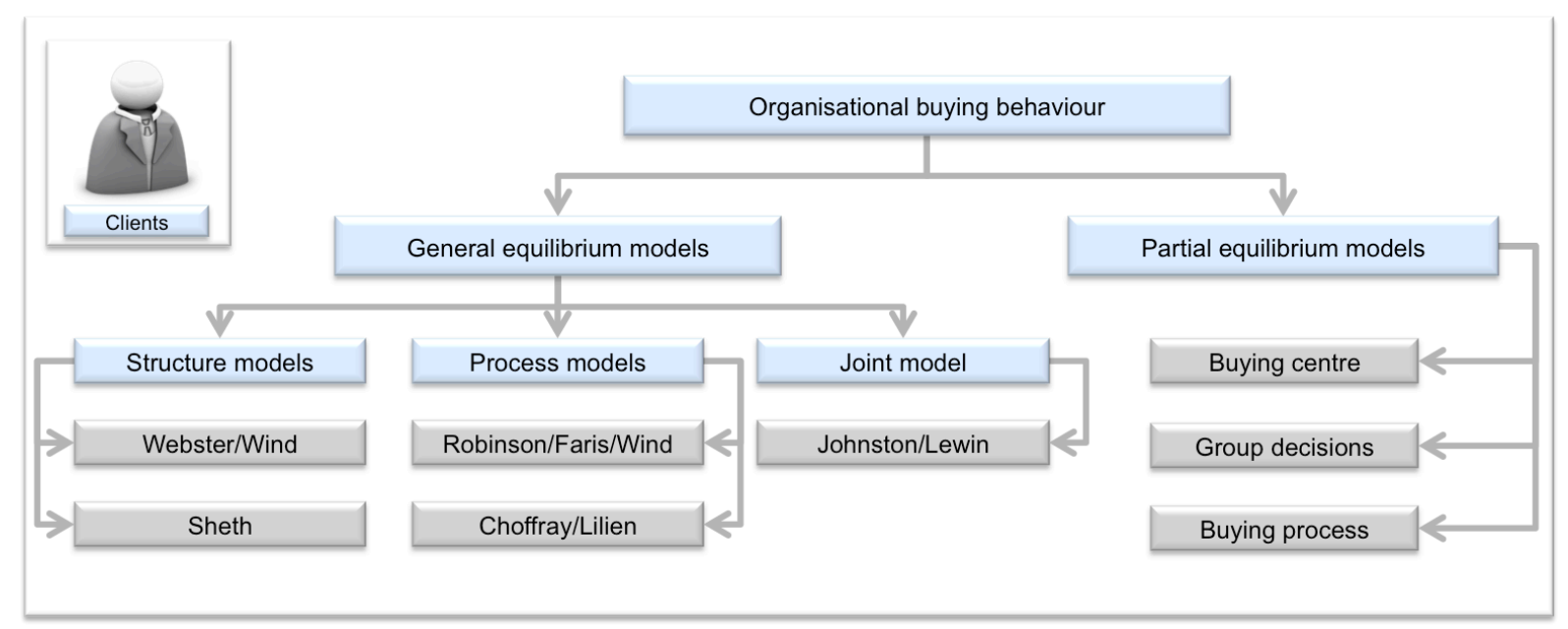

Figure 6: Models of organisational buying behaviour

Source: Developed for the research project based on Backhaus \& Voeth (2009); Foscht \& Swoboda (2007)

Hereinafter, solely the models which have a decisive influence on the research on organisational buying behaviour are mentioned. For further consideration, only relevant and new findings of these models are constituted.

\subsubsection{General Equilibrium Models}

\section{Structure Models}

Webster \& Wind (1972) identified four determinants that define organisational purchasing behaviour: 
1. Environmental influences: They encompass all external influential factors, such as political, legal, and technological restrictions. Their influence has a direct effect on the company's policy.

2. Organisational influences: They outline the frame of action for each individual. Organisational technology, organisational structure, goals, and objectives, as well as the members of the organisation, are taken into consideration.

3. Buying tasks: Buying tasks are the specific tasks necessary to perform the purchase, such as identifying a problem, illustrating and evaluating problem solutions and feasible alternatives, and determining suppliers.

4. Organisational actors: Decision makers are always individuals, so the knowledge extracted from studies of private consumer behaviour is moderately applicable. The decision of an individual depends on psychological factors such as motivation, cognitive structure and type of buyer, learning behaviour, and understanding of one's role.

The model illustrates the complex interaction between the determinants, which have been validated through further studies (Lau, 1999; Lilien \& Wong, 1984; Mattson, 1988; Ronchetto Jr, Hutt, \& Reingen, 1989). Nevertheless, limitations exist, since conflicts, for example, within the buying centre and with the suppliers, are not considered (Foscht \& Swoboda, 2007).

A differentiated view on the buying decision is depicted by Sheth (1973). The model encompasses both a collective and an individual buying decision. Sheth (1973) distinguishes three variables: the background of the participants, the industrial buying process, and the conflict resolutions. Preeminent is the supplementary emphasis on various conflict solutions. In addition, situational factors are introduced, such as price controls, recessions, strikes, and machine breakdowns, for instance, which could lead to a so-called ad hoc decision being made by an individual. Similar to Webster \& Wind (1972), many uncertainties remain. For example, the link to the buying process phases is absent, as well as the indication of feasible allocation of power within the buying centre (Backhaus \& Voeth, 2014). 


\section{Process Models}

The buygrid concept is a combination of various buying situations and purchasing decision phases within the buying process (Robinson, Faris, \& Wind, 1967). The following three buying situations are differentiated:

1. First Buy: Appraised decision patterns are not yet established, since the products or services are to be purchased for the first time.

2. Rebuy: A familiar and already utilised product is ordered upon request. Doyle et al. (1979) considers this to be a routine decision.

3. Modified rebuy: The buyer requests changes in the reacquisition of a product, such as to price, delivery conditions, or product specifications.

The more expensive and complicated services or products are, the more individuals are involved and the more time demanding and complex is the decision-making process (Garrido-Samaniego \& Gutiérrez-Cillán, 2004; Lau, 1999; Lewin \& Donthu, 2005). This circumstance specifically applies to a new-task buying situation (Doyle et al., 1979; Lilien \& Wong, 1984; Wilson et al., 1991). The demand for information and the scope of the purchasing process is directly correlated with the significance of the product (Lewin \& Donthu, 2005). If the product has minor relevance to the buyer on the other side, the complexity of the purchasing process can be reduced, even for a first buy (Garrido-Samaniego \& Gutiérrez-Cillán, 2004; McQuiston, 1989).

Contrary to the buygrid model, Choffray \& Lilien (1978) focus on personal and organisational buying preferences that eventually lead to a buying decision. The buying decision process of Choffray and Lilien (1978) consists of three phases: elimination of alternatives, formation of individual decision preferences, and formation of organisational decision preferences. To make a buying decision, various decision models are utilised (Choffray \& Lilien, 1978).

In regard to practical applicability, both models display significant weaknesses. The buygrid model neglects, for example, the composition and quality of a product and the associated information behaviour. Thus, Choffray and Lilien (1978) additionally differentiate between different product classes. Whether and to what extent the measuring methods proposed by Choffray and Lilien (1978) stand up to empirical scrutiny with an acceptable amount of effort is questionable. 


\section{Joint Model}

Johnston and Lewin (1996) complement the aforementioned models with two factors: decision rules and role conflicts. They describe decision rules as formal and informal procedures within the decision-making process, whereas role conflicts emerge from ambiguities, varying experiences, and expectations, as well as from the consequences of role performance during the buying process. The relevance of relations and existing networks between the supplier and the customer is highlighted. The risk continuum model was derived from these perceptions (Johnston \& Lewin, 1996; Thompson, Mitchell, \& Knox, 1998). The perceived risk of the buying decision is attributed to the implication of the purchasing intention, the uncertainty of the potential solution, the complexity of the compulsion to take action, and the time pressure (Johnston \& Lewin, 1996; Lewin \& Donthu, 2005). The higher the perceived risk, the more individuals are involved in the decision process and the more role conflicts occur (Garrido-Samaniego \& Gutiérrez-Cillán, 2004). In addition, the relevance of existing communication and information networks is increasing (Järvi \& Munnukka, 2009; Johnston \& Bonoma, 1981b; LaForge \& Stone, 1989). The findings of various empirical studies substantiate the efficiency of interrelationships (Backhaus \& Voeth, 2009).

\subsubsection{Partial Equilibrium Models}

\section{Buying Centre}

The buying centre consists of individuals in various positions and roles within the organisation (Johnston \& Bonoma, 1981b). These members have different interactive relations between each other and with external partners during the buying process (Ronchetto Jr et al., 1989; Webster \& Wind, 1972). The reason for the multiplicity of individuals involved in the buying centre is due to the perceived risk of the buying decision being shared among the members (Fließ, 2000). The risk of the buying decision is associated with the importance of the purchase, the time pressure, and the novelty of the purchase situation (Goh, Lau, \& Neo, 1999). In addition to the perceived risk, personal experience has a crucial impact on the decision process and the quantity of the involved members (Ghingold \& Wilson, 1998). Aside from that, the most dominant factor in the decision process is expert power, followed by reinforcement power (Kohli, 1989). 
According to Webster and Wind (1972), the following roles are defined within the buying centre (Figure 7).

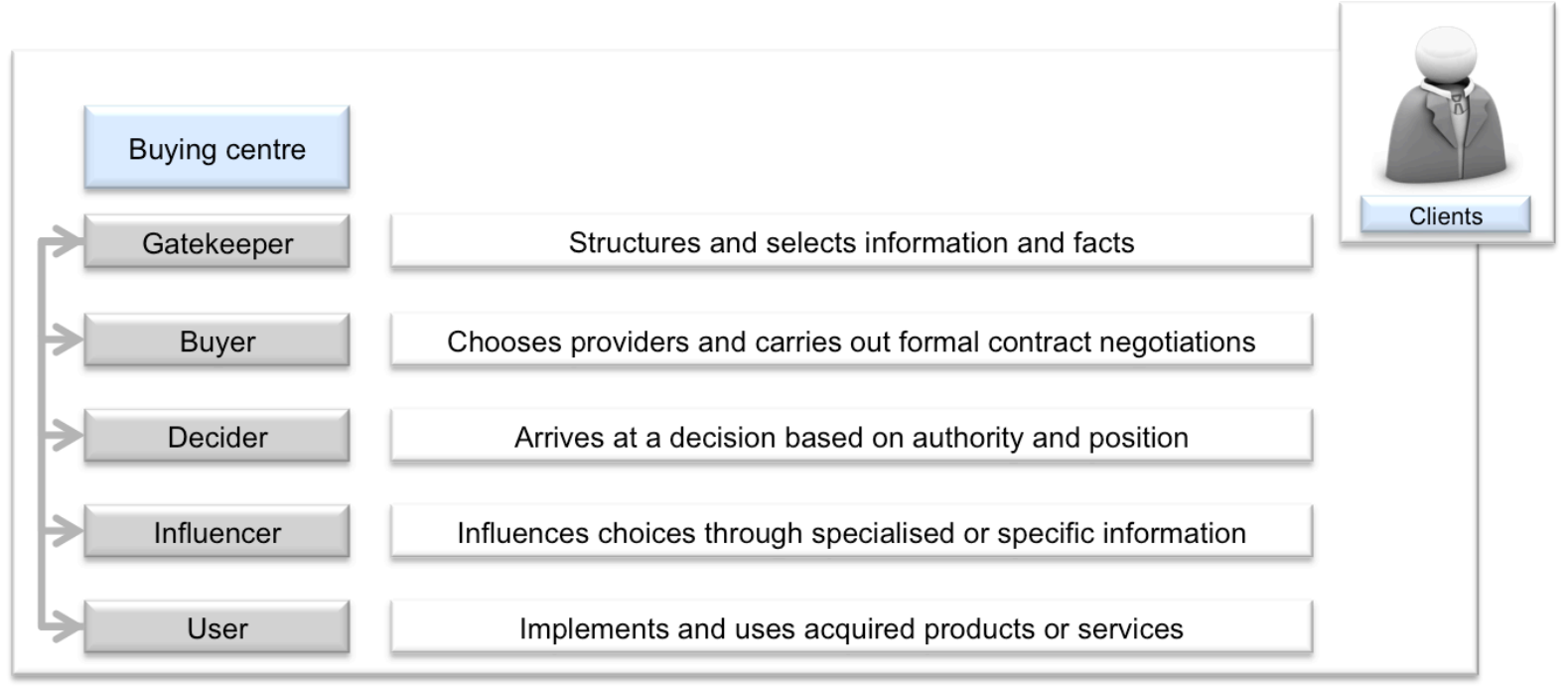

Figure 7: Buying centre

Source: Adapted from Webster \& Wind (1972)

The initiator, who recognises that a problem can be solved or avoided by purchasing a product or service, was added as a sixth role by Bonoma (2006). In addition to the Webster \& Wind model, further role models have been mentioned in the literature. The most popular are the promoter/opponent model (Hauschildt \& Kirchmann, 1997; Witte, 1976, 1999) and the gatekeeper concept (Allen, 1967). They differ from each other in terminology and focus, though the conclusions are ultimately quite similar.

In addition to the exercised roles, the relationship structure among the buying centre members and with external suppliers affects the decision process (Bristor, 1992). According to Johnston and Bonoma (1981), a buying network illustrates the relationships and impacts. They distinguished between five elements of differentiations. The vertical involvement, which represents the first element, states the number of hierarchy levels. The lateral involvement, the second element, focuses on how many departments are participating. The quantity of members, the third element, defines the magnitude of the buying centre. The number of possible communication relations, as the fourth element, reveals the intensity of task-oriented contacts. The fifth element, centrality, scales to which extent and how the purchasing manager intervenes in the process. 
In summary, a buying centre consists of individuals due to their function and role in the organisation (task-oriented) and individuals who pursue and achieve their own personal objectives (self-oriented) (Brinkmann, 2006; Johnston \& Bonoma, 1981a). Sheth (1976) mentions a third orientation, the interaction orientation. For buyers who have an interaction orientation, socialising and personalising is an essential part of the interaction. The primary responsibility of the sales force is to ascertain under which circumstances a decision is made. The crucial question of whether the decision is more likely to be based on expert power or reinforcement power must be answered by the salesman at an early stage in the interaction process (Fließ, 2000; Kohli, 1989). The methodological approach of the salesman depends strongly on the evaluation of the buying network (Weitz \& Bradford, 1999).

\section{Group Decisions}

Group decisions are affected, besides novelty, importance, and complexity of the aspired purchase, by environmental uncertainty, information needs, and the perceived risk (Anderson et al., 1987; Johnston \& Bonoma, 1981b; McQuiston \& Dickson, 1991; Wilson et al., 1991). After elimination of the alternatives that do not meet the requirements of the company, each buying centre member forms personal preferences based on subjective evaluations (Figure 8). These preferences are the key factors in decision making. On the basis of individual preferences, the organisational preferences are deduced and eventually lead to the buying decision (Brinkmann, 2006; Choffray \& Lilien, 1976, 1978). Besides their individual preferences, the relative influence of each individual buying group member plays an important role (Kohli, 1989; McQuiston \& Dickson, 1991; Silk \& Kalwani, 1982). Corfman and Lehmann (1987) constitute the output of the decision process, in addition to the model of Choffray \& Lilien (1978), as "a weighted function of the group members' individual preferences. The weights are defined by the relative influence of the members - each individual's influence over the other" (p. 2). Further impact on the decision is exerted by the decision frame (Tversky \& Kahneman, 1981). The decision frame evaluates the perceived outcome of a decision in relation to the alternative choices (Puto, 1987). Each buyer's determined reference point leads to framing the choice decision as either a gain or a loss (Puto, 1987). Stoddard and Fern (2002) observed that individuals whose choices were framed as gains made cautious choices, while individuals whose choices were framed as losses made risky choices. Group influence tended to 
enhance the effect of the decision frame. If the selection was classified as profit, the group decisions were no more cautious than the average individual decision. The supplier that best covered the most important attribute was selected in mixed multiattribute purchasing groups. Participants who were exposed to a gain decision frame needed to exert less effort and experienced a higher level of subjective decisionmaking certainty than affected participants with a loss decision frame. This increased decision certainty led to increased confirmatory tendencies in the information evaluation and search (Fischer, Jonas, Frey, \& Kastenmu, 2008).

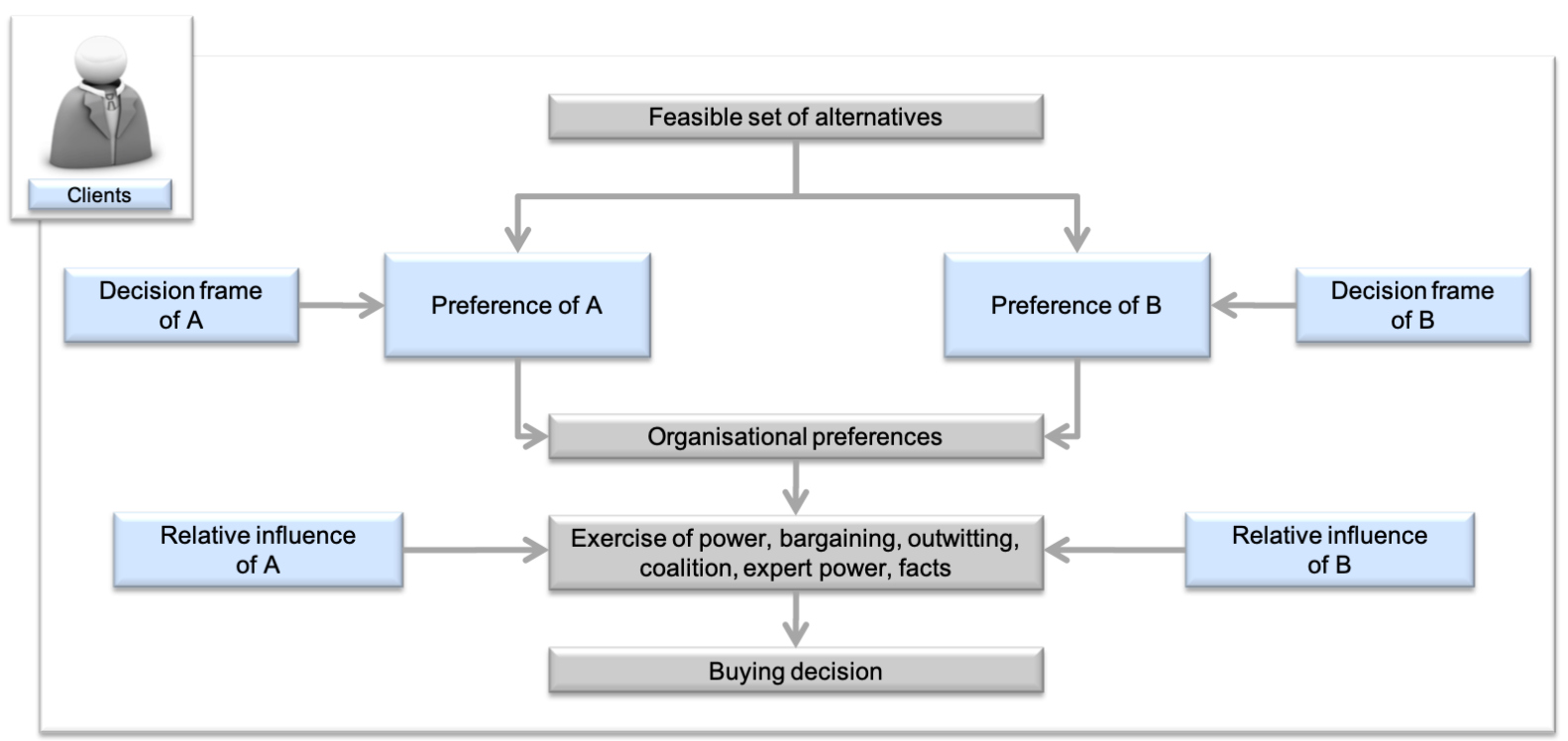

Figure 8: Model of group decision making

Source: Developed for the research project based on Choffray \& Lilien (1978); Corfman \& Lehmann (1987); Puto (1987)

Due to the variety of individual preferences and the complexity of the organisational environment, conflicts can occur during the process of group decision making (Corfman \& Lehmann, 1987; McNally, 2002; Wilson, McMurrian, \& Woodside, 2001). Contrasting aims, false expectations, lack of information, and even wilful deceits need to be considered and challenged (Fließ, 2000). Conflicts can be resolved through exercised power (Fließ, 2000), bargaining (Pruitt \& Carnevale, 2011), outwitting the constituent (Sheth, 1973), forming coalitions (Mummalaneni, 1984), or simply persuasion using facts, expert power, and logic (Daft \& Marcic, 2011). The decisions of the key account buying centre are not simply straightforward, objective, and rational, but rather involve a variety of strong emotions that are triggered during the sales process and influence the buying centre's decisions (Curasi, Boles, \& Reynolds, 2018). 


\section{Buying Process}

The literature provides a broad assortment of phase concepts with differing numbers of definable phases (Backhaus \& Günter, 1976; Backhaus \& Voeth, 2009; Brand, 1972; Heide \& Weiss, 1995; Rackham \& DeVincentis, 1998). The phase concept of Robinson, Faris, \& Wind (1967) distinguishes eight phases from problem recognition to performance review (Figure 9). The buying process as a problem-solving process in the selection of software encompasses the phases from project preparation to performance review (Vering, 2007).

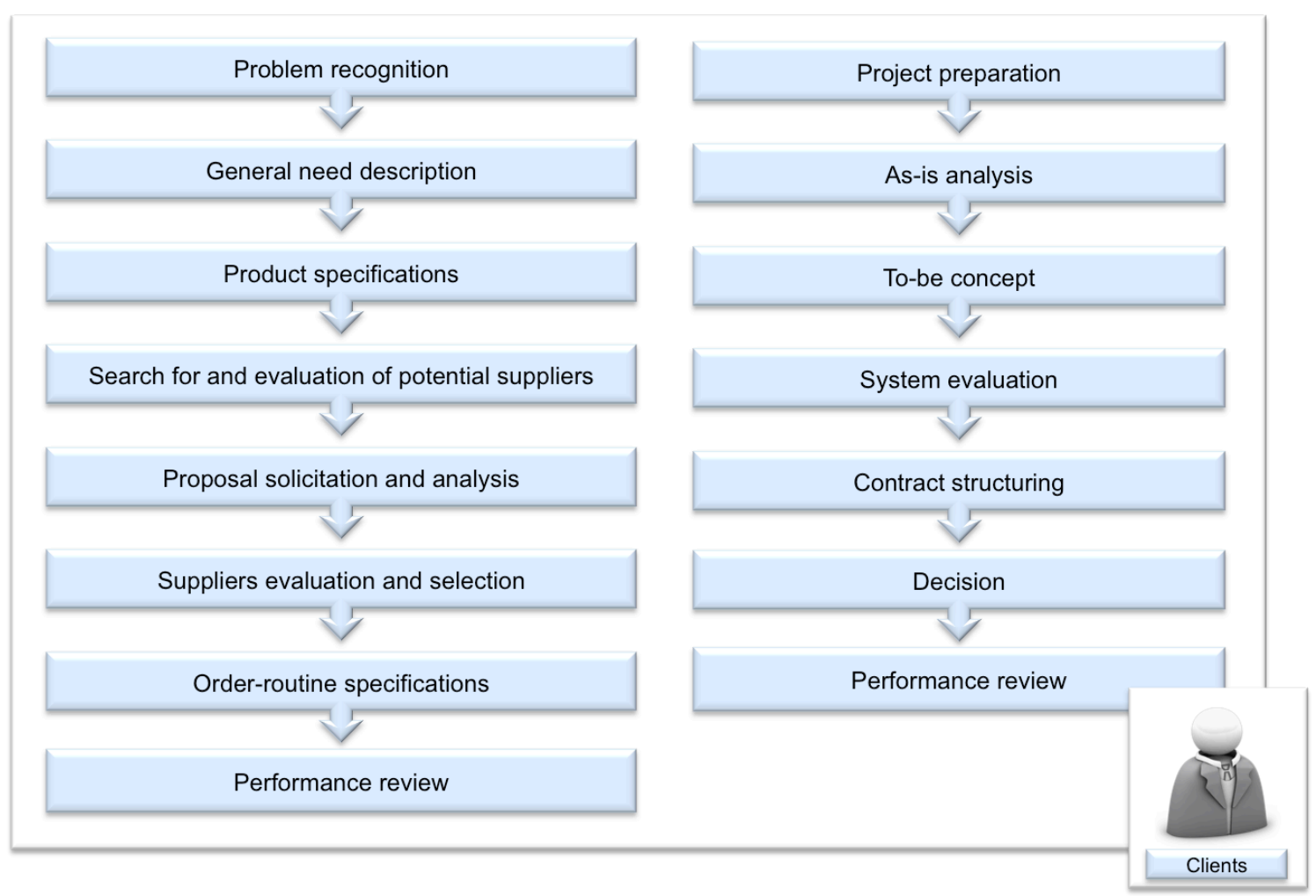

Figure 9: Buying process

Source: Adapted from Robinson et al. (1967) and Vering (2007)

When dealing with the first buy of a complex good, all phases of the buying process are equally significant (Wilson et al., 2001). The meticulousness involved the selection of the supplier is time consuming; however, it also ensures a long-term relationship with the supplier (Cannon \& Perreault Jr, 1999; Jolson, 1997; Rapp, Agnihotri, \& Forbes, 2008; Wilson, 1995). The experiences with the product and/or the supplier will influence future decisions (Mattson, 1988). In the case of a rebuy or minimally modified rebuy, certain phases can be shortened or omitted (Anderson et al., 1987). 


\subsubsection{Sales Force Perspective}

\subsubsection{Personal Selling}

\section{Characteristics}

To understand the motivations of sales forces, it is necessary to illustrate (Table 13) how personal selling has developed over the last 60 years (Hofbauer \& Schöpfel, 2010; Meffert, Burmann, \& Kirchgeorg, 2012; Weitz \& Bradford, 1999; Wotruba, 1991).

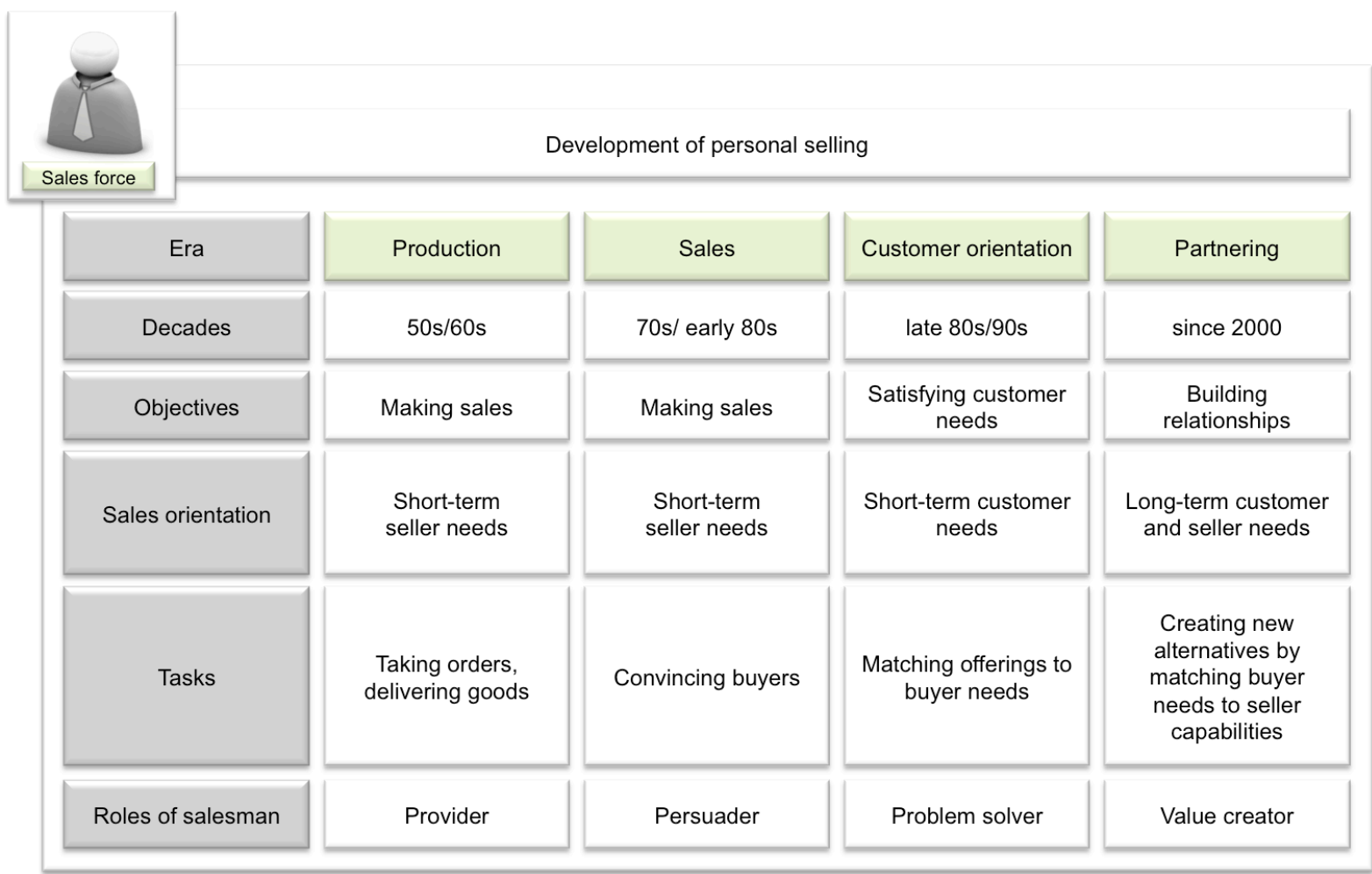

Table 13: Development of personal selling

Source: Developed for the research project based on Hofbauer \& Schöpfel (2010); Weitz \& Bradford (1999)

According to Hofbauer and Schöpfel (2010), in the fifties and sixties, a constant demand for goods was self-evident. It could not genuinely be viewed as an active selling process, but more as an allocation of goods. In the seventies and the beginning of the eighties, personal selling gained significance. Since then, the competition for winning new clients has continued to grow. The constant demand for products, as once taken for granted, has stalled. Thus, products and services must be sold. Starting in the late eighties, then stronger at the beginning of the nineties, the customers' problemsolving approach gained centre stage. Products and services that substantially solved the customers' problems were in focus. The companies realised that long-lasting customer orientation correlates with long-term success (Ulaga \& Eggert, 2006). The following phase, known as partnering, is defined as consciously building relationships 
in conjunction with the fulfilment of customers' expectations in terms of adding ascertained value to their businesses (Weitz \& Bradford, 1999). Artificial pressure, voluntary misstatements, and culminating extortion characterise sales methods with no long-lasting success (Brown, 1990; Delvecchio, Zemanek, McIntyre, \& Claxton, 2004; McFarland, 2003; McFarland, Challagalla, \& Shervani, 2006; Spiro \& Perreault $\mathrm{Jr}, 1979$ ). These aspects are not further explored in this review. Long-lasting and sustainable selling already begins at the first contact (Guenzi, De Luca, \& Troilo, 2011; Jolson, 1997). The customers themselves and the solutions to their problems comprise the origin of the sales process (Bradford et al., 2010; Stafford \& Sharma, 2000).

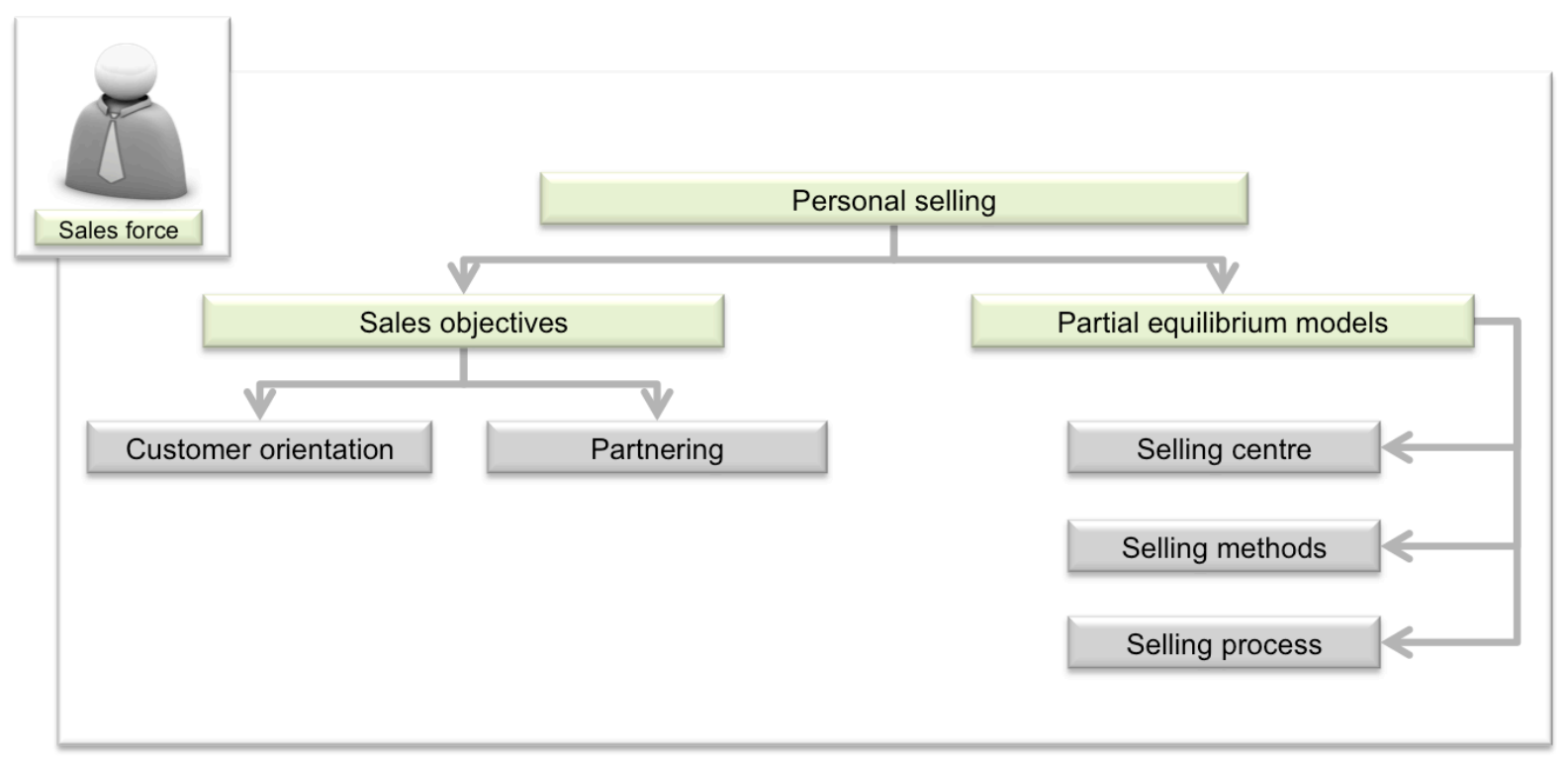

Figure 10: Personal selling

Source: Developed for this review

Sales objectives that support customer orientation and the partnering approach are further elucidated (Figure 10). Beyond that, a variety of partial equilibrium models, which are typical for the B2B market and considered important to the debate on organisational buying behaviour, are explained.

\subsubsection{Sales Objectives}

\section{Customer Orientation}

Saxe and Weitz (1982) defined customer orientation as "the practice of the marketing concept at the level of the individual salesperson and customer" (p. 343). A well-known approach developed for customer orientation is the so-called SOCO scale (Saxe \& Weitz, 1982). The SOCO scale concentrates on two main factors directed at measuring customer orientation. The first factor consists of 12 positive formulated indicators that 
describe the customer orientation. The 12 negatively formulated indicators of the sales orientation comprise the second factor. The positive effect of the customer orientation method on performance, job satisfaction, and commitment of employees has been validated in multiple studies (Brady \& Cronin, 2001; Donavan, Brown, \& Mowen, 2004; Stock \& Hoyer, 2005; Goff, Boles, Bellenger, \& Stojack, 1997). Nevertheless, these results are not indisputable. For example, Franke and Park (2006) were not able to measure the direct correlation between customer orientation and improvement of performance. Even a moderate pressure, considered to be negative on the SOCO scale, has a more positive than negative influence on performance (Brown, 1990; Haas, 2009). In routine buying situations, customer orientation plays a secondary role (Haas, 2009; Kroeber-Riel et al., 2009). A deliberate customer orientation by casual and low routine purchases has displayed no improvement in the results (Bunn, 1993). Plouffe, Hulland, and Wachner (2009) estimate the results of applying the SOCO scale as quite low. Excessive customer focus can even adversely affect employee performance if customer satisfaction comes before the personal interests and interests of the business (Haas, 2009; Müller, 2009), which is reflected in a weak closing of sales (Müller, 2009). Moreover, the increased amount of time delegated to the intensive support of one customer, as well as the increase in time needed for the preparation and follow-up of the leads, must be critically scrutinised (Haas, 2009). At the same time, more customers could be attended to, rather than concentrating all efforts on just a few (Haas, 2009).

The conclusions of the customer orientation approach form the basis for the development of the adaptive selling method (Arli, Bauer, \& Palmatier, 2018; Spiro \& Weitz, 1990). Adaptive selling is the ability to promptly react and adapt to different situations and requirements during the selling process due to recognition and assimilation of information (Weitz et al., 1986). The main elements of the adaptive selling approach include categorising of previous selling experiences, hierarchical organisation of knowledge structure, collection of process knowledge, and the collection of information about the current situation in comparison with the mentioned categories (Spiro \& Weitz, 1990). These conclusions were applied in various studies (Giacobbe, Jackson Jr, Crosby, \& Bridges, 2006). Porter, Wiener, and Frankwick (2003) discovered that the adaptive selling method is quite promising in complex first buys with high risk for the customer. On the other hand, in different studies, it was not 
possible to demonstrate an improvement in performance through the application of adaptive selling, or a sparse application of adaptive selling led to rather good selling results (C. E. Pettijohn et al., 2011; Plouffe et al., 2009). It was also proven that further factors, like the abilities of the selling centre, being street smart, or coincidentally having the same communication style as the buyer, significantly influence the performance of the seller (Seligman \& Schulman, 1986; Sujan, 1999).

\section{Partnering}

Partnering increases the customer's profit through the added value of the services bought, and the customer is able to improve its own position in the market and towards its customers (Shepherd, Miles, \& Munilla, 2011; Weitz \& Bradford, 1999). Persuasion is no longer the key factor; the seller influences the decision-making process to a greater degree with a well-conceived conflict management (Weitz \& Bradford, 1999). The early development of a sustainable customer relationship is helpful (Palmatier et al., 2006; Weitz, 1978). Furthermore, it is important to analyse and understand the objectives of the customer (Rackham, 1995). The objectives and demands of the sales force are not to be disregarded in the process (Bänsch, 2013; Rackham, 1995). Ulaga (2003) discusses, in this context, eight different value drivers that are necessary to establish a sustainable customer relationship: product quality, delivery, time-to-market, price, service support, supplier know-how, personal interaction, and process costs. The seller needs to be able to open a consecutive conversation designed to create customer value and to sell a customer solution, rather than a simple question-andanswer session designed to sell the product to the potential customer (Shepherd et al., 2011).

Selling customer solutions generates customer value and enables differentiation from the competition (Tuli, Kohli, \& Bharadwaj, 2007). Customer solutions are defined as a combination of systematic tailored goods and services that solve an individual customer problem including the individual after sales support (Rackham \& DeVincentis, 1998; Sawhney, 2006; Ulaga \& Eggert, 2006). The most important elements of the customer solution approach are:

- Integration of performance characteristics: Through the integration of performance characteristics, a complete problem solution can be implemented (Sawhney, 2006). Shin, Collier, and Wilson (2000) differentiated four different 
performance characteristics: (1) a long-term relationship with a supplier, (2) integration of the supplier in the product development process, (3) quality performance as the top priority for selecting suppliers, and (4) a reduced number of suppliers. For the customer to have as few contact persons as possible, the goal is to offer the solution and further advisory as one whole package, even if the solution requires different providers (Sawhney, 2006; Schmitz, 2008). In the best-case scenario, the solution as the links between each individual performance characteristic and the application of rational interfaces, as well as the definition of wide-ranging service processes, are embedded in the customer's added value chain (Ahlert et al., 2008; Woisetschläger, Backhaus, \& Michaelis, 2009).

- Customising: The customer solution is specially designed to solve an individual customer's problem (Tuli et al., 2007). The customer therefore acts as the "CoCreator of Value" (Vargo \& Lusch, 2004).

- Relationality: The implementation of a customer's solution and the necessary after-sale support through the setup and further development originate multifaceted and complex business relations (Schmitz \& Eberhardt, 2009; Tuli et al., 2007).

The duties of the so-called solution manager comprise considerably more tasks than for the classical salesperson, for whom the realisation of sales is the main goal (Evans et al., 2002; Schmitz \& Eberhardt, 2009). The coordination and support of the customer through the entire buying and implementation process, culminating in after-sale support, are regarded as additional core tasks (Tuli et al., 2007; Ulaga \& Eggert, 2006).

Partnering and solution selling pose particular challenges to companies (Ahlert et al., 2008; Sawhney, 2006; Shepherd et al., 2011). Various studies have indicated that, due to false or vague sophisticated combinations of products and services, no real added value for the customer and one's own company can be achieved (Neu \& Brown, 2005; Oliva \& Kallenberg, 2003). Furthermore, the training of employees to become value creators and strategic sellers is tedious, prolonged, and, as a result, cost-intensive (Shepherd et al., 2011; Ulaga \& Sharma, 2001; Woisetschläger et al., 2009). Only if one's own company's objectives and the service portfolio are clearly defined can an 
investment in the implementation of partnering be considered worthwhile (Jolson, 1997; Tanner, 1999; Wilson \& Vlosky, 1997).

\subsubsection{Partial Equilibrium Models}

\section{Selling Centre}

The selling centre encompasses all participants from the supplier who are involved in the selling process (Blessington, 1989; Heger, 1984; Weitz \& Bradford, 1999). Contrary to the concept of Smith and Barclay (1989), a selling centre membership is not limited to direct customer contact. This inclusion may contain direct customer contact, but it may also contain information or advice to other members of the selling centre regarding product specifications, expected product changes, and financial alternatives, among others. Moon and Armstrong (1994) distinguish between a core team and a selling centre. The core team focuses on the customer and building a long-term customer relationship, while the selling centre concentrates on the transaction. For every sales opportunity in which the supplier participates, a selling centre is established. The actions of each group affect each other. The selling centre is not given the same consideration as the buying centre in the literature (Wiswede, 2007). The term "selling centre" is more used in practitioner-oriented literature and is not based on theory (Moon \& Armstrong, 1994). Pesch (2010) annotates the differentiation of roles between offender, follower, facilitator, and expert. Moon and Armstrong (1994) designed a role model for the selling centre, which is well recognised in the literature. Figure 11 presents an overview of the distinguished roles and the tasks involved.

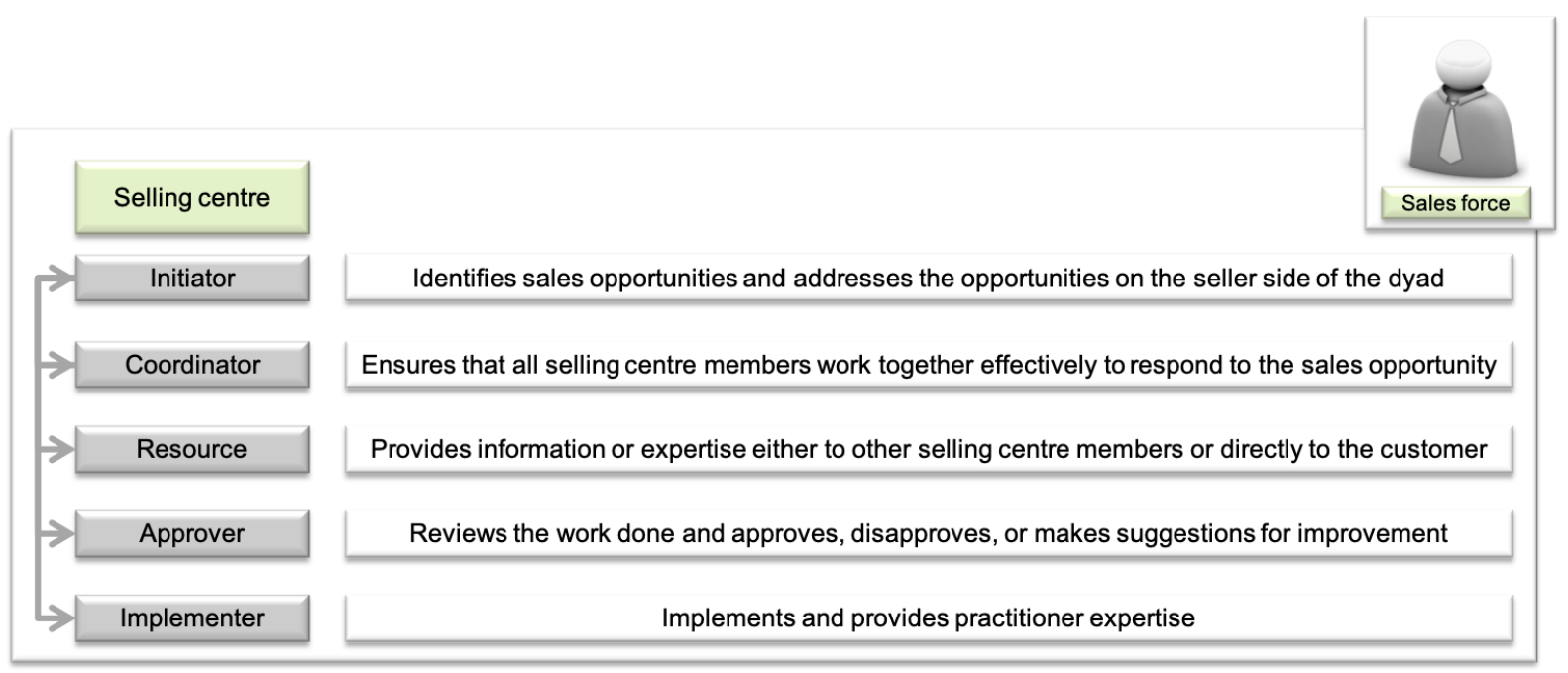

Figure 11: Selling centre

Source: Developed for the research project based on Moon \& Armstrong (1994) 
Johnson, Matthes, and Friend (2019) suggest that the selling centre be expanded to include marketing staff. In addition to improving the understanding of each other, the expanded selling centre can focus more strongly on the customer's questions and needs. The more participants in a group, the more complex the control of the group becomes. The added value for the customer is minimal compared to the disadvantages. Therefore, the concept of Johnson, Matthes, and Friend (2019) is not included in the further considerations of this research.

Selling centres represent the counterpart to buying centres (Figure 12). The interaction process in the industry market between the buying centre and the selling centre is diverse and characterised by various reciprocal actions and reactions (Foscht \& Swoboda, 2007).

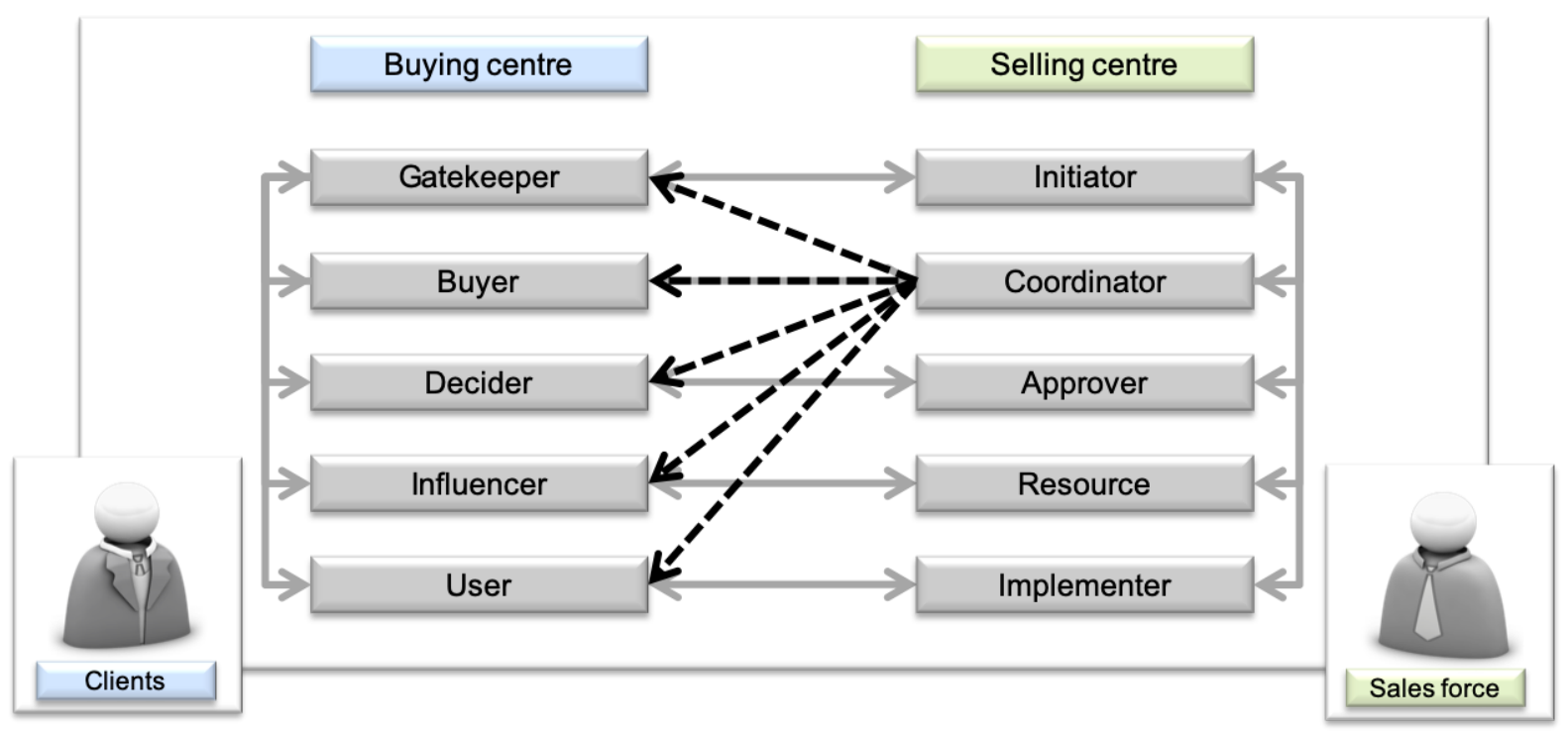

Figure 12: Interaction between buying group and selling centre

Source: Developed for the research project based on Moon \& Armstrong (1994); Webster \& Wind (1972)

The coordinator ensures that all members of the selling centre effectively work together to respond to the sales opportunity. In the investigations of Moon and Armstrong (1994), someone from the product marketing group acted as the coordinator, which is unusual. The role of the coordinator is essential to the success of the selling centre. It should be staffed by a salesperson who has a sufficient understanding of the customer and his or her needs, as well as product knowledge. With the increasing importance of sales for both the seller and the buyer, the organisation of the selling centre is more pronounced in vertical and horizontal terms, more comprehensive, and more connected (Moon \& Armstrong, 1994; Moon \& Forquer Gupta, 1997). It is important to understand how an effective selling centre can be built to facilitate collaboration between functional departments to meet customer needs. Frequently, members of a 
selling centre originate from different departments and are subject to different control systems. Some members of selling centres are more controlled by behavioural controls, while others are more likely to be controlled by results (Murtha, Shervani, Challagalla, \& Kirkman, 2014). Those subject to a behavioural control system are usually more tied to the organisation, are more long-term oriented, accept more authority, and are less at risk than those working in a results-based control system (Oliver \& Anderson, 1995). Although each team member in a selling centre may have his or her own goals, joint sales success is the key driver and glue for the cohesion of the centre (Moon \& Forquer Gupta, 1997). Both social capital and knowledge transfer and absorption are important for selling centre performance (Brashear Alejandro, Boles, \& Yang, 2011). The internal social capital is derived from its internal social network, which refers to the communication network between members of the selling centre (Brashear Alejandro et al., 2011; Murtha, Bharadwaj, \& Van den Bulte, 2009). External social capital originates from the sales centre's external social network, which includes the selling centre's connections to the buying centre (Brashear Alejandro et al., 2011). The diversity of control systems positively correlates with the decisionmaking authority if the task significantly influences the status of the members of the selling centres within the company and the chances of career development (Murtha et al., 2014). The members of the selling centre tend to synchronise their different attitudes and are ready to discuss different perspectives on the task to ensure comprehensive decisions. In the sales process, value orientation plays an increasingly important role, such that pure price-oriented discussion takes a back seat (Papenhoff, Schultz, \& Welle, 2018). For example, in the context of the so-called total cost of ownership in the sales process, direct and indirect costs of a possible investment are discussed. For the members of a selling centre, the increasing value and benefits discussion raises the demands on business management knowledge. Papenhoff et al. (2018) suggest selling centre members should at least have basic knowledge of controlling, investing, and financing.

\section{Selling methods}

McFarland, Challagalla, and Shervani (2006) discovered that two-thirds of all buyers align along multiple orientations according to the different types of the buyersorientation approach (task oriented, interaction oriented, self-oriented [Compare with Section 2.2.2]) of Sheth (1976). As a result, it is concluded that different selling 
methods should be applied to persuade buyers. Different sales methods have been developed on how to proceed with a sales pitch (Bänsch, 2006; Weitz, 1978; Winkelmann, 2008). In this context, a sales method is considered to be a temporal sequence of sales psychological efforts and activities used to influence the buying decision of a buying group, which are applied within the sales pitch or the sales process (Meffert et al., 2018). The oldest method is the AIDA model (attention, interest, desire, action) (Lewis, 1903). This model could not be proven empirically; nevertheless, its use is widespread (Vakratsas \& Ambler, 1999). The method is rarely appropriate in a B2B market situation when selling explanation-requiring products, as the buying behaviour is more problem-solving oriented than striving for pleasure (Winkelmann, 2008). These problem-oriented requirements are fulfilled by the SPIN method (Rackham, 1988; Rackham \& DeVincentis, 1998). The SPIN method (Table 14) is frequently applied by practitioners and acknowledged by academics (Plouffe, Hulland, \& Wachner, 2009; Shepherd, Miles, \& Munilla, 2011). Only through the deliberate constitution of the problem and the involved consequences is the customer willing to accept a solution (Koponen, Julkunen, \& Asai, 2019). Therefore, a severe calculated consternation is provoked (Friend, Ranjan, \& Johnson, 2019). The consternation or dissatisfaction is the key factor for closing the sale (Felser, 2007). Rackham (1995) divided the proceedings into four steps and concentrated on the relevant issues associated with each step (Table 14).

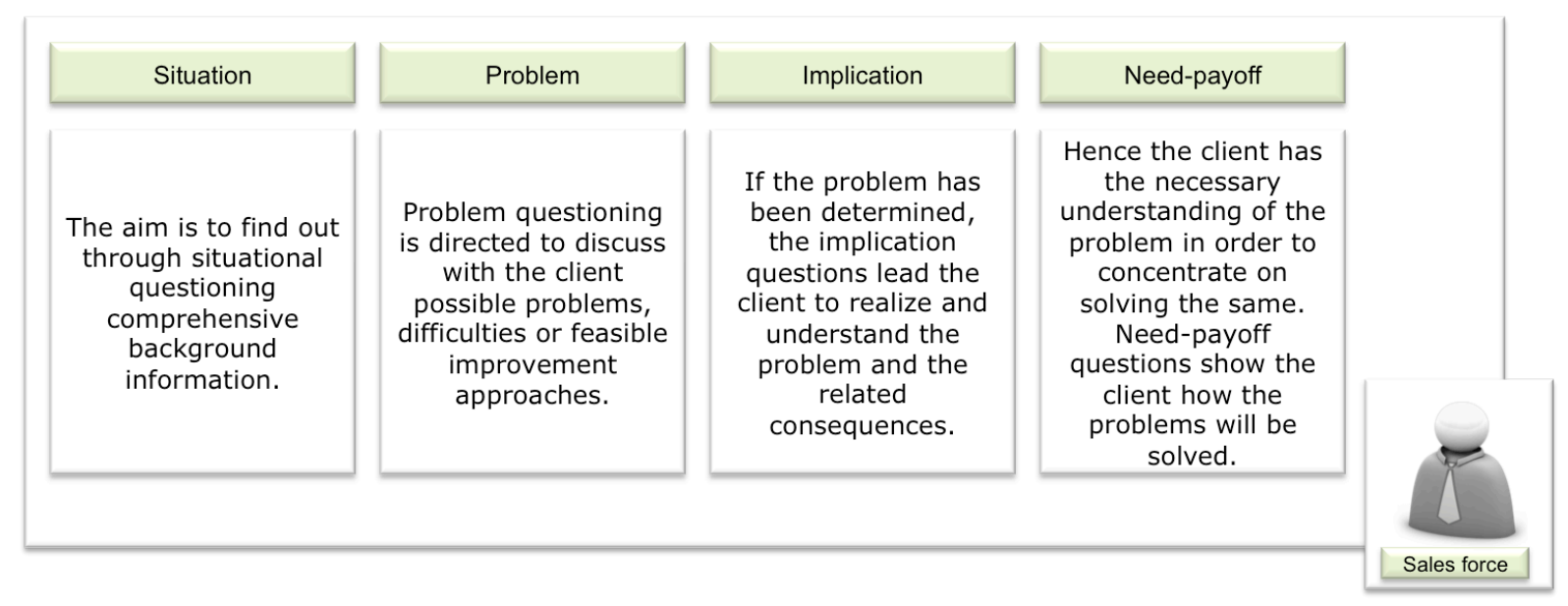

Table 14: SPIN

Source: Developed for this review based on Rackham (1995)

The SPIN method is applicable to complex sales situations, but it is not sufficient to substantially comply with the requirements (Eckert, 2006). The Prime method can thus be seen as a logical further development of the SPIN method (Rackham \& 
DeVincentis, 1998; Thull, 2012). The approach has its foundations in the SPIN method, but it goes into substantially more detail. The Prime method concentrates not only on asking the proper questions, but also on a deep examination and elaboration of customer needs, problems, and requirements to provide a hegemonic, customised solution (Thull, 2012). Four phases are differentiated (Table 15).
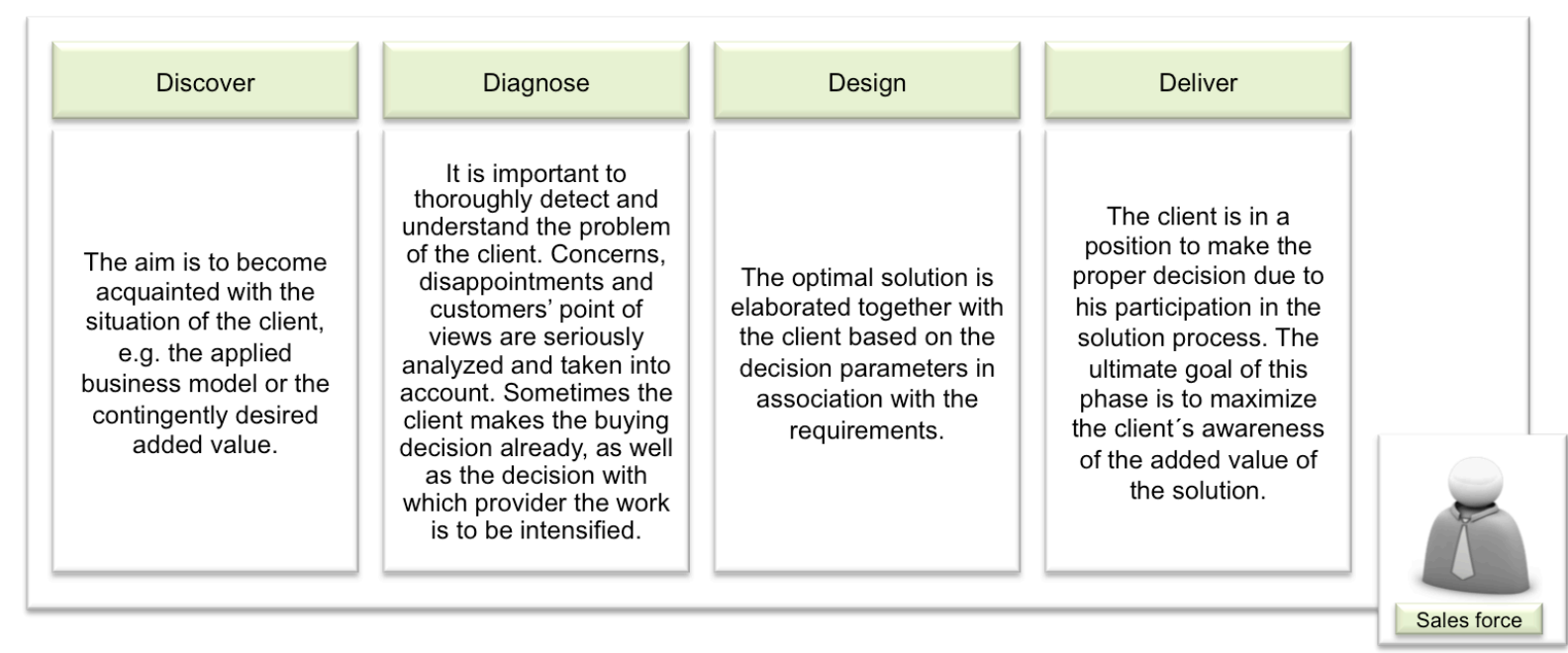

Table 15: Prime method

Source: Developed for the research project based on Thull (2012)

Based on Kohli (1989) and Sheth (1996), a combination of SPIN and Prime optimally supports the solution-selling approach when primarily dealing with task-oriented buyers (Figure 13). 


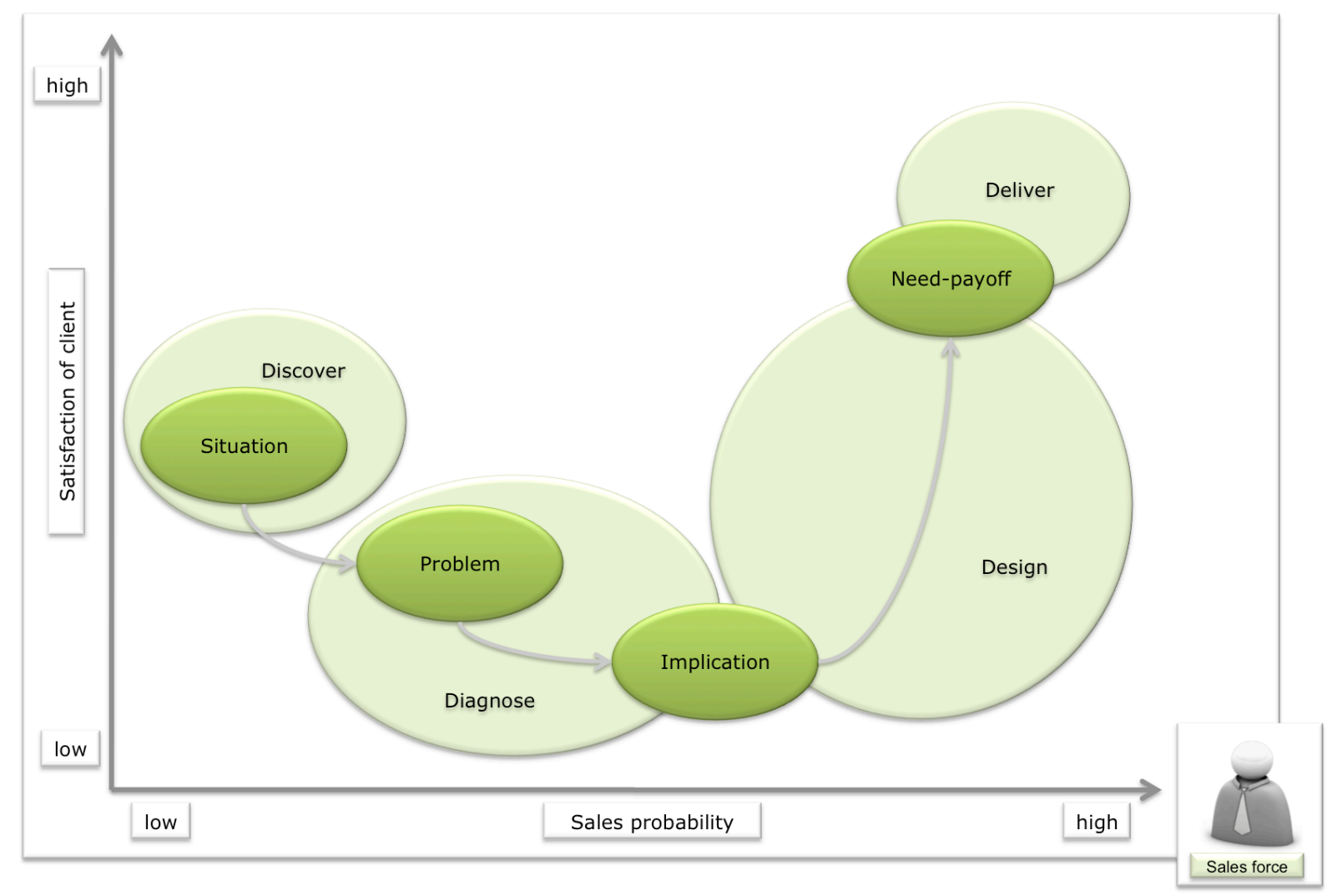

Figure 13: Combination of SPIN and Prime method

Source: Developed for the research project based on Rackham (1995); Thull (2012)

If the buying centre consists predominantly of self-oriented buyers, the seller should place more emphasis on congeniality, ingratiation, and promises (Sheth, 1976). Organisational buying decisions are made under risk and uncertainty (Johnston \& Lewin, 1996). Risk and uncertainty refer to the possibility that the acquired solution is not able to solve the company's requirements. Furthermore, when the wrong decision has been made, the positions of the buying centre members could be compromised (Ulaga \& Kohli, 2018). Therefore, buying centres have keen interests in making appropriate decisions. These interests are distinct from the decision frames of each member (Puto, 1987). Since, in a first buy, the selling centre and its products are not well known, and an extended experimental phase is not usually possible, the buying centre must trust the selling centre (Mallalieu, 2006). Consequently, the goal of the selling centre is to gain the confidence of the customer. The SPIN method and the Prime method are tools the selling centre can use to influence the decision frame of customers (Figure 14). 


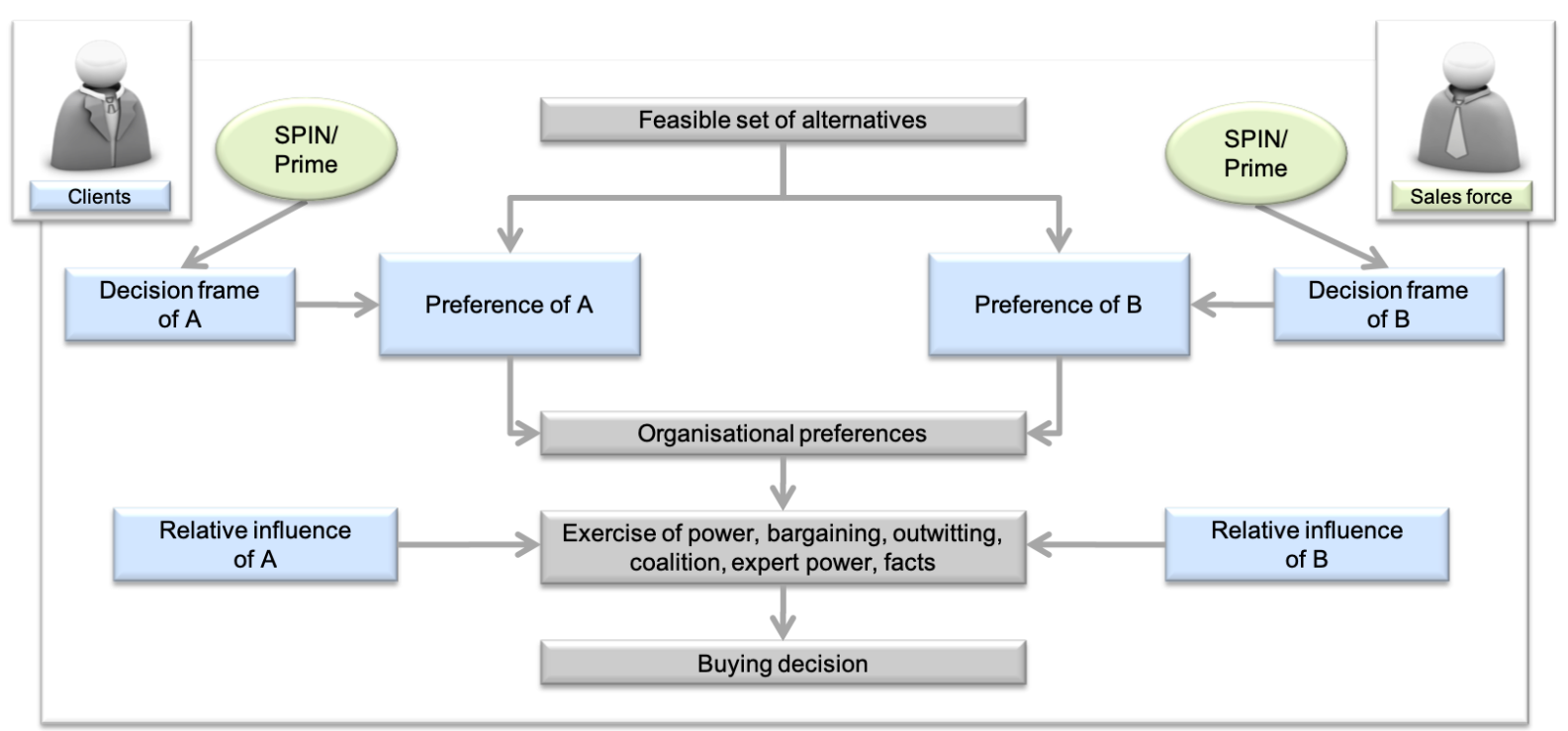

Figure 14: Influence of SPIN/Prime on the buying decision process

Source: Developed for the research project based on Choffray \& Lilien (1978; Corfman \& Lehmann (1987); Puto (1987);

Rackham (1995); Thull (2012)

According to Rotter (1971), trust is based on fulfilling expectations that words, promises, or verbal or written agreements of a person can be relied on. A differentiation is made between specific expectations for a concrete person and situation, and general expectations based on a previously experienced situation.

Various studies have revealed that trust has a strong influence on the perception and customer's preference building through the utilisation of expertise (Busch \& Wilson, 1976; Butler, 1991; Doney \& Cannon, 1997; Sonnentag \& Lange, 2002). Every time the selling centre genuinely understands the buying centre and gets deeply involved, the buying centre perceives acceptance and understanding (Szymanski, 1988). Certainly, the buying centre is not able to solve its problems alone. Therefore, it deliberately seeks out a solution. Generally, it is not able to estimate the value of the solution being bought and must rely on the statements and experience of the selling centre. Trust is originated when the individual problems are being solved. The probability that this happens is much higher when the selling centre can persuade the buying centre with expert power (Busch \& Wilson, 1976). Expert power is displayed, for example, when complicated issues are explained in a simple and comprehensible way, or when all of the customer's questions are answered to his satisfaction. Another indication for expert power is that the sales force is able to speak at eye level with a customer that has a deep technical background and even provides him/her with tips and tricks on how work can be done even more efficiently (Sirdeshmukh et al., 2002; Szymanski, 1988). 
Schmitz and Dietz (2009) identified a link between solution-oriented expert power and method, social, and personal competences. Solution-oriented expert power is derived by the following competences (Figure 15).

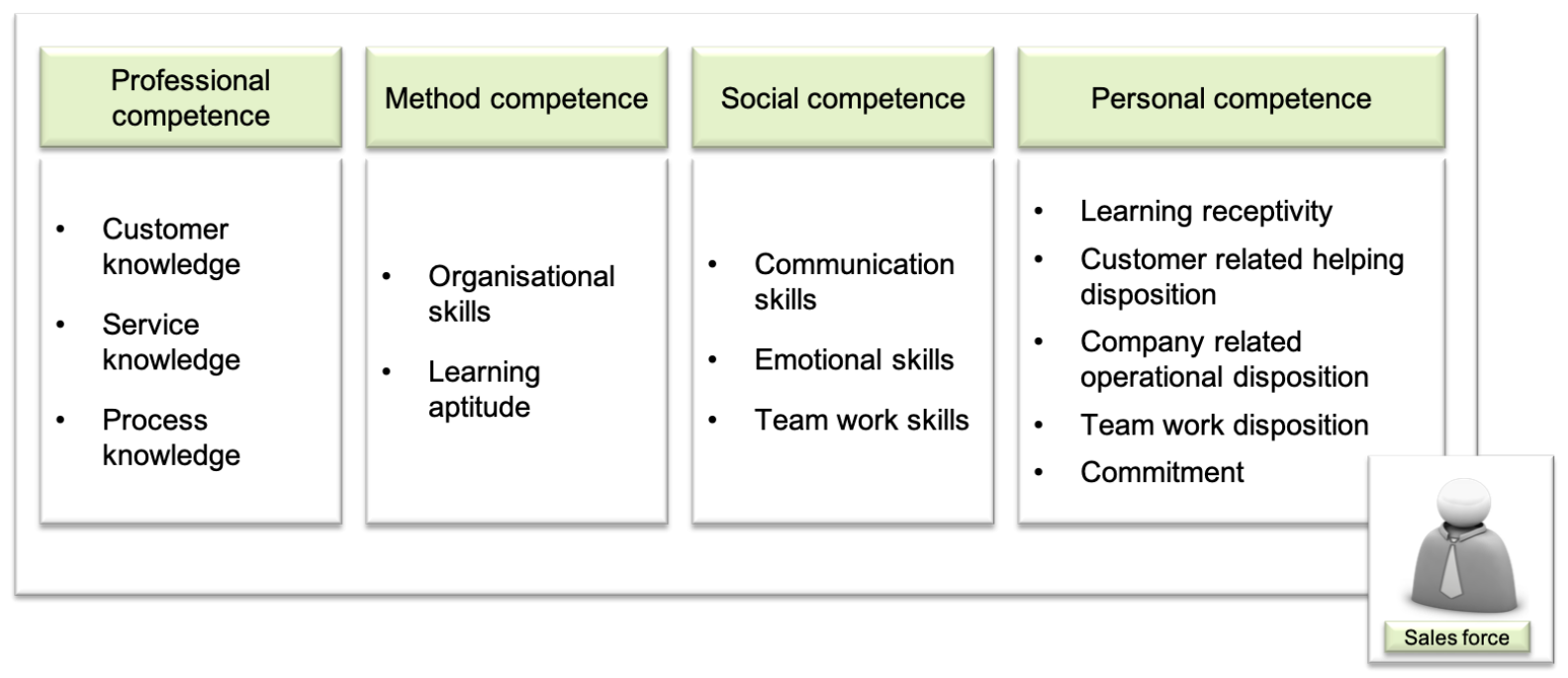

Figure 15: Solution-oriented expert power

Source: Developed for the research project based on Schmitz \& Dietz (2009); Schmitz \& Eberhardt (2009)

Sales forces with high solution-oriented expert power combine the aforementioned skills (Figure 15) and apply them in a goal-oriented way (Homburg, Schäfer, \& Schneider, 2006). They understand customers better and more quickly, they are qualified to solve problems, and they combine the company's offerings and customer's needs more successfully (Bunderson, 2003; Stock \& Hoyer, 2005; Tuli et al., 2007). They build trust with the customer. Further aspects that improve trust are congruent goals, a positive reputation, and good communication (Anderson \& Weitz, 1989). Ulaga and Kohli (2018) outlined the role of a solution vendor as a way to reduce uncertainty throughout the process by providing relevant stakeholders of the customer and supplier organisations with relevant information and promoting the adaptive behaviour of the parties involved.

It is essential by this contemplation that both parties trust each other (Anderson \& Weitz, 1989). Building a long-term partnership is based on trust (Weitz \& Bradford, 1999). Companies that trust each other will continue working together in the future (Doney \& Cannon, 1997; Wren \& Simpson, 1996). Difficult economic situations or differences between these companies are more quickly fixed when trust is the base of the relationship. 
It has been pointed out that risk and uncertainty within a buying centre is diminished through trust and that trust has an influence on building preferences in the buying decision process. Nevertheless, Swan, Bowers, and Richardson (1999) restrained this influence. Through a meta-analysis, they discovered that there is only a moderate correlation between trust and salespeople's competence. According to them, competence is crucial to be able to rely on one's business partner. Sahadev (2005) further argued that expert power is also not strongly associated with trust. In addition to competence, they noted another component to building trust: benevolence. This implies that the sales force has displayed positive intentions towards the customer. Similar to competence, benevolence has only a moderate influence in building trust. Likewise, the influence of experience and selling techniques could not be empirically proven. According to Swan et al. (1999), expert power is only meaningful when building a relationship. During the business relationship, a mutual understanding is developed. Other experiences have a minimal influence on trust. Nevertheless, it can be concluded that a wide range of negative experiences influence trust and that sales techniques are successful. The number of experiences associated with building trust has not been empirically researched, though the utilisation of sales techniques has. Despite the moderate influence of trust on the buying decision, Swan et al. (1999) recommended and supported all measures to develop trust in a business relationship.

\section{Selling Process}

Various selling processes are distinguished, depending on the industry sector, and requirements differ from each other in the various phases (Hofbauer \& Schöpfel, 2012; Moncrief \& Marshall, 2005; Winkelmann, 2008). For further consideration, the sales process is viewed as a formal illustration of the working stages from customer approach to performance mandate. The implementation of opportunity management is typical for an industry sector that is mainly active in project business, or when the product selling requires much explanation (Winkelmann, 2008). This applies to the entire management of meaningful sales projects. The phases are differentiated from each other as follows (Hufgard et al., 2005; Figure 16):

- Lead: The lead is a business object that expresses the basic interest of a customer. This interest has not yet been verified or qualified. 
- Opportunity: The opportunity is an acknowledged possibility for a sale. The sales probabilities, for example, are evaluated in percentages.

- Offer: The business object offer is a declaration of intention from one side to the addressees. It contains the explicit service offer on predetermined conditions. This is to be understood under the premise that there is a conception of solution approaches and the demonstration that it can be implemented.

- Order: The order is placed under the predetermined conditions. If the addressee accepts the offer, the deal is closed.

- Performance mandate: The order becomes a performance mandate when the salesperson has forwarded the order to the department, which is responsible for the implementation or for providing the service. This is the starting point, for example, for the consultant to begin with the implementation.

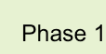

Lead
Phase 2 Opportunity
Phase 3

Offer
Phase 4

Order
Phase 5

Performance

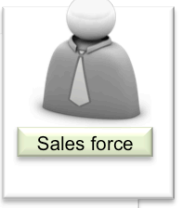

Figure 16: Selling process

Source: Developed for the research project based on Hufgard et al. (2005)

To be able to place an offer, the requirements and general conditions between the contracting parties must be clarified. In the case of complex products, or when many explanations for the problems or requirements are necessary, the contracting party prepares a user requirement specification (URS) (Santos Soares \& Vrancken, 2008). The equivalent document from the counterparty is the functional specification document (FSD) (DeMarco, 2002). The selling centre defines its services in the FSD on the basis of the customer requirements. These requirements allow the prospective contractor to make a firm offer to carry out a project (Stolle \& Herrmann, 2006). 


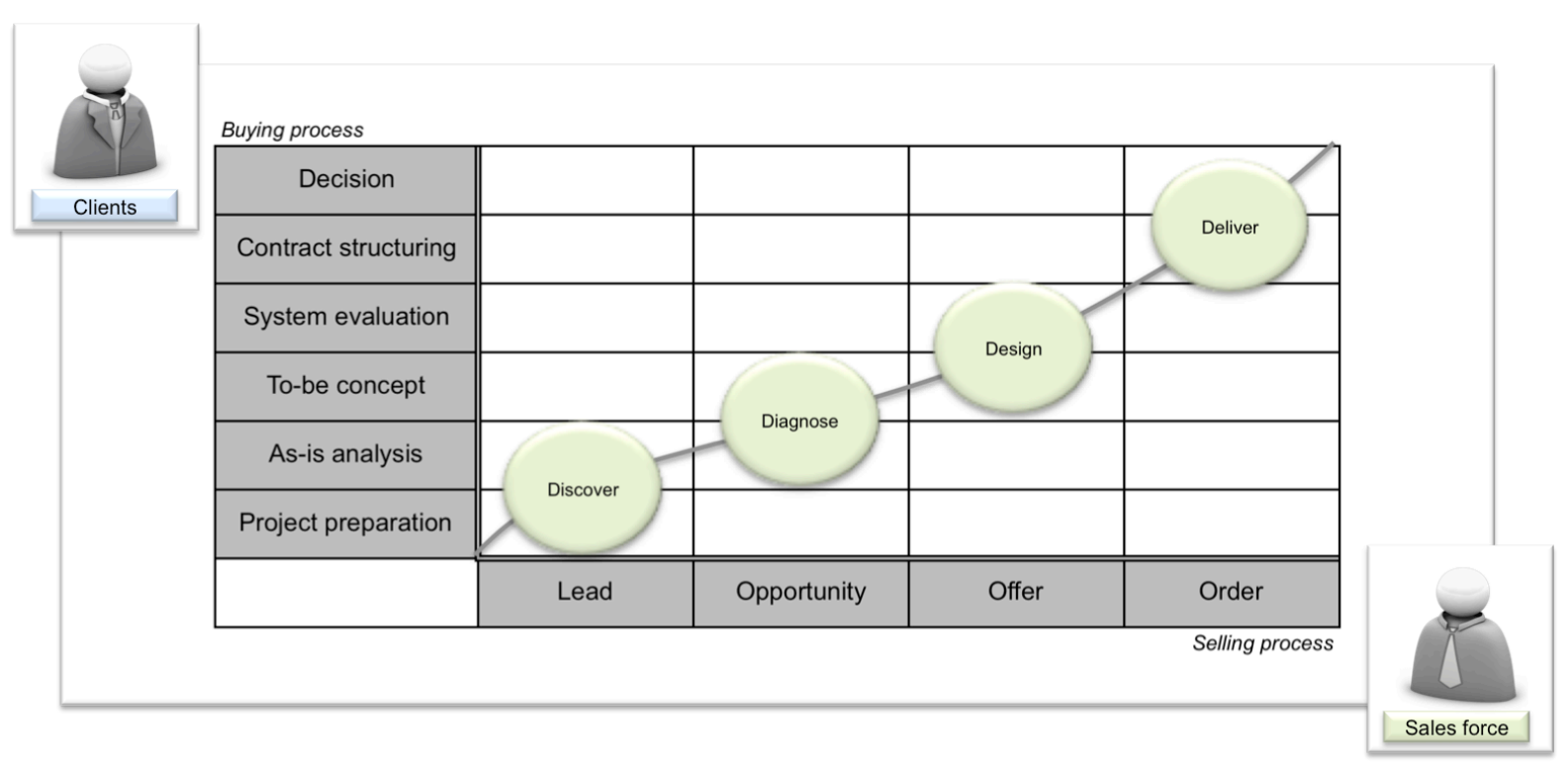

Figure 17: Synchronisation of selling and buying process

Source: Developed for the research project based on Hufgard et al. (2005; Rackham (1995; Thull (2012); Vering (2007)

For further consideration, the sales process is synchronised with the purchasing process. Both processes run parallel and are mutually dependent. The synchronisation creates transparency for the selling centre. It provides clarity on the results expected of the selling centre at each stage of the sales process and on the appropriate measures to respond to the requirements and parameters of the buying centre. Figure 17 illustrates the three dimensions of the acquisition process in a sales process model. The abscissa axis displays the phases of the sales process. The phases of the buying process are arranged on the ordinate axis. The meeting point of the axes indicates the task definitions of the selling centre, according to Rackham (1995) and Thull (2012). The selling centre accompanies the buying centre in all phases of the purchasing process. The selling centre focuses intensively on the respective customer and is mentally in the same phase of the purchasing process. His arguments fit with the problems and solution expectations of the customer (Ulaga \& Kohli, 2018). The selling centre questions the personal situation of the buying centre in all phases of the purchasing process, as it can change throughout the various process steps. If the selling centre can adapt to the new situation, it will not lose the buying centre (Hofbauer \& Schöpfel, 2010). Both simultaneously take the next steps in the purchasing process, and the negotiating position of the selling centre increases. Only when it has all of the essential information and has questioned its relevance and influence on sales success is it able to solve the customer's problem (Koponen et al., 2019). The selling centre gradually becomes closer to the customer. The size of the buying centre is not decisive 
(Brinkmann \& Voeth, 2007; Patton, 1997); the buying centre is equally important for all customers. Fears, resistance, manipulation, and delays are recognised by the selling centre early on (Conrad, 2013). The selling centre should have the methodical and social competence to handle them successfully (Töllner, Blut, \& Holzmüller, 2011).

Buying processes are not homogeneous. The processes can vary greatly depending on the industry, company, and product (Backhaus \& Voeth, 2014; Hofbauer \& Schöpfel, 2010). In which phase of the buying process the selling centre becomes included is crucial. The later the selling centre is involved in the purchasing process, the lower the probability of success (Ulaga \& Kohli, 2018; Woisetschläger et al., 2009), whereas the sooner the buying centre begins negotiating in the purchasing process, the higher the likelihood of success (Rolfes, 2007).

Excessive routine and overconfidence lead to losing focus on the customer (Arli et al., 2018). The danger of getting away from the customer then increases. The ability to self-reflect is a necessary skill that every successful salesperson should possess (Kwak et al., 2019).

\subsection{Characteristics of Perception}

\subsubsection{Involvement}

The behaviour of buyers and their effects in the organisational buying context has its foundations in consumer buying behaviour. Even if organisational focus is on companies, it is the people who make the decisions. A company makes no decisions. Various theories and models have been developed to explain consumer behaviour (Meffert et al., 2018). They differ according to the nature and extent of the situation and the condition constellations involved (Kroeber-Riel et al., 2013). In addition to observable and measurable variables, unobservable processes in the organism are taken into account to explain human behaviour, which can only be detected indirectly via indicators (Meffert et al., 2018). Meffert et al. (2018) describe these models as genuine behavioural models. The S-O-R paradigm, as a representation of a genuine behavioural model (Figure 18), states that certain stimuli (S) encounter an organism $(\mathrm{O})$ and together lead to a reaction $(\mathrm{R})$. A response does not directly follow a stimulus; rather, a number of internal events transpire between a stimulus and a response (Foscht et al., 2017; Rutschmann, 2005). 


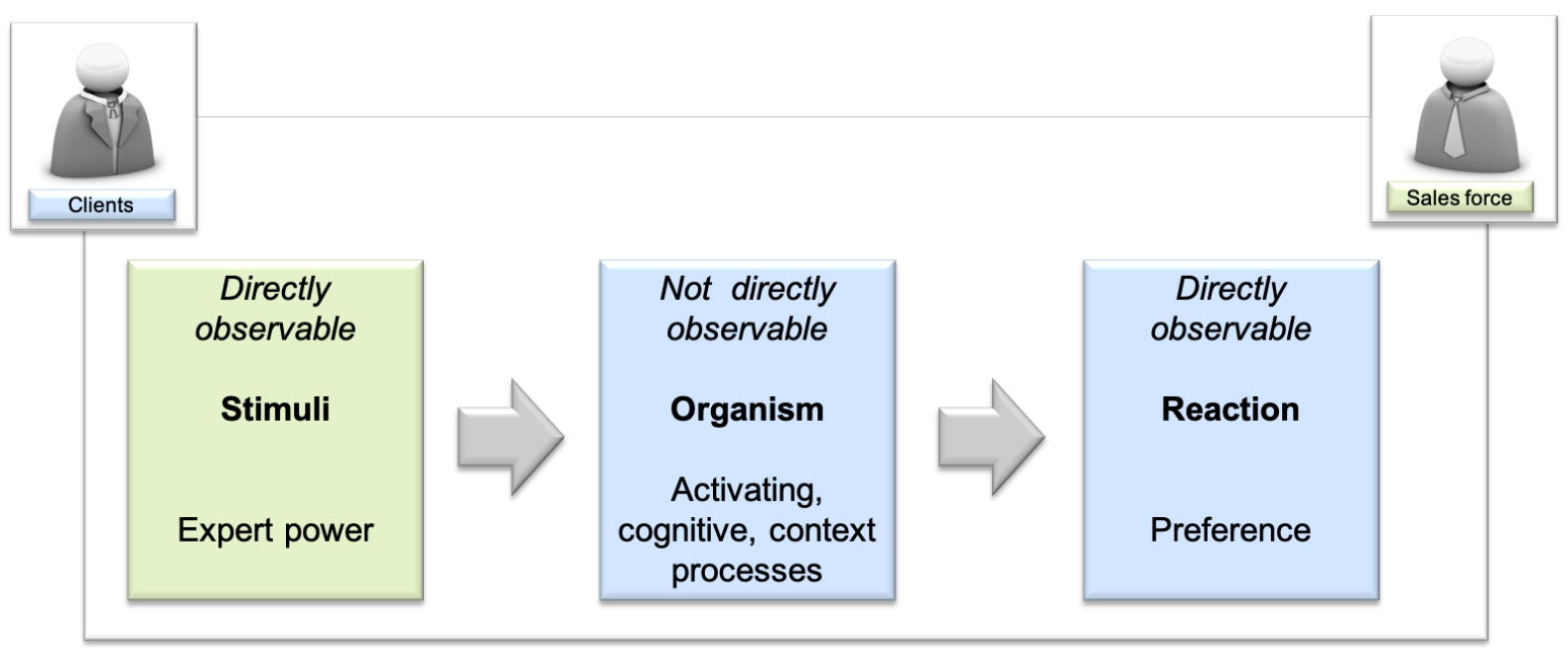

Figure 18: S-O-R paradigm

Source: Developed for the research project based on Foscht et al. (2017)

The S-O-R paradigm of consumer behaviour research is not generally applicable to organisational purchasing decisions, because a decision is rarely made by one person and without organisational constraints (Foscht et al., 2017; Kroeber-Riel et al., 2013). Transaction processes, in which services and products are interactively negotiated, often take place between the buyer and the supplier (Hofbauer \& Hellwig, 2016). Interaction processes are characterised by two or more partners reacting verbally and non-verbally, whereby the action and reaction are interdependent (Backhaus \& Voeth, 2014). Before a person can participate in a decision-making process, however, that person must form his or her own opinion. In this view, expert power acts as stimuli. By perceiving and processing the expert power of the sales force and the associated information, one or more preferences for a product or a solution are created by the buyer. With these preferences, the buyer participates in the decision-making process and represents it as far as possible, where the mechanisms of organisational buying find application (Figure 22).

The interaction approaches differ according to the number of parties involved and the type of participants (Figure 19). 


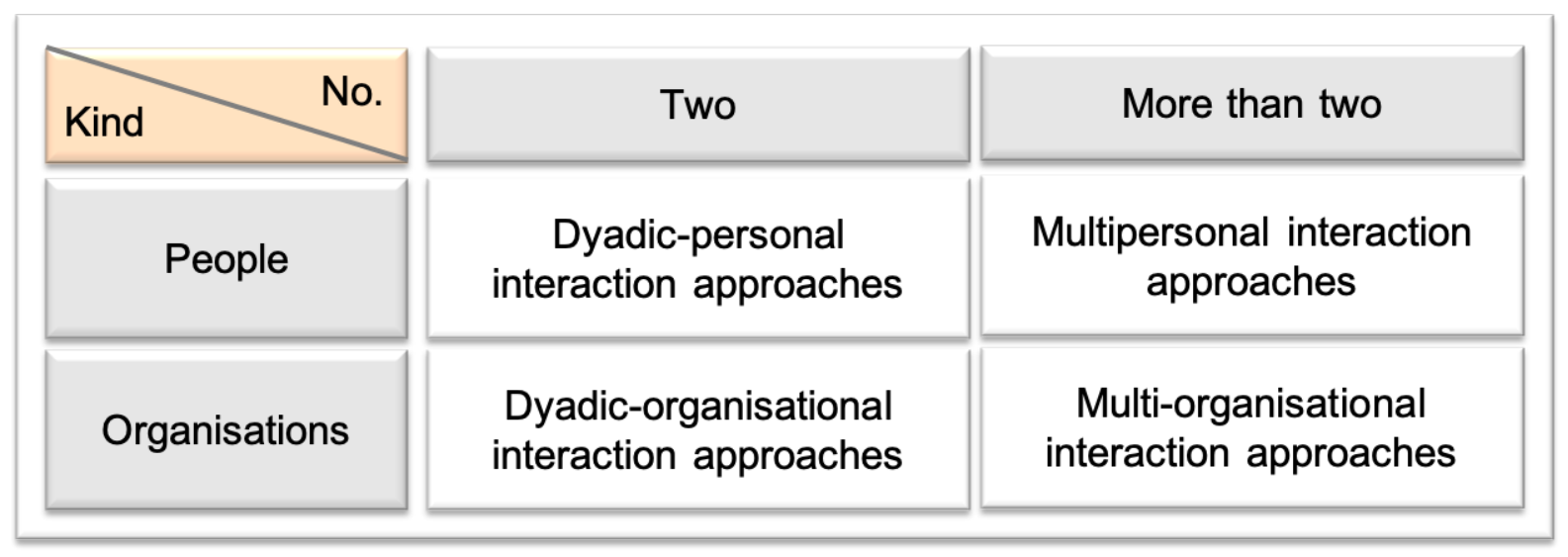

Figure 19: Systematics of the interaction approaches

Source: Developed for the research project based on Foscht et al. (2017)

Even if several persons participate in multi-personal interactions, and the exchange relationships are decisive, findings regarding consumer behaviour are transferable (Kroeber-Riel et al., 2013). Every person involved in the buying process contributes their individual wishes, goals, habits, experiences, information, attitudes, and preferences (Foscht et al., 2017). The personality of the individual, his /her role understanding, his motivations, his cognitive structures, and his learning processes form basic psychological processes that determine his reactions to certain buying situations and marketing stimuli offered by sellers (Bänsch, 2013).

Figure 20 summarises the determinants of consumer behaviour. The learning theory distinguishes two approaches: stimulus-response theories ( $S-R$ theories) and cognitive theories (S-S theories) (Foscht et al., 2017). According to S-R theories, humans learn through connections between stimuli and reactions. This is where S-S theories differ (Kroeber-Riel et al., 2013). They assume that everybody learns through the acquisition of connections between stimuli (Felser, 2007). The solution to a problem is not recognised through trial and error, but rather by insight and understanding of the essential problem relations (Bänsch, 2013). According to the dissonance theory, every person strives for harmony between his or her opinions and values (Foscht et al., 2017). Dissonances occurring during and after the purchase process can lead to selfdoubt. A committed salesman consciously reduces the dissonances that occur in the conversation by using the right arguments (Bänsch, 2013). 


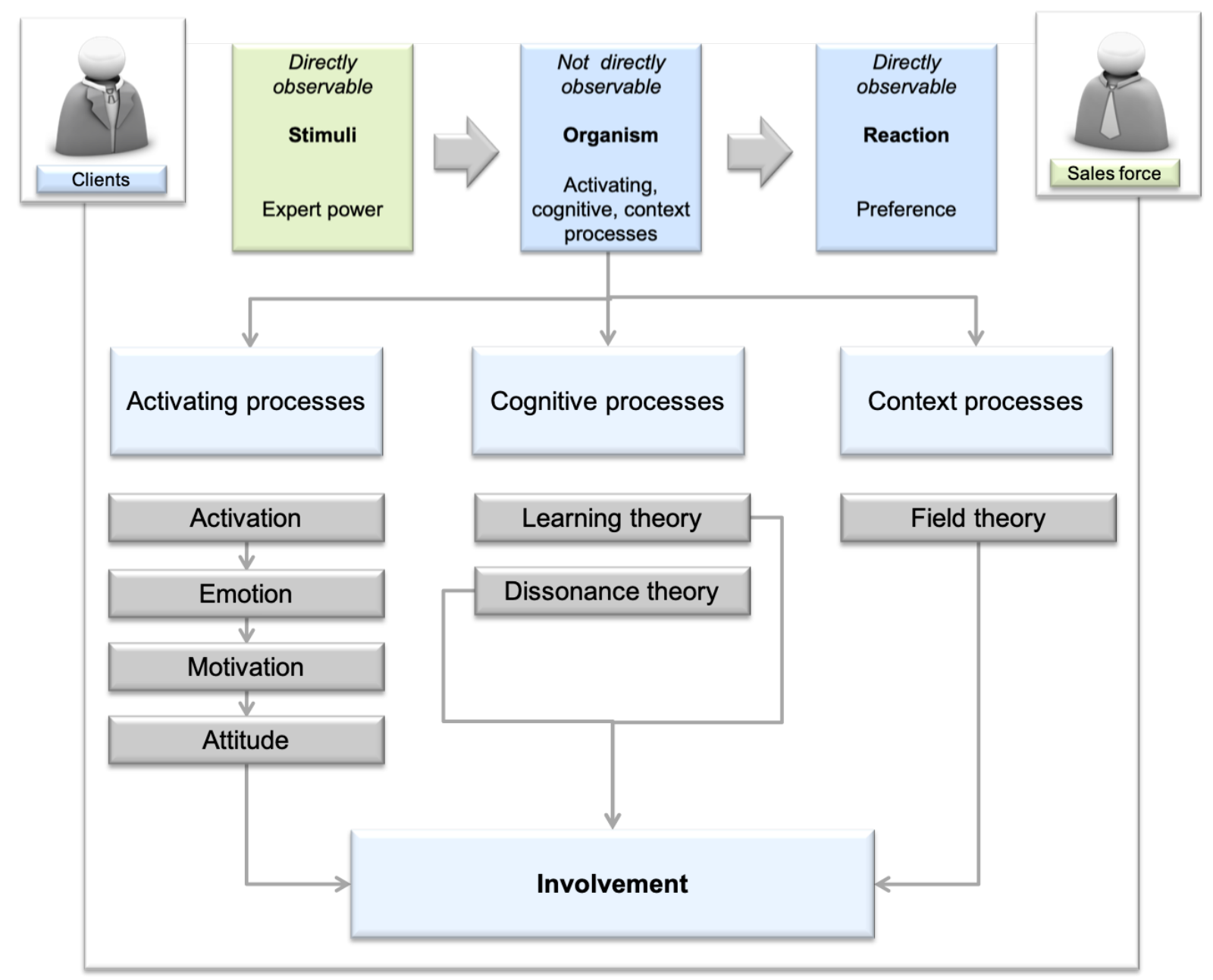

Figure 20: Determinants of consumer behaviour

Source: Developed for the research project based on Bänsch (2013)

To sit in the customer's chair and understand his world is the core message of field theory. The behaviour of a person results from the totality of all simultaneously occurring facts (Bänsch, 2013).

Targeting the customer's attention towards specific products or services is the aim of marketing (Meffert et al., 2018). Human drivers are crucial for this. They drive individuals and provide them with the necessary energy to trigger a behaviour. This activation is the basic requirement for potential consumer involvement. Emotion, motivation, and attitude in this context are three components that make it possible to explain human behaviour (Kroeber-Riel et al., 2013). Emotions are physiological processes that describe the consciously experienced feeling and the feeling expressed as nonverbal behaviour. The moods of both the buyer and the seller influence the buying process (Nerdinger, 2001). Likewise, in the capital goods market, it can be assumed that the motives for a decision cannot be rationalised on their own (Backhaus 
\& Voeth, 2014). They can also be emotionally determined. Motives, as the willingness of a person to behave in a certain way, form the basis for motivations (Foscht et al., 2017). Motivations refer to activated motives for a behaviour (Kroeber-Riel et al., 2013). The job of the seller is to determine the buyer's motives by questioning and listening (Bänsch, 2013). If the seller knows the motives, he/she can adapt his argumentation and positively influence the buying process (Hofbauer \& Hellwig, 2016; Homburg et al., 2016). A general rationale of the motives does not exist. Each human being can react in a completely different way in the same situation (Kroeber-Riel et al., 2013). It should also be noted that, in the buying process, not just one motive is decisive; rather, a combination of several results in the overall picture (Homburg et al., 2016). Attitude is the perceived aptitude of a subject for satisfying motives (Foscht et al., 2017). The subject is understood as both a product and a service. It is thus the result of motivation and cognitive objectivity assessment. The behaviour of a customer varies depending on whether his or her involvement a buying process is high or low (Felser, 2007; Puto, 1987; Stoddard \& Fern, 2002). Involvement is understood as a measure of personal participation, as well as the depth and quality of information processing (Kroeber-Riel et al., 2013). The activating and cognitive processes have a direct influence on the involvement of a customer, and thus on the willingness of the customer to purchase a product or service (Felser, 2007). A high buying involvement occurs when the product or service is important to the buyer and closely connects with his individual personality and self-assessment, whereas the opposite is true of low buying involvement (Meffert et al., 2018).

\subsubsection{Information Processing}

Involvement has a significant impact on buying behaviour, particularly for information absorption and processing (Figure 21). Empirical studies indicate that highly motivated buyers seek and process more information than less motivated buyers (Kroeber-Riel et al., 2013). The greater amount of cognitive processing that takes place among highly motivated buyers leads them to place greater demands on the quality of the arguments and credibility of the source than do less motivated buyers (Bänsch, 2013; KroeberRiel et al., 2013). Expert power of the sales force is thus a decisive factor for fulfilling the requirements and thus for making a purchase decision (Busch \& Wilson, 1976; Kohli, 1989; Shanteau, 1992). 
Absorption of information refers to the processes that lead to the adoption of information in the memory (Kroeber-Riel et al., 2013). The stimuli applied to the individual are absorbed by the sensory organs and selectively carried over to the central processor of the brain, where they are decrypted and processed in more detail (Kroeber-Riel et al., 2013). After being decrypted, they stimulate complex activating and cognitive processes. They may evoke feelings or associations or stimulate decisions (Felser, 2007). Important processes and conditions involved in the storage of information include thinking, knowledge, learning, and memory, which are closely related (Foscht et al., 2017). Existing knowledge plays a key role in learning, because obtaining new knowledge (for example, about a product or service) is only possible if it relates to the knowledge already stored (Foscht et al., 2017; Kroeber-Riel et al., 2013).

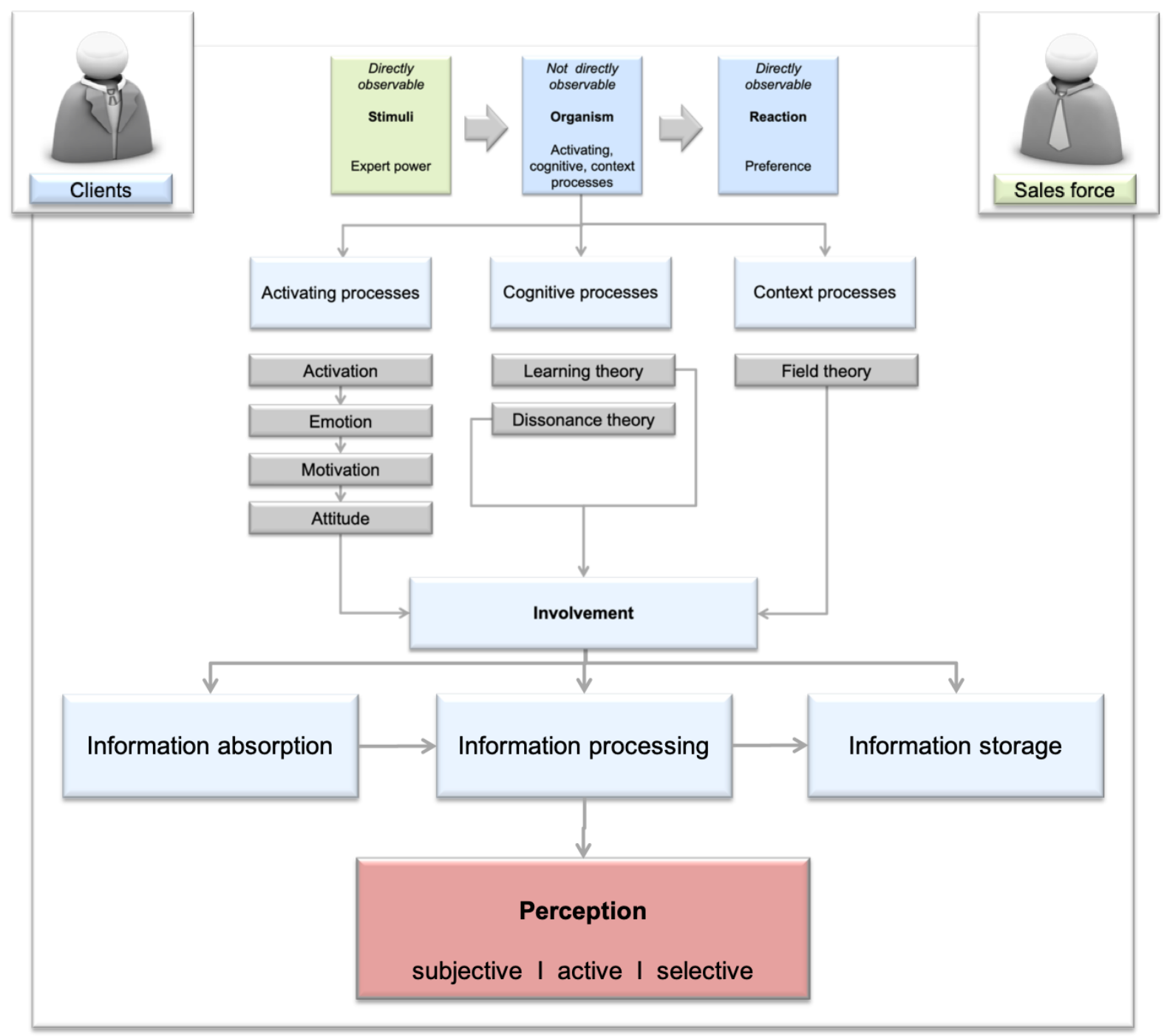

Figure 21: The role of perception in consumer buying behaviour

Source: Developed for the research project based on Bänsch (2013); Foscht et al. (2017); Kroeber-Riel et al. (2013) 
Perception is a process of information processing. Through this process, recorded environmental stimuli and inner signals are decoded (Kroeber-Riel et al., 2013). Perception gives them a feeling for the person and, together with other information, they are processed into an inner picture of the environment and the person (Foscht et al., 2017). Perception is, on the one hand, a subjective, selective and active process and, on the other hand, cognitive information processing with a focus on product allocation or, in the case of this investigation, the sales force's expert power (KroeberRiel et al., 2013). Perception is always subjective to the individual (Foscht et al., 2017). The complex environment is transformed into a simplified, subjective environment, and subjective interpretations and assessments create deviations from the perceived environment and reality. Moreover, perception is not only a passive reception of external stimuli; it also describes active information processing by which the individual constructs his or her own subjective environment (Felser, 2007). The perception must also be selective; without this selection process, any information processing system would be overwhelmed (Foscht et al., 2017). Of the unmanageable number of stimuli acting on one's sensory organs, a small portion relevant to the individual is selected (Kroeber-Riel et al., 2013). Information is distorted by personal interpretations. Kotler, Keller, and Opresnik (2017) described this as selective distortions. According to the dissonance theory, information is interpreted in such a way that one's biases are supported without question. People forget much of what they learn (Bänsch, 2013). They tend to store excess information and selectively use it only when the information supports their attitudes and beliefs with regard to possible alternatives.

To measure the perception of product features, tests are typically used to obtain the first impression of cursory perception (for instance, through direct observation of the participant) and the understanding and assessment of precise perception (for instance, via a log of noisy thinking, in which the participants immediately verbalise their thoughts) (Foscht et al., 2017; Kroeber-Riel et al., 2013). Expert power in a sales pitch is more difficult to test. Testing the first impression and the resulting reactions is much more demanding. The seller must be highly sensitive to the verbal and non-verbal reactions of his counterpart and draw the right conclusions (Bänsch, 2013). Of course, this perception is selective and subjective and can lead to a contradictory and therefore incorrect result (Foscht et al., 2017; Kroeber-Riel et al., 2013). Even a log of loud thinking is not applicable in a sales pitch, as buyers do not verbalise their true thoughts. 
On the contrary, buyers often behave tactically so as not to disclose their motives to the seller and to gain a better bargaining position. The seller remains unaware of the buyer's perception of his expert power. He also cannot pin down his expert power based on a purchase decision, since expert power is not always responsible for a purchase decision (Table 12). In other words, despite a lack of sales force expert power, the customer may decide in favour of the product.

\subsubsection{Expert Power and the Decision Frame}

As previously mentioned, a one-sided view of the S-O-R paradigm is not sufficient to explain organisational purchasing decisions (see Section 2.4.1.). Figure 22 vividly illustrates the role that the S-O-R paradigm plays in organisational buying decisions. It directly influences the individual decision frames of the participants (Puto, 1987). Decisions are also made by people involved in organisational buying decisions (Foscht et al., 2017). Everyone involved in a buying process forms their own judgments and opinions about a product or service (Kroeber-Riel et al., 2013). Based on these judgements and opinions, a preference is developed (Corfman \& Lehmann, 1987). This applies equally to all involved members of the buying centre. From these varying preferences, organisational preferences develop (Choffray \& Lilien, 1978). Depending on the relative influence and power each member has in the purchase decision, a purchase decision is made.

A theoretical framework to explain and define the decision-making framework of industrial buyers, and then demonstrated the relationship between the decisionmaking framework of buyers and their subsequent selection behaviour is introduced by Puto (1987). A buying centre who chooses between two suppliers, for whom at least one is somewhat uncertain about the performance (e.g. whether a project can be carried out successfully) would make a risk-tasking choice. Risk aversion is the opposite and refers to the preference for a guaranteed outcome over a probabilistic one with the same expected value. Puto (1987) assumed that when evaluating a supplier's offer, the buyer initially set a first point of reference (e.g. a target value for a key dimension such as the brand or buying objectives), which then changes due to environmental factors and influences of the selling centre changes continuously until the time of the decision. A reference point that results in the outcomes being classified as gains tends to promote risk-averse voting behaviour (Qualls \& Puto, 1989). That is, 
buying centres whose reference points have a positive (gain) decision framework tend to choose the supplier whose offer represent the least risk, while buying centres whose reference points have a negative (loss) decision framework tend to choose the riskier alternative (Qualls \& Puto, 1989). Individual decision-makers have a fundamental disposition or attitude to take risks, which for some people remains unchangeable even due to external influences, for example from a selling centre (Puto, 1987). The buyer's willingness to take risks had no influence on the original reference point (Qualls \& Puto, 1989). The organisational climate actually influences the choice behaviour of buying centres, albeit indirectly via the original reference point and the decision-making framework. Buying centres who frame the alternatives as gains tend to choose the certain (safe) alternative and buying centres who frame the alternatives as losses tend to choose the risky (probabilistic) alternative (Qualls \& Puto, 1989).

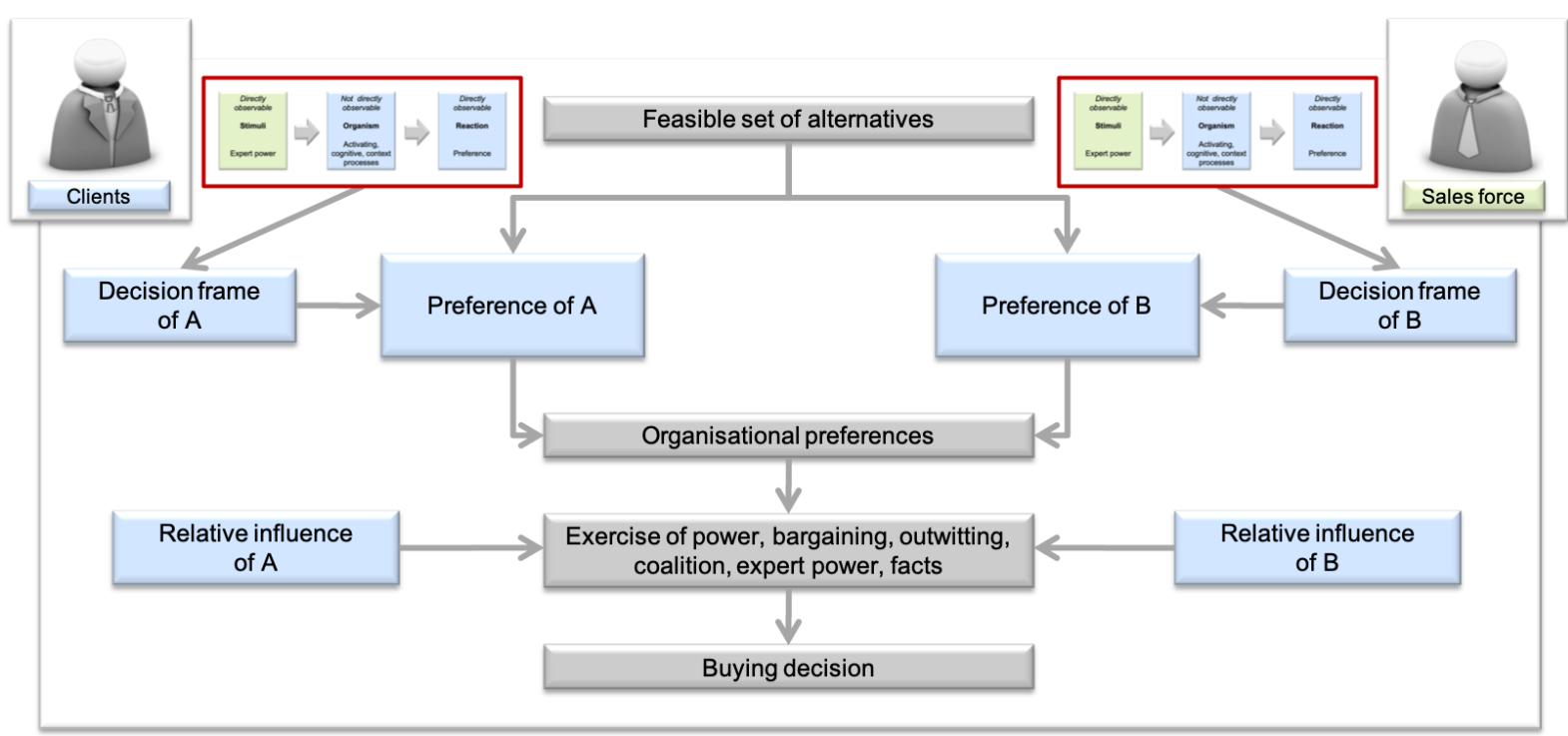

Figure 22: Role of the S-O-R paradigm in a group decision process

Source: Developed for the research project based on Choffray \& Lilien (1978); Corfman \& Lehmann (1987); Foscht et al. (2017); Puto (1987)

To illustrate the role of sales force expert power in the purchasing decision, the effect of expert power as a stimulus in forming a decision frame is explained based on Puto's (1987) findings (Figure 23). The starting point for the considerations is the initial reference point of each member of the buying centre. The initial reference point provides information about what a buyer thinks about a product or service. The assessment of the initial reference point of the buyer may be based on experience with the product or brand and on the particular requirements that make a purchase necessary. Each member of a buying centre has an individual initial reference point. The sum of all reference points reflects where the initial reference point of the buying 
centre is located. Puto (1987) speaks here of an initial reference point because the buying centre or buying organisation is not yet in a position to make a decision. For this reason, a buying centre is formed with the most important representatives from the involved areas (Webster \& Wind, 1972), with the aim to ensure that the best possible decision is made for the company (Fließ, 2000). To facilitate a decision, the buying centre contacts the supplier's sales force. The buying and selling centres both enter into the interaction (Johnston \& Lewin, 1996), and information is exchanged. If the initial reference point is low, meaning that the opinion about a product is not yet conclusive and the expectations for the brand are low, then the effect of expert power is maximised and can positively influence the formation of the final reference point (Mallalieu, 2006; Sharma, 1990). The final reference point refers to the point at which a decision is made or a preference has been formed for a product or service (Puto, 1987). If the expert power or the product or as in this research project the conversion project is formulated as a profit, the buyer recognises a positive benefit for him-/herself or the organisation (Stoddard \& Fern, 2002). A low initial reference point becomes a high final reference point, which then gives a buyer or a buying centre certainty because the goals are easier to attain (Fischer et al., 2008; Puto, 1987). The decision or preference is risk averse (Stoddard \& Fern, 2002). This increased decision certainty leads to increased confirmatory tendencies in the information evaluation and search process (Fischer et al., 2008). The composition and stages of the buying centre's purchasing process are important for the effectiveness of sales force expert power. A task-oriented buying centre that aims to establish long-term relationships with a supplier who delivers innovative and customised solutions, and strives for quality, is particularly receptive to sales force expert power (Kohli, 1989; McFarland et al., 2006; Paesbrugghe et al., 2017). If the initial reference point is already high for the supplier, meaning the product or brand is well known, sales force expert power does not play a decisive role (Mallalieu, 2006; Puto, 1987; Sharma, 1990; Stoddard \& Fern, 2002). In such cases, the buying centre has essentially already decided. 


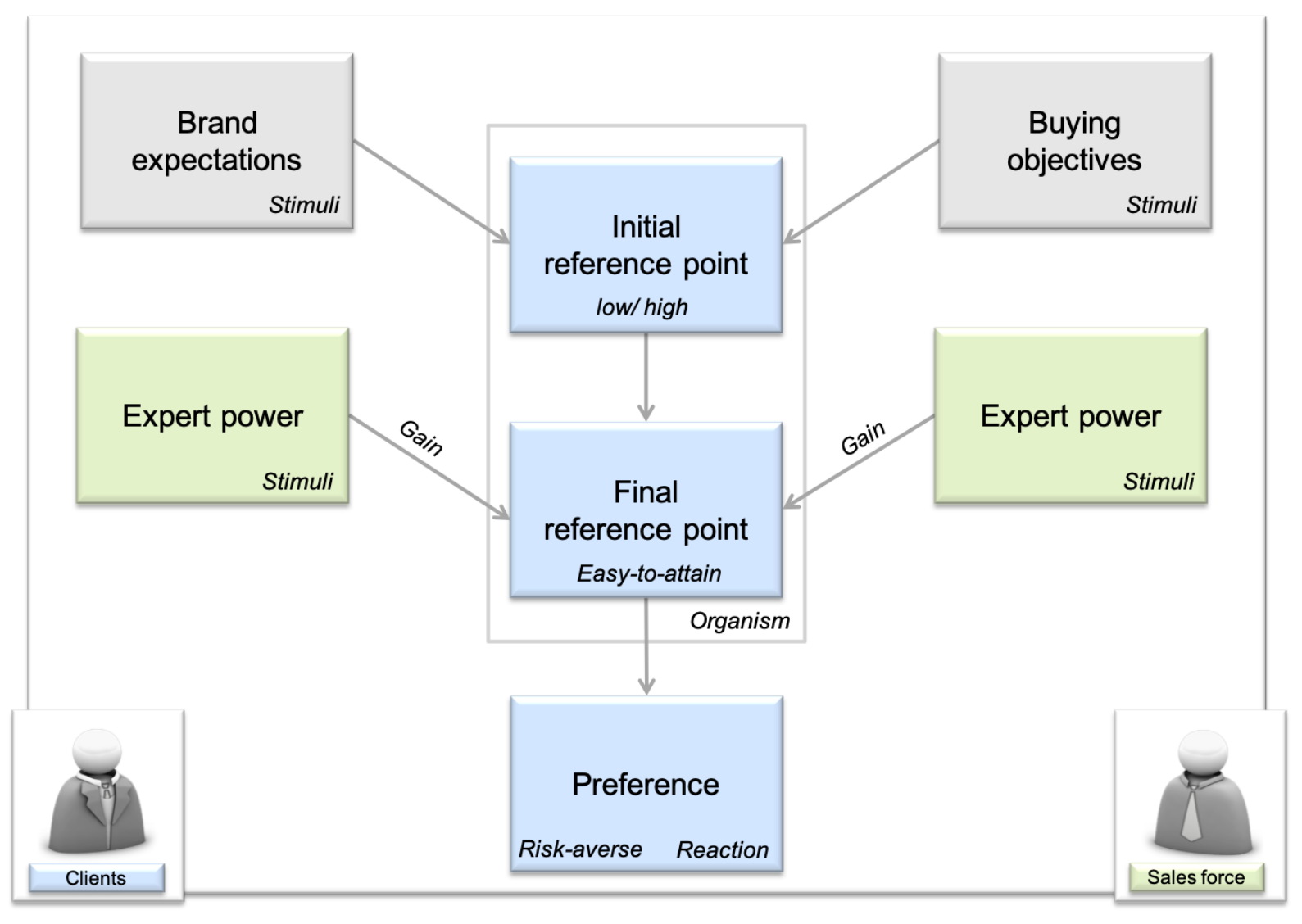

Figure 23: Effect of expert power as stimuli on the reference points to build a decision frame Source: Developed for the research project based on Puto (1987)

The forming of the decision frame and the resulting preference (risk-averse vs. risktaking) is influenced by the organisational change and the intensity with which it is perceived.

Organisational change is an empirical observation of variations in organisational units in form, quality or condition over time after the conscious introduction of new ways of thinking, acting and working. The overall goal of organisational change is to adapt to the environment or improve performance (Pardo del Val \& Fuentes, 2003). Lines (2005) defines organisational change as an intentionally planned change in an organisation's formal structure, systems, processes, or product market area to improve the achievement of one or more organizational goals. The initiatives emerging at every level of the organisational hierarchy can be the source of change.

The essential characteristics that describe the nature and form of the change and the properties that make the change what it is are called the type of change. Al-Haddad \& Kotnour (2015) distinguishes two categories of changes: change scale and change duration. The change scale can be defined as the degree of change required to achieve the desired result. These changes can be large or small with regard to the 
mobilised resources and the perceived consequences for those affected by the change (Lines, 2005). A large-scale change can be defined as a holistic change in processes and behaviors in a system that results in a gradual change in the results of that system. It involves all stakeholders in the change process and requires strong collaboration and visionary leadership to be successful. Small changes can be defined as minor with less significant changes in the organisation. Small changes are easier to initiate and manage, and do not require the level of leadership that large changes require (AlHaddad \& Kotnour, 2015). The change in size in relation to the scaling may not correlate very strongly with the perception of the change by each of the concerned (see also Figure 21). For example, a minor change in the organisation of work can be considered serious for those affected, for example if work and social relationships are equally affected (Lines, 2005). From a company's perspective, a software conversion project is not a large-scale change. From the HR department's point of view, it is already a drastic change when the payroll program is replaced. Whether it is a largescale or small-scale change for the members of the buying center is very individual and depends profoundly on experience and previous knowledge. Each member has to make the assessment for himself/herself, which of course has an impact on the personal decision frame and the preference (risk-averse vs. risk-taking). The change duration can be defined as the period over which the change takes place. Long-term changes can be challenging for a company and require strong leadership that actively engages employees throughout the change process. Human behaviour must be considered when dealing with long-term changes (Al-Haddad \& Kotnour, 2015). The perception and the intensity of the changes have a significant influence on the behaviour of the employees concerned and in relation to the research on the buying centre and the individual decision frames of each member of the buying centre. Shortterm changes have been recognised in the literature as more successful compared to long-term changes. Companies that predict small changes in conditions and respond promptly to those changes gain a competitive advantage. Ongoing processes offer a wide range of options for implementing change and improvement initiatives, especially in complex systems (Al-Haddad \& Kotnour, 2015). A software conversion project thus offers the possibility of a competitive advantage and can be counted among the aforementioned change and improvement initiatives. Since it is a project and it has a defined end with a manageable term, subsequently two payroll programs run in parallel make little sense, it is more of a short-term than a long-term change. A software 
conversion project can thus be defined as a change project (Appelbaum, Habashy, Malo, \& Shafiq, 2012). Each initiative in which organisations gradually change some elements or develop new strategies is an incremental change (Mintzberg, 1979).

\subsection{Conclusion}

Several attributes of expert power have been identified in scientific investigations in recent decades (Table 12). Knowledge is the most recognised attribute of expert power (Woodside \& Davenport Jr., 1974). A distinction is made between product knowledge (Mallalieu, 2006), market knowledge (Crosby et al., 1990), process knowledge (Lines, 2007; Sahadev, 2005), and knowledge about logistics to make promised deliveries (Crosby et al., 1990; Paesbrugghe et al., 2017). Other attributes that contribute to perceptions of expert power include experience (Busch \& Wilson, 1976; Mallalieu, 2006; Sharma, 1990; Taylor \& Woodside, 1982), qualification/education (Belonax et al., 2007; Lines, 2007; Mallalieu, 2006; Sharma, 1990), information (McFarland et al., 2006; Paesbrugghe et al., 2017), and confidence (Doney \& Cannon, 1997). Applying expert power in sales situations builds customer trust (Busch \& Wilson, 1976; Liu \& Leach, 2001), long-term relationships (Sharma, 1990), customer satisfaction (Liu \& Leach, 2001; Mallalieu, 2006), loyalty (Liu \& Leach, 2001; Nyaga et al., 2013), and exit barriers (Clauss \& Bouncken, 2018; Liu \& Leach, 2001). The formation of trust is not clearly documented. Sahadev (2005) observed no strong effect of expert power on building trust. The aforementioned attributes of expert power are not specified in the literature. 


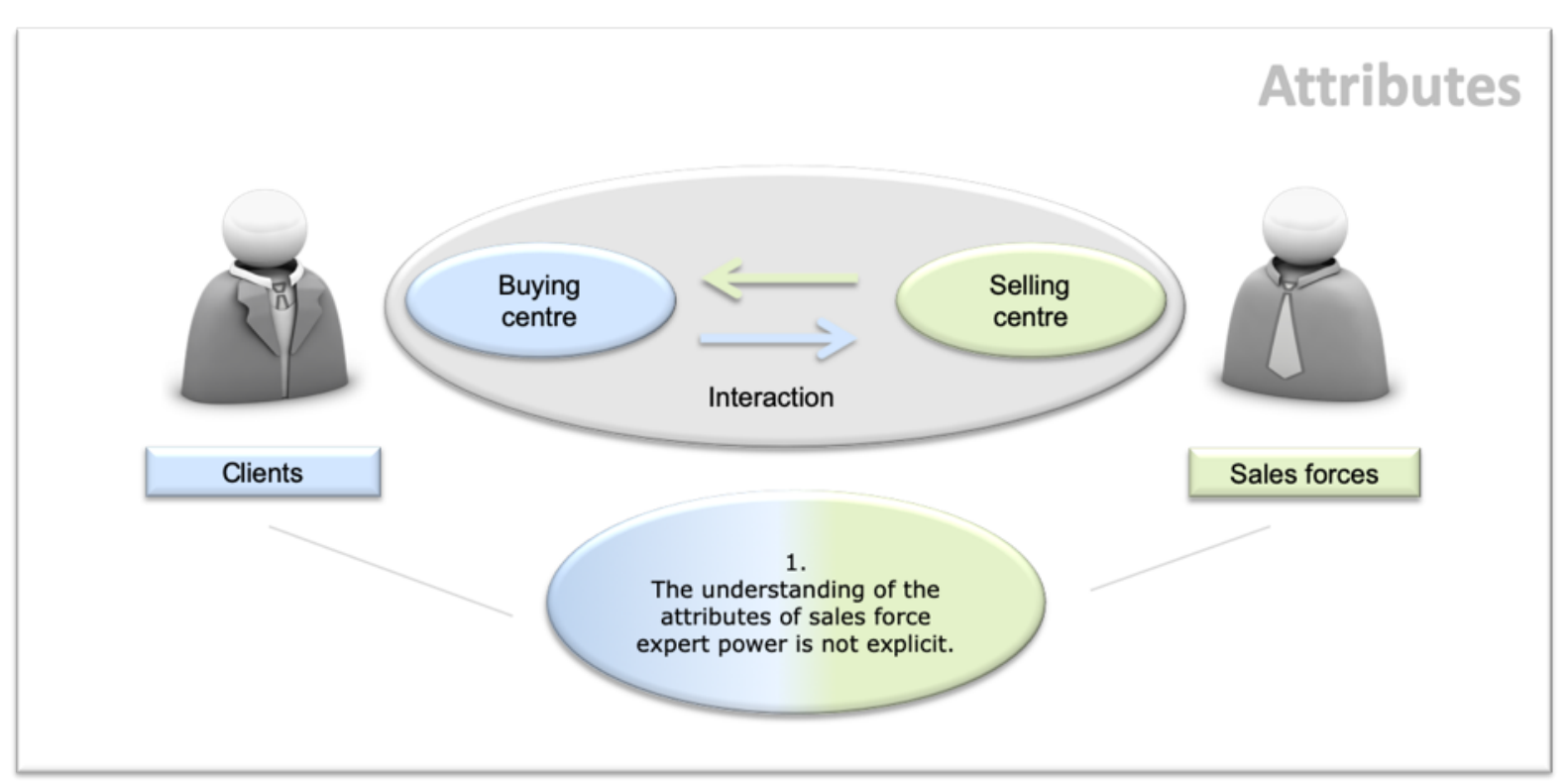

Figure 24: Attributes of sales force expert power

Source: Developed for the research project

Busch and Wilson (1976), Kohli (1989), Lines (2007), and Liu and Leach (2001), for instance, refer to differentiated attributions. For example, Lines (2007) regards knowledge as scarce and critical for the performance of organisational tasks. Kohli (1989) subdivides knowledge into knowledge about the usage of the product and expertise to make the best decision. Furthermore, some findings focus on accurate, current, and specialised knowledge (Liu \& Leach, 2001) and on the ratings of knowledgeability made by peers, superiors, and customers (Busch \& Wilson, 1976). An understanding of the attributes of sales force expert power is not clear in the literature (Figure 24). Which attributes and involved characteristics are relevant for the clients of Alpha Software? It is therefore necessary to identify and understand the specific attributes that contribute to clients' perceptions of Alpha Software's sales force expert power. Based on the findings, the first research question is derived, along with the associated research issue (Table 16).

Research question 1: What are the attributes of clients' perceptions of sales force expert power?

\section{Research Issue}

1.

The understanding of the attributes of sales force expert power is not explicit.

Table 16: Research Question 1 with research issue

Source: Developed for this research project 
The clients are forced to question each statement and every action of the sales force during the buying process. Subsequently, when and how the perception of sales force expert power arises for the first time, what intensifies or diminishes the perceptions, and whether expert power holds equal importance throughout the process deserves attention from the process perspective (Figure 25). Mallalieu (2006) noted that expert power is more important to consumers in an early stage of the process than in a final stage.

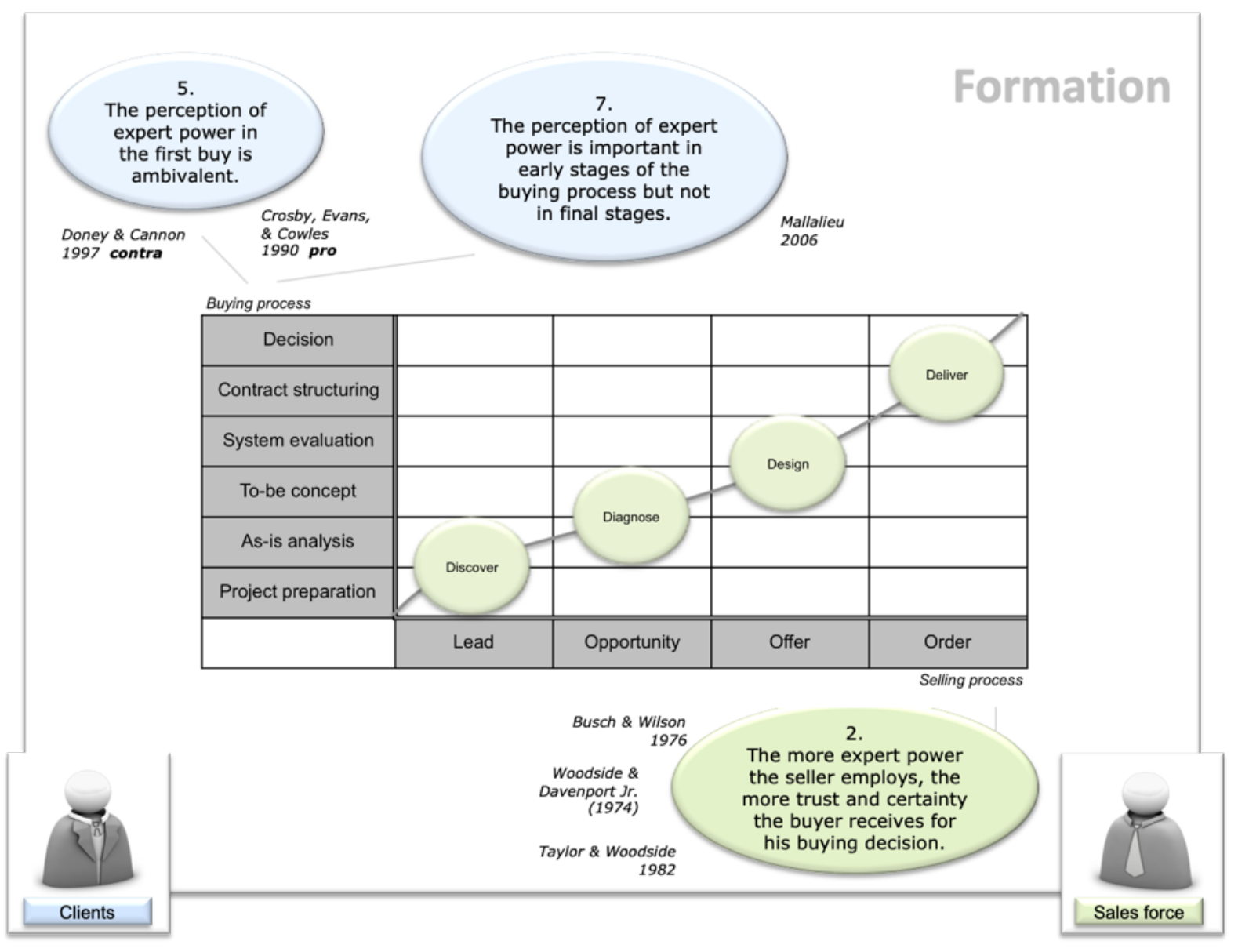

Figure 25: Formation of expert power in the synchronised buying and selling process

Source: Developed for the research project based on Hufgard et al. (2005); Rackham (1995) Thull (2012); Vering (2007)

The role of expert power in a first buy is not entirely understood. According to Crosby et al. (1990) expert power plays a crucial role in a first buy; however, Doney and Cannon (1997) disagree. The frequency of attempts to establish expert power in the selling process has a positive influence on sale success, according to Taylor \& Woodside (1982). However, this statement is quite general; they do not specify whether this applies equally to all process steps or whether the frequency can be overdone, causing expert power to negatively impact sales success. The quality of the interaction (Liu \& Leach, 2001) and the related behaviour-based coordination 
strategies (Sahadev, 2005) have a direct impact on the buying and selling process. The way the sales force behaves and acts throughout the process can have a positive or negative impact on the group decision process (Figure 26).

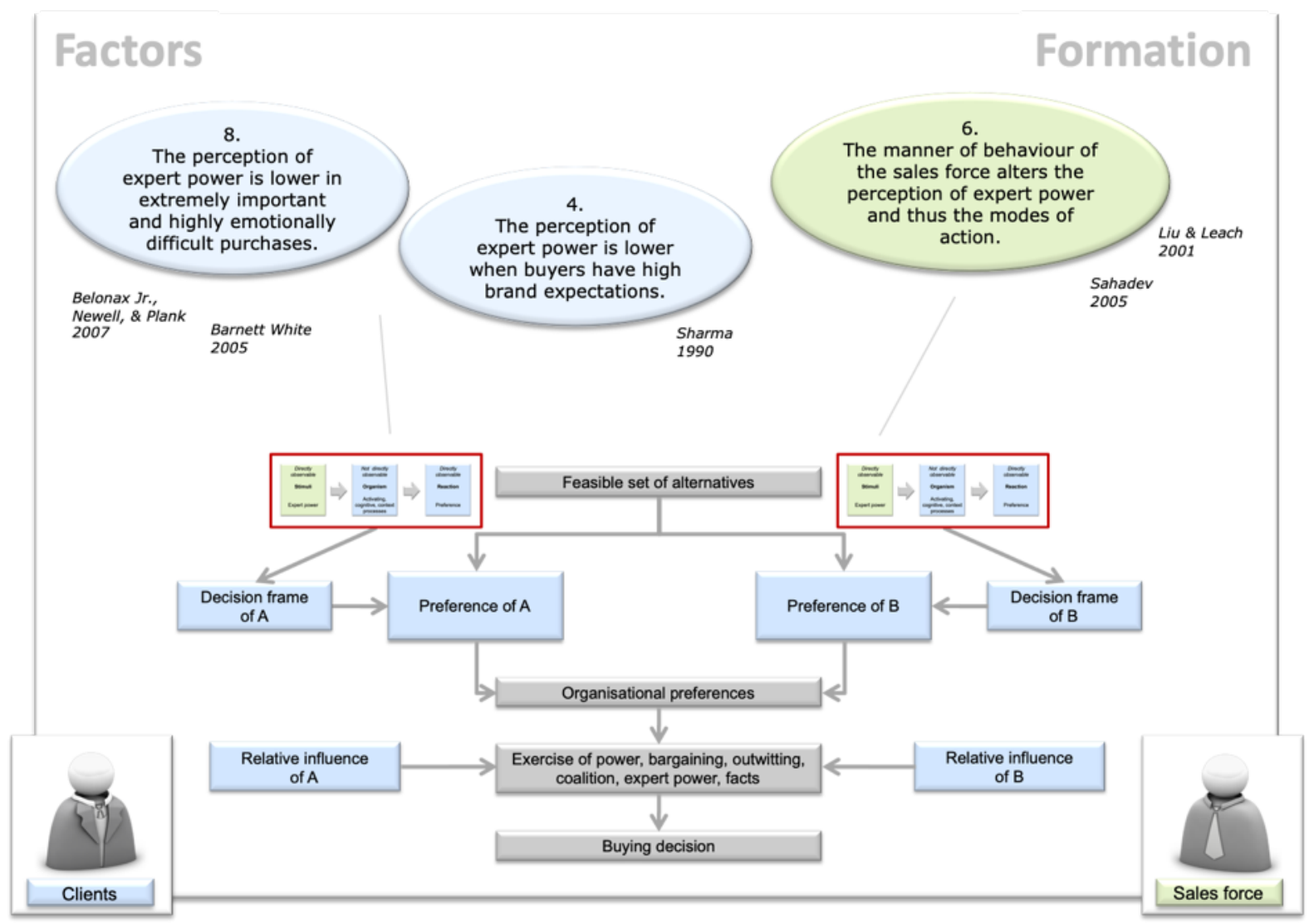

Figure 26: Factors and formation of expert power perception in buying group decisions

Source: Developed for the research project based on Choffray \& Lilien (1978); Corfman \& Lehmann (1987); Foscht et al. (2017); Puto (1987)

Despite the aforementioned findings, previous research lacks a deeper understanding of the perception formation process and the relevance of sales force expert power during the buying and selling process. Based on this knowledge gap, the second research question is derived, along with the associated research issues (Table 17). 
Research question 2: How do clients form their perceptions of sales force expert power?

Research Issues

2.

The more expert power the seller employs, the more trust and certainty the buyer receives for his buying decision.

5.

The perception of expert power in the first buy is ambivalent.

6.

The manner of behaviour of the sales force alters the perception of expert power and thus the modes of action.

7.

The perception of expert power is important in early stages of the buying process but not in final stages.

Few studies have considered the factors that affect the formation of perceptions of expert power. For instance, Sharma (1990) noted that low or no prior brand expectations strengthens the perception of expert power and makes it necessary to the buyer's certainty of a decision. The importance of the purchase (Barnett White, 2005; Belonax et al., 2007) and the intensity of change (Lines, 2007) that triggers a purchase decision act on the decision frames of the buyers and support their perceptions of expert power (Figure 26). The aforementioned factors primarily affect the formation of expert power during the purchase decision. Their impact, albeit weaker, has an effect on the composition of the buying centre as well (Figure 27). Depending on this composition, the effect of expert power can vary (Kohli, 1989). Taskoriented buying centres (McFarland et al., 2006), which themselves have means of expert power (Clauss \& Bouncken, 2018) and are in a supportive or inclusive stage in their purchasing evolution (Paesbrugghe et al., 2017), respond positively to and appreciate expert power more than buying centres that have few means of expert power. On the one hand, a lack of expert power can be compensated for by the expert power of the sales force (Chinomona \& Pretorius, 2011). On the other hand, it can provoke a buying centre to consciously follow the recommendations and requirements of the sales force, for example through process adjustments or process changes (Nyaga et al., 2013).

According to Liu \& Leach (2001), the position and perception of the sales force or the power they have in their own company, as well as quotas and ratings (Busch \& Wilson, 
1976), have a decisive effect on the formation of perceptions of sales force expert power (Figure 27).

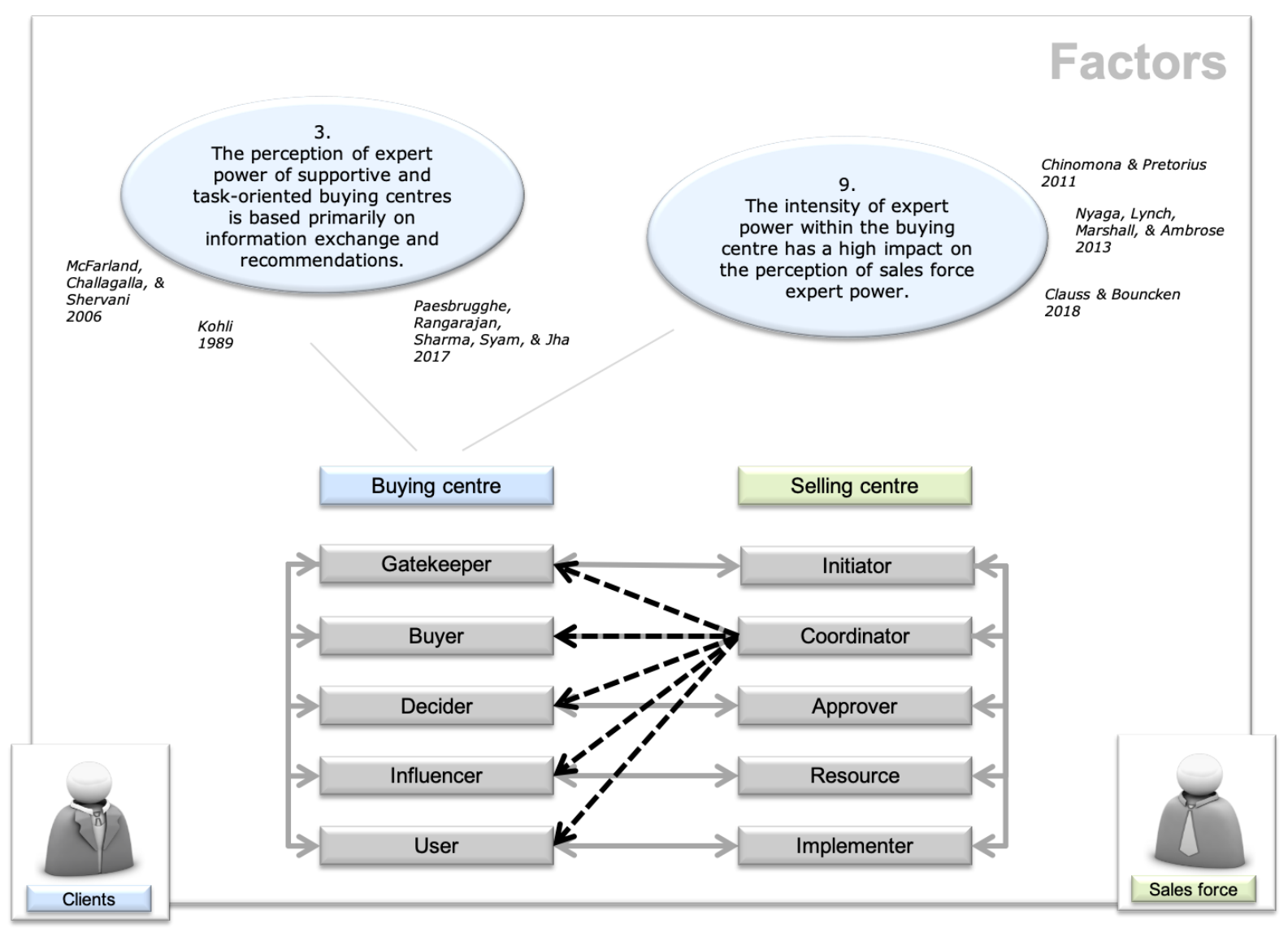

Figure 27: Factors affecting the formation of expert power in the interaction between the buying and selling centre Source: Developed for the research project based on Moon \& Armstrong (1994); Webster \& Wind (1972)

Previous studies have revealed that certain factors affect the formation of perceptions of expert power, but their modes of action have received little or no attention. It remains unclear whether specific patterns of factors exist and how the sales force is able to adjust. Based on the findings, the third research question is derived, along with the associated research issues (Table 18). 
Research question 3: Which factors affect the formation of clients' perceptions of sales force expert power?

\section{Research Issue}

3.

The perception of expert power of supportive and task-oriented buying centres is based primarily on information exchange and recommendations.

4.

The perception of expert power is lower when buyers have high brand expectations.

8.

The perception of expert power is lower in extremely important and highly emotionally difficult purchases.

9.

The intensity of expert power within the buying centre has a high impact on the perception of sales force expert power.

Table 18: Research Question 3 with research issues

Source: Developed for this research project

It is striking that, in most studies, questionnaires were used, and the findings are based on quantitative results (Table 12). It can be assumed that there is was no direct relation to a purchase or a sale. Respondents answered based on their past experiences or forward-looking assumptions. Only Liu and Leach (2001) and Paesbrugghe, Rangarajan, Sharma, Syam, and Jha (2017) provided more insight, via their rather complementary qualitative methods, into the motives of the buyers and sellers. The next chapter focuses on methodology and discusses the best approach for answering the research questions.

Figure 28 illustrates the conceptual framework of the present research project. 


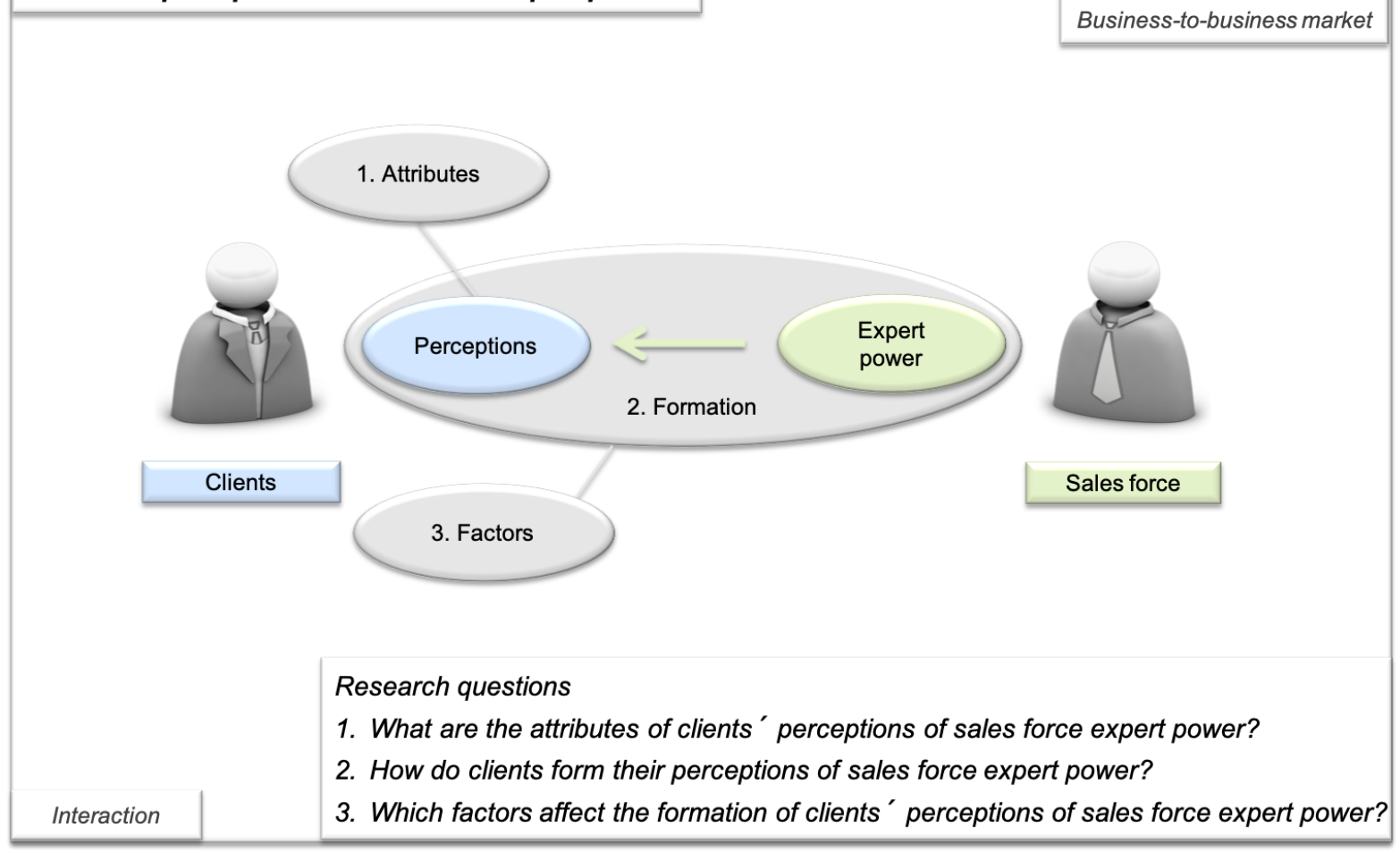

Figure 28: Conceptual framework of the research project

Source: Developed for the research project based on the literature review (Table 12)

Four principal objectives accompany this research:

1) To identify the attributes of clients' perceptions of sales force expert power.

2) To explore the process by which clients form their perceptions of sales force expert power.

3) To examine the factors that affect the formation of clients' perceptions of sales force expert power.

4) To derive an approach by which sales forces can consciously manage and enhance clients' perceptions of sales force expert power.

The intention is that the results of the inquiry will contribute to sophisticated sales force training and that the findings will enable sales forces to appropriately tailor their use of expert power to distinct sales situations. The theoretical contribution of this scientific work is to supplement the previous findings and definitions of expert power to better classify and understand the mode of action in the decision-making process of buying centres. 


\section{Research Methodology}

\subsection{Objectives of the Chapter}

With the research questions having been formulated, this chapter describes the methodology for collecting, analysing, and interpreting data to obtain insights from clients regarding their perceptions of sales force expert power.

There are five key methodological steps that need to be conducted during the research process: (a) choice of research philosophy, (b) selecting the research strategy, and (c) collecting, (d) processing, and (e) analysing the collected data (Bryman et al., 2018; Saunders et al., 2015). Each of these steps is discussed in depth in the present section, in addition to key criteria of business research, such as ethics, as well as reliability and validity.

\subsection{Review and Selection of Research Philosophy}

\subsubsection{Research Philosophy}

It is essential to understand the position of the author regarding the incurrence and deployment of knowledge to appraise and evaluate a research design. Thus, it must be clear how the results of the study were obtained and interpreted. Saunders, Lewis, and Thornhill (2015) describe this as the research philosophy. In addition to research philosophy, the term 'paradigm' is also mentioned in the literature. A paradigm is a conceptual framework that describes the view of the world as a mixture of convictions and assumptions about it (Bryman et al., 2018; Creswell, 2009; Easterby-Smith, Thorpe, \& Lowe, 2001), which cannot be proved (Lincoln \& Guba, 1985).

Epistemological considerations define what determines and substantiates knowledge and what is considered acceptable knowledge in a discipline (Bryman et al., 2018). In business and management research, three main views are distinguished: positivism, interpretivism, and realism (Saunders et al., 2015).

The research is focused on knowledge development through interpretivism and answering the research question is supremely based on personal interpretations. Following the requirements of interpretivism, the researcher's goal is to understand the thoughts and subjective reality of the participants (Bryman et al., 2018; Saunders et 
al., 2015). Each individual lives in his own world and sees the world through his own eyes (Thomas, 2015; Yin, 2018).

Positivism emphasises quantifiable observations with the purpose of statistical analysis (Saunders et al., 2015). The challenge of answering the research questions consists of identifying the actual perceptions of sales force expert power and the reasons for the participants' buying decisions. Empirical studies often concentrate on the examination of sales closures and past buying behaviour. As a consequence, the surveyed individuals must recall decisions that were made in the past (e.g. Busch \& Wilson, 1976; Doney \& Cannon, 1997; Sonnentag \& Lange, 2002). Perceptions, cognitions, and approaches are affected through this time delay. It is assumed that, by interviewing customers during or shortly after the purchase process, the researcher has a better chance of obtaining information about the actual impact of the expert power. This is because the perceptions and memories of the sales force are present and fresh. The research questions deal with the problems that interfere with the daily work of the sales force. They contemplate real situations, real people, real problems (Sarantakos, 1998), and managerial processes (Yin, 2018). A reality that exists independently of human thoughts and beliefs is the basic idea of realism (Bryman et al., 2018). Therefore, neither positivism nor realism is an applicable research philosophy for conducting this particular research.

Ontology refers to what can be known of the world (Albertazzi, 2010). According to Bryman et al. (2018), "Questions of social ontology are concerned with the nature of social entities" (p. 20). In business and management research, two ontological positions are frequently mentioned: objectivism and constructivism (Bryman et al., 2018). Following constructivism, the perceptions and actions of social actors construct the social reality (Bryman et al., 2018; Sarantakos, 1998). As distinguished from objectivism, social phenomena and their meanings depend on the social actors (Saunders et al., 2015).

The research focuses on constructivism due to the fact that, despite the decision of the buying centre admittedly yielding to the restraints of organisational buying decisions, each individual person exerts an immense impact on the final buying decision (Felser, 2007; Foscht et al., 2017). People have different interpretations of the 
situations in which they are involved due to their varying cultural backgrounds, experiences, knowledge, and expectations, among other factors (Wiswede, 2007).

Since the interpretivism tradition is the basis for this research, social actors play a crucial role in understanding the phenomenon (Saunders et al., 2015). Following the requirements of interpretivism, the researcher's goal is to understand the thoughts and subjective reality of the participants (Bryman et al., 2018). The participants are likely to have different perceptions of the situation, which have an effect on their actions (Saunders et al., 2015). Therefore, the study strives to visualise and align the perceptions of the participants to understand their (intended) actions in a specific situation in relation to a specific concern - the interaction of clients and the sales force. Thus, the research is an interpretivist inquiry, which is designed to follow an inductive approach and uses qualitative methods to collect and analyse the data. The view that qualitative research, in contrast to quantitative research, focuses on verbal descriptions, images, and explanations of human behaviour, rather than numbers, has been strengthened by researchers and academia (Schreier, 2012; Thomas, 2015; Yin, 2018). Qualitative research requires detailed descriptions of social practices to understand how participants explain and experience their own world (Jackson, 2003). Ticehurst \& Veal (2000) categorised the qualitative approach as more involved in obtaining a large quantity of information from a small number of individuals or organisations (e.g. using individual interviews as qualitative data collection techniques) than a small amount of data from a large sample of individuals or organisations (e.g. using telephone surveys as quantitative data collection techniques). In contrast to the goals of quantitative research, the findings of qualitative research cannot be generalised and straightforwardly reproduced (Bryman et. al, 2018). In quantitative research, a large and representative amount of information should be collected and analysed (Saunders et al., 2015).

In the collection of qualitative data and the understanding of the meanings that a person attributes to a particular situation, the inductive approach becomes apparent, in which different results of the data collection and analysis provide the basis for the formation of the theory. The theory follows data, rather than the reverse, as is the case of the deductive approach (Saunders et al., 2015). 
Furthermore, the three purposes of research (exploratory, descriptive and explanatory) are considered (Saunders et al., 2015). Exploratory fieldwork is necessary to generate data given that the perceptions and resulting actions, particularly interactions, are the basis for further examinations. The object of exploratory research is to strive for new perceptions of concepts, to ask questions, and to evaluate the concepts from a different perspective, based on the so-called iterative strategy (Bryman et al., 2018). It involves jumping back and forth between theory and practice. Prior to data collection, it is important to clearly understand the participants' situation, which is demonstrated through descriptive research (Thomas, 2015). The aim of descriptive research is "to portray an accurate profile of persons, events or situations" (Robson, 2002). The explanatory contribution of this research is the derivation of an approach, based on causal relationships that emerge from the data, by which sales forces can recognise and appraise the attributes and factors influencing the formation of clients' perceptions of sales force expert power. Explanatory research explains the relationships between variables (Saunders et al., 2015).

\subsubsection{Research Strategy}

The research strategy is the plan to complete the research (Saunders et al., 2015). It provides a general orientation on how the research questions were answered and how the aims of the inquiry were accomplished (Bryman et al., 2018). There are multiple potential strategies to answer a research question (i.e. action research, case study, grounded theory, and survey) in the field of business and management (Saunders et al., 2015). Surveys are widely used in business and management research and are commonly associated with an inductive approach (Bryman et al., 2018). Meaning is derived from numerical and standardised data (Saunders et al., 2015). EasterbySmith, Thorpe, \& Jackson (2008) argue that constructivist grounded theory and action research are especially well congruous. The aim, content, and determining factors define the choice of method. While action research attempts to initiate a change (Bryman et al., 2018), grounded theory is used more as a method to analyse data and generate new theory. Therefore, it is reasonable to elaborate on the research question through the application of the case study method, which is preferred when a real-life situation is the basis for the research (Yin, 2018). Robson (2002) referred, in this regard, to an empirical study of a contemporary phenomenon in its real context using numerous foundations of verification. Case study research is applied to analyse 
persons, events, decisions, periods, projects, and other systems (Thomas, 2015). Therefore, it is necessary for the case to include a methodical setting "within which the study is conducted and which the case illuminates and explicates" (Thomas, 2015, p. 23). These features precisely pertain to the sketched problem and parameters of the research inquiry.

The research inquiry deals with the problems that interfere with the daily work of the sales force. It contemplates a real situation, real people, real problems (Sarantakos, 1998), and managerial processes (Yin, 2018). As the literature review has revealed, little is currently known about the topic. This is an additional argument for the application of a case study (Gill \& Johnson, 2010). Through case study research, the researcher can obtain a holistic view of a particular phenomenon or series of events (Bryman et al., 2018). The case study allows for a generalisation, as results from findings using multiple cases may lead to a kind of duplication (Thomas, 2015; Yin, 2018).

The research design gives information on how the case study is to be conducted (Thomas, 2015). It describes the plan from the initial question to the interpretation of the results (Yin, 2018). At the beginning of the plan, which type of case study should be applied is decided on. In this research, the focus is the utilisation of a key case (Thomas, 2015) or, to be precise, a representative case (Bryman et al., 2018) in the field of interest, since the significance can be especially well transmitted and it is a useful example of the actual situation (Yin, 2018). The goal is to improve the daily work of the sales force, which is optimally supported by a case of day-to-day work.

How the case study is structured is referred to as a process by Thomas (2015). He differentiates between single cases and multiple cases. In the literature, multiple cases are also identified as collective or comparative cases (Bryman et al., 2018). The focus in this research lies on a single case. The case study takes place in one sample company; therefore, the framework conditions remain the same. The sales processes, as well as the products involved, are largely homogenous. Moreover, the customer structure shows great similarity (see Section 4). Minimizing the risk of data loss that is inevitably considered higher than multiple case studies (Yin, 2018), not just one interaction between a buying centre and sales force is examined, but rather 10. One case is contemplated, but the ten interactions are considered as embedded units of 
analysis (Thomas, 2015; Yin, 2018). Hence, the risk is minimised, and the significance is improved.

Case studies often appear to be unscientific, particularly when they are conducted unsystematically and sparsely conceived (Saunders et al., 2015). Today, case studies are scientifically acknowledged and are commonly used in business and management research (Eisenhardt \& Graebner, 2007; Taylor, 2007).

The aim of this research is to contribute insight to improve sales activities. The generalisation of case study results and the associated interpretations represents a major concern in this cohesion. The generalisation is not undisputed (Thomas, 2015; Yin, 2018). Ultimately, in a case study, specific situations and events which are not always comparable with purportedly related situations and events are analysed. Thomas (2015) argues that generalisability is not the main goal of a case study; in fact, "some of the most inspired and insightful research, has come as the result of case studies" (p. 23). In contrast, Eisenhardt (1989) and Flyvbjerg (2006) argue that generalisation is possible. Theory is likely to be replicated, unprecedented, and empirically valid, but it is not considered to be the "grand theory" (Eisenhardt, 1989).

A formidable challenge of conducting a case study is to handle the quantity of data and the associated time resources as a result of longevity of the research (Gill \& Johnson, 2010; Mintzberg, 1973; Yin, 2018). This implies a tight time management, thorough preparation of data collection, and an overall plan to carry out the case study (Bryman et al., 2018; Eisenhardt, 1989; Thomas, 2015). The case study provides this research with the flexibility and depth necessary to achieve its goals.

The selection of the interactions to be analysed between clients and the sales force was made by purposive sampling (Saunders et al., 2015). Purposive sampling is a non-probability form of sampling and is often used when a small sample size is applied, such as in case studies (Bryman et al., 2018; Thomas, 2015). Mason (2018) argues that sample size should help understand the process rather than represent the population (statistically). The interviews were conducted during or shortly after the completion of the sales process. As a result, the probability that the answers reflect intrinsic perceptions is higher than if a considerable time lag had occurred, which could have led to memory lapses and perceptions already having become indistinct (Foscht 
et al., 2017). This is what differentiates this research project from others in which the data collection was conducted via questionnaire, with time lags, and the participants did not have a specific interaction to draw on (Busch \& Wilson, 1976; Doney \& Cannon, 1997; Liu \& Leach, 2001). Following the idea of purposive sampling, the samples cannot be considered statistically representative, nor as randomly selected samples (Bryman et al., 2018; Thomas, 2015). On the contrary, they illustrate what is typical for the sales interaction (Saunders et al., 2015). They demonstrate a good variety of the key characteristics (e.g. bid sum greater than 50,000 euros and higher complexity of customer requirements). In addition, customers came from many different industries, and the size of the company varied (Table 19). The size is evaluated in this context based on the number of employees. Two reasons (a. improve the ability to generalize, b. the cross-case analysis deepens the understanding and explanation of the researchers) for performing a cross-case analysis are defined by Miles, Hubermann, and Saldana (2018). Multiple sample increase confidence in the results (Silverman, 2020). Several cases help to find negative cases to strengthen the theory and to examine similarities and differences between the cases (Mason, 2018). Miles et al., (2018) claim that several cases not only determine the specific conditions under which a finding will occur, but also help the researcher form the more general categories of how these conditions can be related. Many researchers approach the comparison between cases by forming types or families (as in this research project: 8 sales success and 2 sales failure). When selecting the samples, care was taken to consider both sales failures and sales successes. Two sales failures could be observed, even though the willingness of customers who did not buy from Alpha Software to interview was comparatively low. An interview request was made to nine customers, of which two agreed. In total, 22 customers who met the requirements were approached, whereupon 10 customers agreed to an interview. 


\begin{tabular}{|c|c|c|c|}
\hline Industry & $\begin{array}{c}\text { Size } \\
\text { (Employees) }\end{array}$ & Position & $\begin{array}{l}\text { Members of } \\
\text { Buying Centre }\end{array}$ \\
\hline Security & $10000+$ & Director Payroll Accounting & 7 \\
\hline Hospitals & $10000+$ & Director HR & 8 \\
\hline Food & $4000+$ & Finance Director & 6 \\
\hline Retail & $3000+$ & Payroll Manager & 5 \\
\hline Sports & $2000+$ & Director Accounting and HR & 7 \\
\hline Entertainment & $2000+$ & Director HR & 8 \\
\hline Various & $1500+$ & HR Director & 5 \\
\hline Food & $1000+$ & Director HR & 5 \\
\hline Automotive & $1000-$ & Payroll Manager & 4 \\
\hline Sports & $500-$ & Director Organisation and Projects & 3 \\
\hline
\end{tabular}

Table 19: Interview participants

Source: Developed for this research project

\subsubsection{Collecting Data}

Yin (2018) suggested six sources of evidence: documentation, archive records, interviews, direct observations, participant observation, and physical artefacts. Documentary information, such as letters, e-mails, announcements, and administrative documents, such as proposals and reports, is likely to be relevant to every topic in the case study. Archive records are considered as "public use files", service records, organisational records, maps and diagrams, etc. (Bryman et al., 2018). According to Yin (2018), the interview is one of the key sources of case study information. The interview is a targeted discussion between two or more people (Kahn \& Cannell, 1957). An observation can range from formal to occasional data collection activities such as meetings, presentations, and factory work (Yin, 2018). During a field visit, direct observations can be made, including cases in which other evidence, such as that obtained from interviews, is collected (Saunders et al., 2015). Participant observation is a special observation method in which the researcher is not just a passive observer, but can actually participate in the events studied (Thomas, 2015). A final source of 
evidence is a physical artefact - a technological device, tool, or instrument, artwork, or other physical evidence (Bryman et al., 2018).

No single source is exceptional compared to the others. On the contrary, the various sources largely complement each other. A good case study, according to Yin (2018), should use as many sources as possible. If the multiple sources of evidence are duly recorded and validated, the result will be invaluable added value (Thomas, 2015). For this research, ten interviews were employed as the main source of data collection, supplemented by reviewing documents and observations.

The interview method is not uncommon in case study research (Thomas, 2015; Yin, 2018). Saunders et al. (2015) differentiate three kinds of interviews: structured, semistructured, and in-depth interviews.

The difference between semi-structured and structured interviews is that, in the semistructured approach, the interviewer modifies the defined questions and themes depending on the given answers and the situation (Saunders et al., 2015). Thus, the interviewer has the chance to conduct the interview in a dialog format. It allows him/her to respond more intensively to the interviewee to uncover what he intends and claims to express. For this purpose, open questions are employed. In contrast to closed questions, open questions allow the interviewees to answer on their own terms and formulate their own thoughts (Thomas, 2015). These questions do not provoke certain kinds of answers. They are useful for exploring new ideas (Bryman et al., 2018). Thomas (2015) advises specifying the issues, rather than the specific questions. The interview method, as a useful way to quickly retrieve large amounts of data, was favoured by Marshall and Rossman (1999). The evaluation is more difficult and time consuming, but it is crucial to answering the research question. In preparation for a semi-structured interview, an interview guide was created (Bryman et al., 2018) and a pilot interview was conducted (Bryman et al., 2018; Yin, 2018). As a result, reasonable adjustments according to the feedback and improvement suggestions could easily be made to the interview questions and the procedure. The adaption of the procedure and the semi-structured approach strengthened the individuality of the interviews. As a result, it was more difficult to evaluate the data regarding comparability of the answers, and the danger that important topics and questions could be omitted increased (Patton, 2002). Furthermore, it was perceivable that the interviews would not be without 
interviewer or interviewee biases (Yin, 2018). The primary reason for employing semistructured interviews lies in its major advantage: while it remains focused on the topic, it does not predetermine the interviewee's potential answers (Denzin, 1978). Semistructured interviews unveil how clients' perceptions regarding sales force expert power are identified and which factors affect their formation.

As Yin (2018) noted, "For case studies, the most important use of documents is to corroborate and augment evidence from other sources" (p. 103) He also stated, "Because of their overall value, documents play an explicit role in any data collection in doing case studies" (p. 103). Gathering data from documents represents an entirely different proposition from gathering data from people (Thomas, 2015). As supporting material, Alpha Software provides a significant amount of internal and external documentation. Annual reports, publications, and the website were utilised in this research to obtain a better understanding of the organisation and its context. Additional support was gained through the permanent access to the customer relationship management (CRM) tool. All documents regarding the sales transaction, such as emails, protocols, proposals, and contracts, are stored in the CRM tool.

Observational evidence is often helpful to provide additional information about the investigated topic (Thomas, 2015). Observed field notes were collected via a case study notepad, as recommended by Yin (2018). Thomas (2015) differentiated between structured and unstructured observations. Structured observations are "... where you watch for particular kinds of behaviour" (Thomas, 2015, p. 165). In contrast, Thomas described unstructured observations as, "... where you are in the situation, take part, record and watch from within it” (p. 165). The researcher immerses himself in a social situation to understand it. Observing the participants during the interview sessions is an unstructured observation and provides the basis for further information. The case study notepad serves as a record of the fieldwork, as well as complementary data and information to be used in the data analysis.

\section{Information on Industry}

Bitkom represents more than 2,500 companies in the digital economy. Through IT and communication services alone, the members generate a domestic annual turnover of 190 billion euros. The members employ more than two million people in Germany. They offer a wide range of software technologies, IT services, and telecommunications 
or internet services, produce hardware and consumer electronics, operate in the digital media sector, and are in other ways affiliated with the digital economy (Bitkom e.V., 2019).

According to Stübinger and Grimm (2018), "The ITC market is growing: In the area of information technology, telecommunications and consumer electronics, sales of 164.0 billion euros (+1.7 percent) are expected for 2018 ".

With an anticipated turnover of 88.8 billion euros and growth of 3.1 percent, IT continues to be the growth driver of the ITC sector. With a volume of 24.4 billion euros, the software segment grew strongly in 2018 and is, by far, the most in demand $(+6.3$ percent). The IT services posted decent growth of 2.6 percent to a market volume of 40.0 billion euros. Information technology hardware grew to 24.4 billion euros $(+0.9$ percent) (Stübinger \& Grimm, 2018).

Seufert and Suhren (2016) pointed out that "the German HR software market reached a volume of about 1.3 billion euros in 2015 and is expected to grow annually by approximately $5 \%$ to total some 1.7 billion Euros by 2020 " (p. 5 ).

The market can be broken down into three administrative human resources (HR) product segments: employee data administration (EDA), compensation \& benefits (including payroll), and workforce management (WFM). Recruiting, performance \& talent management, learning \& development, and employee collaboration \& engagement are the four strategic HR product segments (Seufert \& Suhren, 2016).

Digitalisation is increasingly pushing professional and leisure lives and thus sustainably changing society. The advantages of modern computer systems often outweigh an analogous procedure, such that any disadvantages are deliberately accepted (Bitkom e.V., 2019). This also applies to the development of payroll accounting in companies. While an HR employee was working to spend cash or prepare a so-called pay check just a few decades ago, an HR administrator today must be able to operate highly complex and fully automated computer systems to pay and manage employee salaries.

In the 1990s, payroll processing programs were increasingly in demand, allowing for the management of mass data with few personnel. This allowed a founder a more 
efficient and thus more cost-effective HR management. Today, the technical possibilities have developed further. In addition to the aforementioned reason, there are many advantages to the use of a modern payroll software. It allows web-based solutions to be accessed almost anywhere in the world. At the same time, the systems, with their electronically managed personnel files, offer greater (data) security, which cannot be guaranteed using the conventional method. Even if a company's data are damaged by hazards, it would be ensured that vital personnel files are preserved through cloud services - that is, through the external storage of the data in data centres. A payroll program also has the ability to evaluate reports and statistics, allowing a company's management to more effectively manage its personnel.

In the new digital world, the departmental printer is eliminated. By eliminating paper, digital records not only protect the environment and reduce costs, but they also provide a wealth of additional HR analysis, reporting, and planning tools. Thus, working in the HR department is not just about speed, but also about quality increases. The paperless HR department also includes digital certificate generators and digital payroll. Employment reference generators use a simple evaluation form, which executives can fill out with the click of a mouse and create the work certificate with a large number of suitable text modules. This saves valuable working time. Digital payrolls are particularly suitable for companies whose employees are rarely on site. Secure online access gives them access to their salary documents, which saves both paper and postage.

In addition, entrepreneurs are required to comply with tax and social law requirements and to know the individual circumstances of their lives (for example, marital status and number of children). Collective bargaining, trade unions, and politics are constantly changing HR law, making the law difficult to handle sufficiently. As a result, the requirements for a lawful payroll system have increased.

\section{Insights on Alpha Software}

In 2018, Alpha Software ranked highly among business software providers in Germany (Lünendonk, 2018). The range of services primarily covers the areas of accounting, HR management, business consulting, taxes, law firm organization, enterprise resource planning (ERP), IT services, and training and consulting. With their solutions, the company improves the business processes of companies, municipalities, associations, and institutions. Alpha Software's diverse range of services extends from 
more than 200 PC programs via cloud services, such as online applications, data processing, and archiving in the data centre, to outsourcing and security services. They also offer consulting services and knowledge transfer in Germany and some other European countries.

Alpha Software offers flexible design options for all topics relating to payroll accounting: organised and secure exchange of payroll data and documents between branches and central payroll accounting, legally up-to-date preparation of the payroll, the sending of pay slips to employees, and automatic transmission of data to or from institutions such as banks, health insurance funds, or the financial administration. The solutions interconnect. Interfaces to upstream and downstream systems enable consistent workflows, all at maximum data security. The advantages include the efficient process of payroll accounting through digital workflows, all employee data being readily available at a glance, and rapid processing of recruiting processes in the HR department. These offerings are supplemented with service, individual advice, and a comprehensive range of further education.

The company's identity, including the brand, specifics of internal processes as well as the interviewees' identities of the employees and clients are modified or completely anonymised. Specific attention was given not to undermine the competitive position of the company. In addition, it was important that the company provided access to the sales force and the decision makers of the client companies. A research project involving an in-organisation case study that reveals clients' relationships and internal processes raises inevitable concerns. Special care was necessary to ensure anonymity; otherwise, access to the clients would be denied. Therefore, a coding system was developed to ensure the anonymity of the participants and the involved companies, as proposed and described by Saunders et al. (2015).

\subsubsection{Processing Data}

To prevent any validity concerns, a set of methods was designed before the beginning of the data collection (Saunders et al., 2015). These methods included an interview guide and a case study book. A relevant coding scheme was designed after the data collection during the data analysis. 
An interview guide "...can be employed to refer to the brief list of memory prompts of areas to be covered...or to the somewhat more structured list of issues to be addressed..." (Bryman et al., 2018, p. 473). According to Thomas (2015), it is a list of issues that are intended to be covered, not necessarily point by point, but as a reminder of what needs to be examined.

Regarding the preparation of the interview guide, Bryman et al. (2018) recommend the following elements:

- Creation of an appropriate amount of sequences of the topics to allow for a smooth conduction of the interviews

- Formulation of relatively unspecific questions so the interviewee is able to comprehensively represent his social world

- Usage of language that is tailored to the interviewees' perspectives

- Avoidance of leading questions

- Gathering general interviewee data, e.g. age, gender, position in company, etc., for use in the data analysis.

The interview guide used for this research included the following categories and the associated questions in accordance with the research questions:

I. Attributes of the perceptions of sales force expert power

Q1 What is your understanding of sales force expert power?

Q2 Which attributes do you use to describe sales force expert power?

Q3 How important is sales force expert power to you?

Q4 What is the basis for your buying decision?

Q5 To what extent is the buying decision based on sales force expert power?

Q6 Did you have doubts regarding sales force expert power during the buying process? Was there a moment when sales force expert power was disturbing?

Q7 Has the sales force noticed the disturbance?

Q8 Would you make a decision if you doubted the sales force's expert power? 
II. Formation of the perceptions of sales force expert power

Q9 Could you please describe your decision process?

Q10 When and how did the perceptions of sales force expert power arise for the first time?

Q11 What intensifies or diminishes the perceptions of sales force expert power?

Q12 Is sales force expert power equally important in every process step?

Q13 How did you perceive the sales force in the process and how satisfied were you with it?

III. Factors affecting the formation of the perceptions of expert power

Q14 Which factors affect the formation of sales force expert power?

Q15 Is the power and the position of the salesperson in the supplier company of importance to you?

Q16 How intensively did the sales force address the different participants of the buying centre?

Q17 Which sales force recommendations did you accept?

Q18 Which factors are also important for your buying decision?

IV. Tips/suggestions

Q19 What could the sales force have done better?

Q20 What tips would you give the sales force along the way?

A pilot interview was conducted prior to the fieldwork. Pilot interviews forge a good understanding of the interview guide and the interview questions. They eliminate misunderstandings and identify the estimated interview duration. The questions and the interview process can then be altered and refined as necessary (Saunders et al., 2015). Every researcher, no matter how unstructured or inductive he comes to the field work with some orienting ideas (Miles et al., 2018). In the initial phase of the pilot interview, when interesting answers were given that needed further investigation, the respondent was asked for further clarification. Therefore, new questions were added to the interview schedule after the pilot interview. These questions were checked for suitability at the next interviews in order to generate data that can be analysed both 
empirically and conceptually. A more intensive presentation of the research project was also carried out priot to in the following interviews, because for some of the interviewees, terminology and content were not known enough to give qualified answers.

In addition to the interview guide, a case study book was established, in which all comments regarding the sales interaction (process, documents, etc.) and the interviews were noted. A case study book is a method by which observations, experiences, important key figures, field procedures, and data collections issues can be noted in written form (Bryman et al., 2018). Important contextual data and interviewrelated data can be recorded and attributed to the respective source, which will increase the trustworthiness of the data (Saunders et al., 2015). According to Bryman et al. (2018), field notes "... should be fairly detailed summaries of events and behaviour and the researcher's initial reflections on them. The notes need to specify key dimensions of whatever is observed or heard" (p. 444). Field notes summarise data of a particular contact (Thomas, 2015). The notes must be vivid, clear, and written in detail without any time delay. Notes were used in this research to prepare for the impending interviews and to make comments on impressions and key observations during the interview process.

A relevant coding scheme was developed during the data analysis to ensure research validity and reliability. A coding scheme typically represents a framework displaying the categories used for coding qualitative data (Bryman et al., 2018). The construction of a coding scheme is described in detail in the following section.

\subsubsection{Analysing Data}

A key characteristic of qualitative data is that it focuses on naturally occurring, ordinary events in natural environments and thus reflects real life. Another feature of qualitative data is its richness and holism with strong potential to reveal complexity. Such data provide robust descriptions that are alive, embedded in a real context, and contain a truth that has a strong impact on the reader (Miles et al., 2018).

Qualitative content analysis was used and followed three steps: (1) categorisation and coding of the data, (2) finding patterns and recognizing relationships between categories, and (3) developing theories and drawing conclusions (Bryman et al., 2018; 
Saunders et al., 2015; Yin, 2018). To understand how and why participants perceive the way they do, qualitative content analysis is a more suitable approach than counting certain words, which is the basis for quantitative content analysis (Schreier, 2012). The nature of qualitative content analysis is interpretive. It deals with symbolic material, and different interpretations of the same material can be valid (Schreier, 2012). For this purpose, Schreier (2012) suggests making the interpretations "plausible to others and taking potential rivalling interpretations into account" (p. 32). A classic series of analytical sequences (Table 20) that are arranged one after the other to guide the researchers through the extensive transcripts that are generated from the interviews, is described by Miles et al. (2018).

\section{Sequence of Steps}

\section{Attaching codes to field notes from interviews}

Annotating considerations or other comments in the margin

Sorting and searching this material to identify similar phrases, relationships between variables, pattern topics, clear differences between subgroups and common sequences

Isolating the patterns and processes, commonalities and differences and bring them out the field in the next round of data collection

Developing a small set of generalisations covering the consistencies found in the database

Confrontation of these generalisations with a formalised knowledge base in the form of constructs or theories

Table 20: Classic sequence of steps to analysing qualitative data

Source: Developed for this research project based on Miles et al. (2018)

Based on Bryman et al., (2018); Miles et al., (2018), and Schreier, (2012), a separate iterative approach was developed to generate, analyse and then formulate conclusions from the results. The processes developed are shown graphically in Figure 29. While the steps are displayed sequentially, the process of achieving the results has been anything but sequential. The analysis and generation of a broader understanding of the qualitative transcripts was made possible by the iterative form of learning. 


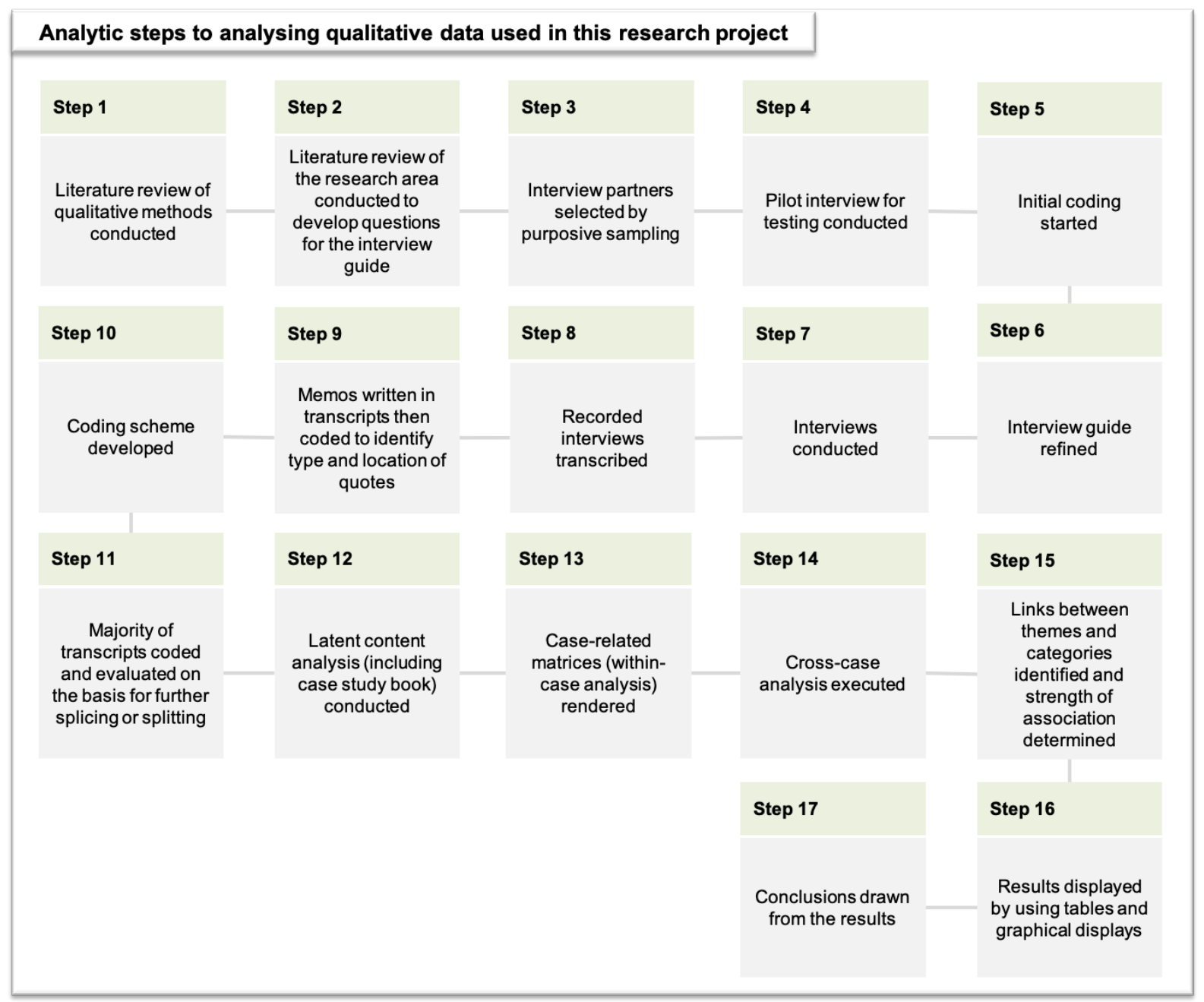

Figure 29: Analytic steps to analysing qualitative data used in this research project

Source: Developed for this research project based on (Bryman et al., 2018; Miles et al., 2018; Schreier, 2012)

The selection of the interview partners by purpursive sampling and the structure of the interview guide was described in detail in the previous sections (see section 3.2.2 and 3.2.4).

Memos are primarily conceptual because they do not just report data. They combine different data into recognisable clusters, often to show that this data is an instance of the general concept. Miles et al. (2018) claim that memos are one of the most useful and powerful tools for sensory perception. Silverman (2020) encourages researchers to record their observations and ideas on the data to prepare the ground for further analysis. Detailed memos were created for every idea that was developed when reading the transcripts and later when coding.

When pilot interviews are carried out, it is a good time to start creating coding categories, as they will help preliminary analysis of your data and help researchers 
create and code categories (Mason, 2018). Miles et al. (2018) strongly recommend early analysis because they suggest that it is helpful to alternate between thinking about existing data and generating strategies to collect new and often better data. As soon as the initial coding was started after the pilot interview was carried out, not only did it become clear how sensible and practical (or not) the coding categories were, but new categories could also be developed and also coded.

After the completed data collection, a coding scheme was developed during the data analysis to act as an initial basis and was altered during the analysis process as required (Bryman et al., 2018). Schreier (2012) defined the coding scheme as "...a way of structuring your material. It consists of main categories specifying relevant aspects and of subcategories for each main category specifying meanings concerning this aspect" (p.61). The main categories of the coding scheme are the aspects on which the analysis will be focussed (Schreier, 2012). In the course of coding, ideas and reactions to the importance of comments emerged. Miles et al. (2018) claim that these ideas are important in suggesting new interpretations, pointers, and connections to other parts of the data, and often point out questions and problems that the next data collection should address. The purpose of the research expressed in the research questions and objectives guides to the identification of various categories (Saunders et al., 2015). Strauss and Corbin (1998) identified three main sources to deduce terms for the categories: (1) terms arising from the data, (2) terms used by the participants, (3) terms used in the literature. The first two sources are considered to be data-driven techniques (inductive), while the third source is a concept-driven technique (deductive) (Schreier, 2012). It is unusual to build a coding scheme that is exclusively conceptdriven or exclusively data-driven. Most analyses mix both strategies (Schreier, 2012). An interview guide was used in this research to collect the data, and the topics were the starting point for the coding (Figure 30). Miles et al. (2018) encourage researchers to be aware that codes may and often change because some codes do not work while others expire. This was realised by the author during the early coding of the primary interviews, in which the codes often developed into more subtle codes as the author transcribed more interviews and gained a better understanding of the phenomenon. The next step in building a coding scheme is "...to attach relevant 'bits' or 'chunks' of your data, which will refer to as units of data, to the appropriate category or categories..." (Saunders et al., 2015, p. 381). Schreier (2012) used the expression 
'subcategories', rather than units. According to her, the specifications of the aspects serve as subcategories. The subcategories were generated inductively using data from the interviews. A strategy for generating the subcategories involved subsumption, which is especially useful when the main categories are already determined. According to Mayring (2010), the strategy consists of examining the relevant passages, deciding whether the concept is new and should become a category or passed up and continuing with the next relevant concept. After creating and assigning subcategories to the data, the next step was to explore ways to refine or focus the analysis. To achieve this, attention has been shifted from the "original" data itself back to the data that has been redesigned, e.g. reorganised around a specific subcategory. This made it possible to organise and analyse the data in relation to the developed subcategoeries. As a result, it was useful to assign subcategories to the data bits in which the data could be examined in a new context. The categories of the coding frame were then developed from the merging of the subcategories, which had a high level of content. 


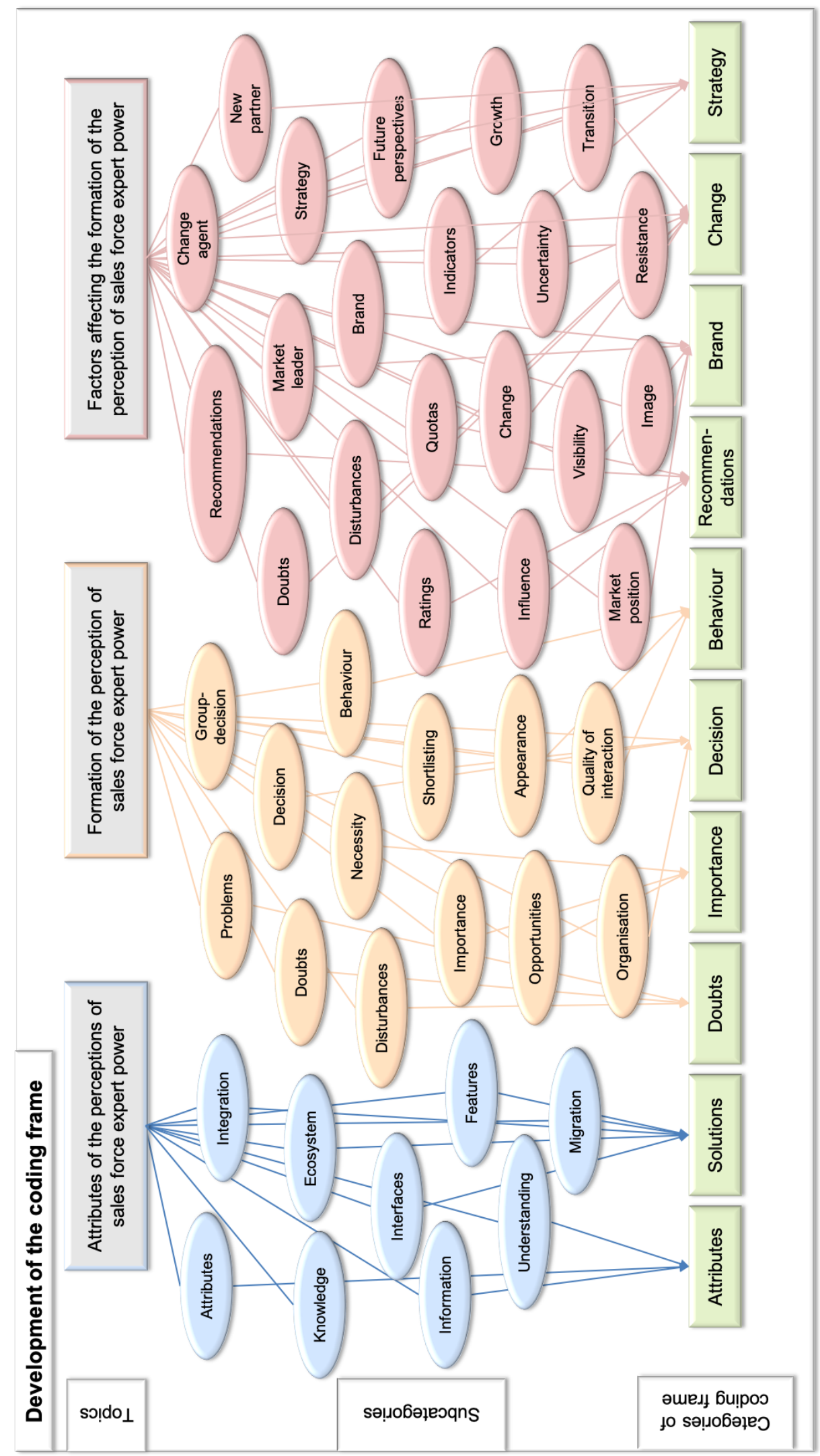

Figure 30: Development of the coding frame

Source: Developed for this research project

Content analysis can be differentiated into manifest or latent content analysis (Schreier, 2012). In manifest content analysis, the content is investigated according to 
the number of times a certain word was used or in what context it was applied (Bryman et al., 2018). According to Berelson (1952), it is characterised as direct, clear, and simple. The analysis of the latent content focuses more on the meaning behind the written words and relates to all information contained in the case study book, such as the answers of the interview partners, the observations and the documents evaluated. It is obscure and likely to differ for different readers (Schreier, 2012). The researcher has to engage in more interpretation and must look at the context in more depth (Bryman et al., 2018). To increase validity when analysing latent meaning, indicators will not facilitate the analysis, since the meaning is under the surface and not obvious or clear (Schreier, 2012). Schreier (2012) recommends phrasing the categories "in conceptual terms more than in terms of concrete indicators and examples" (p. 179) to help when implying latent meaning. Many authors argue that analysing meaning always requires interpretation, whether this meaning is manifest or latent (Neuendorf, 2002). To identify the client's perception of sales force expert power, latent content analysis is more appropriate. It permits the usage of unspoken words and thoughts so as to gain a comprehensive picture of the client's perception of sales force expert power.

After building the coding scheme and giving meaning to the collected data through coding, relationships and patterns need to be recognised and identified. The first step is indicating the relevant parts of the material and marking the units of coding within these relevant parts (Schreier, 2012). In the literature, two methods are described by which understanding can be achieved: clustering of data and using text matrices to describe the coding scheme (Bryman et al., 2018; Neuendorf, 2002; Schreier, 2012). In the clustering of data process, the data are grouped into logical clusters of fragments (Bryman et al., 2018). Schreier (2012) suggests describing and illustrating the findings by using continuous texts, either by category or by cases. If the findings are organised by case, quotes for each case on those categories are provided that describe the most qualified case. If the coding frame is complex, text matrices are used in combination with continuous texts to summarise the information (Schreier, 2012). Text matrices summarise and illustrate the selected parts of the findings (Bazeley \& Jackson, 2013). Since the present research focusses on a single case with embedded units of analysis, case-related matrices were created as part of the within-case anlysis. This is beneficial for "describing a small number of cases in depth and for illustrating a particular kind of 
case" (Schreier, 2012, p. 224). After describing the case and each embedded unit, the results were compared with each other in cross-case-analysis (Berelson, 1952; Miles et al., 2018; Neuendorf, 2002; Schreier, 2012). Co-occurrences became visible. The next step was to concentrate on relations between categories and to identify connections to design conceptual frameworks or theories (Bryman et al., 2018; Saunders et al., 2015). By focusing on identifying patterns in the data, the associations between different categories were examined to create an image of the data that is both clearer and more complex than the first impressions. By identifying such patterns, the data could be viewed from a new perspective. By linking data, the analyses were refined or some connections between categories could be derived from the results. Linking data provides a powerful way to uncover connections between categories in an empirically based analysis of relationships within the data (Miles et al., 2018). Linking can also be a useful tool for narrative description and analysis of processes within the data (Silverman, 2020).

Researchers have to face the fact that both numbers and words are needed to understand the world (Miles et al., 2018). To achieve this, the qualitative data must first be reduced. After the data has been reduced, the second main flow of analysis activities is the data display, which is why the results of the within-case analysis and the cross-case analysis were displayed in table formats and graphical displays (Miles et al., 2018; Silverman, 2020). A display is an organised, compressed assembly of information that permits conclusion drawing and action (Silverman, 2020). Miles et al. (2018) also asked the researchers not to consider the creation and use of displays as separate from the analysis, since the displays play an essential role in the analysis. Graphical displays help to clarify the main points of the analysis and their interrelations. In addition, they can help with more everyday tasks, e.g. when comparing between categories or when recognising data gaps. Dey (1993) further argues that they enable the researcher to think more systematically, logically, and imaginatively about the data. A variety of techniques, as advocated by Dey (1993), have been used to represent the connections between the categories, including:

- Different intensity of a line to represent the strength of the relationship,

- Arrows to indicate the direction of the relationship. 


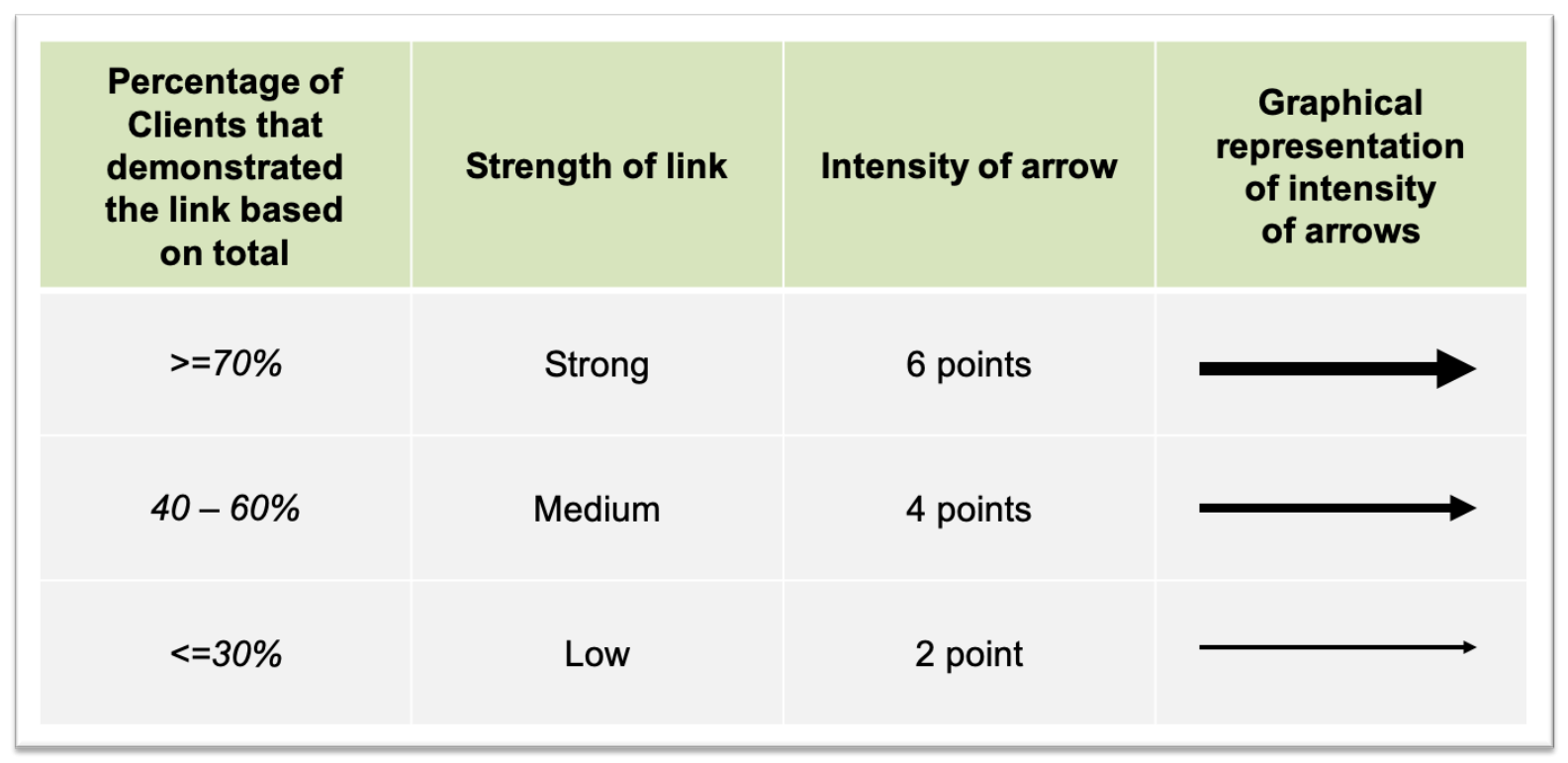

Table 21: Determination of the strength of the link Source: Developed for this research project

Based on the above criteria, different intensities in the size of the arrow direction were used to demonstrate the strength of the link between the categories (Table 21). This rule was applied consistently in all graphic displays. The direction of the arrowhead indicates the direction of the relationship. On the basis of the results, the areas of findings were identified and discussed to formulate conclusions and recommendations.

Since the researcher is employed in a management position at the sample firm, subjectivity and reliability represented key issues and needed to be ensured. An additional person coded the collected material, and the results were compared for analytical consistency (Schreier, 2012). Schreier (2012) noted intersubjectivity as the underlying concept of reliability: "The coding frame is considered reliable to the extent that the results of the analysis are not only subjective, but intersubjective, i.e. apply across persons" (Schreier, 2012, p. 167). Bryman et al. (2018) referred to internal reliability. The coding frame is considered reliable to the extent that the coding is consistent (Bryman et al., 2018).

NVivo was used to support the qualitative analysis. The NVivo software supports qualitative and mixed methods research by helping researchers to organise, analyse, and gain insights from unstructured, high-quality data (Bazeley \& Jackson, 2013). The software helped to create the codes and subsequently insert the codes in categories. The assignment of attributes aided with identifying patterns. In addition, NVivo recognised relationships within the coded parts of the interviews (Schreier, 2012). 


\subsection{Criteria in Business Research}

\subsubsection{Ethics}

Ethics is outlined as the code of conduct regarding the rights of those who take part in the study (Saunders et al., 2015). Ethical issues were a major concern in the present research because the researcher was closely involved with the research participants (Thomas, 2015). It is not unethical to ask for people's preferences or decision patterns, as long as the questions are asked respectfully and in a well-mannered way and the answers are handled as determined. For this reason, the anonymity of the interviewee and the associated company is to be strictly respected. It is precluded that the received information is used in any harmful way (Bryman et al., 2018).

The information of neither the clients nor the sales force will be considered for performance evaluations of the sales force. No names of the involved parties or client companies will be released or mentioned. An informed consent form regarding the handling of the collected data was signed by each participant. Each participant had the right to withdraw or refuse responses at any stage prior to, during, and after the interviews. The respondents were told that they did not have to participate or stay in the study if they decided to resign. They were free to choose the interview location. Videoconferences were most commonly chosen as the interview method. A coding system was developed to assure the anonymity of the participants and the involved companies, as proposed and described by Saunders et al. (2015).

The interviewer and interviewees signed off on a verbatim transcript of each interview. The participants were instructed to contact the researcher if they had problems with the content of the transcription. Upon request, they were offered a copy of the digital audio or a verbatim transcript of the interview. The personal data were collected for specific, explicit, and legitimate purposes and were not further processed. The data are password encrypted and will be destroyed after completion of the research project. After the research project is completed, the participants are invited to read the DBA thesis.

All reasonable steps have been taken to guarantee that respondents were fully informed about the data collection process and the concept of the search. At no time were the participants involved in data collection against their will, and the interviews 
were conducted in an environment of the respondents' choosing to ensure their wellbeing. The interview transcripts were validated by the interviewees, and the data collection was conducted in accordance with recognised academic research protocols.

\subsubsection{Reliability and Validity}

Reliability is confirmed when the measurement results are the same on other occurrences, when other observers make similar observations, and when it is transparent how the inferences are derived from the raw data for Easterby-Smith et al. (2008). The question is whether a case study can ensure this as well. According to Thomas (2015), it cannot, and it does not have to. This statement also refers to validity. The probability that a case study can be replicated exactly as the original is very small to impossible. The knowledge gained from a case study is therefore no less valuable.

According to Robson (2002), the greatest threats to reliability are, on the one hand, due to the mistakes that participants or observers deliberately or unconsciously make, and on the other hand due to biases that interfere with the observations. By its nature, qualitative research poses a major challenge in terms of reliability. The likelihood that the results will be exactly replicated in future research is low, as the situation and individuals change over time, since qualitative research focuses on the study of situations and individuals (Schreier, 2012).

To ensure reliability in the research, each interview was recorded and transcribed verbatim. The verbatim transcript of each interview was returned to the participants for review. The data analysis was based on qualitative content analysis (Bryman et al., 2018; Saunders et al., 2015; Yin, 2018). The constant comparison between theory and practice, as well as the results from the interviews, indicate whether the interpretations make sense and are accurate.

Validity measures whether the findings of a study are accurate and to what extent the results can be generalised (Creswell, 2009). According to Bryman et al. (2018), "Validity is concerned with the integrity of the conclusions that are generated from a piece of research" (p. 42). Yin (2018) proposed three approaches to addressing the issue of validity: external validity, internal validity, and construct validity. Construct validity involves "identifying correct operational measures for the concepts being studied" (Yin, 2018). As a solution, he recommends using multiple sources to establish 
a chain of evidence and having the inquiry reviewed by key participants. All three tactics were applied in the present research. The use of multiple sources of evidence was guaranteed through the application of embedded units of analysis and the employment of multiple sources (i.e. semi-structured interviews, complemented by observations and documents). The chain of evidence was ensured through the approach implied by the qualitative content analysis. Continuous analysing and formulating was done until the generalisations applied to all relevant data, as well as quantifying the relevant data to provide a sense of the entire data set (Silverman, 2009). Internal validity seeks to establish a causal link, with certain conditions leading to other conditions that differ from incorrect connections (Yin, 2018). Internal validity is achieved by pattern matching and constructing explanations in the coding, interpretation, and presentation of data (Yin, 2018). The generalisability of the findings refers to external validity (Saunders et al., 2015). This is generally a problem in qualitative research due to the smaller sample size and the tendency to use case study theory (Bryman et al., 2018). Thomas (2015) added that, due to this fact, the results of a case study will not fit in all situations but will still render an important input to the field of research. Qualitative researchers neither attempt to control the environment or the relationship between the researcher and the subject, nor attempt to realise high standardisation (Sarantakos, 1998). The quality of a case study is less dependent on validity, sampling, and reliability than on the design, construction, and execution of the study (Thomas, 2015).

The researcher is part of the organisation of the sample firm, Alpha Software, in a management position. Therefore, subjectivity and reliability are issues that needed to be ensured. An additional person coded the collected material, and the results were compared for analytical consistency (Schreier, 2012). Figure 31 shows the degree of agreement (kappa coefficient as a statistical measure) that can be expected by chance (Bazeley \& Jackson, 2013; Schreier, 2012). The kappa coefficient has a weighted value of 0.75 which is a fair to excellent agreement (Bazeley \& Jackson, 2013). As stated previously, Schreier (2012) noted intersubjectivity as the underlying concept of reliability: "The coding frame is considered reliable to the extent that the results of the analysis are not only subjective, but intersubjective, i.e. apply across persons" (Schreier, 2012, p. 167). Bryman et al. (2018) referred to internal reliability. The coding 
frame is considered reliable to the extent that the coding is consistent (Bryman et al., 2018).

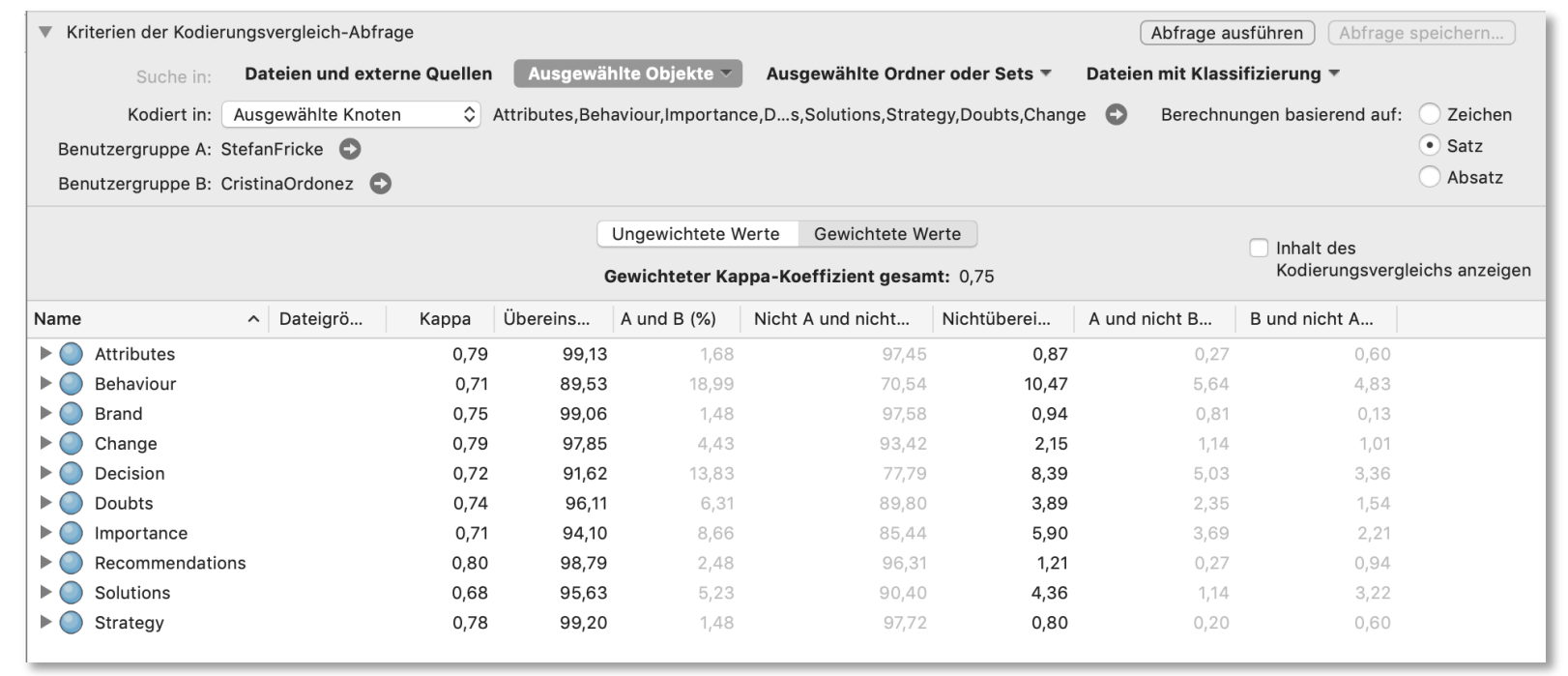

Figure 31: Coding comparison query

Source: Developed for the research project

The values of the researcher gained particular importance through his participation in the research process. He decided which questions were posed and how, which persons would be involved and to what extent, and how focus areas were to be defined. His personal perception, preferences, beliefs, and feelings were decisive for the evaluation and, consequently, the interpretation of the findings (Bryman et al., 2018). The personal perception and preferences cannot be considered objective. The researcher cannot deny, despite the consideration of validity and credibility, that he is biased and that he has influenced the results either consciously or unconsciously (Saunders et al., 2015; Yin, 2018). The case study here is a method used to gather subjective perceptions and concrete and specific presentations of real-life problems and solutions by evaluating and interpreting the perception of the participants (e.g. the members of the sales force and the buying group) (Bryman et al., 2018; Thomas, 2015).

In conducting the case study, the researcher needed to exert certain competencies. The ability to adapt promptly and flexibly to new situations and human beings was crucial. He needed to accurately observe to recognise details. Beyond that, the researcher created confidence by asking the right questions and, through active listening, was able to determine the real motives of the participants. The researcher needed to have or acquire the ability to ask relevant questions and interpret the 
answers, as well as be a good listener while being adaptable and flexible to respond to different situations. Having suitable knowledge of the issues under investigation and being unbiased by preconceived terminology were additional requirements (Yin, 2018).

The researcher had inside knowledge of the organisation, the market, and its employees. He knew, for example, legitimate and taboo issues and how they had been handled in the company. He was aware that he also played a double role. Not only was he a member of the organisation, but he was also a researcher (Coghlan, 2001). There was a possibility that this would lead to a role conflict, manifesting itself such that the researcher would feel like an outsider in both roles (Coghlan, 2007). However, the largest risk came from organisational politics. The researcher needed to be aware of the organisation's political dynamics, which could influence the research endeavour (Coghlan, 2007).

\subsection{Conclusion}

This research followed the tradition of interpretivism. As social actors play a crucial role in understanding a phenomenon, the researcher needed to comprehend the subjective reality and perceptions of the participants. The research is an interpretivist inquiry that was designed to follow an inductive approach and used qualitative methods to collect and analyse the data. The three purposes of research (exploratory, descriptive, and explanatory) were considered. Exploratory fieldwork was necessary to generate data, given that the perceptions and resulting actions, particularly interactions, provided the basis for further examinations. Prior to data collection, it was essential to have a rich comprehension of the situation of the participants, which was obtained through descriptive research. The explanatory contribution of the study is the derivation of an approach by which sales forces can recognise and appraise the attributes and factors influencing the formation of clients' perceptions of sales force expert power based on causal relationships emerging from the data generation. Semistructured interviews were conducted with ten clients that were involved with one sample firm (Alpha Software). The chosen research strategy was a case study. One single case was contemplated, but the sales interactions between the client and the sales force were considered as embedded units of analysis. The selection of the interactions to be analysed between clients and the sales force was made via purposive sampling. The interviews were conducted during or shortly after the 
completion of the sales process. Qualitative content analysis was used and followed three steps: (1) categorising and coding the data, (2) finding patterns and recognising relationships between categories, and (3) developing theories and drawing conclusions. After the data collection, a coding scheme was developed during the data analysis to act as an initial basis and was altered during the analysis process as required. An additional person coded the collected material, and the results were compared for analytical consistency. No client or sales force responses have been or will be taken into consideration for performance evaluations of the sales force. No names of the involved parties or client companies have been or will be released.

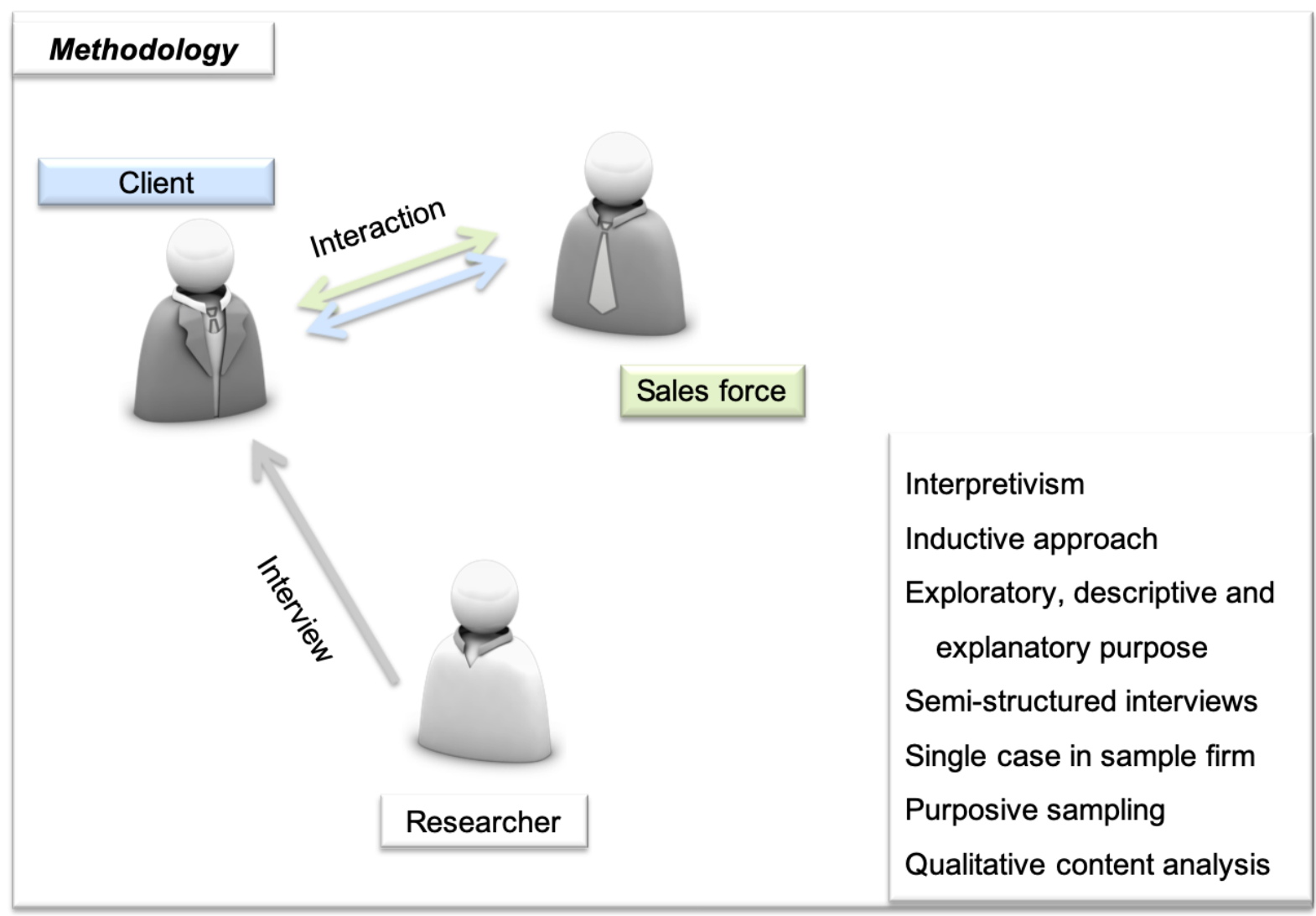

Figure 32: Summary of methodology

Source: Developed for the research project based on Bryman et al. (2018); Saunders et al. (2015); Schreier (2012)

A robust and rigorous research methodology in terms of research method, validity, reliability, and ethical considerations has been developed (Figure 32). Thus, the next step is to describe the case study in detail and conduct and interpret the collected raw data. 


\section{Data Analysis and Findings}

\subsection{Objectives of the Chapter}

The objective of Chapter 4 is to succinctly present the results of the semi-structured interviews and to evaluate their relevance with regard to the research questions. The results presented and summarised in this chapter are then discussed in Chapter 5 in the context of the literature review, and, as a result, derivations for the practical implementation are found and explained.

\begin{tabular}{|c|c|}
\hline $\begin{array}{l}\text { Categories of } \\
\text { Coding Frame }\end{array}$ & Description \\
\hline Attributes & $\begin{array}{l}\text { Consolidation of the attributes of sale force expert power mentioned by the } \\
\text { participants. }\end{array}$ \\
\hline Solutions & All topics with the subject of software and product solutions. \\
\hline Strategy & All topics related to strategic issues. \\
\hline Doubts & All issues regarding the doubts of sales force expert power. \\
\hline Importance & $\begin{array}{l}\text { The contend related to the importance of sales force expert power in general and } \\
\text { specifically in the buying process. }\end{array}$ \\
\hline Decision & $\begin{array}{l}\text { In the category, all content is collected that focusses on the decision-making process } \\
\text { within the buying centre. }\end{array}$ \\
\hline Behaviour & All relevant issues that focus on the behaviour of the sales force. \\
\hline Recommendations & $\begin{array}{l}\text { All issues related to the recommendations of the sales force and products or } \\
\text { solutions. }\end{array}$ \\
\hline Brand & The topics that relate to the brand and brand recognition. \\
\hline Change & The feedback that in any way addresses the change or change agent theme. \\
\hline Observations & What was observed during the interviews? \\
\hline
\end{tabular}

Table 22: Categories of coding frame

Source: Developed for the research project

The results are presented qualitatively (Schreier, 2012). Data-driven categories are used as a basis for the investigation of the material. The final coding frame used is considered to be the most important result (Table 22). A sharp separation of the results in the categories is not possible; therefore, subject overlaps in the respective categories are possible and are deliberately accepted. The following case classifications are examined more closely for the data analysis (Table 23). Each case is subsequently described in terms of coding frame, case classification, and observations using continuous text (Schreier, 2012). 


\begin{tabular}{|c|c|}
\hline Case classifications & Description \\
\hline Experience with Alpha & Are there any past experience with Alpha Software? \\
\hline Project experience & Have larger or comparable projects been carried out in the past? \\
\hline Evaluation of expert power & What is the evaluation of expert power in the buying centre? \\
\hline Importance of purchase & What importance or necessity does the purchase have for the company? \\
\hline Complexity of project & $\begin{array}{l}\text { How complex is the project in terms of human resources, } \\
\text { budget, and duration? }\end{array}$ \\
\hline Intensity of change & $\begin{array}{l}\text { How intense is the perception of the change for the organisation and } \\
\text { employees in introducing the new solution? }\end{array}$ \\
\hline Orientation of buying centre & $\begin{array}{l}\text { What is the main orientation of the buying centre-task (goal-oriented), self } \\
\text { (focus on own welfare), or interaction (focus on interpersonal relationships? }\end{array}$ \\
\hline Stage of purchasing evolution & $\begin{array}{l}\text { In which of the four stages of purchasing evolution the buying centre values } \\
\text { itself - passive (price focused), independent (cost focused), supportive } \\
\text { (solution/innovation focused), or integrative (strategy focused)? }\end{array}$ \\
\hline $\begin{array}{l}\text { Specific shortcomings } \\
\text { in expert power }\end{array}$ & What are specific shortcomings in expert power of the buying centre? \\
\hline Sales success & Have the sales activities been successful? \\
\hline Particularities & What are the particularities of the data collection? \\
\hline
\end{tabular}

Table 23: Case classifications

Source: Developed for the research project

To better illustrate the results, examples from the material are given for the numerous categories (Bazeley \& Jackson, 2013). Finally, all essential results of the categories are summarised and presented in tables, which generate the basis for further discussions in the context of literature research (Miles et al., 2018).

\subsection{Interview Client $\mathbf{A}$}

\section{Case Classifications}

The complexity of the project was rated very highly by Client A (Table 24). Project experience and experience with Alpha Software exist. The importance of the purchase, the intensity of change, and the evaluation of expert power were rated highly. The buying centre is task-oriented and is in the supportive stage. Specific shortcomings in expert power are not noticed. The purchase decision was made for Alpha Software.

The sales activities were time-consuming and very intensive. The customer demanded everything from the sales force. The sales process spanned twelve months and had 
four four-hour sales pitches framed in up to one hunderd emails. The complexity of the requirements and the associated different questions made it necessary to involve software development intensively in the sales process. This was unique to the Alpha software.

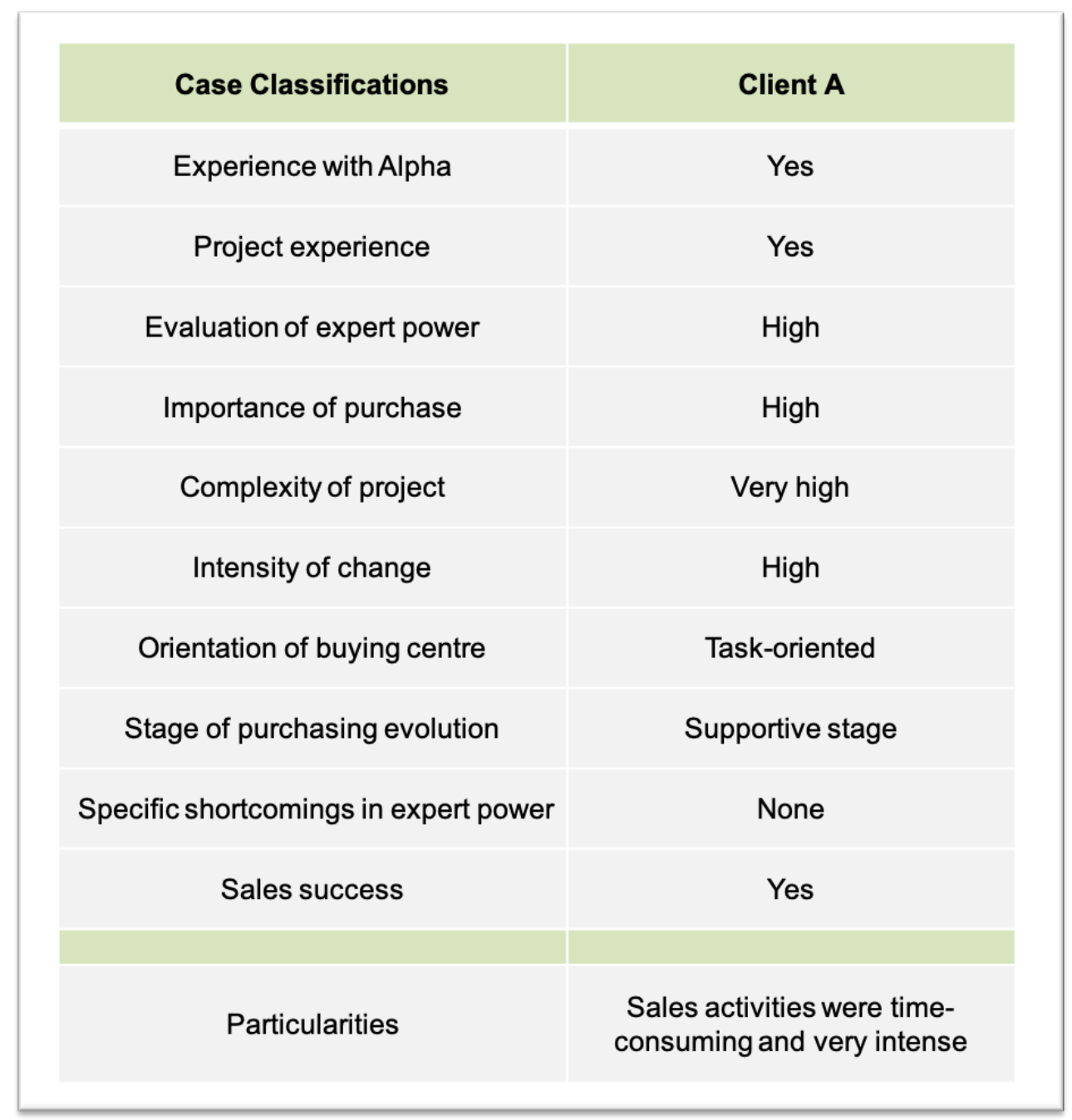

Table 24: Case classifications - Client A

Source: Developed for this research project based on the interview

\section{Attributes}

According to Client A, sales force expert power is the expertise a salesperson has in his or her field. The salesperson needs to know the products and know how they are used and implemented by customers. 


\section{Client $A$}

"Product knowledge, process knowledge, the ability to think in my processes and my needs, the ability to show me how a project can be implemented."

Client A focuses not only on product knowledge, but also on process knowledge. To him, it is crucial that the sales force knows and focuses on his processes and that the solution is tailored to these processes.

\section{Solutions}

Crucial for Client $A$ is that the solution solves the given problems. He also deliberately speaks of a solution here, referring to the different products that are used and the associated advice and training for the follow-up care. The overall offer is more important than individual features in the software.

\section{Client $A$}

"The most important thing is that the solution suits us and our problems are solved. We want to make compromises as little as possible. [...] Think in solutions, not in problems."

The costs of the implementation are not decisive if the solution fits. The costs must be within the budget; however, the budget is generous to purposely leave a margin.

\section{Strategy}

Important to the buying decision of Client A is that he can rely on the partner in the future.

\section{Client A}

"We wanted a partner we can rely on."

Doubts 
Client $A$ experienced doubts during the acquisition process. At times, he did not feel that the acquisition was successful. The sales force was too busy with the problems and lost sight of the solutions to those problems.

\section{Client $A$}

"Yes, there was such a moment. In one of the sales pitches, I did not feel that we would find a solution in between. [...] The motivation for a migration was at a low point."

Client A was worried that his employees were losing motivation to change. However, changing the software was of critical importance to the company, as the existing software was no longer state-of-the-art. According to Client $A$, the sales force did not notice the customer's doubts.

\section{Importance}

Expert power is important to Client $A$ when making a purchase decision, but only to a certain extent, as, depending on the solution or product, he embraces doubts about the skills of the sales force.

\section{Client $A$}

"It's important for us. If you ask me for a percentage, I would say 60 to $70 \%$." "Right in the first conversation. [...] In the exploratory phase, it is certainly something more important. [...] If the talks are more advanced, you know the products and solutions better. That's where the importance diminishes. It is crucial again when the final decision is made."

To Client A, expert power is important from the first contact. Every contact and every answer count. The way the sales force responds to his questions is critical to the perception of expert power. Perceptions improve as the solution to the issues becomes more concrete and confidence in resolving the issues increases. When the solution is visible and understood, the importance of expert power decreases; however, the reliability of the sales force should never decrease. Expert power regains importance when the decision is pending, and the final questions and open points need to be clarified. It is not imperative that all open points are clarified; only those that are important for a decision must be addressed. The remaining open points will be clarified 
for Client A during implementation. However, this confidence only exists when the sales force gives Client $A$ the feeling that the solution really fits and can be implemented.

The position and power of the sales force at the supplier is important to Client A. Since Client A's requirements are not always up to standard, special solutions need to be found. Adjustments can result from the pressure that a sales force exerts on its own organisation.

\section{Decision}

In addition to Alpha Software, Client A explores two other vendors to make a more informed decision and to establish options in case collaboration with a vendor is not possible. The decision is based on the trust in the solution, experience with the provider, and the experiences by others. He views the expert power of the sales force as particularly vital in this phase of the decision.

\section{Client $A$}

"Here in our case in the migration of the payroll software we had two more options. [...] For me it is important that my team stands behind the decision. [...] Individual phases were for me: the phase of the fundamental decision that we migrate, the phase of market research, then the exploratory talks with the suppliers, the selection of the 2 alternatives, the design phase and the phase I would call the final decision phase."

Client A does not make the decision alone. The employees are not only involved in the decision-making process, but they must also be able to support the decision. If this is not the case, no decision is made. However, Client A influences the decision through his position and experience.

The number of sales pitches was sufficient for Client A to make a decision. If that had not been the case, more pitches would have occurred. The number of pitches was thus controlled by Client $\mathrm{A}$.

\section{Behaviour}

Client A emphasised, on several occasions, that he needs to have a good feeling about and confidence in the choice of the new software and that his problems need to be 
solved. The sales force establishes this affirmative feeling and confidence by attentively listening to the client and understanding where his issues lie and why change is meaningful. In addition, the sales force should be open, transparent, and solution oriented, and must focus on the essentials. The solution, rather than the problem, should be the focus. On the contrary, if the sales force comes to the fore, it takes up too much room, asks no or few questions, appears to know it all, does not listen, and diminishes the perception of expert power. If the sales force wants to solve every problem in the acquisition phase, this unsettles the employees and decreases the perception of expert power.

\section{Client $A$}

"And he should really understand what I want as a customer. Where my pain is and why I have a need to change something. [...] I want to have a good feeling. [...] If you talk about problems all the time, it decreases. That does not help anyone. I also do not like it when the seller takes up much space. When he is always talking about himself and always knows better. [...] The sales force has involved all persons on our side. From the vice president to the clerk. The intensity was adequate for me."

The involvement of the participants of the buying centre was, from the point of view of Client $\mathrm{A}$, adequate and largely target-group compliant. His boss and he would have wanted fewer details in some places. However, they were necessary for the employees.

\section{Recommendations}

Client A was not given recommendations that directly relate to sales force competence. Rather, the given recommendations related to process enhancements and job tasks for individual employees. The recommendations the sales force made were important to and positively influenced his decision making.

\section{Client $A$}

"The recommendations have a bigger impact on the decision. They make me feel that Alpha Software understands their job." 


\section{Brand}

The reputation of the brand and the experiences associated with it have been addressed by Client $A$ as being worthwhile.

\section{Client $A$}

"It also depends a lot on the reputation of the company and experiences. [...]

I've already worked with the software and gained many good experiences."

Client A has already had positive personal experiences with Alpha Software and noted that the software has many satisfied users.

\section{Change}

According to Client A, not all questions and topics must be clarified within the scope of the acquisition, as this would overwhelm and frustrate the employees. A migration is hard work for everyone. After all, they are the ones who have to work with the software. The employees must be given special consideration when making a purchase decision. When all issues were clarified, the employees became unsettled or downright frustrated, such that a conversion was considered to be undesirable. Mistrust and uncertainty spread among the employees.

\section{Client A}

"Recognize that problem solving is not possible at this moment and that you trust that a solution will be found later. [...] I secretly hoped that all the open questions would be resolved in the course of the project. The questions, as long as they are not an absolute co-criterion, should be postponed."

Only through many personal and trust-building conversations with his team was Client A able to normalise the situation. Client $A$ wanted the sales force to conduct these confidence-building measures.

Observations 
The topic of change moved Client A during the interview. This was perceptible through the changed breathing and the noticeable tension. It was felt that this topic had a special meaning for Client $A$ and the employees concerned.

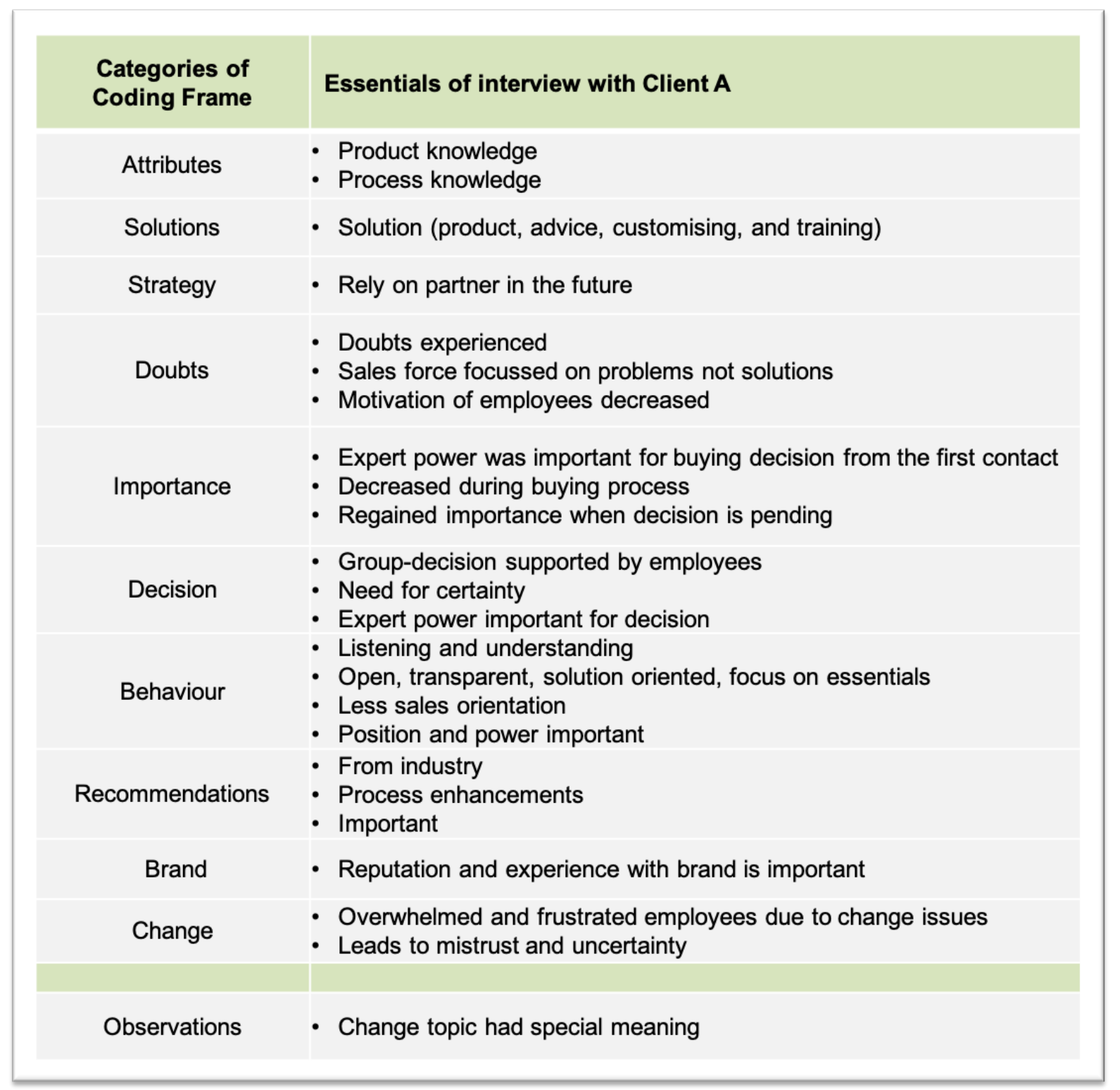

Table 25: Essentials of interview with Client A

Source: Developed for this research project

The essential results of the categories of the coding frame of the interview with Client A are summerised in Table 25.

\subsection{Interview Client B}

\section{Case Classifications}

The complexity of the project was rated medium by Client B (Table 26). Project experience and experience with Alpha Software are not available. The importance of 
the purchase was rated low, the intensity of change medium, and the evaluation of expert power high. The buying centre is task-oriented and is in the supportive stage. Low specific shortcomings in expert power are noticed. The purchase decision was made for Alpha Software.

The sales talks were technical and very detailed and sometimes exceeded the skills of the sales people. The consultants who were to implement the project had to be regularly consulted and involved. Client B wanted every detail clarified before making a decision.

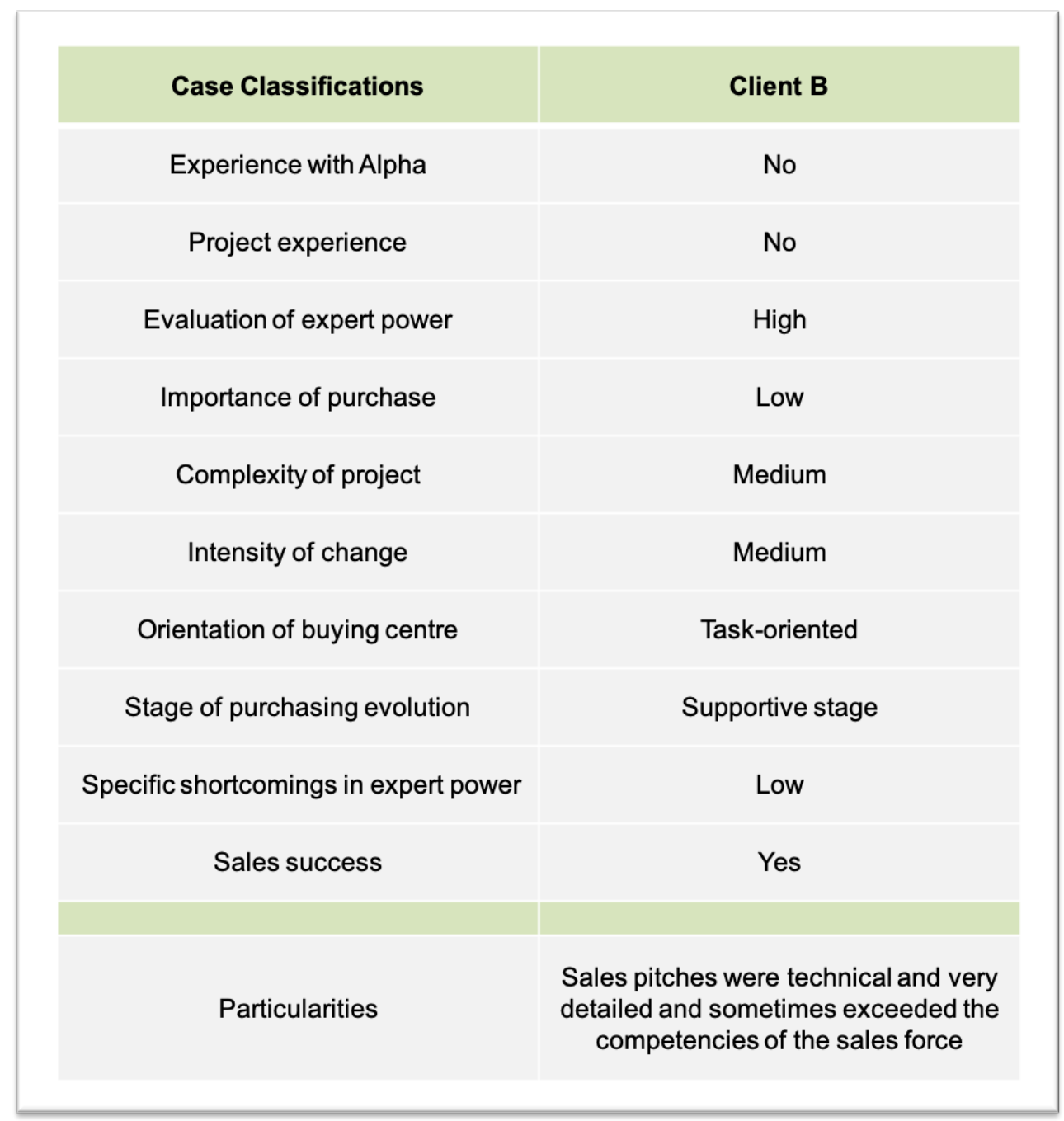

Table 26: Case classifications - Client B

Source: Developed for this research project based on the interview

\section{Attributes}

Regarding the characterisation of sales force expert power, Client B requires that the software and the associated benefits are explained to him. 


\section{Client B}

"For me, the intensive knowledge of the software and how this software is used in our company to best meet our requirements."

Detailed knowledge of the software and how it is used in practice to best meet the requirements is, according to Client $\mathrm{B}$, key in describing expert power.

\section{Solutions}

For Client B, Alpha Software offers a complete package consisting of software, IT environment, training, and legal changes.

\section{Client B}

"Alpha offers everything we need. In addition to the software, it offers us the IT environment, training and always the latest case law."

The costs of software migration and the software itself are not decisive issues, provided that these costs are within the budget. It is crucial to Client $B$ that the requirements are met.

\section{Strategy}

No findings.

Doubts

Client B did not have direct doubts about the sales force, but rather uncertainty, due to the fact that the differences between the respective software were minimal and a clear decision was therefore difficult. Client $B$ wanted to transfer the decision to the sales force. The sales force refused to decide, whereupon Client B was confused and did not feel properly taken along. 


\section{Client B}

"Doubts is not the right word. As I mentioned earlier, we were having a tough time deciding on a payroll program. ... We felt a bit abandoned by the sales force. [...] We were confused and not really taken along."

This uncertainty could only be resolved through a clarifying conversation with a responsible person from Alpha Software. According to Client B, the sales force had noticed the doubts, and conversations in the background must have taken place. The sales force adapted to the situation through changed behaviour.

\section{Importance}

The expert power of the sales force is important to Client B in making a decision. Without expert power, a topic as complex as payroll software cannot be sold. Client $B$ even went so far as to say that, without expert power, he has no confidence in the company's products, and a decision would thus be negative. Client $B$ needs to detect expert power from the first minute of contact with the sales force. This perception comes from the sales force answering the questions, primarily the complicated questions, as well as how they handle the answers. The sales force must adequately understand Client B's issues. Only then is a satisfactory solution possible.

\section{Client B}

"This is very important for me and my staff. Without sale force expert power, in my view, no sale is possible. [...] If the sales force is not good, I have no confidence in the company's products. [...] The perception of sales force expert power rose at the very first appointment. From the first minute, the sales force was required. [...] At the beginning of the process, e.g. in the first conversations when it comes to the formation of trust, it is more important. Very important in the phase is the product knowledge and the ability to recognize and address the problem.

At the beginning of the purchasing process, expert power plays a greater role for clients. Product knowledge and the ability to grasp the problem correctly are crucial here. According to Client $B$, the importance of expert power decreases only when trust has been established. Trust is also built when questions are not answered 
immediately, or a response takes longer because the question is not easy to answer. A delayed answer is better than a quick but wrong answer.

\section{Decision}

The basis for the purchase decision is the good feeling and the security of Client B and the employees, that all questions have been answered satisfactorily, and that the software improves the working conditions. To achieve this feeling and level of certainty with Alpha Software, several meetings (five pitches on site and two pitches online) were necessary. The initial expectation of Client B was that the sales force would decide which software was the right one. However, as the sales force refused, Client $B$ and the team had to make that decision first. The frequency of meetings is of no importance to Client B. It is crucial that the open points are clarified, and it is fine if several meetings are necessary.

\section{Client B}

"The basis for our decision is my good feeling and that of my employees. If our questions are answered, we have a certain feeling, we decide for it. [...] For this decision we needed several intensive discussions. [...] In order to make a purchase decision, we have to present alternatives. [...] The actual decision for the Alpha I did with my staff. [...] The frequency is not decisive, in my opinion. It is crucial that all our questions are answered. If it takes longer, it will take longer."

Two providers were intensively studied in addition to Alpha Software. Client B chose Alpha Software in collaboration with the staff. This decision was presented to the management and sought approval.

\section{Behaviour}

The sales force needs to show Client B how the work will improve after the software has been introduced. The benefits of the software must be evident. The language of the sales force should be binding and clear. A well-groomed and friendly demeanour underpins the perception of competence. How questions are handled, whether they are answered promptly, what happens if the question is not answered, and whether the sales force really understands what the issues are also contribute to the perception of expert power. 


\section{Client B}

"The sales force has to make us feel that we can do our job better afterwards. [...] Friendly and nice appearance and clear and binding language. [...] In addition, it is crucial for me how our questions are dealt with. Does the seller really want to understand what we want, or does he just want to sell something? And how does he deal with it when he does not know something? Does he clarify this in a timely manner, and does he also give me the feeling that he is really doing it or is he trying to circumvent all problems and talk away? [...] The perception decreases when our questions are not answered satisfactorily or not at all. Even then, it diminishes when problems are not recognized or simply dissipated. [...] Clarity, openness, support in decisionmaking and honesty when something does not work out. [...] Due to the different levels of knowledge in our buying centre many questions arose with a different depth...our impression was that they have taken good care of us."

Honesty and openness when requirements are not met are positively valued by Client $B$. Due to the various levels of knowledge in the buying centre, many questions with different depths of knowledge emerged. Client $B$ and the employees felt that they were in good hands with the sales force and that the sales force met their various needs.

\section{Recommendations}

Recommendations from industry colleagues have a positive effect on Client B's decision. These recommendations are based on experience with Alpha Software and the software to be used. Recommendations that relate to the skills and capabilities of the sales force have no relevance.

\section{Client $B$}

"...the recommendations of our colleagues from the other companies. [...] The recommendations related to the organisation of my department and the processes. [...] The recommendations show that the sales force has an idea. That impressed me and had a big impact on the decision."

Meanwhile, recommendations made by the sales force, such as the organisation of the department and individual processes, are viewed quite positively. These recommendations increase Client B's perception of expert power.

\section{Brand}


The brand and recommendations of users positively contributed to Client B's decision on Alpha Software. Regular industry-internal knowledge exchange, through which opinion forming is conducted, takes place. The reputation and the ability of the user to see the software live and in real-time has given Alpha Software a competitive advantage.

\section{Client B}

"Alpha Software has a lot of experience in the industry. [...] Recommendations and experiences of others, corporate image..."

\section{Change}

Choosing the right software has far-reaching future-oriented consequences for Client B. It must be well thought out. The software available for selection differs only minimally in some areas. Client B expects the sales force to provide certainty and support when choosing the right software. In the decision-making process, Client B did not always feel adequately supported. Mistrust came up.

\section{Client $B$}

"We felt a bit abandoned by the sales force."

The existing software was not competitive compared to the presented software. It was clear to Client B after the conversations that a change was inevitable.

\section{Observations}

Client B was expecting the sales force to choose the software. In the interview it was observed that there were clearly different expectations regarding this topic, which could have prevented the sales success. The issue of change was only of minor importance for Client B. 


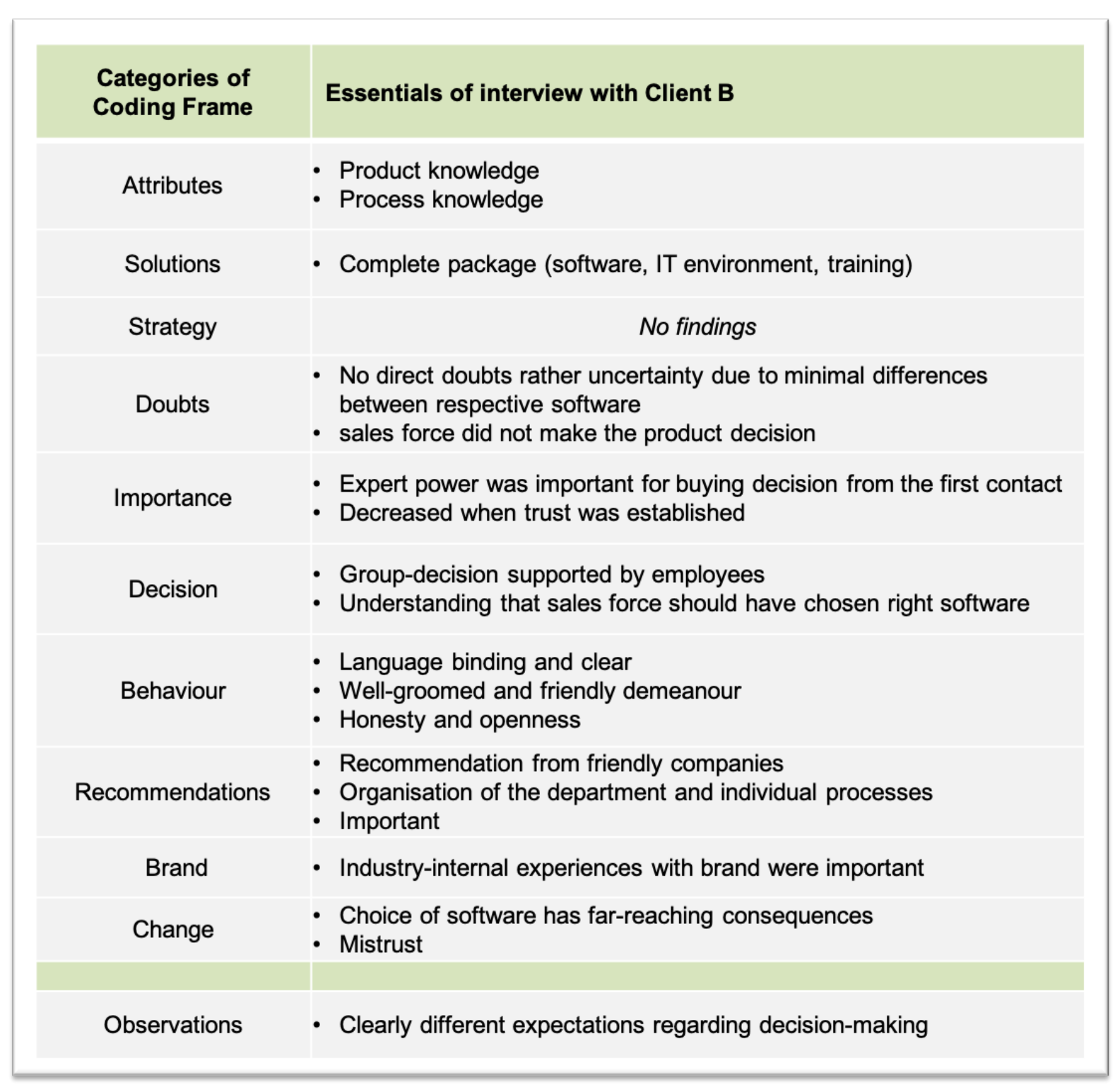

Table 27: Essentials of interview with Client B

Source: Developed for this research project

The essential results of the categories of the coding frame of the interview with Client $\mathrm{B}$ are summerised in Table 27.

\subsection{Interview Client C}

\section{Case Classifications}

The complexity of the project was rated highly by Client $C$ (Table 28). Project experience is available, while experience with Alpha Software is not. The importance of the purchase, the intensity of change, and the evaluation of expert power were rated highly. The buying centre is task-oriented and is in the supportive stage. Specific shortcomings in expert power are not noticed. The purchase decision was made for Alpha Software. 
Due to the high number of participating companies that operate in different industries, which increases the complexity of the requirements massively, the sales process could be completed in 4 months.

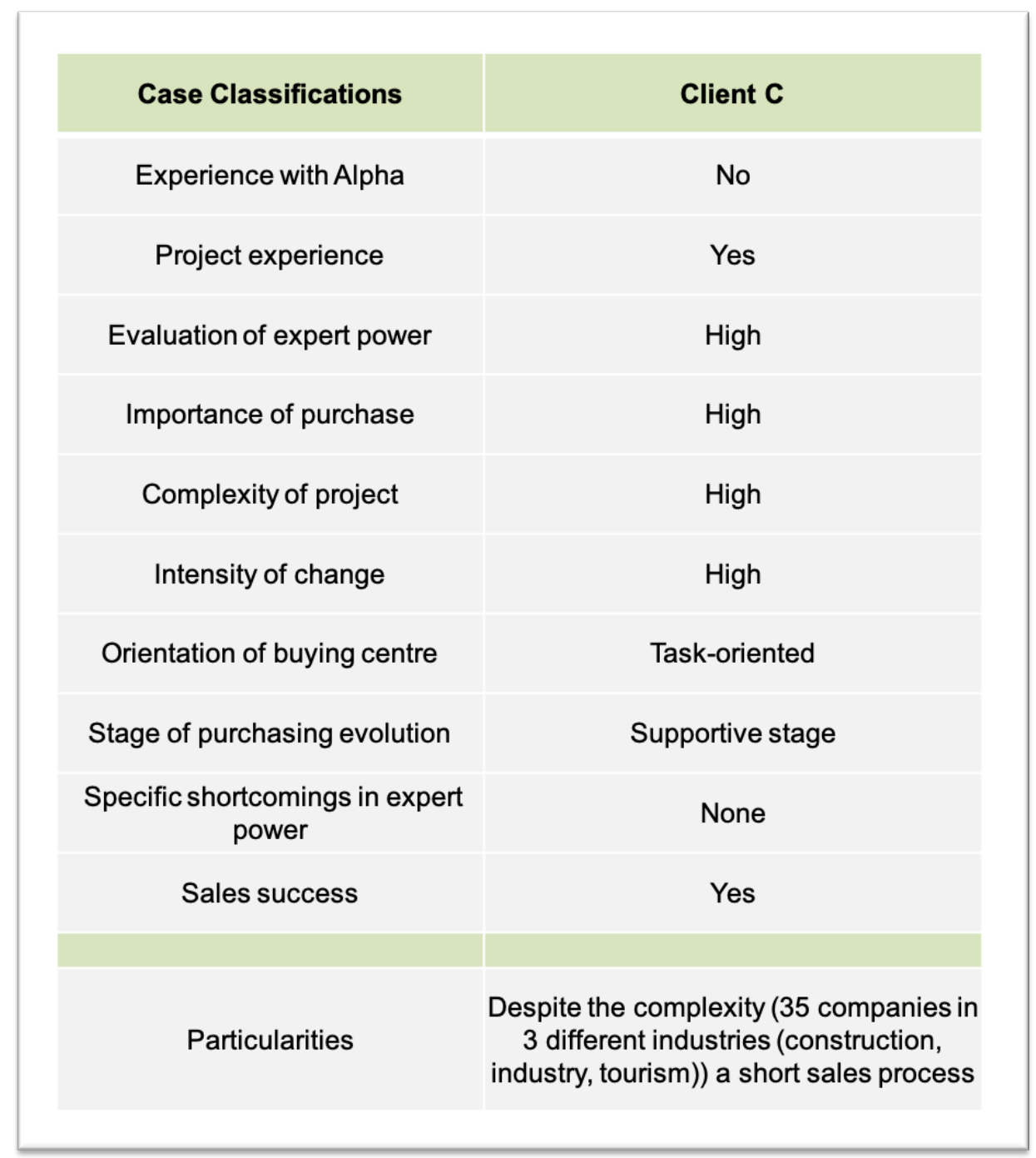

Table 28: Case classifications - Client C

Source: Developed for this research project based on the interview

\section{Attributes}

According to Client $\mathrm{C}$, expert power is the ability to sell a product or a solution. For this, the sales force needs to understand the customer's problem and how it can be solved. The best solution will be found in collaboration with the customer. For Client $\mathrm{C}$, knowledge about the software and the legal framework is part of expert power, as is knowledge about the processes and the industry. 


\section{Client $C$}

"Sales force expert power is what it takes to sell a program or a solution. In order to be able to sell a solution, the problem of the customer must be worked out cleanly and together the best solution must be found. [...] Software knowledge, legislative expertise [...] Process knowledge, industry knowledge"

\section{Solutions}

Client $\mathrm{C}$ does not only think about the software when deciding. For Client $\mathrm{C}$, the whole package must fit. This package consists of software, consulting, and service. Although some components of the package may be better solved by other vendors, Client $C$ is ready to tolerate this if the combination suits all components.

\section{Client $\mathrm{C}$}

"The solution consists of different components. There is the software, the advice, the service and what the provider offers me. [...] The solution must fit with our problems. As just mentioned, the package must fit. It can also be that individual components are better solved by other providers. The software offers more features, for example. But if the service is bad, it does not bring us any farther. The mix, the package, has to be right. [...] In addition to the solution, the supplier has to convince us as a whole."

The supplier as an entity plays an important role and completes the aforementioned components.

\section{Strategy}

Client $\mathrm{C}$ thinks about long-term cooperation when choosing the right supplier. From this perspective, it is important that the partner keeps his solutions up to date and continues developing them.

\section{Client C}

"I want a partner who is up to date."

Doubts 
Client $C$ had strong doubts about the competence of the sales force. According to Client $\mathrm{C}$, too much information had been exchanged that benefitted the critics of the project. The opponents of the project used this information to oppose the project. The sales force did not notice this, however, and felt that this information was necessary to make a decision. Client $C$ disagreed with this. On the contrary, Client $C$ viewed the implementation of the new software as vulnerable. Only through Client C's intervention did the situation subside. The sales force underestimated the complexity of the requirements.

\section{Client $C$}

"Yes, definitely there was this moment. It became critical after the third sales pitch. I nearly got out of my skin. [...] Every point you have explained in detail. And talked further and further. They did not understand that that was not important to us at the moment. [...] I also have employees who see this project critically. Not everyone wants to change and learn new software. The more open questions the more arguments the employees have. [...] The situation could be remedied when the sales force stops talking. That sounds very simple, but it is. The sales force needs to know when it needs to be enough and things have to stand that way. Knowing too much is a problem in such a moment."

From Client C's point of view, the doubts in the sales force stemmed from their unwillingness to overstate their undisputed knowledge without paying attention to the situation. According to Client $\mathrm{C}$, the sales force did not notice these doubts. Only by taking over the conversation could Client $\mathrm{C}$ correct the situation.

\section{Importance}

To Client $\mathrm{C}$, the expert power of the sales force is important from the first contact, and, even before this first contact, through the website. Client $\mathrm{C}$ expects facts that can only be communicated with expert power. Client $C$ believes that the importance of expert power varies in the decision-making process. 


\section{Client $\mathrm{C}$}

"It is very important. I expect facts. [...] Even before the first appointment. The presentation of the website and the first phone call gave us the first impression. [...] It is very important at the beginning and at the end of the process. In between, other factors play a bigger role. For me these are the features in the software, the consulting offer, service. [...] At the beginning of the purchasing process it is about trust and expertise, in the end "the bag" has to be closed by the sales force."

In the initial phase, when it comes to building trust and expertise, and in the decisionmaking phase, when the sales force closes the sale, expert power is more important. In the phases in between, Client $\mathrm{C}$ believes that the package consisting of software, consulting, and service is of greater importance.

\section{Decision}

Client $\mathrm{C}$ made the decision in collaboration with the involved employees and the IT based on the composition of the solution, which consisted of the software, the consulting, and the service offer. Important to this decision was trust in the sales force. The number of sales pitches was appropriate and necessary from Client C's point of view. The decision was made when their own sample data was implemented in the software as an example and the timesheets were linked. Client $\mathrm{C}$ could clearly see that the solution worked.

\section{Client $C$}

"The mix, the package, has to be right. [...] If I distrust the sales force properly, I cannot make a decision. [...] We then briefly probed the market, talked to IT partners and informed ourselves in working groups. [...] Yes, we needed them all. [...] The breakthrough in the process was made when we saw how our wage types are being implemented in the new software and how our timesheets are being linked. [...] Great impact. They were the deciding factor that we chose Alpha."

The recommendations of the sales force positively influenced this decision.

Behaviour 
According to Client $\mathrm{C}$, the behaviour of the sales force intensifies the perception of expert power. This includes timely answers, honesty, precision, empathy, and good listening. The sales force does not need to know everything, but they must strive for the answers, get to the point, and always focus on the essentials.

\section{Client $C$}

"Empathy, speed, honesty, good rhetoric, listening... [...] ...precision, informed... [...] Perception is intensified by the behaviour of the sales force. By that I mean the way answers are given, fast and precise they come. I do not mean that the sales force needs to know everything. But they have to get the information in a timely manner. The better the sales force does it the better my perception. Conversely, the perception decreases. [...] You must get to the point and take care of the essentials. [...] Many questions could only be clarified by the specialist departments. In my opinion, it needed hierarchy. Otherwise they would not have moved."

The position of the sales force in the company is important to Client C. Hierarchy enables faster viewing of requests and topics. Client $C$ has much experience with requests.

\section{Recommendations}

To Client $\mathrm{C}$, recommendations from the industry regarding the company and its employees are important and have a significant impact on the buying decision. In addition, Client $\mathrm{C}$ expects stimulus for his daily business.

\section{Client $C$}

"New impulses, suggestions for my business. [...] The recommendations related to our processes and employee training. [...] ...and the recommendations about the company from others. [...] From industry colleagues I've gotten quotas that the company and its employees are very knowledgeable."

The sales force has provided Client $C$ with suggestions for process improvements and employee training. According to the client, the Alpha Software sales force has positively distinguished itself from the sales forces of the other providers. 


\section{Brand}

Even before the initial contact with the sales force, Client $C$ had a positive impression of Alpha Software. This positive impression was strengthened through discussions with industry colleagues and through the website and was confirmed by the sales force in the initial conversations.

\section{Client $C$}

"Even before the first appointment. The presentation of the website and the first phone call gave us the first impression. Of course, we had already heard a lot of good things from Alpha Software in advance. [...] The performance was very professional and informative. [...] From industry colleagues I've gotten quotas that the company and its employees are very knowledgeable"

\section{Change}

According to Client $\mathrm{C}$, the introduction of a new solution means greater change for employees. Not all employees are positive about this change. To feel secure with this change, they ask many questions. Unfortunately, not all questions can be answered conclusively at the time of the purchase decision, which creates a level of mistrust and uncertainty. Resistance to the project was formed by few employees.

\section{Client $\mathrm{C}$}

"Not everyone wants to change and learn new software."

The critical employees use this uncertainty to oppose a possible change. The sales force must be aware of this. Client $C$ has experienced the failure of a project before it even started.

\section{Observations}

Client $\mathrm{C}$ was upset about the behaviour of the sales force, because the way the sales force occurred, the project opponents worked against him and the project and almost overturned it. 


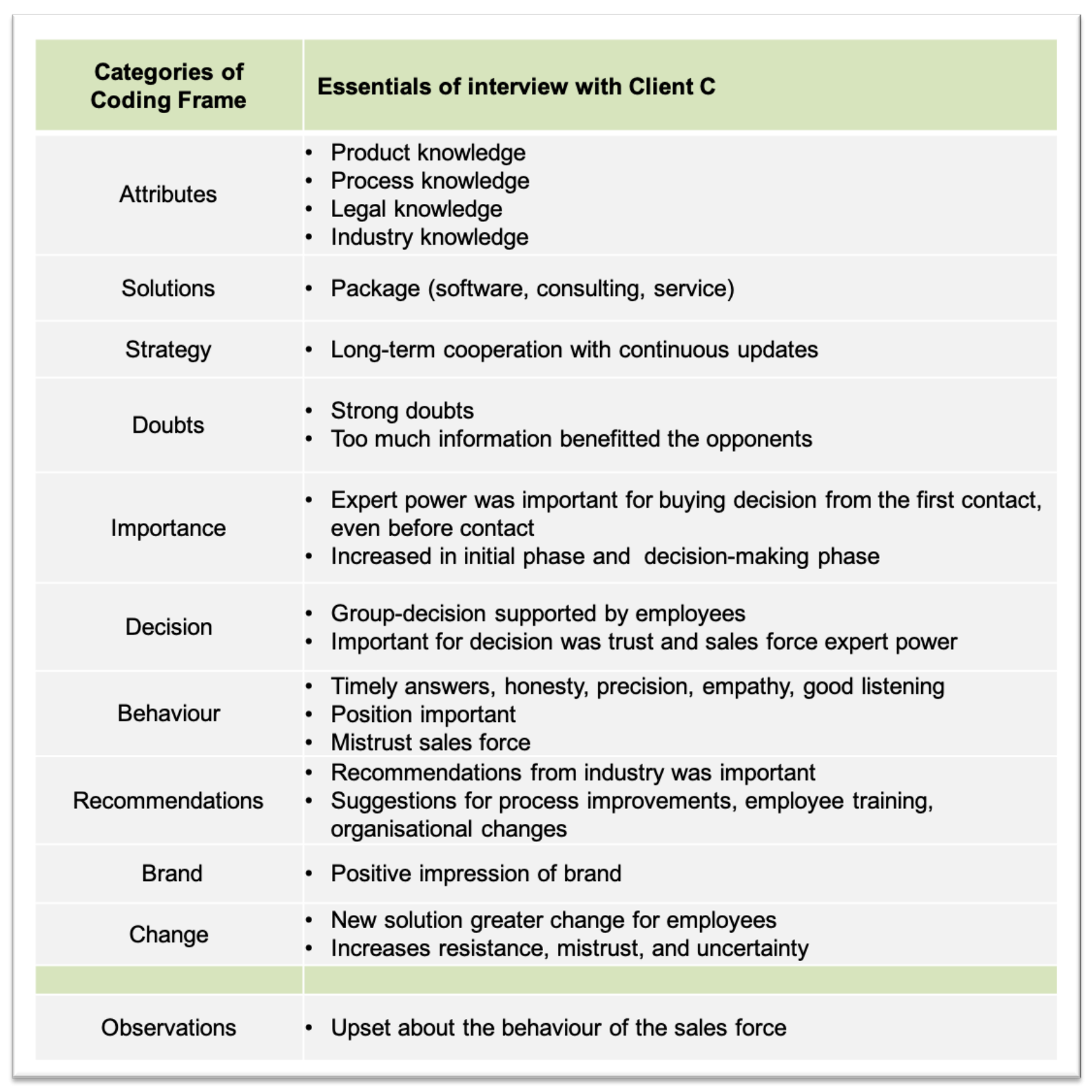

Table 29: Essentials of interview with Client C

Source: Developed for this research project

The essential results of the categories of the coding frame of the interview with Client C are summerised in Table 29.

\subsection{Interview Client D}

\section{Case Classifications}

The complexity of the project was rated low by Client D (Table 30). Project experience is available, while experience with Alpha Software is not. The evaluation of expert power and the importance of the purchase were rated highly, and the intensity of change medium. The buying centre is task-oriented and is in the supportive stage. 
Specific shortcomings in expert power are not noticed. The purchase decision was made for Alpha Software.

No particularities were found during the sales process.

\begin{tabular}{|c|c|}
\hline Case Classifications & Client D \\
\hline Experience with Alpha & No \\
\hline Project experience & Yes \\
\hline Evaluation of expert power & High \\
\hline Importance of purchase & High \\
\hline Complexity of project & Low \\
\hline Intensity of change & Medium \\
\hline Orientation of buying centre & Task-oriented \\
\hline Stage of purchasing evolution & Supportive stage \\
\hline Specific shortcomings in expert power & None \\
\hline Sales success & Yes \\
\hline Particularities & None \\
\hline
\end{tabular}

Table 30: Case classifications - Client D

Source: Developed for this research project based on the interview

\section{Attributes}

According to Client $D$, expert power of the sales force is the ability to convince customers of the product and the solution. For this, the sales force needs knowledge about the product, the processes, and the interfaces.

\section{Client $D$}

"The knowledge to convince a customer of the products and solutions. [...] Product knowledge, process knowledge, interface knowledge." 


\section{Solutions}

The integration of Alpha Software's products into the existing IT landscape and the consistent processes that can be realised as a result represent the solution for Client D.

\section{$\underline{\text { Client } D}$}

"They offer a consistent process in payroll and can connect to our feeder system with an interface. And finding employees for this software is easier than with our current system. [...] Integration into our existing processes is important to us."

\section{Strategy}

No findings.

Doubts

Client $D$ had no doubts about the expert power of the sales force during the buying process. At the beginning of the conversations, there were only slight frustrations, which resulted from the sales force taking much space and determining the conversation.

\section{Client $D$}

"Only the beginning was bumpy as mentioned. I did not find the sales force expert power disturbing at any stage. [...] The sales force was very cautious and got on well with us. They were never intrusive and did not want to force the sale. We always had the necessary space to exchange ideas in a team."

\section{Importance}

Sales force expert power is highly important to Client $D$ in all phases of the purchasing process, as only then does the supplier understand the processes and offer a solution. For Client $D, 80 \%$ of the purchasing decision is made from the expert power of the sales force. 


\section{Client $D$}

"Sales force expert power is important. Only then can you understand our processes and offer us a solution. [...] The first appointment is crucial. If it is going bad, the supplier must already have a very good name. Product knowledge and process know-how are important to me at all stages."

Client D attaches particular importance to the initial contact. A satisfactory initial contact provides a sound basis for further discussions. If the initial contact is not satisfactory, the supplier must already have a respectable name so that the sales force is invited back.

\section{Decision}

To Client $\mathrm{D}$, the basis for a purchase decision is to what extent the solution meets the requirements and is convincing. Client $\mathrm{D}$ makes the purchase decision in collaboration with his employees. The personal feeling plays a crucial role in the decision. If any doubts remain, Client $D$ does not make a decision.

\section{Client $D$}

"The basis is a good solution that meets our requirements. [...] My employees and I have to be convinced. We will make the decision together. [...] I need a good feeling for a decision. [...] We did not contact another supplier. [...] The recommendations were important and have positively influenced our decision."

Providers other than Alpha Software were not addressed in the decision-making process. According to Client $\mathrm{D}$, this was not necessary, since Alpha Software was already considered to be the ideal partner after the first call. The number of calls was adequate and sufficient.

\section{Behaviour}

A restrained and space-giving sales force is considered by Client $D$ to be pleasant and capable. This sales force would respond accordingly to the specific needs of the interlocutors and give the necessary attention to the customer. The right questions and answers reinforce Client D's perception of expert power. A sales force that pushes 
itself into the foreground, whether through too much general information or through self-centred communication, destroys the perception of expert power.

\section{Client $D$}

"They were never intrusive and did not want to force the sale. We always had the necessary space to exchange ideas in a team. [...] ... the ability to adapt to each customer individually... [...] The perception of sales force expert power is intensified by good questions and competent answers. [...] Pay attention to me as a customer and give me the right appreciation. [...] The sales force has presented itself for too long. I would have liked it better if we had previously talked about our topics. [...] Less general, more concrete information."

Client D's motto is to talk more to the customer than about one's own company. The customers and their issues must be in the foreground. The position in the company is not important to Client $D$ - when Client $D$ receives a request, he locates the right person in the company. He does not need the sales force for this.

\section{Recommendations}

Recommendations have a positive influence on Client D's purchase decision. This applies both to the recommendations of others and to the recommendations given by the sales force. These increasingly refer to process improvements.

\section{Client $D$}

"The recommendations were important and have positively influenced our decision. [...] The recommendations and experiences of other colleagues. [...] Process improvements."

Recommendations that also refer to the sales force itself have no relevance to Client D.

\section{Brand}

In addition to the sales force's expert power, which is $80 \%$ decisive for Client D's decision to buy, is the brand or image of the company and the experiences that others have had with the brand. 


\section{Client $D$}

"The remaining percentages are image and experience of others."

\section{Change}

Client $D$ and Client D's employees are aware that the introduction of new software involves additional effort. According to Client $D$, the advantages of the change justify this additional effort. The change led to mixed feelings among the employees. The result was mistrust of the change and the sales force.

\section{Client $D$}

"After the first sales pitch, my co-workers and I sat down and evaluated the presentation. The advantages of a change were presented vividly to us. Despite some concerns about the extra work during the transition, we have called for a change."

\section{Observations}

No particular observations. 


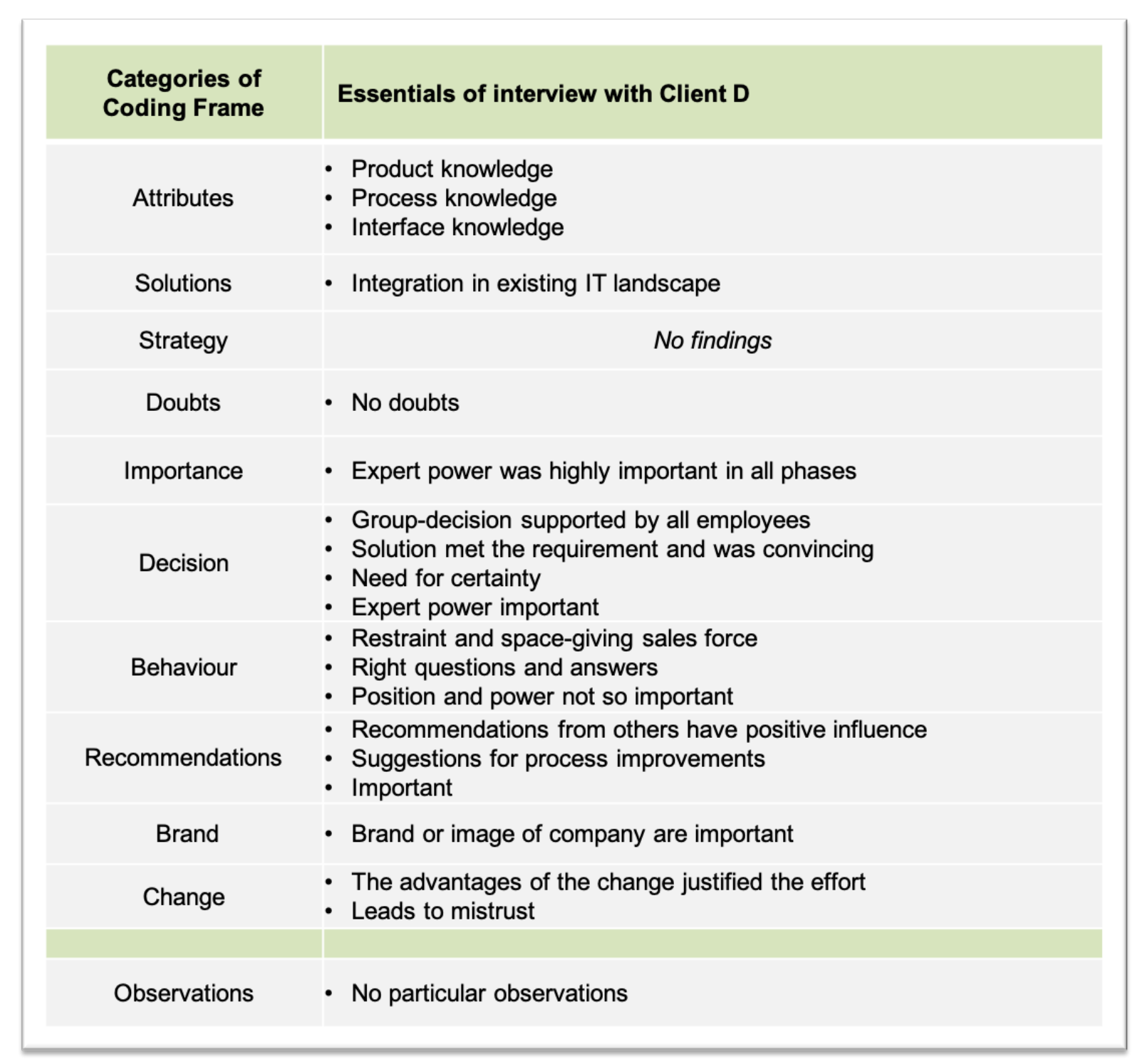

Table 31: Essentials of interview with Client $D$

Source: Developed for this research project

The essential results of the categories of the coding frame of the interview with Client $\mathrm{D}$ are summerised in Table 31.

\subsection{Interview Client E}

\section{Case Classifications}

The complexity of the project was rated medium by Client $E$ (Table 32). Project experience is available, while experience with Alpha Software is not. The evaluation of expert power and the importance of the purchase were rated highly, and the intensity of change medium. The buying centre is task-oriented and is in the supportive stage. Specific shortcomings in expert power are not noticed. The purchase decision was made against Alpha Software. 
The client was not very willing to make decisions and needed a lot of support in making decisions. The sales process took 13 months and the contact to the sales force was constant. Despite the efforts, the sales activities were not successful.

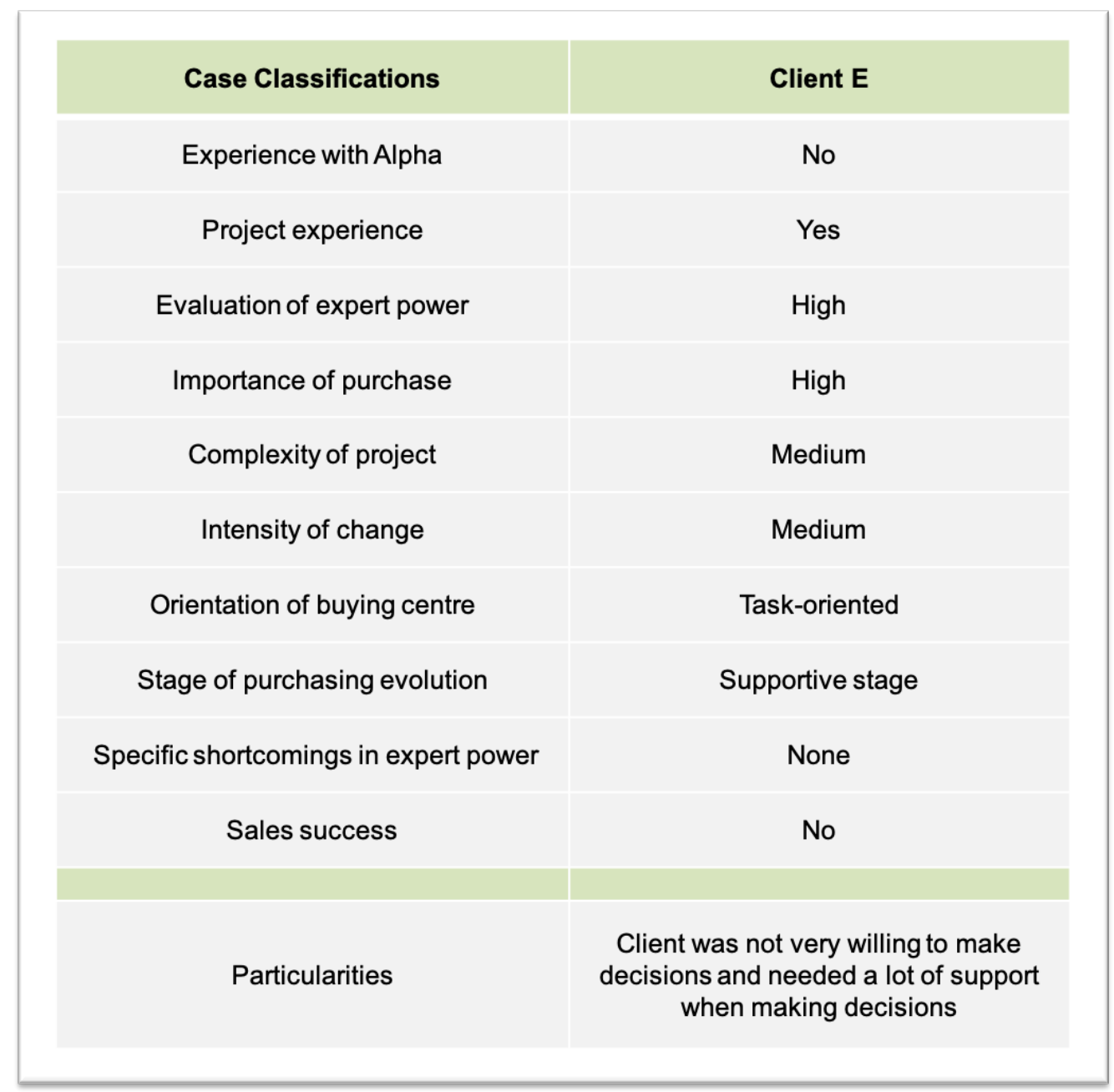

Table 32: Case classifications - Client E

Source: Developed for this research project based on the interview

\section{Attributes}

According to Client E, sales force expert power is the ability to explain a product or service. For this, the sales force must have a combination of product knowledge and a technical and procedural understanding.

\section{Client E}

"Sales force expert power is the ability of the salesman to explain his products and services. [...] Product knowledge. [...] By that I mean the combination of technical and process knowledge,..." 


\section{Solutions}

A software solution must be easy and seamless for Client $E$ to integrate into the existing IT environment. If this is not the case, it does not make sense for Client $E$ to opt for such a solution. Effort and follow-up costs will always exceed the actual benefit.

\section{Client $E$}

"The appearance is old, and the interfaces are not state of the art. The effort to implement the software and to integrate it in our environment is difficult and time-consuming. [...] .... and that the new system can be integrated in our environment. [...] If the software does not integrate easily, we choose another one."

Alpha Software was not chosen because of its complex and difficult integration, the old-fashioned appearance, and the outdated interfaces.

\section{Strategy}

A partnership with a company whose software cannot be completely integrated into the IT landscape makes little sense, according to Client E, from a strategic point of view.

\section{Client E}

"If the software does not integrate easily, we choose another one."

\section{Doubts}

Client $E$ had doubts about the sales force when a decision needed to be made as to which software should be used. The doubt was there before it was clear that the integration of the software would be cumbersome. Client E expected that the sales force would make the decision because they had all of the facts. However, this was not the case, as the sales force only provides the information needed for a decision. 


\section{Client E}

"As I mentioned earlier, the sales force always gave us a lot of freedom. In this decision phase I would have wished that she would take us by the hand and take the decision. [...] I would have preferred a clear decision. [...] The sales force has given me to understand that they deliberately do not take a position because I should decide as a customer. They only support this decision. They give me all the information to decide. In my opinion, that was not helpful. As I said, a clear position would have been better for me."

The decision must be made by the customer himself. Client $\mathrm{E}$ expected a clear position of the sales force. According to Client E, the sales force had recognised the client's doubts but would not address the topic itself. Client E addressed his issues directly; however, the sales force did not change its behaviour on the issues.

\section{Importance}

To Client E, expert power of the sales force is highly important, as is feeling good about the purchase and the involved people. Truth and honesty are two attributes that determine Client E's feelings.

\section{Client E}

"Very important. I need to have a good feeling of the purchase and about the people I am involved with. I need to have the feeling that $\mathrm{i}$ am told the truth and treated honestly. [...] I would say $50 \%$. [...] The other $50 \%$ are based on our own expertise. The buying group is deciding if the software fits or not. We have a lot of expertise in the house. [...] I expect a consistent quality. The above attributes do not change for me."

In addition to sales force expert power, the expert power of the buying centre is $50 \%$ decisive for the purchase decision of Client E. The buying centre has extensive expertise and decides whether to purchase the software.

\section{Decision}

When deciding on the right choice, Client $\mathrm{E}$ has no clear position. On the one hand, Client $E$ expects the sales force to make the decision; on the other hand, he is confident that his own competent buying centre is able to make the decision alone. The decision 
against Alpha was made by the HR department and the IT department. If the decision was positive for Alpha Software, the final purchase decision would have been made by the Director of Finance. According to Client E, the employees who work with the software after the introduction have a significant influence on the purchase decision. Who makes the final decision remains unclear.

\section{Client $E$}

"The buying group is deciding if the software fits or not. [...] In this decision phase I would have wished that she would take us by the hand and take the decision. [...] The sales force has given me to understand that the sales force deliberately does not take a position because I should decide as a customer. They only support this decision. [...] The decision is made by the specialised department (our case the HR department) and the IT department. IT advises us and together we make the decision, or we make a recommendation. The final decision will be made by our Director Finance. [...] My employees have a strong influence on the decision for a software."

The number of pitches was appropriate for the decision.

\section{Behaviour}

The appearance of the sales force and their adaptation to the different characters in the buying centre positively affect Client E's perception of expert power. Good listening, asking questions, openness, a positive attitude, empathy, and reliability support this perception.

\section{Client $E$}

"In addition, he adapts to the different characters of his customers individually. [...] ... empathy, the ability to respond to people individually, listening, asking questions, commitment, reliability, openness, friendliness, positive attitude... [...] Sales force expert power is intensified if, as a customer, I get the freedom to handle my concerns. I focus on my needs. The sales force guides me through the right questions and together we elaborate my needs and requirements. Sales force expert power will decrease if only the salesperson speaks all the time and does not ask questions. [...] Good demeanour, quick answers, helpful and empathetic. [...] The sales force must withstand the critical questions of the customer." 
If the sales force can withstand even the most unpleasant questions, Client $E$ finds trust. However, if the sales force comes into focus and the customer becomes a minor matter, the perception is clouded. Client $E$ rates the position of the sales force in the company as important due to the fact that the response time can be shortened.

\section{Recommendations}

Recommendations played no role for Client $\mathrm{E}$ in the buying process. These included recommendations that affected the sales force itself, as well as recommendations issued by the sales force.

\section{Client E}

"None"

\section{Brand}

No findings.

\section{Change}

No findings.

\section{Observations}

It was important for Client $E$ to point out that the sales force was not responsible for the alpha software not being chosen. It was because of other factors. The sales force did a good job throughout the acquisition period, even if there were differences of opinion regarding the decision making. 


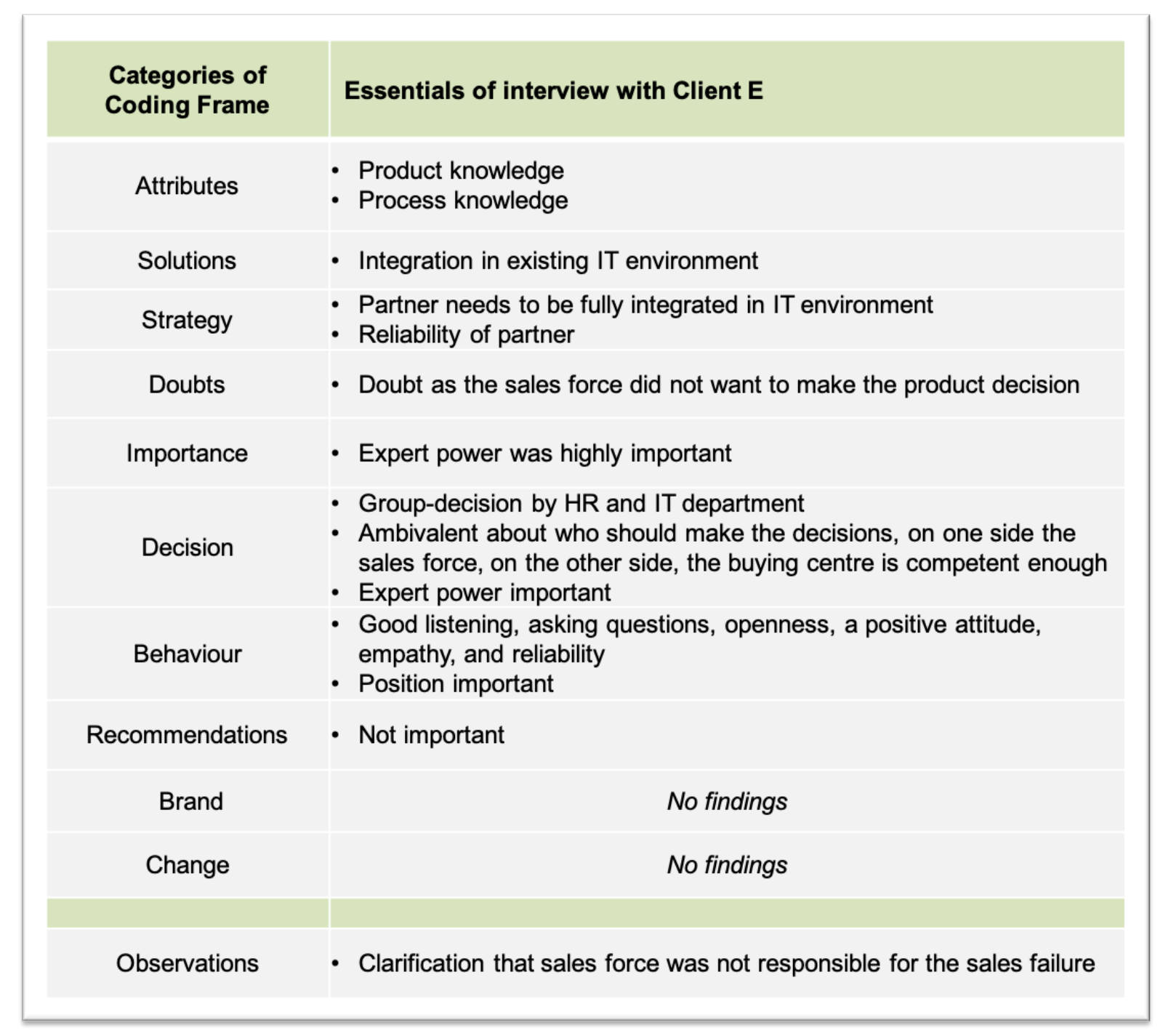

Table 33: Essentials of interview with Client E

Source: Developed for this research project

The essential results of the categories of the coding frame of the interview with Client E are summerised in Table 33.

\subsection{Interview Client F}

\section{Case Classifications}

The complexity of the project was rated medium by Client $F$ (Table 34). Project experience and experience with Alpha Software is available. The importance of the purchase, the intensity of change, and the evaluation of expert power were rated highly. The buying centre is task-oriented and is in the supportive stage. Specific shortcomings in expert power are not noticed. The purchase decision was made for Alpha Software. 
The sales force had to pay particular attention to the IT department. It was instrumental in the purchase decision, since IT had a strong voice in the buying centre.

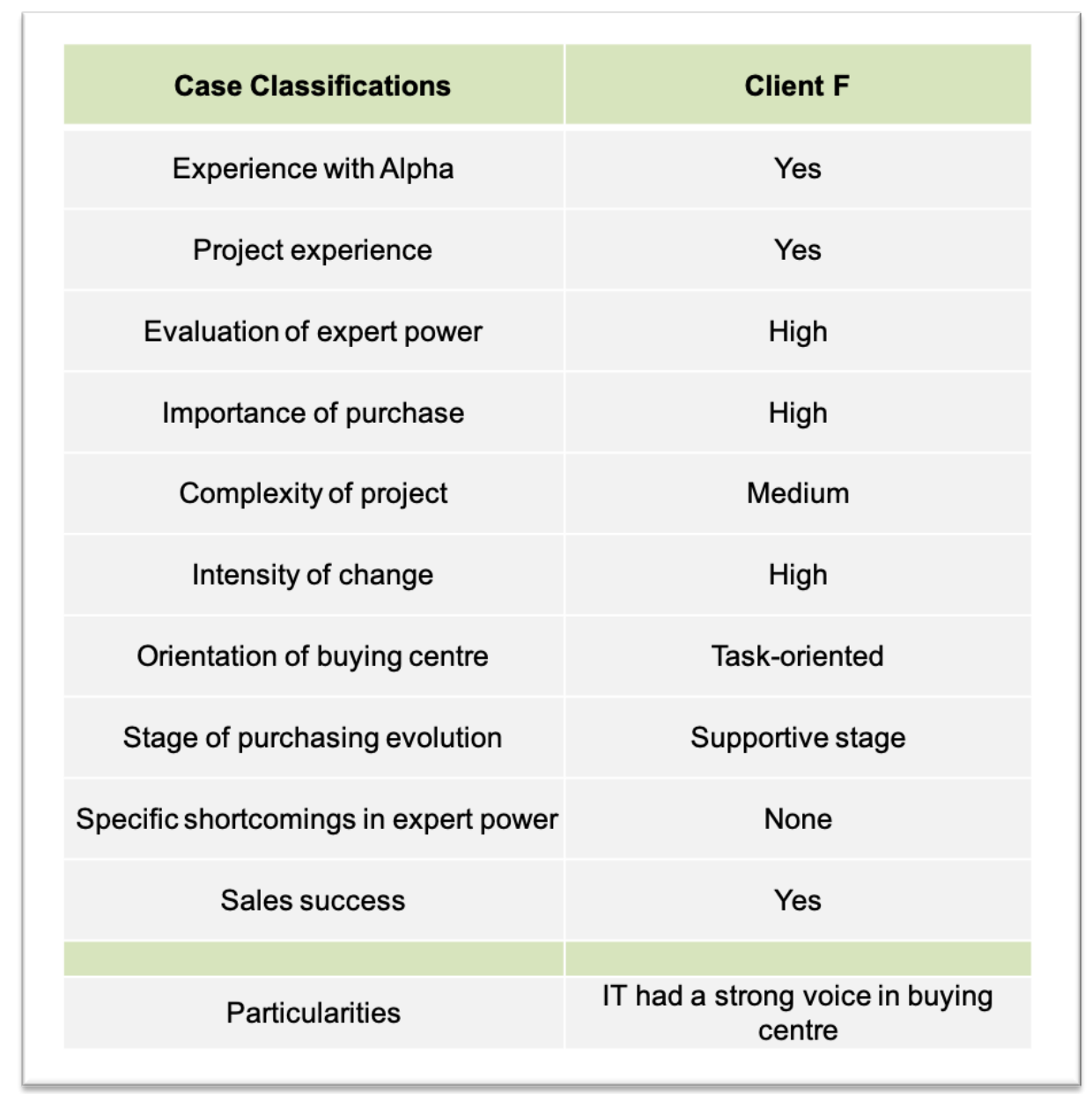

Table 34: Case classifications - Client F

Source: Developed for this research project based on the interview

\section{Attributes}

For Client F, expert power of the sales force is product knowledge and knowledge of how the product is used in daily work. Thus, it is crucial that the sales force knows and understands the work processes and controlling processes. Industry knowledge is also vital, as every industry has its own characteristics.

\section{Client $F$}

"Expert power is product knowledge and how this product is used in practice. [...] ...how our work processes and controlling processes work. [...] Industry knowledge must also exist because we have different specifics that only exist in our industry." 
For Client F, the industry requirements are severe, and the sales force is expected to meet these requirements in terms of wording and processes.

\section{Solutions}

Client $\mathrm{F}$ describes the solution for which he likes to be decisive as perfect fit. By this, Client $F$ refers not only to the products being adapted to the customer's requirements, but also the connection to the existing software systems, the consulting, and the training of the employees.

\section{Client $F$}

"A good sale force not only knows the product, but also has the ability to tailor the product to the needs of the customer and present it in such a way that it feels like a perfect fit. [...] By solution we mean the software itself but also the interfaces and the advice and training for our employees. The solution must fit into our ecosystem. The interfaces to our existing solutions have to work. The solution must have proven itself in everyday life and continue to prove its worth."

The solution must fit into Client F's ecosystem. In addition, the solution must have been reinforced in practice.

\section{Strategy}

Client $F$ is looking for a long-term partner who can also implement his future requirements. Client $F$ is also interested in the further development of the software and how Alpha Software is facing future challenges, such as digitisation.

\section{Client $F$}

"...that Alpha is the right partner for us in the future too. It is important for us to see how the software and solutions are evolving. For example, how does Alpha adjust to the topic of payroll digitisation? [...] Especially when we want to place our wishes and requirements for further developments."

Doubts

Client F himself had no doubt about the sales force, but rather about his staff. When it was time to sketch a solution, the employees were overwhelmed with too much 
information at once and could not stand any more. In addition, new software means extra work. However, the existing work must continue unchanged. Salaries must continue to be paid.

\section{Client $F$}

"Not me. But my employees. When it came to sketch the solution, they felt overwhelmed. [...] I think it was because they got too much information and faced too many problems."

According to Client F, the sales force did not notice the employees' situation. However, Client $\mathrm{F}$ did not address the sales force. Taking small steps and noticing the reactions of the interlocutors would have made sense, in the described situation, for the employees of Client F.

\section{Importance}

Expert power of the sales force is important to Client $F$ at every stage of the buying process. Without expert power, conversations would be difficult and would quickly be over. Product knowledge is more important to Client $F$ in the early stages of the buying decision. Later in the process, when it comes to working out a solution, process knowledge and sensitivity to change play a more significant role. Client F only decides on a solution if it really fits. If the sales force does not convince the client on the solution, neither can the supplier as a whole.

\section{Client $F$}

"Very important. We only choose a solution if it suits us. [...] If the sales force does not convince me, how is the company going to convince me? The sales force ultimately represents the company. [...] $t$ is important in every process step. It's not possible without expert power. [...] Yes, influence and position are important. [...] In the initial phase, product knowledge plays a bigger role. First of all, the software has to convince. Later, when it comes to working out a possible solution, process knowledge and the ability to fear a change, plays a more significant role."

According to Client $F$, the sales force represents the supplier. Influence and position are important to Client $F$. 


\section{Decision}

The purchase decision is decided collectively at Client F's company. The basis for a decision is that the involved parties have come to an equal understanding. The decision is also discussed until there is a unanimous position. If this is not the case, Client $\mathrm{F}$ may restart the discussions from the beginning. For the selection of the right software, a previously developed list of criteria was compared with the shortlisted providers. The IT department was instrumental in the buying decision.

\section{Client $F$}

"The basis for a decision is the same understanding. No one decides alone. The decision is always spread over several shoulders. [...] ...to come to the conviction that we are doing the right thing. We do not decide before that. If one of this group has a different position, we discuss until we have a unified position or orient ourselves and start fresh again. [...] If the sales force does not convince me, how is the company going to convince me? The sales force ultimately represents the company. [...] A catalogue of criteria helped us evaluate the solutions and make a decision. [...] Knowledge and experience of the persons involved on our side."

The buying centre has extensive knowledge and experience in payroll accounting. The expectations placed on the sales force were accordingly high and represented an important factor in the perception of the expert power of the sales force. The frequency of sales pitches was appropriate.

\section{Behaviour}

To Client $F$, the behaviour of the sales force influences the perception of expert power in terms of correct questions, precise answers, goal orientation, reliability, and openness. Lengthy conversations without real content should be avoided. Since the employees are in a process of change, a thoughtful and sensitive approach is vital to them. Therefore, it is important to Client $F$ that the sales force addresses the members of the buying centre differently, depending on their level of knowledge and emotional state. 


\section{Client $F$}

"In the way questions are asked and how answers are given. The questions should be targeted and precise. The answers should be clear and understandable and answered in a nutshell. [...] Empathy, problem-solving, experience, confidence, solution power. [...] I perceived the sales force as open, competent, professional, goal-oriented and reliable. [...] The sales force could have been more sensitive to the fact that introducing new software means a major change for employees."

\section{Recommendations}

Recommendations of the sales force, particularly in relation to the process changes within the payroll, have been helpful to Client $F$ and have had a positive effect on the purchasing decision. Client $\mathrm{F}$ has not received recommendations that relate to the sales force itself.

\section{Client $F$}

"The recommendations were important and positively influenced the decision. [...] The recommendations related to our processes and to changes in the payroll process."

\section{Brand}

Alpha Software is a strong brand for Client F. It is a brand that stands for trust, confidence in the future, and specifically for data security, which was a special requirement for Client $\mathrm{F}$ due to the client's initial situation. The brand and its positioning in the market had a significant impact on Client F's choice of the right delivery and decision-making process.

\section{Client $F$}

"Strong brand. [...] Confidence in the brand, that Alpha is the right partner for us in the future too. [...] We came to Alpha because they have a good name and are one of the key players in the segment. [...] Alpha is well known for data security."

\section{Change}


For Client F, the change, which means a software introduction for the employees, has special relevance. Client $F$ views the sales force more as a change agent than a salesperson. This requires special skills, such as the sensitive handling of the affected employees, which must be intensified a sales force. Client $F$ has already implemented various projects and has had good experiences with change agents.

\section{Client $F$}

"The sales force should no longer be seen as a salesperson, but rather as a change agent. [...] The sales force could have been more sensitive to the fact that introducing new software means a major change for employees. [...] Later, when it comes to working out a possible solution, process knowledge and the ability to fear a change, play a more significant role. Fear may be a bit harsh. Worries and concerns as wording are better."

A sales force should be able to respond to the worries and hardships of employees and replace these feelings with confidence and trust. Only in this way, according to Client F, can the software be successfully implemented and used in practice.

\section{Observations}

Client $\mathrm{F}$ brought the concept of change agents into the discussion and how they should respond to the concerns of employees in order to give them confidence and trust. It was felt that client $F$ dealt very intensively with the uncertainty of change and that the correct handling is therefore a guarantee of success for the successful implementation of the project. 


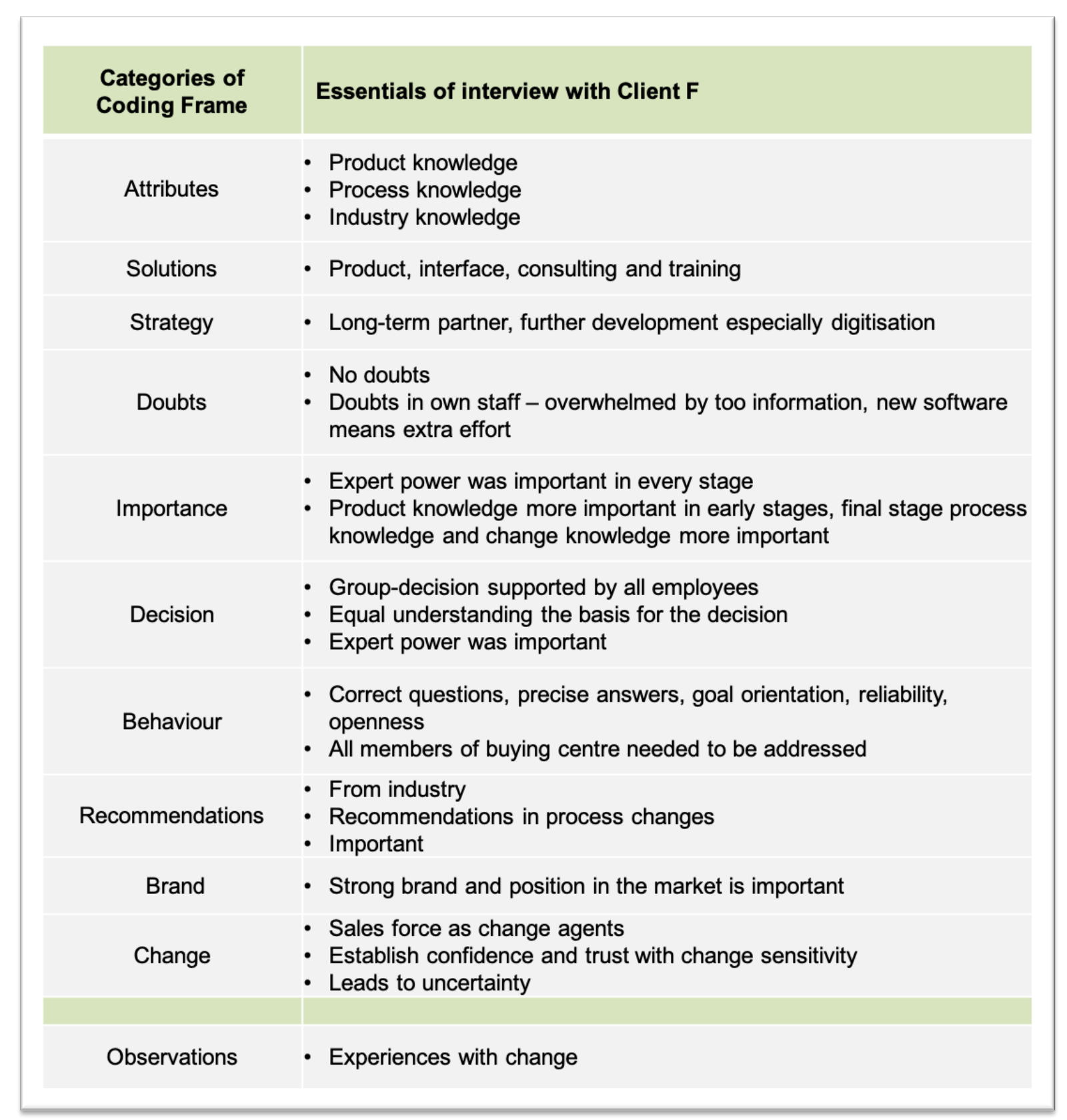

Table 35: Essentials of interview with Client F

Source: Developed for this research project

The essential results of the categories of the coding frame of the interview with Client $\mathrm{F}$ are summerised in Table 35.

\subsection{Interview Client G}

\section{Case Classifications}

The complexity of the project was rated highly by Client G (Table 36). Project experience and experience with Alpha Software are available. The importance of the purchase and the intensity of change were rated medium, while the evaluation of expert power was rated highly. The buying centre is task-oriented and is in the 
supportive stage. Specific shortcomings in expert power are not noticed. The purchase decision was made against Alpha Software.

No particularities were found during the sales process.

\begin{tabular}{|c|c|}
\hline Case Classifications & Client G \\
\hline Experience with Alpha & Yes \\
\hline Project experience & Yes \\
\hline Evaluation of expert power & High \\
\hline Importance of purchase & Medium \\
\hline Complexity of project & High \\
\hline Intensity of change & Medium \\
\hline Orientation of buying centre & Task-oriented \\
\hline Stage of purchasing evolution & Supportive stage \\
\hline Sales success & None \\
\hline
\end{tabular}

Table 36: Case classifications - Client G

Source: Developed for this research project based on the interview

\section{Attributes}

Product knowledge, process knowledge, and industry knowledge are, according to Client $G$, the attributes of expert power of the sales force. In addition, Client $G$ expects the sales force to guide him through the buying decision process and give him all the necessary information for an informed decision. 


\section{Client $\mathrm{G}$}

"Product knowledge, process and industry knowledge. [...] When the sales force guides me through the sales process, helping me make the decision, or giving me all the information, I need to make a decision."

\section{Solutions}

Client $\mathrm{G}$ does not view the selection of the right software as an independent topic. Rather, the focus is on integration into existing systems. No software solution exits today without interfaces.

\section{Client $G$}

"The connection to upstream and downstream systems. [...] The usability is modern and self-explanatory. And the sales force gave me more confidence in the evolution of the software."

The connection to upstream and downstream systems must be guaranteed. According to Client G, Alpha Software has deficits in this area in terms of modernity and usability.

\section{Strategy}

When selecting the right partner, Client $G$ places value on the future prospects that this partner brings. Trust in a partner is created for Client $\mathrm{G}$ by the future perspectives that the partner has. Regarding this point, the sales force of another supplier was more concrete and thus more convincing than Alpha Software.

\section{Client $G$}

"Future perspectives, trust in the supplier. [...] And the sales force gave me more confidence in the evolution of the software. The road map for product innovations was more concrete and convincing. [...] I only choose a company that can meet my requirements in the future. The outlook on product innovations is important to me."

Doubts

Client $\mathrm{G}$ did not have doubts regarding the Alpha Software sales force. According to Client G, they did a good job. They were not the reason Alpha Software was not 
chosen. Rather, Client G had doubts about the solution that the sales force presented; the solution was not convincing.

\section{Client $G$}

"I had no doubt about the sales force. Only on the product I had doubts."

Client $G$ suspects that the sales force guessed that their solution was not chosen. The sales force did not appeal.

\section{Importance}

Expert power is crucial for Client $G$ and is considered effective right from the first contact. The more complex a product is, the more expert power is necessary, particularly when the software no longer meets the current demands. In these situations, more needs to be argued and explained. To Client G, expert power increases in importance when it comes to finding a solution.

\section{Client $G$}

"Very important. Without expert power, a complicated product / solution cannot be sold. [...] The complexity of the products influences the making of expert power. The more that needs to be explained, the more expert power becomes visible. [...] Especially when the software is outdated, more needs to be explained and argued. [...] When it comes to presenting a solution, expert power becomes even more important."

For Client G, expert power increases in importance when it comes to finding a solution.

\section{Decision}

The decision against Alpha Software was made on the management level. The employees assisted in the decision making and prepared the information on the participating suppliers. The recommendations of the sales force and the sales force itself had no influence on the decision. The decision was made on the basis of the presented solution. 


\section{Client G}

"When the sales force guides me through the sales process, helping me make the decision, or giving me all the information, I need to make a decision. [...] The decision was then prepared by my team. My boss and I then made the decision. Against the Alpha software for a competitor."

The number of sales pitches was sufficient for Client G.

\section{Behaviour}

According to Client $G$, the sales force should be engaged and hard working. Good questions and answers from the sales force give Client $G$ the confidence that the solution is the right one. In addition, it is important to this client that the sales force adapts to the different characters of the buying centre.

\section{$\underline{\text { Client } G}$}

"Good answers so that we get confidence that we are investing in the right solution. [...] Engaged and hard-working... [...] Yes, that's important in terms of positioning suggestions and new requirements. [...] The sales force has responded well to our different levels of knowledge and questions."

The employees have different levels of knowledge and thus require an individual approach. To qualify the proposals and requirements regarding the further development of products and solutions, a good positioning of the sales force in the company is necessary for Client G.

\section{Recommendations}

The sales force's recommendations for process improvements were helpful to Client G. However, they did not affect the decision. Client $\mathrm{G}$ did not receive recommendations that would affect the sales force itself.

\section{Client $\mathrm{G}$}

"The recommendations were helpful but had no impact on the decision. [...] Process improvements." 


\section{Brand}

For Client G, the brand and what a supplier stands for are important criteria for a purchase decision. The market of the providers is large and unmanageable. For Client G, every supplier should stand for something special, so the supplier receives attention.

\section{Client G}

"The name of the company and what it stands for."

\section{Change}

No findings.

\section{Observations}

It was important for Client $G$ to point out that the sales force was not responsible for the alpha software not being chosen. It was because of other factors. The sales force did a good job throughout the acquisition period. 


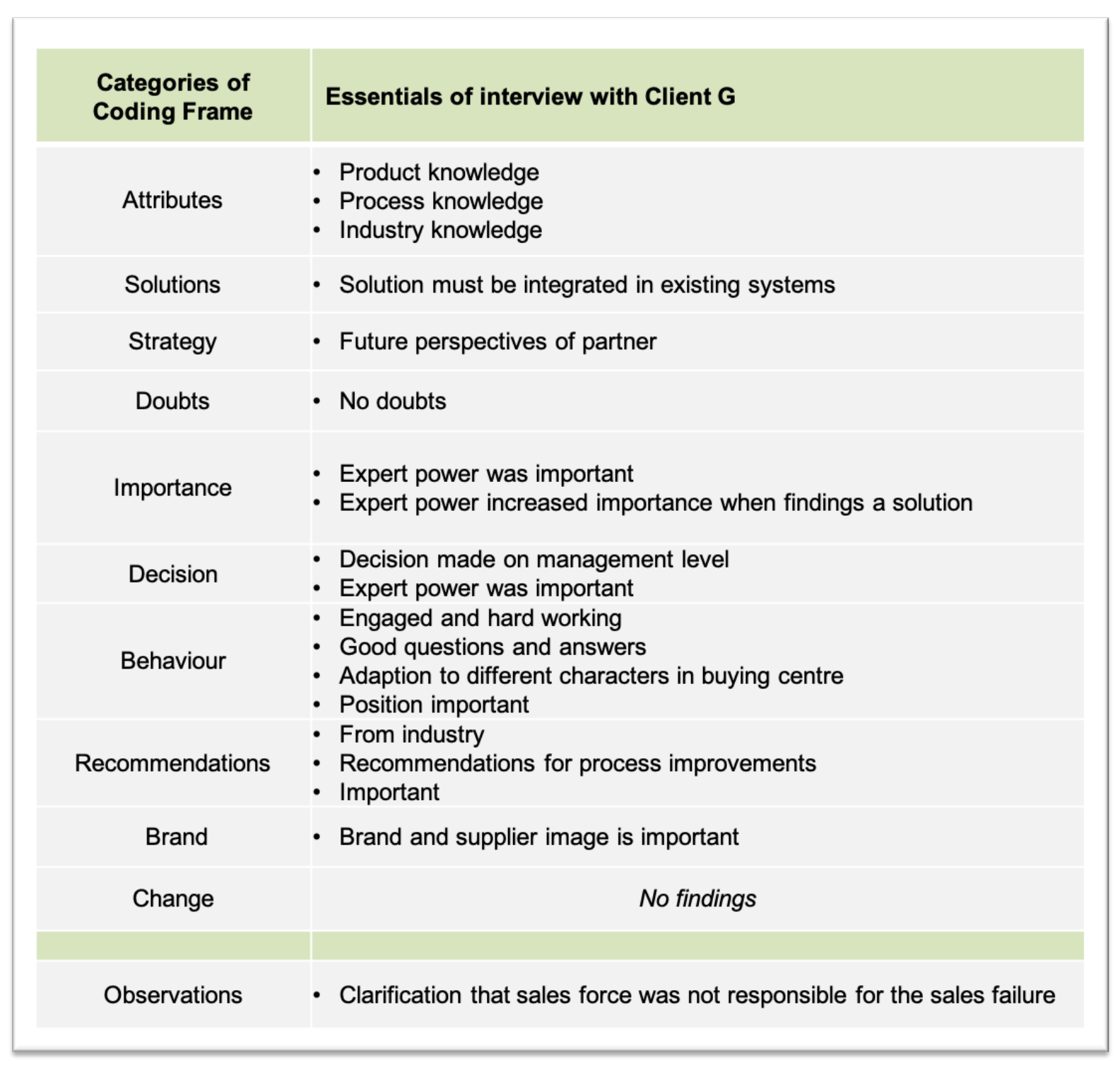

Table 37: Essentials of interview with Client $\mathrm{G}$

Source: Developed for this research project

The essential results of the categories of the coding frame of the interview with Client $\mathrm{G}$ are summerised in Table 37.

\subsection{Interview Client $\mathrm{H}$}

\section{Case classifications}

The complexity of the project was rated very highly by Client $\mathrm{H}$ (Table 38). Project experience is available, while experience with Alpha Software is not. The importance of the purchase, the intensity of change, and the evaluation of expert power were rated highly. The buying centre is task-oriented and is in the supportive stage. Specific shortcomings in expert power are not noticed. The purchase decision was made for Alpha Software. 
Client $\mathrm{H}$ is investor driven. This means that they attach great importance to the costbenefit ratio. Only what is actually needed is purchased. It is better not to do something than to invest too much. The sales force had to work out the benefits more intensively than usual, since client $\mathrm{H}$ had to explain all costs to the investor.

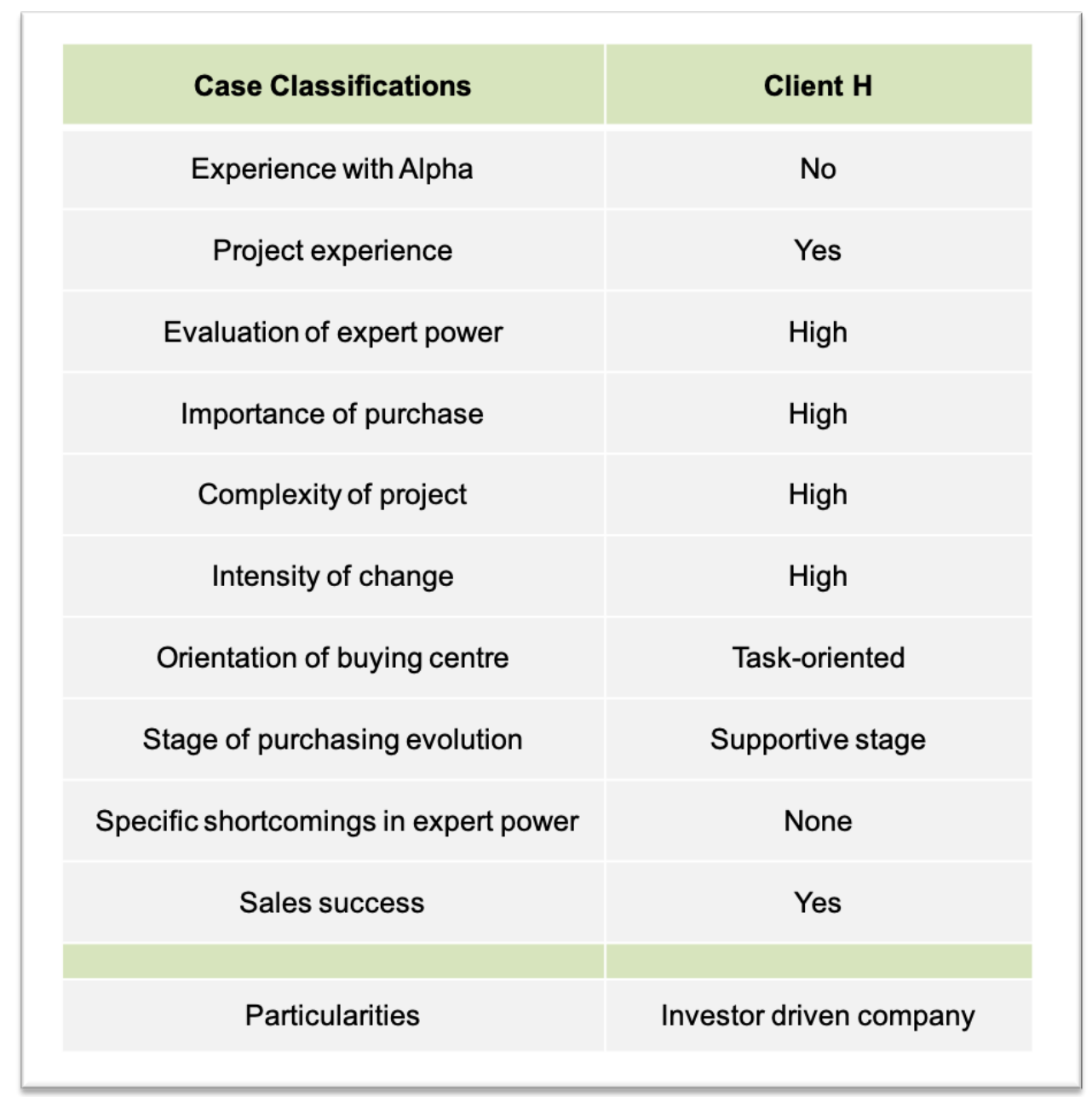

Table 38: Case classifications - Client $\mathrm{H}$

Source: Developed for this research project based on the interview

\section{Attributes}

For Client $\mathrm{H}$, the attributes that characterise expert power are product knowledge, process and legal knowledge, and how an ecosystem works. The sales force needs to determine what a customer wants.

\section{Client $H$}

"Product knowledge, process knowledge, how an ecosystem works, legal knowledge. [...] To sell the product by finding out what I want as a customer." 


\section{Solutions}

Client $\mathrm{H}$ has various interfaces to internal partners, such as IT, Controlling, Finance, and the specialist departments, so that tasks are completed promptly. Close interaction with the relevant departments is especially necessary for monthly controlling. The new software solution needs to fit into this ecosystem. Interfaces must work smoothly.

\section{Client $\mathrm{H}$}

"We have many partners and stakeholders (IT department, controlling, finance, specialty departments). Our investor always wants to have punctual numbers. [...] The solution convinced us,..."

\section{Strategy}

To Client $\mathrm{H}$, a long-term partnership is important in choosing the right solution. The confidence in a common future is strengthened for Client $\mathrm{H}$ if the partner consistently develops its own solutions and realises trends and requirements in the market in a timely manner.

\section{Client $H$}

"I would like to know if the supplier can accompany us permanently. How does he develop his products? Does he pick up trends, is he on the ball or is he only running after. [...] Trust in the future..."

\section{Doubts}

Client $\mathrm{H}$ did not have doubts about the sales force, but rather about the implementation. According to Client $\mathrm{H}$, the implementation would require special efforts. Client $\mathrm{H}$ clearly expressed all doubts and gave the employees a platform to discuss the issues and eliminate these doubts. The sales force responded well to Client H's doubt. The sales force took the concerns seriously and made a strong effort to understand the situation. 


\section{Client $H$}

"As far as the product I was concerned, only regarding the implementation. An implementation is stress for the employees. [...] We have clearly addressed it. We gave the employees a platform to express their concerns."

If Client $\mathrm{H}$ had any doubts about the sales force, Client $\mathrm{H}$ would not have made a decision in favour of Alpha Software. The sales force represents the entire company, so Client $\mathrm{H}$ would have questioned the partnership.

\section{Importance}

According to Client $\mathrm{H}$, expert power is necessary to understand the customer's problems and to develop a solution. This client believes that expert power is especially important in the initial phase of discussions, as trust is built up in this phase, and the problems must be understood correctly. In addition to expert power, the size of a sales force also plays a role in the experience that Client $\mathrm{H}$ has.

\section{Client $H$}

"Very important. How else should the sales force grasp our problems and offer us a solution? [...] The sales force represents the company. She stands for it. How should I trust the company? [...] At the beginning very important. The problems must be understood. When it comes to the solution, it's about sketching it together with the employees and building trust that it can be implemented."

The position and influence of the sales force in the company is important to Client $\mathrm{H}$, as this can speed up the implementation of solutions. A customer of this size typically requires customised solutions, which usually take time to implement.

\section{Decision}

To Client $\mathrm{H}$, a buying decision should collectively be made by the people who will work with it afterwards. Client $\mathrm{H}$ has already experienced a situation in which this claim could not be realised. This resulted in the project's failure. A collective decision takes longer; however, according to Client $\mathrm{H}$, a collectively decided project is less prone to problems and conflicts. 


\section{Client $H$}

"A decision supported by all. [...] Everything is based on common decisions. If they do not exist, we will not decide. Everyone must agree. This sometimes slows down the process but is very important for later implementation and then reduces the problems because everyone is involved. [...] I had to introduce a software against the will of the workforce, because the management wanted it that way. That almost failed because of the resistance of the employees."

For Client $\mathrm{H}$, the number of sales pitches was adequate. This number was not important. It is crucial that all topics are mentioned and clarified in the pitches.

\section{Behaviour}

Client $\mathrm{H}$ wants to be taken seriously as a customer. For Client $\mathrm{H}$ to get that feeling, the sales force must ask questions and really intend to understand the trial setup. For this purpose, the sales force best adjusts to the individual situation of each affected employee. Client $\mathrm{H}$ has experienced the sales force of Alpha Software to be competent, reliable, reflective, and conscientious.

\section{Client $H$}

"The sales force has asked good and the right questions. [...] They took us seriously. They really wanted to understand what's going on. [...] Competent, reliable, reflective and conscientious. [...] Put yourself in the shoes of your client and especially in the situation of the employees who are most affected."

\section{Recommendations}

The recommendations made by the sales force focused on process changes, employee responsibilities, and employee training, and had a strong impact on Client H's purchasing decision.

\section{Client $H$}

"The recommendations have had a positive impact on decision-making. [...] The recommendations related to the training and task distribution of employees and changes in process steps." 
In addition to expert power, the brand experience is important to the purchase decision of Client $\mathrm{H}$.

\section{Client $H$}

"...brand experience..."

\section{Change}

According to Client $\mathrm{H}$, a software migration is associated large changes for employees. They must be prepared for the new software and new processes. For many employees, this means a significant change and uncertainty, which not everyone on the team may be ready for. According to Client $\mathrm{H}$, the sales force did not pay enough attention to this aspect of change. After clarifying all issues, the employees were unsettled or downright frustrated, such that a migration was considered to be undesirable.

\section{Client $H$}

"An implementation is stress for the employees. Especially for a company of our size, it can have a strong impact. In the worst case, salaries cannot be paid. [...] ...sketching it together with the employees and building trust that it can be implemented. [...] Our helplessness in implementing such a project and how a supplier deals with it. The employees have different skills and tasks. [...] Integrate the employees earlier and more intensively. [...] For complex topics, the focus should be on change rather than sale."

The employees have different skills and tasks other than the accompaniment of a change. The daily business has to continue. Salaries have to be paid. Otherwise, the existence of the company is at stake. The sales force should, in Client H's opinion, concentrate on change, rather than sales, in such complex projects.

\section{Observations}

Client $\mathrm{H}$ takes the interests of the investor into account and acted cautiously in the interview. Client $\mathrm{H}$ only gave up the reluctance to change and became emotional. If a software change does not work in this sensitive area, the company may be at risk. 
Client $\mathrm{H}$ sees the sales force as being obliged to correctly address change issues among employees.

\begin{tabular}{|c|c|}
\hline $\begin{array}{l}\text { Categories of } \\
\text { Coding Frame }\end{array}$ & Essentials of interview with Client $\mathrm{H}$ \\
\hline Attributes & $\begin{array}{l}\text { - Product knowledge } \\
\text { - Process knowledge } \\
\text { - Legal knowledge } \\
\text { - Ecosystem knowledge }\end{array}$ \\
\hline Solutions & - Fit into ecosystem \\
\hline Strategy & $\begin{array}{l}\text { - Long-term partnership } \\
\text { - Further development of solution and integration of trends }\end{array}$ \\
\hline Doubts & $\begin{array}{l}\text { - No doubts about the sales force } \\
\text { - Doubts about implementation due to special effort }\end{array}$ \\
\hline Importance & $\begin{array}{l}\text { - Expert power was important } \\
\text { - Especially important in initial phase }\end{array}$ \\
\hline Decision & $\begin{array}{l}\text { - Group-decision supported by all employees } \\
\text { - Need for certainty } \\
\text { - Expert power is important }\end{array}$ \\
\hline Behaviour & $\begin{array}{l}\text { - Sale force took client seriously } \\
\text { - Ask questions and intend to understand } \\
\text { - Competent, reliable, reflective, conscientious } \\
\text { - Mistrust and uncertainty caused by sales force }\end{array}$ \\
\hline Recommendations & $\begin{array}{l}\text { - Recommendations on process changes, employee responsibilities, } \\
\text { employee training } \\
\text { - Important }\end{array}$ \\
\hline Brand & - Brand experience is important \\
\hline Change & $\begin{array}{l}\text { - Significant change for employees }=>\text { Overextension } \\
\text { - Sales force did not consider aspects of change } \\
\text { - Concentration rather on change than on sales } \\
\text { - Increases uncertainty }\end{array}$ \\
\hline Observations & - Emotional reaction to change issues \\
\hline
\end{tabular}

Table 39: Essentials of interview with Client $\mathrm{H}$

Source: Developed for this research project

The essential results of the categories of the coding frame of the interview with Client $\mathrm{H}$ are summerised in Table 39.

\subsection{Interview Client I}

\section{Case Classifications}


The complexity of the project was rated medium by Client I (Table 40). Project experience and experience with Alpha Software are available. The importance of the purchase and the intensity of change were rated medium, while the evaluation of expert power was rated highly. The buying centre is task-oriented and is in the supportive stage. Specific shortcomings in expert power are not noticed. The purchase decision was made for Alpha Software.

No particularities were found during the sales process.

\begin{tabular}{|c|c|}
\hline Case Classifications & Client I \\
\hline Experience with Alpha & Yes \\
\hline Project experience & Yes \\
\hline Evaluation of expert power & High \\
\hline Importance of purchase & Medium \\
\hline Complexity of project & Medium \\
\hline Intensity of change & Medium \\
\hline Orientation of buying centre & Task-oriented \\
\hline Stage of purchasing evolution & Supportive stage \\
\hline Specific shortcomings in expert power & None \\
\hline Sales success & Yes \\
\hline Particularities & None \\
\hline
\end{tabular}

Table 40: Case classifications - Client I

Source: Developed for this research project based on the interview

\section{Attributes}

Client I understands product knowledge and industry knowledge to be the key attributes of expert power. It is important to Client I that the sales force sells the solution to him such that he would like to buy it from them again. 


\section{Client I}

"Product knowledge, industry knowledge. [...] The ability to find out what i want as a customer, to sell me the software and that I feel good about it. And that I want to buy again from the sales force."

\section{Solutions}

Client l's department and processes are firmly integrated into the company processes. This requires smoothly functioning interfaces in upstream and downstream systems, which have to work with additional, external software partners.

\section{Client I}

"We have other software partners who need to be connected to the payroll software. BI systems and our time tracking for example. The interfaces should be known and integrated."

\section{Strategy}

From a strategic point of view, Client I expects the software to grow with the needs of his own department. This certainty must be guaranteed by the supplier.

\section{Client I}

"And the certainty that the software can grow with our demands. [...] ...,growth opportunities."

\section{Doubts}

Client I had no doubts about the sales force expert power.

\section{Client I}

"No."

Importance 
Sales force expert power is vital to Client I, as payroll is not a simple topic and only expert power can sufficiently understand where the customer's problems lie. Expert power is equally important to Client I in all process steps. Client I makes no distinction in the respective process phases.

\section{Client I}

"Very important, since the payroll is not easy in itself and then understand the specifics of a customer is demanding. [...] Right at the first contact we had with Alpha. The appearance and the way they approached us, we found very pleasant. [...] I do not see a distinction."

\section{Decision}

Client I must trust the sales force to make a decision. Honesty and directly addressing the open issues are important to Client I. His employees and his boss must agree with the purchase decision. Client I did not mention who ultimately makes the purchase decision, though recommendations made by the sales force had a certain impact on the decision. The number of sales pitches was appropriate for Client I.

\section{Client I}

"I have to trust the sales force. You have to be honest. In the project, every dishonesty, every false statement comes out. I've already seen some projects in the company fail. [...] But it was a good decision to get a good understand of our requirements. [...] Yes, the recommendations have influenced our decision. [...] The satisfaction with the software related to my employees and my boss."

\section{Behaviour}

For Client I, a calm, reserved, goal-oriented, helpful, and professional demeanour promotes the perception of expert power. In this context, loyal behaviour towards the client and the company is important to Client I and ensures a long-term connection. The sales force should always be present and responsive. Bragging, self-indulgence, and arrogance diminish the perception of expert power. 


\section{Client I}

"Competent, professional, helpful. [...] Honesty, loyalty to the own company, because the salesman then works for his own company and for the well-being of the customers, because they ensure the long-term success, goal orientation, accuracy. [...] They were quite reserved but present and always approachable. The competitors talked a lot and always told us how great they are. [...] A calm, decisive appearance intensifies the perception. Bragging, self-indulgence, and arrogance diminish the perception."

\section{Recommendations}

Client I drew recommendations from the experiences he had already had with Alpha Software. The sales force issued further recommendations regarding litigation concerning daily work. These recommendations had a positive impact on the purchase decision. They showed that the sales force provides stimulus for daily work, which Client I clearly views as an advantage.

\section{Client I}

"These are the experiences I have already made with the supplier. [...] Improvements in daily work related to individual process steps. [...] Yes, the recommendations have influenced our decision. They show that we have a good partner who helps us in our daily work."

Client I did not receive recommendations related to the sales force.

\section{Brand}

The position of the provider in the market and what is behind the brand has an influence on Client I's buying decision. Client I is looking for a long-term partnership to shape the future together. Client I believes that a strong brand is an indication of maintaining the market position for many years.

\section{Client I}

"Alpha is a strong brand and leader in the industry. [...] What the company or brand stands for. What reputation they have in the industry."

\section{Change}


No findings.

\section{Observations}

No particular observations.

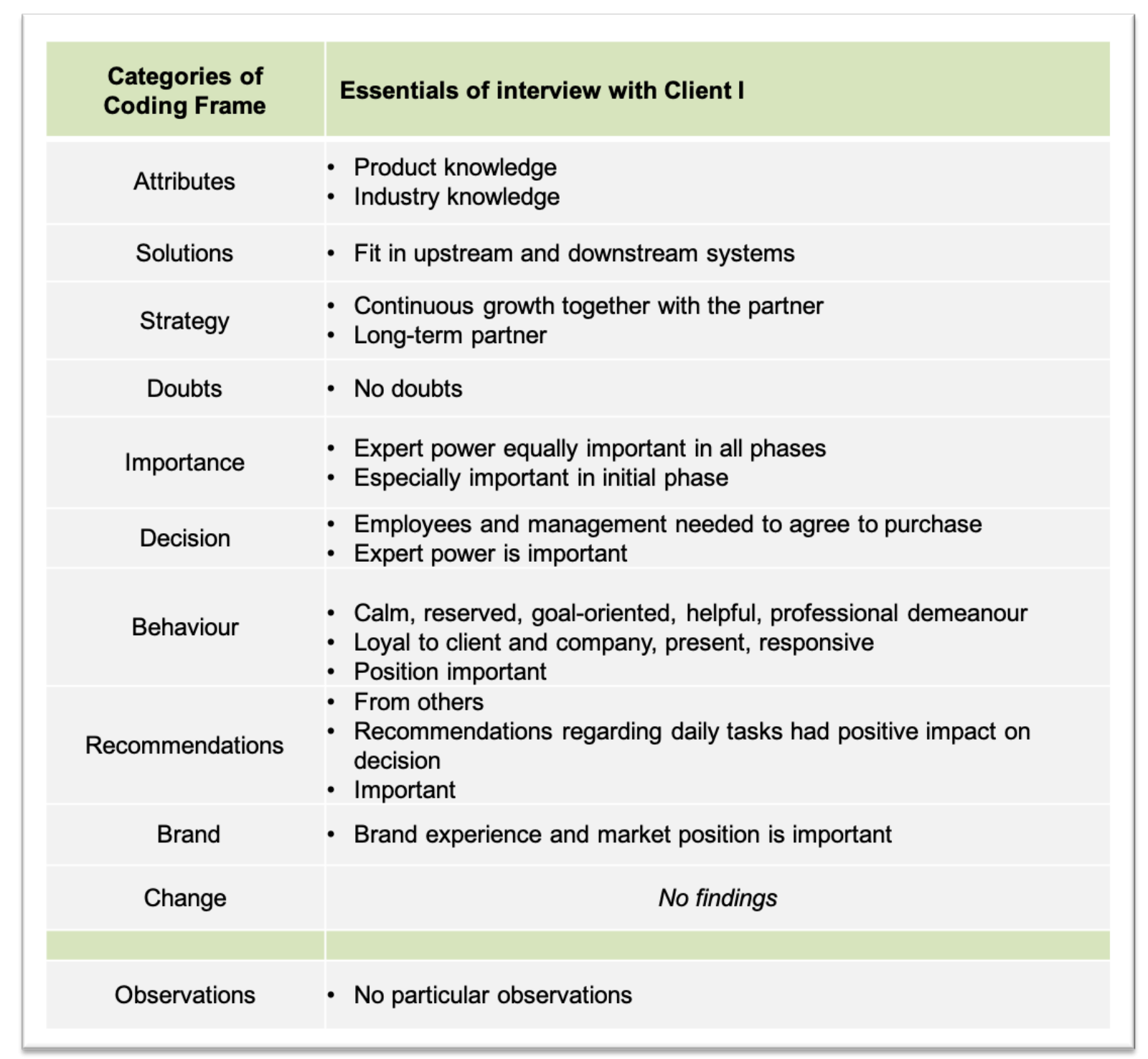

Table 41: Essentials of interview with Client I

Source: Developed for this research project

The essential results of the categories of the coding frame of the interview with Client I are summerised in Table 41.

\subsection{Interview Client $\mathbf{J}$}

\section{Case Classifications}

The complexity of the project was rated highly by Client J (Table 42). Project experience is available, while experience with Alpha Software is not. The importance 
of the purchase, the intensity of change, and the evaluation of expert power were rated highly. The buying centre is task-oriented and is in the supportive stage. Specific shortcomings in expert power are not noticed. The purchase decision was made for Alpha Software.

The duration of the sales process was the shortest compared to the other interviews at 2 months. There was only one sales pitch at the client site.

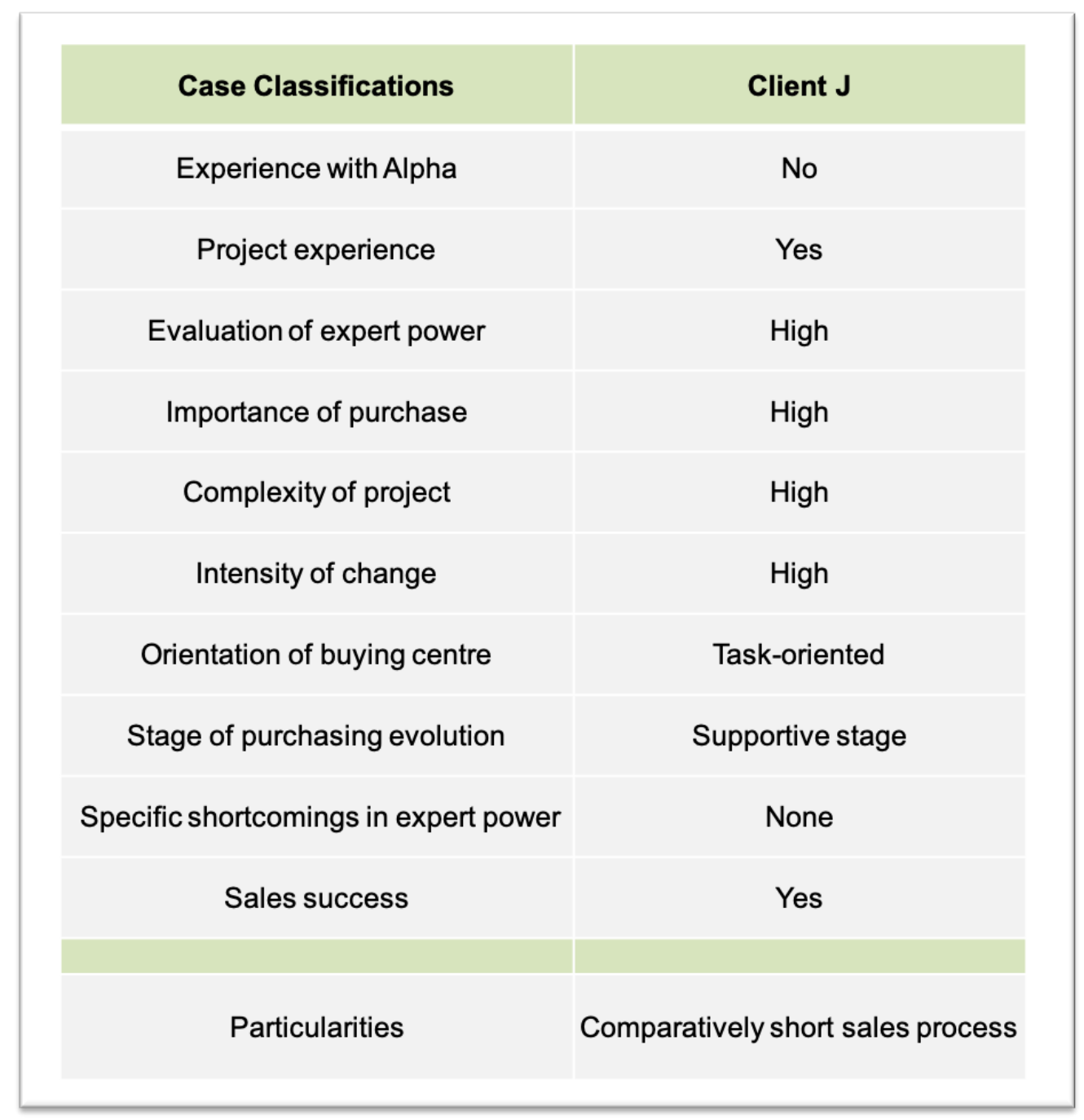

Table 42: Case classifications - Client J

Source: Developed for this research project based on the interview

\section{Attributes}

For Client $\mathrm{J}$, product knowledge is the attribute that defines expert power, as is the ability to explain the benefits such that a non-specialist could understand them to avoid mistakes and inconveniences. 


\section{Client J}

"That they he knows the product he is selling, that he can explain it to me and that he is familiar with the weaknesses of the product and the possible failures/inconveniences in the process and tells me how to avoid them. [...] ...can explain things with a few words and not too technical..."

\section{Solutions}

No findings.

\section{Strategy}

No findings.

\section{Doubts}

Client $\mathrm{J}$ mentioned that doubts occurred about the expert power of the sales force when the sales force wanted to show off their knowledge. The sales force ignored the client as a customer and gave too much unnecessary information. The sales force did not notice the disturbance.

\section{Client J}

"There was a point when I had the feeling he was showing to me how much of an expert he is regarding the product, but the information was not relevant for my purpose. I needed him to listen at the new requirement we were introducing and if the software was able to solve it, but he did not answer my question. [...] I interrupted him after a while and posed the question again. [...] It depends on how familiar I am with the product myself and if the doubts I had, have been answered to my satisfaction."

Only when Client $\mathrm{J}$ interrupted the sales force and posed his question again did the sales force withdraw and adapt his behaviour. The client's doubts then subsided, as the questions were answered to his satisfaction.

\section{Importance}

According to Client $\mathrm{J}$, expert power is crucial because the sales force should understand the client's problems. Without expert power, every conversation with the 
sales force would be a waste of time, especially when the sales force does not understand the topics and proceeds to offer a product or a solution.

\section{Client $J$}

"Very important, since I want him to understand my needs and present me a product that serves my purposes. I don't want to waste my time listening about his best product when it has no relevance for me. [...] Competent advice from a sales person certainly makes the steps through the decision process easy but it is important that he knows when he needs to step down and let others make the decision. In the beginning it is more important. In the decision process advice is getting more important and trust that everything will work as designed."

Competent advice from the sales force considerably facilitates the purchase decision process. The effect of this advice unfolds at the time of the purchase decision. In the initial phase, expert power is more crucial for building trust.

\section{Decision}

In making a purchase decision, Client $\mathrm{J}$ likes to take advice from the sales force, but it is important that the sales force then gives Client $\mathrm{J}$ the opportunity to decide for himself. Knowledge and experience of the involved members of the buying centre on Client J's side is high. They were in the position of asking very detailed questions. Client J's aspirations and expectations of the sales force are correspondingly high. The purchase decision was then made in collaboration with the top management.

\section{Client $J$}

"Competent advice from a sales person certainly makes the steps through the decision process easy but it is important that he knows when he needs to step down and let others make the decision. In the beginning it is more important. [...] HR and IT had a long questionnaire. For everybody it is important to understand the details and backgrounds. They ask questions until they get an answer that satisfies them. [...] Knowledge and experience of the persons involved on our side. They are in the position of asking very detailed questions."

The number of sales pitches was appropriate. The number has no significance for Client $\mathrm{J}$. 


\section{Behaviour}

Good listening and focusing on the essentials with a friendly, calm, and competent demeanour promote Client J's perception of expert power. The sales force should pay attention to what the customer wants and should not sell anything to the customer. Client $\mathrm{J}$ wants to be taken seriously as a customer.

\section{Client $J$}

"Good listener, can explain things with a few words and not too technical, calm, competent, smart/well informed. [...] Confidence and friendliness... [...] Do not sell the same product to everyone. Sell them exactly the solution they need. [...] Sometimes the explanations were too long and for things that were not relevant for us. They could be more compact and emphasise on the features that are relevant."

\section{Recommendations}

Client $\mathrm{J}$ received recommendations regarding process changes that had a major impact on the purchase decision. These recommendations showed that the sales force has knowledge on the matter and certainly has expert power. There were no recommendations regarding the sales force.

\section{Client J}

"Recommendations on altering certain processes... [...] Great impact. It shows that the sales force is competent and is helping us beyond any products."

\section{Brand}

Positive experiences with the Alpha Software brand had an influence on Client J's buying decision.

\section{Client $\mathrm{J}$}

"Brand experiences."

\section{Change}

No findings. 


\section{Observations}

Client J's responses were short and concise. Client $\mathrm{J}$ also focused on the essentials. The employees were no longer involved in the purchase decision as necessary. The decision was made together with the management.

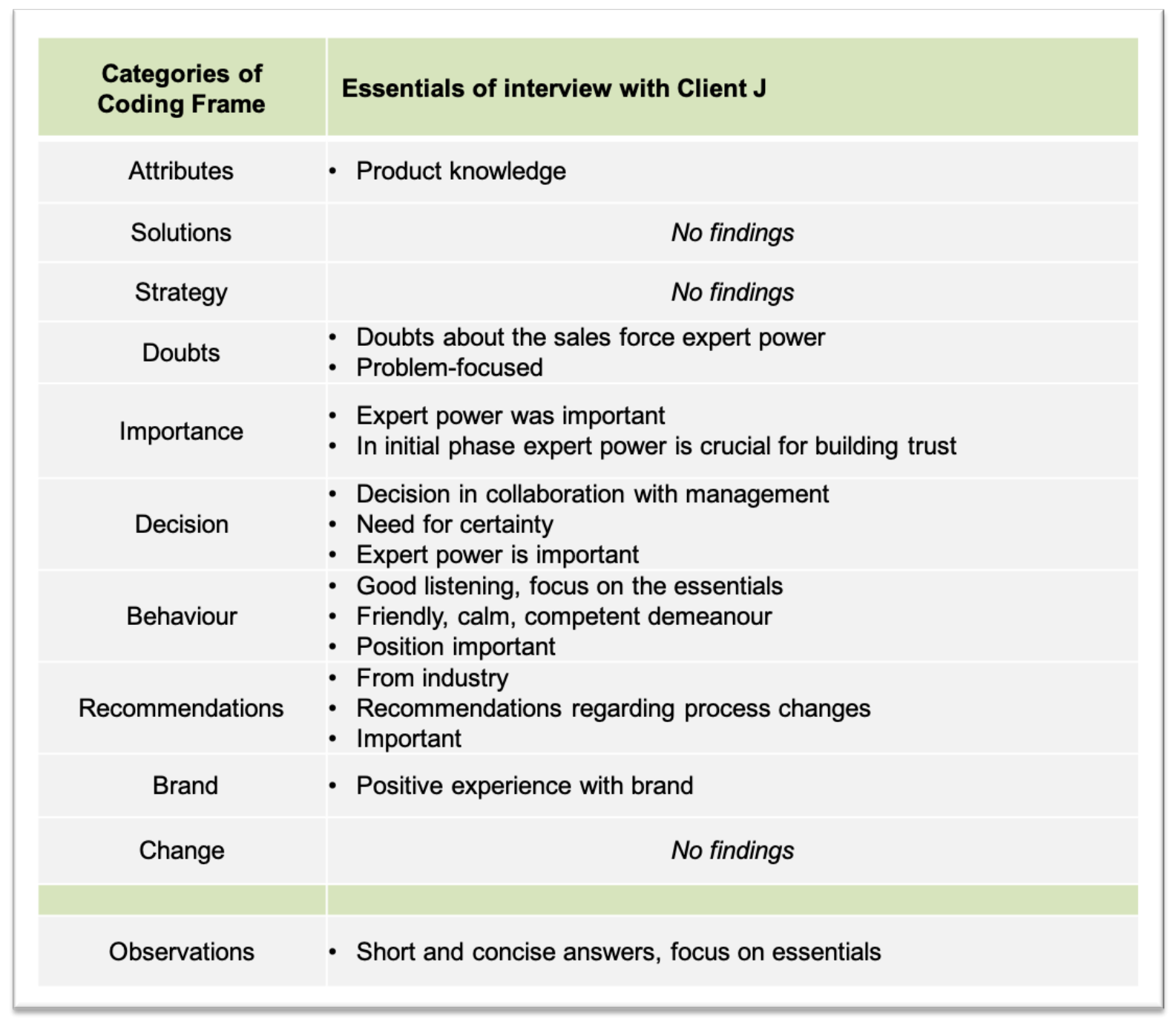

Table 43: Essentials of interview with Client $\mathrm{J}$

Source: Developed for this research project

The essential results of the categories of the coding frame of the interview with Client $\mathrm{J}$ are summerised in Table 43.

\subsection{Summary of the Interviews}

\subsubsection{Introduction}

After the cases have been individually described and the particular findings have been worked out, the case classifications (Table 45) and the essential findings of the categories of the coding frame (Table 44) are summarised. 


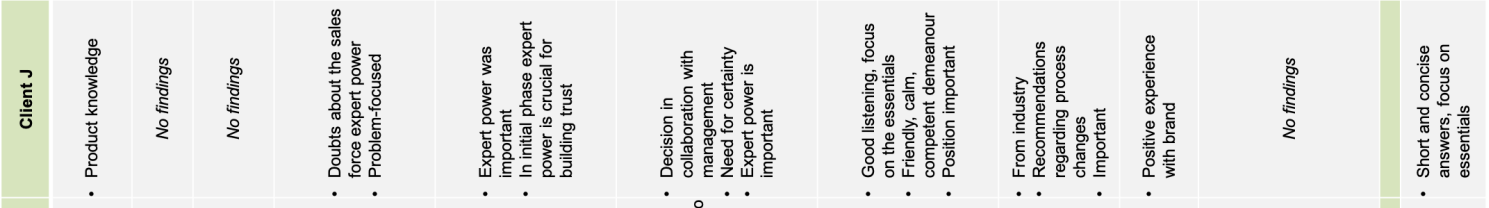

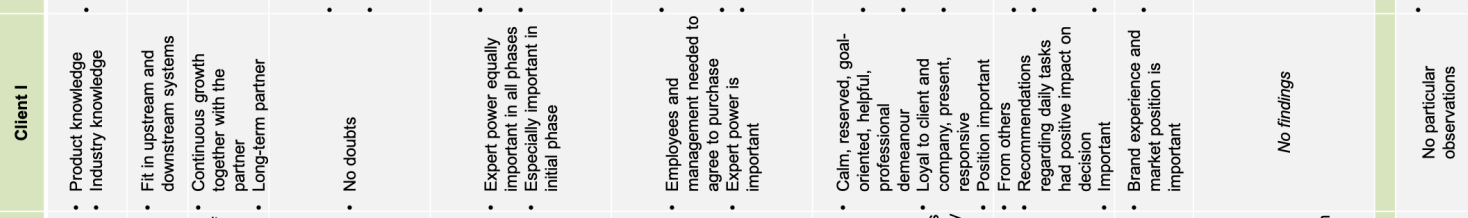

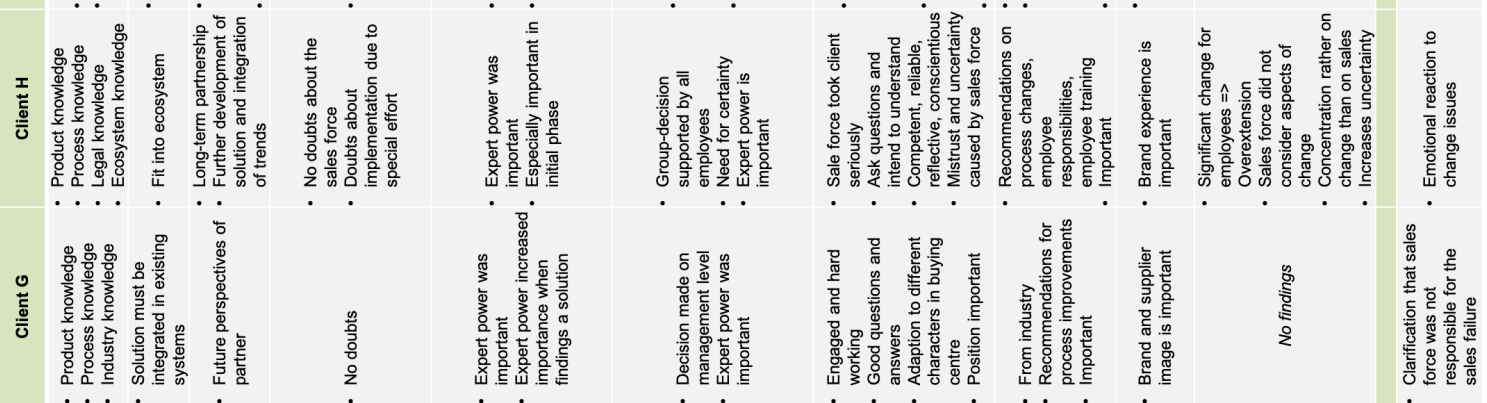

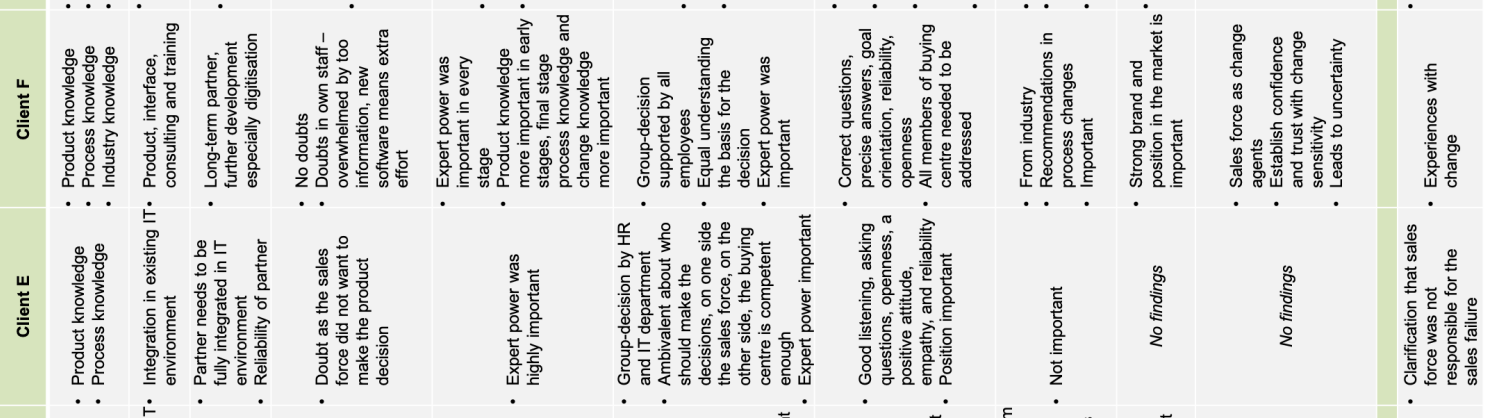

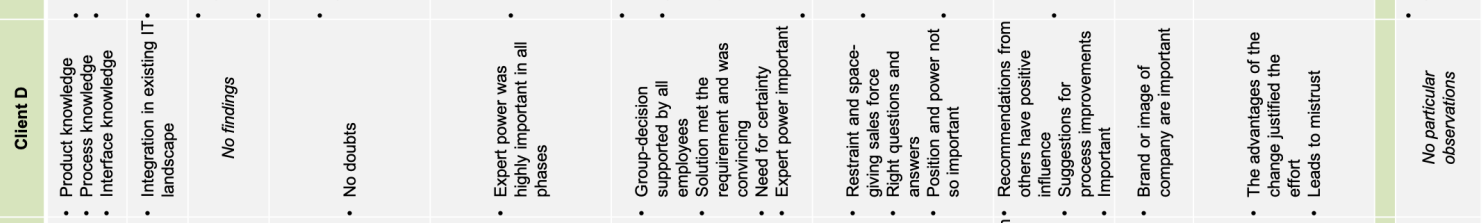

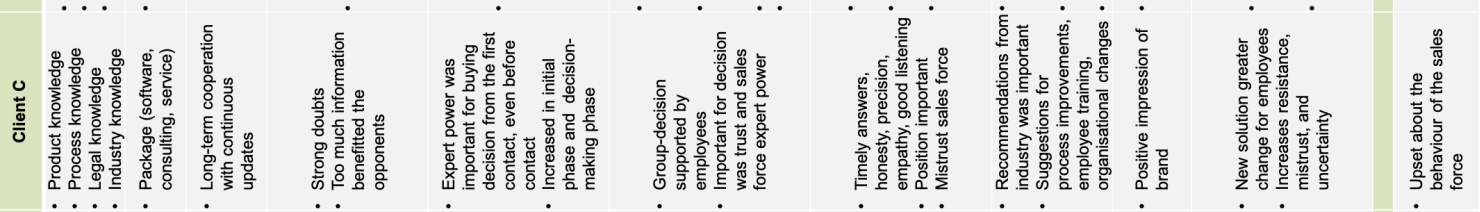

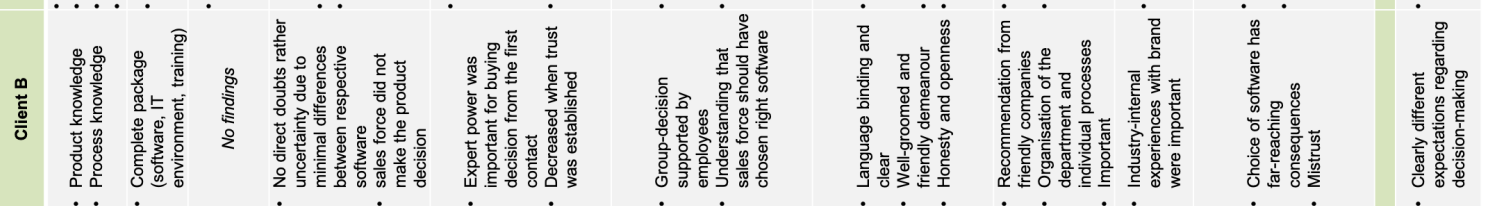

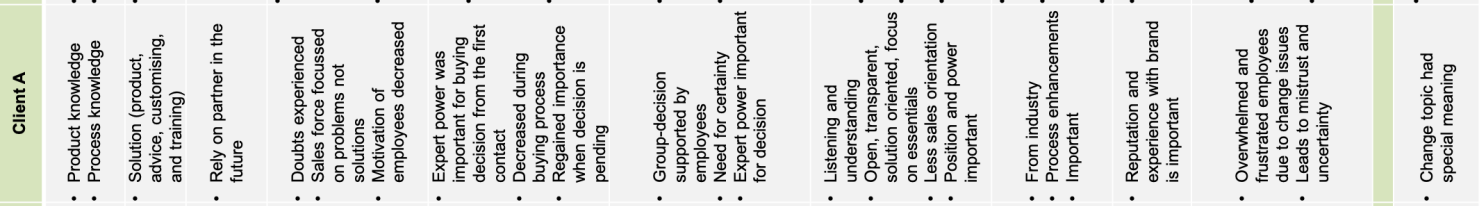
\begin{tabular}{llllll|lll|}
$\|1\|$ & 1 & 1 & $\mid$ & 1 & 1 & 1 & 1
\end{tabular}

Table 44: Categories of coding frame summary

Source: Developed for this research project 


\section{Case Classifications}

The interviewees evaluated the case classifications according to their individual perceptions. Table 45 illustrates a summary of the reviews of the case classifications. Striking in the reviews is that all interviewees classified their buying centres as task oriented. In addition, all buying centres are in the supportive stage. The evaluation of expert power has consistently been rated highly. Only one interviewee saw minor shortcomings in terms of expert power in the buying centre. The findings resulting from the case classifications are considered and described in greater detail in the summary of the categories of the coding frame. Due to the complexity of the project, the sales process at Client A was very lengthy. However, this was also the case with Client B, although the project was classified as medium-complex. It is possible that Client B's lack of project experience has led to the longer sales process. However, the higher complexity of the project does not necessarily result in longer sales activities. The sales activities for clients $C$ and $J$ were carried out comparatively rapidly. The sales activities did not lead to success for two clients. Despite the support of the Salesdforce in the decision-making process, Client $E$ did not choose Alpha. Client $G$ also decided against Alpha, although experience with Alpha was available. 


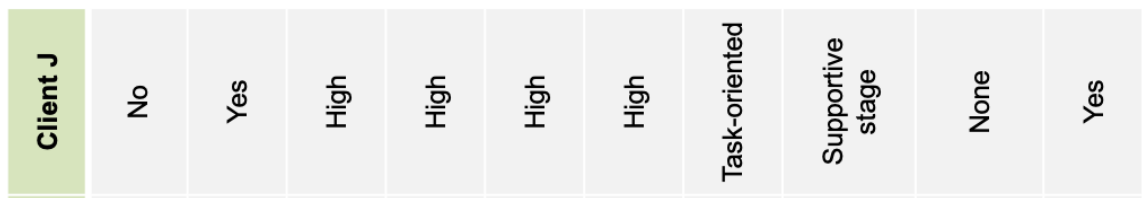

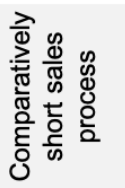

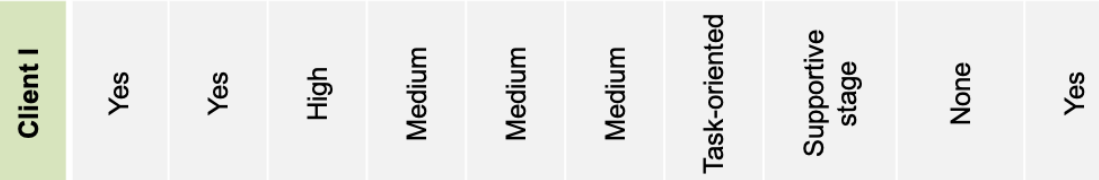

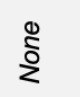

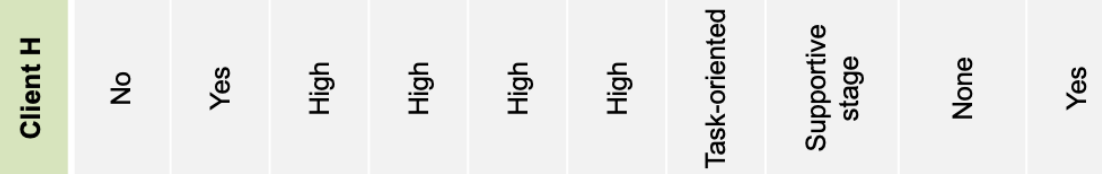

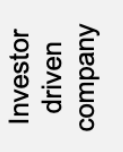

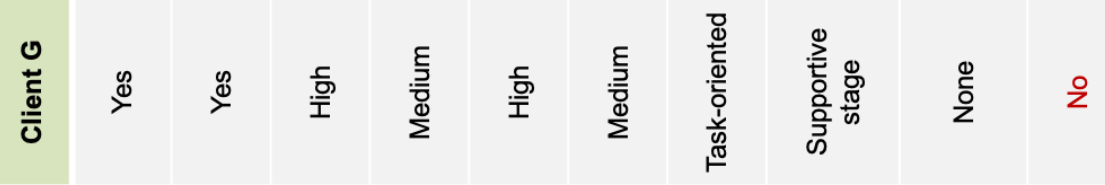

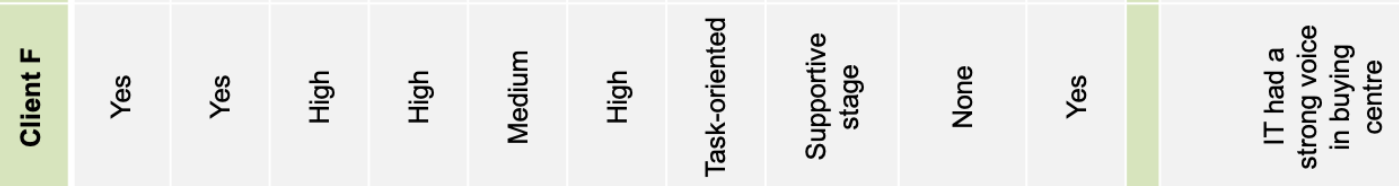

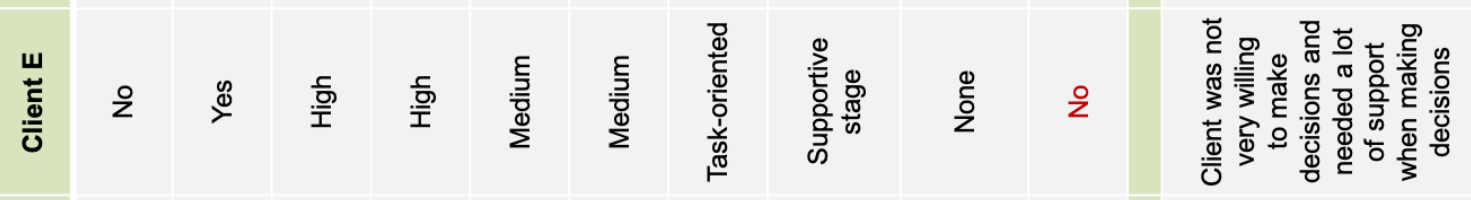

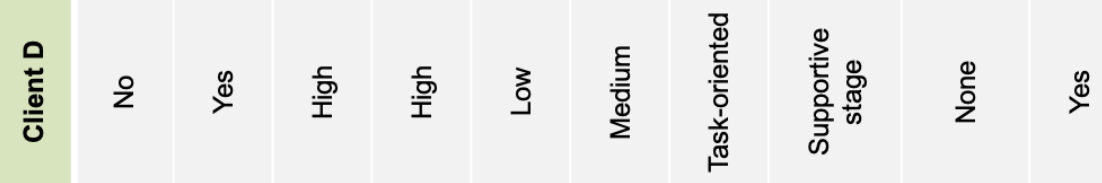

รั้

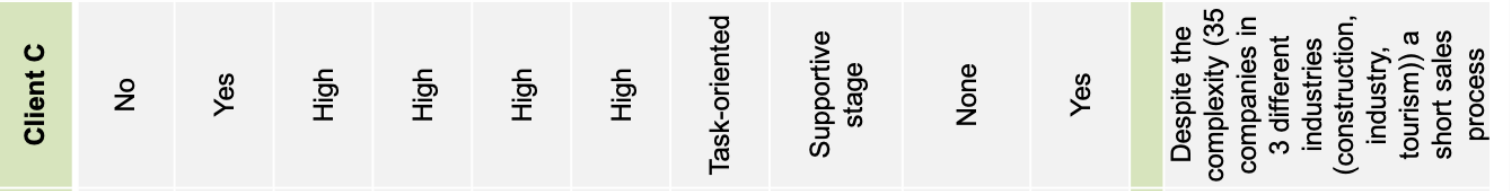

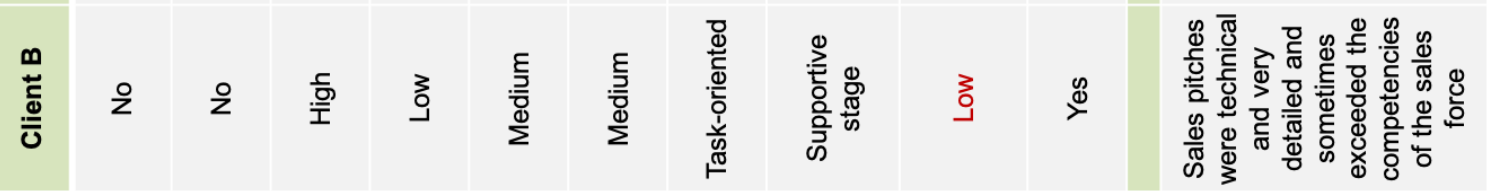

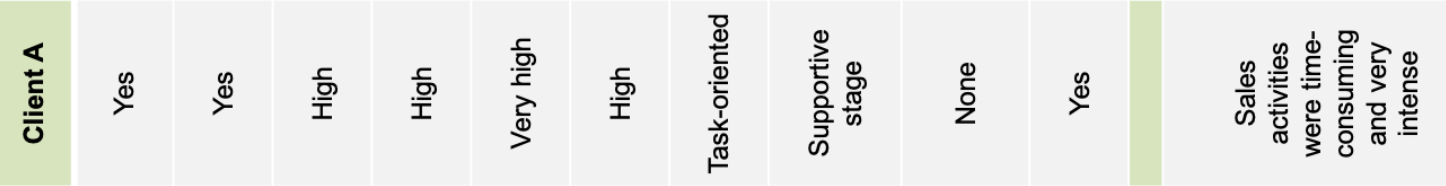

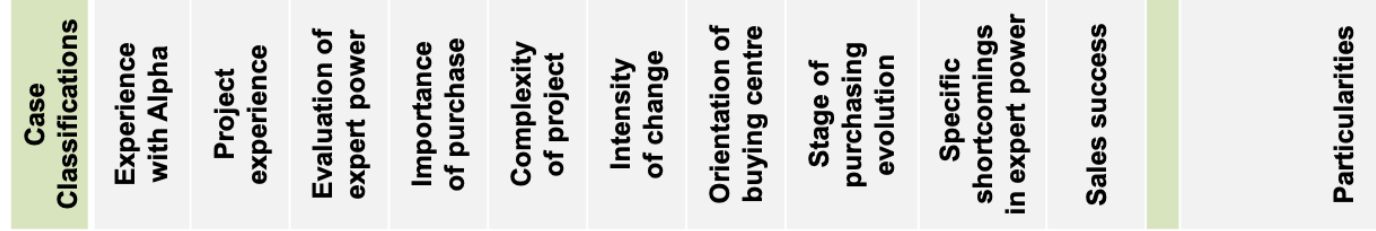

Table 45: Case classifications summary

Source: Developed for this research project 


\subsubsection{Attributes}

The results of the category are summarised in Table 46. According to the interviewees, sales force expert power is the ability to present and explain a solution in such a way that it is purchased by a customer. To do this, the sales force has to understand the customer's requirements to develop an individual customer solution and to show how the solution works in practice. For this, the sales force needs product knowledge (i.e. software features), industry knowledge (e.g. special requirements, important partners within the industry, and terminology), and legal knowledge (e.g. social legislation, tax legislation, and working time legislation), according to the interviewees. In addition, the interviewees expect the sales force to have experience and knowledge of how to implement a solution and to demonstrate how the individual solution would be implemented on the customer's premises. Detailed process knowledge and interface knowledge must be present within the sales force. Individual clients use the term 'ecosystem' in this context, meaning that the sales force must understand how to integrate the solution into a comprehensive process landscape (ecosystem) where different systems and stakeholders (internal and external) interact with each other (Client F). This extends beyond the integration of upstream and downstream systems.

\begin{tabular}{|c|c|c|c|c|c|}
\hline $\begin{array}{l}\text { Categories of } \\
\text { Coding Frame }\end{array}$ & Client A & Client B & Client C & Client D & Client E \\
\hline Attributes & $\begin{array}{l}\text { - Product } \\
\text { knowledge } \\
\text { - Process } \\
\text { knowledge }\end{array}$ & $\begin{array}{l}\text { - Product } \\
\text { knowledge } \\
\text { - Process } \\
\text { knowledge }\end{array}$ & $\begin{array}{l}\text { - Product } \\
\text { knowledge } \\
\text { - Process } \\
\text { knowledge } \\
\text { - Legal knowledge } \\
\text { - Industry } \\
\text { knowledge }\end{array}$ & $\begin{array}{l}\text {-Product } \\
\text { knowledge } \\
\text { - Process } \\
\text { knowledge } \\
\text { - Interface } \\
\text { knowledge }\end{array}$ & $\begin{array}{l}\text { - Product } \\
\text { knowledge } \\
\text { - Process } \\
\text { knowledge }\end{array}$ \\
\hline $\begin{array}{l}\text { Categories of } \\
\text { Coding Frame }\end{array}$ & Client F & Client G & Client H & Client I & Client J \\
\hline Attributes & $\begin{array}{l}\text { - Product } \\
\text { knowledge } \\
\text { - Process } \\
\text { knowledge } \\
\text { - Industry } \\
\text { knowledge }\end{array}$ & $\begin{array}{l}\text { - Product } \\
\text { knowledge } \\
\text { - Process } \\
\text { knowledge } \\
\text { - Industry } \\
\text { knowledge }\end{array}$ & $\begin{array}{l}\text { - Product } \\
\text { knowledge } \\
\text { - Process } \\
\text { knowledge } \\
\text { - Legal knowledge } \\
\text { - Ecosystem } \\
\text { knowledge }\end{array}$ & $\begin{array}{l}\text { - Product } \\
\text { knowledge } \\
\text { - Industry } \\
\text { knowledge }\end{array}$ & $\begin{array}{l}\text { - Product } \\
\text { knowledge }\end{array}$ \\
\hline
\end{tabular}

Table 46: Category Attributes summary

Source: Developed for this research project 
In summary, the interviewees expect the sales force to support the decision-making process by providing all necessary information for an enlightened purchase decision. In some cases, this expectation even goes so far as to say that the sales force should make the product decision for the customer (Client B, Client E). The attributes of sales force expert power, according to the interviewees, are product knowledge, industry knowledge, legal knowledge, process knowledge, interface knowledge, and knowledge of the customer's ecosystem (Figure 33).

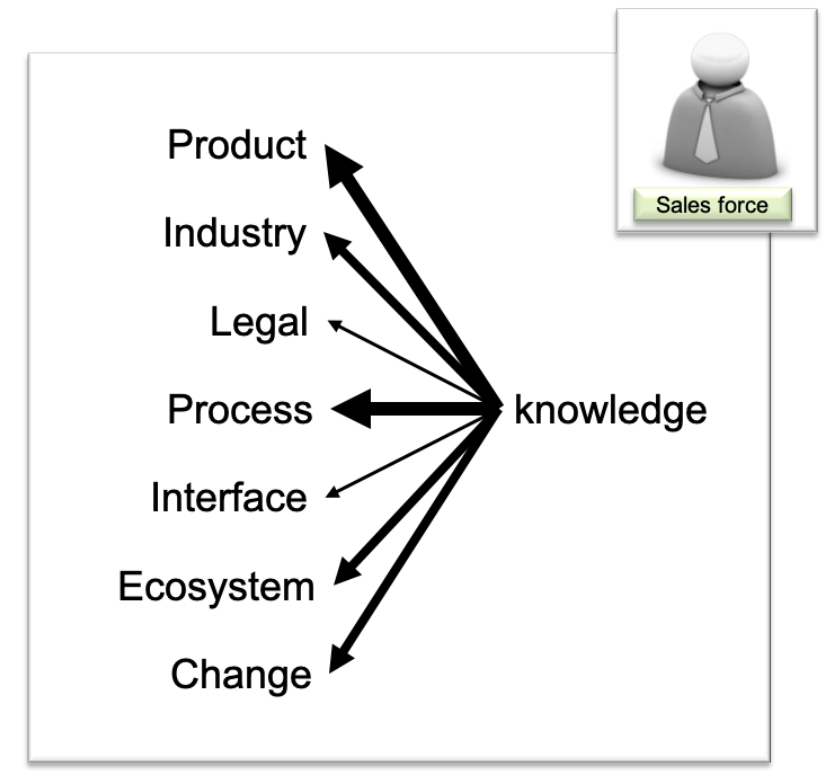

Figure 33: Attributes of sales force expert power

Source: Developed for this research project

\subsubsection{Solutions}

The results of the category are summarised in Table 47. The interviewees have the understanding that their purchase decision does not just refer to a single product, but rather a solution. A solution consists of various components which together generate added value for the customer (Figure 34). The complexity of the solution correlates with the complexity of the requirements. For example, the less different software components are used, the weaker the integration into the IT landscape. It is not crucial that all components are the best solution in their own right. While individual components may not always represent the ideal solution, they are effective in the interaction of all components. Only when at least one component is considered a KO criterion do the effects of the other components become obsolete. 


\begin{tabular}{|c|c|c|c|c|c|}
\hline $\begin{array}{l}\text { Categories of } \\
\text { Coding Frame }\end{array}$ & Client A & Client B & Client C & Client D & Client E \\
\hline Solutions & $\begin{array}{l}\text { - Solution (product, } \\
\text { advice, } \\
\text { customising, and } \\
\text { training) }\end{array}$ & $\begin{array}{l}\text { - Complete } \\
\text { package } \\
\text { (software, IT } \\
\text { environment, } \\
\text { training) }\end{array}$ & $\begin{array}{l}\text { - Package } \\
\text { (software, } \\
\text { consulting, } \\
\text { service) }\end{array}$ & $\begin{array}{l}\text { - Integration in } \\
\text { existing IT } \\
\text { landscape }\end{array}$ & $\begin{array}{l}\text { - Integration in } \\
\text { existing IT } \\
\text { environment }\end{array}$ \\
\hline $\begin{array}{l}\text { Categories of } \\
\text { Coding Frame }\end{array}$ & Client F & Client G & Client H & Client I & Client J \\
\hline Solutions & $\begin{array}{l}\text { - Product, interface, } \\
\text { consulting and } \\
\text { training }\end{array}$ & $\begin{array}{l}\text { Solution must be } \\
\text { integrated in } \\
\text { existing systems }\end{array}$ & - Fit into ecosystem & $\begin{array}{l}\text { - Fit in upstream } \\
\text { and downstream } \\
\text { systems }\end{array}$ & No findings \\
\hline
\end{tabular}

Table 47: Category Solutions summary

Source: Developed for this research project

Thus, for Client E, the integration of the Alpha software into the existing IT landscape is a KO criterion, although the other components of the solution are considered positive. The same applies to Client $G$, for whom the software itself does not meet today's needs and requirements. This leads in both cases to a negative purchase decision. For the interviewees, the solution essentially consists of six components. The software is one component and contains all software features that meet the customer's requirements. Since the software has a certain complexity, accompaniment by experienced consultants who control the implementation process, as well as comprehensive training of the later users of the software, is required. Once the software has been set up and rolled out, the ongoing support of the customer is taken over by service units, so the customer sends his service requests directly to the appropriate locations. Due to their size, the companies of the interviewees often have special and individual requirements for a software solution that cannot be served by the standard. Customisation solutions are used here, as well as in the integration of the software into the existing IT landscape. It is therefore important to the interviewees to determine what position the sales force has in the company to qualify the customisation requests and to make particularly extensive adjustments in the software possible. The costs of a solution are not decisive for a purchase decision among the interviewees. As long as the cost-benefit ratio is balanced, the fit of the software is more important. 


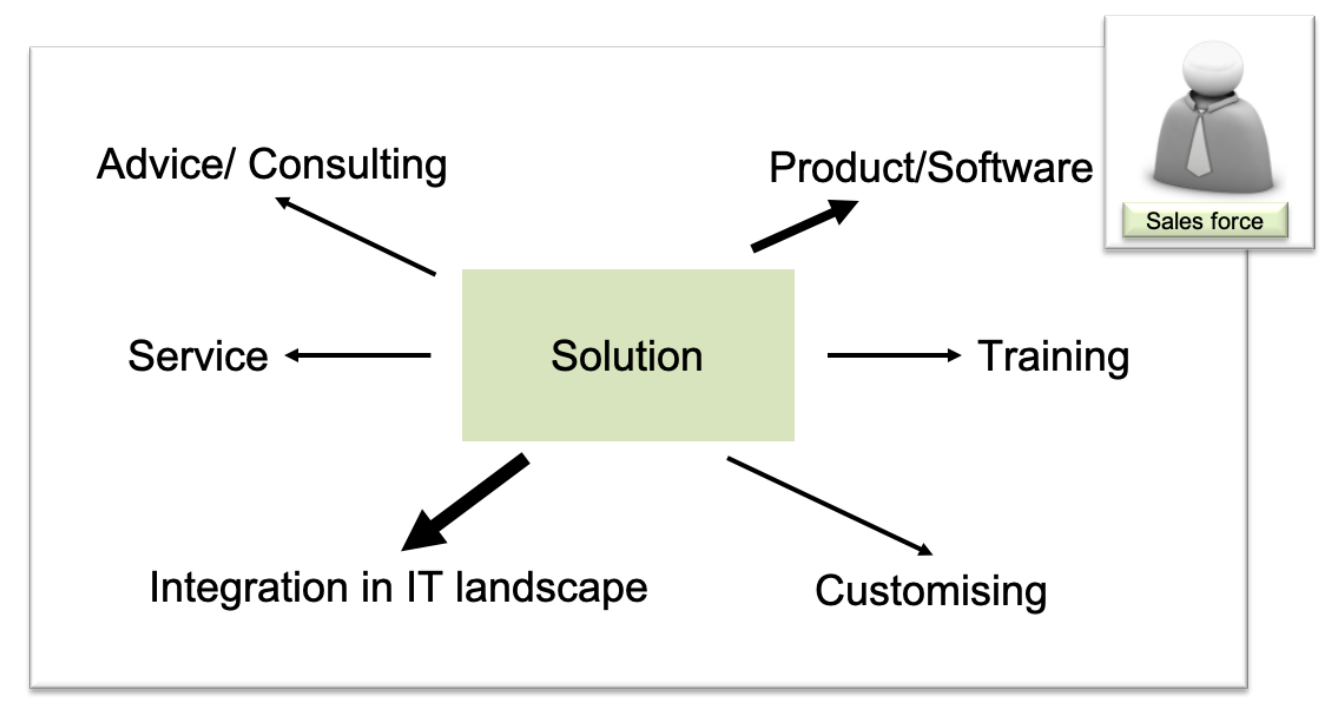

Figure 34: Components of a solution

Source: Developed for this research project

\subsubsection{Importance}

The results of the category are summarised in Table 48. Sales force expert power is highly important to the interviewees. Without expert power, the sales force cannot provide meaningful support for the purchase decision. The customer processes and customer requirements must be understood so that the sales force can offer a solution. The interviewees are interested in facts. General information does not add value and is considered a waste of time. The more complex the requirement, the more expert power becomes necessary and visible (Client $G$ ). The same applies to complex products or solutions. The solutions offered by Alpha Software serve complicated issues in the companies due to the tax and social security law issues; thus, they provide an ideal opportunity for the sales force to display expert power. The interviewees do not offer a consistent picture as to what extent the importance of sales force expert power varies throughout the purchasing process (Figure 35). Overall, expert power is important throughout the entire purchasing process. Client $\mathrm{E}$ and $\mathrm{Client}$ I see no variations within the purchasing process. Among the remaining interviewees, it is clear that sales force expert power gains importance in the initial phase and towards the end when the purchase decision is made. In the initial phase (the exploratory phase), it is crucial right from the first contact and initial conversations to build trust in the sales force and the provider. Sales force expert power is key for this. The interviewees expect that the sales force will pose the right questions and provide satisfactory answers. This is not possible without sales force expert power. Client $C$ considers sales force expert power to be important even before the actual talks. Initial 
information about websites and the way in which appointments are arranged, for example, are clear indicators of sales force expert power for Client C.

\begin{tabular}{|c|c|c|c|c|c|}
\hline $\begin{array}{l}\text { Categories of } \\
\text { Coding Frame }\end{array}$ & Client A & Client B & Client C & Client D & Client E \\
\hline Importance & $\begin{array}{l}\text { - Expert power was } \\
\text { important for } \\
\text { buying decision } \\
\text { from the first } \\
\text { contact } \\
\text { - Decreased during } \\
\text { buying process } \\
\text { - Regained } \\
\text { importance when } \\
\text { decision is } \\
\text { pending }\end{array}$ & $\begin{array}{l}\text { - Expert power was } \\
\text { important for } \\
\text { buying decision } \\
\text { from the first } \\
\text { contact } \\
\text { - Decreased when } \\
\text { trust was } \\
\text { established }\end{array}$ & $\begin{array}{l}\text { - Expert power was } \\
\text { important for } \\
\text { buying decision } \\
\text { from the first } \\
\text { contact, even } \\
\text { before contact } \\
\text { - Increased in initial } \\
\text { phase and } \\
\text { decision-making } \\
\text { phase }\end{array}$ & $\begin{array}{l}\text { Expert power was } \\
\text { highly important in } \\
\text { all phases }\end{array}$ & $\begin{array}{l}\text { Expert power was } \\
\text { highly important }\end{array}$ \\
\hline $\begin{array}{l}\text { Categories of } \\
\text { Coding Frame }\end{array}$ & Client F & Client G & Client H & Client I & Client J \\
\hline Importance & $\begin{array}{l}\text { - Expert power was } \\
\text { important in every } \\
\text { stage } \\
\text { - Product } \\
\text { knowledge more } \\
\text { important in early } \\
\text { stages, final stage } \\
\text { process } \\
\text { knowledge and } \\
\text { change } \\
\text { knowledge more } \\
\text { important }\end{array}$ & $\begin{array}{l}\text { - Expert power was } \\
\text { important } \\
\text { - Expert power } \\
\text { increased } \\
\text { importance when } \\
\text { findings a solution }\end{array}$ & $\begin{array}{l}\text { - Expert power was } \\
\text { important } \\
\text { - Especially } \\
\text { important in initial } \\
\text { phase }\end{array}$ & $\begin{array}{l}\text { - Expert power } \\
\text { equally important } \\
\text { in all phases } \\
\text { - Especially } \\
\text { important in initial } \\
\text { phase }\end{array}$ & $\begin{array}{l}\text { - Expert power was } \\
\text { important } \\
\text { - In initial phase } \\
\text { expert power is } \\
\text { crucial for building } \\
\text { trust }\end{array}$ \\
\hline
\end{tabular}

Table 48: Category Importance summary

Source: Developed for this research project

If the sales force and the products are better known, expert power loses this additional importance. For example, for Client $\mathrm{C}$, the products and the associated features are more in the foreground. For Client $A$, sales force expert power can certainly vary throughout the process. Not all topics and questions can be answered satisfactorily (Client B). However, what must never let up is the reliability of the sales force in clarifying the open points in a timely and consistent manner. If the sales force does not do this, the interviewees lose confidence in the sales force. Once the solution is designed and the purchase decision is made, the sales force gains expert power beyond the normal level. This is a crucial phase for both the interviewees and the sales force. Any mistake or faulty behaviour can ruin any previous efforts made. In this phase, the interviewees gain process and change knowledge. Product knowledge loses focus as compared to the beginning of the buying process. 


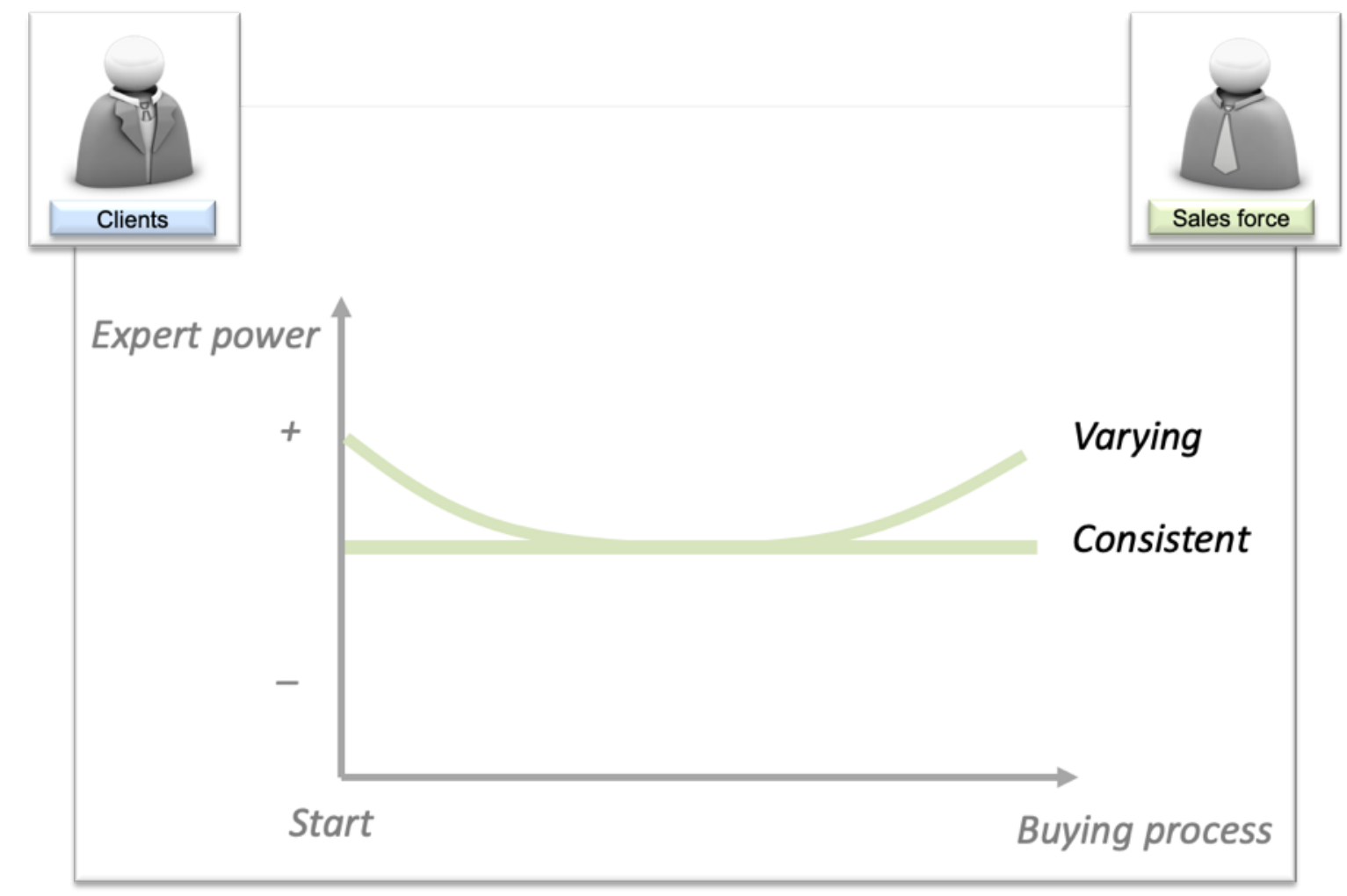

Figure 35: Change of importance in the course of the buying process Source: Developed for this research project

\subsubsection{Behaviour}

The results of the category are summarised in Table 49. To make a purchase decision, according to the interviewees, four feelings are needed: esteem, trust, confidence, and certainty (Figure 36). The interviewees feel valued and appreciated when the sales force understands their problem and requirements and derives an individual solution for them. This requires that the sales force deals intensively with their customers. The interviewees want to trust that the sales force will act honestly and in their best interest. The interviewees need confidence that the software will be implemented successfully, and that daily business will not be affected. Moreover, the interviewees need to be certain that the solutions will improve the status quo, that their requirements will be met, and that the solutions will work in practice. In addition to the recommendations and experiences of others and a strong brand perception, sales force expert power is crucial for the purchase decision of the interviewees. Thus, sales force expert power acts directly on the four aforementioned feelings. According to the interviewees, expert power is transported and made visible by the behaviour of the sales force. It is important that the sales force addresses each member in a buying centre target group individually, specifically based on their personal knowledge and state of mind. The interviewees make decisions as far as possible in the group. The opinion of the 
individual counts and, in the case of doubt, can not only delay a decision but overturn it altogether.

\begin{tabular}{|c|c|c|c|c|c|}
\hline $\begin{array}{l}\text { Categories of } \\
\text { Coding Frame }\end{array}$ & Client A & Client B & Client C & Client D & Client E \\
\hline Behaviour & $\begin{array}{l}\text { - Listening and } \\
\text { understanding } \\
\text { - Open, } \\
\text { transparent, } \\
\text { solution oriented, } \\
\text { focus on } \\
\text { essentials } \\
\text { - Less sales } \\
\text { orientation } \\
\text { - Position and } \\
\text { power important }\end{array}$ & $\begin{array}{l}\text { - Language binding } \\
\text { and clear } \\
\text { - Well-groomed } \\
\text { and friendly } \\
\text { demeanour } \\
\text { - Honesty and } \\
\text { openness }\end{array}$ & $\begin{array}{l}\text { - Timely answers, } \\
\text { honesty, } \\
\text { precision, } \\
\text { empathy, good } \\
\text { listening } \\
\text { - Position important } \\
\text { - Mistrust sales } \\
\text { force }\end{array}$ & $\begin{array}{l}\text { - Restraint and } \\
\text { space-giving } \\
\text { sales force } \\
\text { - Right questions } \\
\text { and answers } \\
\text { - Position and } \\
\text { power not so } \\
\text { important }\end{array}$ & $\begin{array}{l}\text { - Good listening, } \\
\text { asking questions, } \\
\text { openness, a } \\
\text { positive attitude, } \\
\text { empathy, and } \\
\text { reliability } \\
\text { - Position important }\end{array}$ \\
\hline $\begin{array}{l}\text { Categories of } \\
\text { Coding Frame }\end{array}$ & Client F & Client G & Client H & Client I & Client J \\
\hline Behaviour & $\begin{array}{l}\text { - Correct questions, } \\
\text { precise answers, } \\
\text { goal orientation, } \\
\text { reliability, } \\
\text { openness } \\
\text { - All members of } \\
\text { buying centre } \\
\text { needed to be } \\
\text { addressed }\end{array}$ & $\begin{array}{l}\text { - Engaged and } \\
\text {, hard working } \\
\text { - Good questions } \\
\text { and answers } \\
\text { - Adaption to } \\
\text { different } \\
\text { characters in } \\
\text { buying centre } \\
\text { - Position important }\end{array}$ & $\begin{array}{l}\text {-Sale force took } \\
\text { client seriously } \\
\text { - Ask questions } \\
\text { and intend to } \\
\text { understand } \\
\text { - Competent, } \\
\text { reliable, reflective, } \\
\text { conscientious } \\
\text { - Mistrust and } \\
\text { uncertainty } \\
\text { caused by sales } \\
\text { force }\end{array}$ & $\begin{array}{l}\text { - Calm, reserved, } \\
\text { goal-oriented, } \\
\text { helpful, } \\
\text { professional } \\
\text { demeanour } \\
\text { - Loyal to client and } \\
\text { company, } \\
\text { present, } \\
\text { responsive } \\
\text { - Position important }\end{array}$ & $\begin{array}{l}\text { - Good listening, } \\
\text { focus on the } \\
\text { essentials } \\
\text { - Friendly, calm, } \\
\text { competent } \\
\text { demeanour } \\
\text { - Position important }\end{array}$ \\
\hline
\end{tabular}

Table 49: Category Behaviour summary

Source: Developed for this research project

To positively influence behaviour, the following sales force characteristics and approaches are important. According to the interviewees, the sales force needs to have a positive attitude towards the customers and the desired solutions. The positive attitude changes the charisma. An open mind enables new and creative solutions. Through empathy, the sales force can empathise with the customer and respond more sensitively to its needs. A friendly, modest, and concentrated but still clean-cut appearance is perceived by the interviewees as pleasant. Honesty, coupled with helpfulness and sensitivity, shows that the sales force has an interest in the customer and its needs. The interviewees expect the sales force to guide them through the decision-making process in a goal-oriented and decisive manner. They would like to 
be able to rely on the sales force at any time. To display competence, the sales force should ask many questions that focus on the essentials from the perspective of the interviewees. Listening and giving the client room to address and discuss his issues promotes appreciation and shows that he is the centre of attention. The sales force would do well to sit back in the talks and speak less. If the sales force expresses himself, the language used should be clear and binding.

The position and influence, as well as the associated position of power, are important to the majority of the interviewees. Due to their requirements, this results in a complexity that often cannot be mapped with standard solutions. Tailored and customised changes must be made to the standard solutions. These changes require time and effort of the supplier. The importance that a customer has is not immediately apparent to everyone in the supplier company, according to the interviewees. Here, the interviewees need the influence and power of the sales force to sharpen their meaning in-house and speed up change processes. The interviewees' perception of sales force expert power is increased by position and influence in the supplier firm.

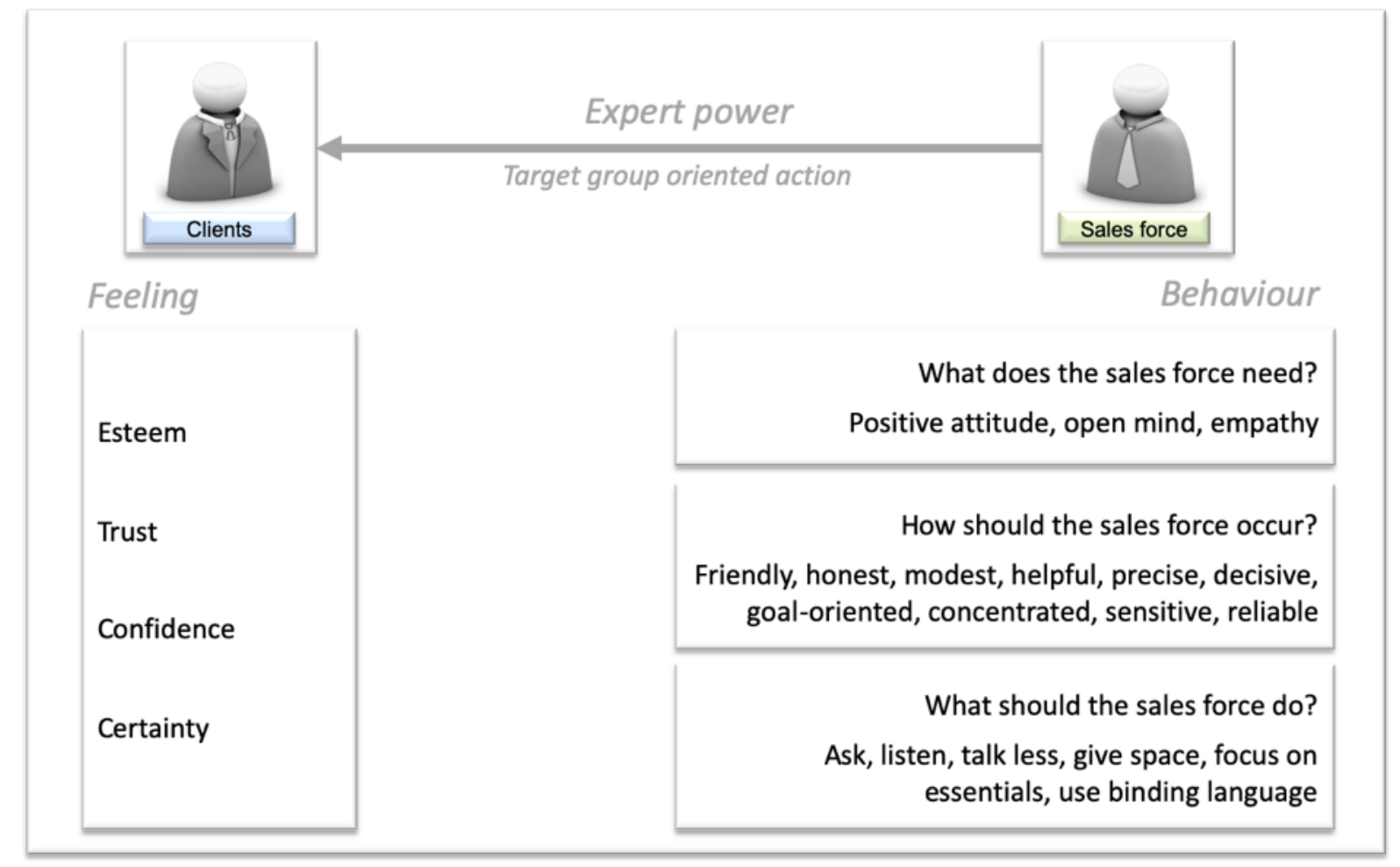

Figure 36: Behaviour of the sales force to impart expert power and what expert power induces Source: Developed for this research project 


\subsubsection{Decision}

The results of the category are summarised in Table 50. It is striking that the interviewees made the purchase decision as a group in the buying centres. Essentially all members had to stand behind the decision. Client $\mathrm{H}$ even went so far that the purchase decision was postponed or not carried out if not all participants were convinced of the solution. This also carries the risk that continued search for a new supplier would bind resources and lead to a double burden in the daily work. According to Client $\mathrm{H}$, software implementation fails if the participating employees are not convinced that the new solution adds value to the organisation. The basis for a purchase decision was, for the interviewees, that the solution fit, and the requirements were met. The sales force assists with the purchase decision and provides all necessary information for an informed decision. In two cases, the expectation was that the product decision would be made by the sales force (Client B, Client E).

\begin{tabular}{|c|c|c|c|c|c|}
\hline $\begin{array}{l}\text { Categories of } \\
\text { Coding Frame }\end{array}$ & Client A & Client B & Client C & Client D & Client E \\
\hline Decision & $\begin{array}{l}\text { - Group-decision } \\
\text { supported by } \\
\text { employees } \\
\text { - Need for certainty } \\
\text { - Expert power } \\
\text { important for } \\
\text { decision }\end{array}$ & $\begin{array}{l}\text { - Group-decision } \\
\text { supported by } \\
\text { employees } \\
\text { - Understanding } \\
\text { that sales force } \\
\text { should have } \\
\text { chosen right } \\
\text { software }\end{array}$ & $\begin{array}{l}\text { - Group-decision } \\
\text { supported by } \\
\text { employees } \\
\text { - Important for } \\
\text { decision was trust } \\
\text { and sales force } \\
\text { expert power }\end{array}$ & $\begin{array}{l}\text { - Group-decision } \\
\text { supported by all } \\
\text { employees } \\
\text { - Solution met the } \\
\text { requirement and } \\
\text { was convincing } \\
\text { - Need for certainty } \\
\text { - Expert power } \\
\text { important }\end{array}$ & $\begin{array}{l}\text { - Group-decision by } \\
\text { HR and IT } \\
\text { department } \\
\text { - Ambivalent about } \\
\text { who should make } \\
\text { the decisions, on } \\
\text { one side the sales } \\
\text { force, on the other } \\
\text { side, the buying } \\
\text { centre is } \\
\text { competent } \\
\text { enough } \\
\text { - Expert power } \\
\text { important }\end{array}$ \\
\hline $\begin{array}{l}\text { Categories of } \\
\text { Coding Frame }\end{array}$ & Client F & Client G & Client H & Client I & Client J \\
\hline Decision & $\begin{array}{l}\text { - Group-decision } \\
\text { supported by all } \\
\text { employees } \\
\text { - Equal } \\
\text { understanding the } \\
\text { basis for the } \\
\text { decision } \\
\text { - Expert power was } \\
\text { important }\end{array}$ & $\begin{array}{l}\text { - Decision made on } \\
\text { management } \\
\text { level } \\
\text { - Expert power was } \\
\text { important }\end{array}$ & $\begin{array}{l}\text { - Group-decision } \\
\text { supported by all } \\
\text { employees } \\
\text { - Need for certainty } \\
\text { - Expert power is } \\
\text { important }\end{array}$ & $\begin{array}{l}\text { - Employees and } \\
\text { management } \\
\text { needed to agree } \\
\text { to purchase } \\
\text { - Expert power is } \\
\text { important }\end{array}$ & $\begin{array}{l}\text { - Decision in } \\
\text { collaboration with } \\
\text { management } \\
\text { - Need for certainty } \\
\text { - Expert power is } \\
\text { important }\end{array}$ \\
\hline
\end{tabular}

Table 50: Category Decision summary

Source: Developed for this research project 
The starting point for the purchase decision process is always an open or latent (Client B) dissatisfaction with the existing software solution (Figure 37). The reason for dissatisfaction always depends on the initial situation. Several clients today use obsolete software that no longer meets the legal requirements or modern procedures (Client A, Client B, Client E, Client G). Other clients have had bad experiences with audits by public authorities and institutions (Client $\mathrm{C}$, Client $\mathrm{F}$, Client $\mathrm{H}$, Client $\mathrm{J}$ ) or want to change because the existing software is no longer serviced or poorly serviced (Client D, Client I). All clients agree that the software migration changes the work situation of their employees and their departments. Once the decision to replace the existing solution has been made and the requirements for a new solution have been defined, market research begins, where a limited number of suppliers (up to five suppliers) are shortlisted to enter exploratory talks. Decisive for the shortlisting are existing experiences and the respective brand of the supplier for which they stand and are known. From the exploratory talks, there is a further restriction to one to three alternative suppliers. These remaining suppliers design possible solutions so that a concrete offer can be submitted for a decision. A clear recommendation is prepared for the management by the buying centres so that a final decision can be made. Management representatives are part of the buying centres.

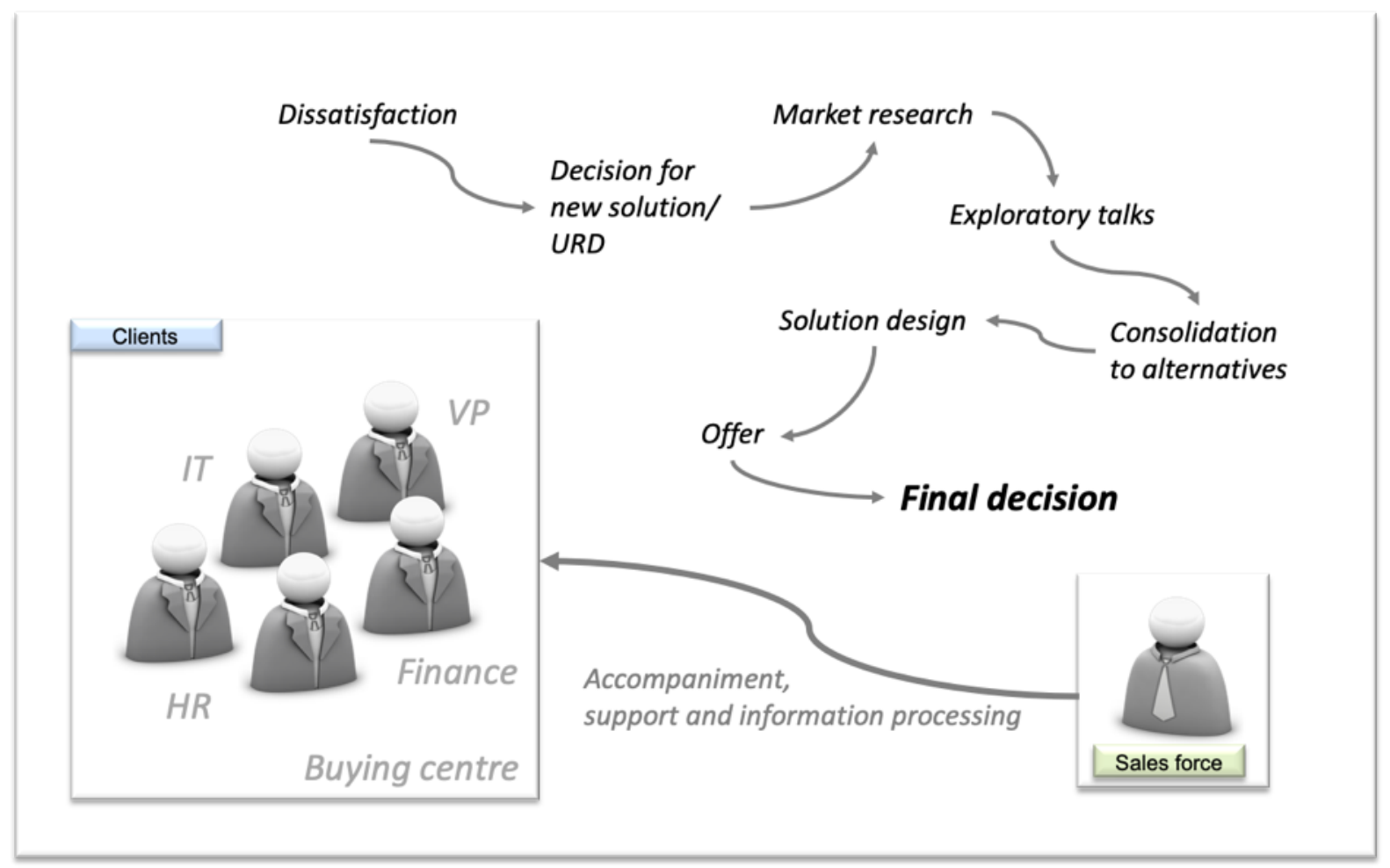

Figure 37: Simplified representation of decision-making process Source: Developed for this research project 
Recommendations from other companies and the sales force had a positive effect on the purchase decision. Recommendations that were related to the sales force either did not exist or were of no importance to the purchase decision.

The number of sales pitches was rated by all interviewees as adequate and appropriate for the situation. They felt able to make a purchase decision. If more were needed, more would have occurred. There was no limitation on the part of the sales force. The number of sales pitches varied depending on complexity, buying experiences, and experience with Alpha Software. However, a dependency is not recognisable.

\subsubsection{Doubts}

The results of the category are summarised in Table 51. The interviewees were convinced of Alpha Software's sales force capabilities and found their support to be highly valuable in making a purchase decision. Three of the ten interviewees had no doubts in the sales force and found the way they were led to a decision to be appropriate. Client $G$ had doubts about the product but not about the sales force. Interviewees who decided against Alpha Software were also positive about the sales force and made it clear that their decision did not depend on the skills of the sales force (Client E, Client G). Nevertheless, during the purchasing process, doubts arose regarding the sales force's expert power. On the one hand, Client B and Client E expected that the sales force would make the product decision for them. Both products were similar in their designs and differed only minimally. The sales force had rejected this and repeatedly encouraged the two clients to make the decision themselves. The claim of the sales force was that they advise the customer until he is in a position to make a meaningful decision. On the other hand, doubts arose regarding the skills of the sales force: strong focus on the problem, being too detailed, information overload, and mental overload (Figure 38). The interviewees complained that the sales force was sometimes too focused on the issues and ignored the solution. The interviewees are primarily solution-oriented people who are more interested in a solution than in the problems. At times, they felt that a solution was impossible because of all the problems. This, in turn, had a negative effect on the mood of employees, as did the fact that changing the software can mean a change for the employees (see Change in this chapter). The sales force focused too heavily on the problems and wanted to solve all 
questions during the sales pitches. Client $A$, in particular, dealt with these doubts. However, according to the interviewees, this is not possible and does not make sense. A clarification within the conversion project is sufficient for many topics, as long as they are not KO topics. Another reason for doubts about the expert power of the sales force arose when the sales force pushed itself to the fore and offered too much information, rather than asking questions to find out what was going on with the customer.

\begin{tabular}{|c|c|c|c|c|c|}
\hline $\begin{array}{l}\text { Categories of } \\
\text { Coding Frame }\end{array}$ & Client A & Client B & Client C & Client D & Client E \\
\hline Doubts & $\begin{array}{l}\text { - Doubts } \\
\text { experienced } \\
\text { - Sales force } \\
\text { focussed on } \\
\text { problems not } \\
\text { solutions } \\
\text { - Motivation of } \\
\text { employees } \\
\text { decreased }\end{array}$ & $\begin{array}{l}\text { - No direct doubts } \\
\text { rather uncertainty } \\
\text { due to minimal } \\
\text { differences } \\
\text { between } \\
\text { respective } \\
\text { software } \\
\text { - Sales force did } \\
\text { not make the } \\
\text { product decision }\end{array}$ & $\begin{array}{l}\text { - Strong doubts } \\
\text { - Too much } \\
\text { information } \\
\text { benefitted the } \\
\text { opponents }\end{array}$ & - No doubts & $\begin{array}{l}\text { - Doubt as the } \\
\text { sales force did not } \\
\text { want to make the } \\
\text { product decision }\end{array}$ \\
\hline $\begin{array}{l}\text { Categories of } \\
\text { Coding Frame }\end{array}$ & Client F & Client G & Client H & Client I & Client J \\
\hline Doubts & $\begin{array}{l}\text { - No doubts } \\
\text { - Doubts in own } \\
\text { staff - } \\
\text { overwhelmed by } \\
\text { too information, } \\
\text { new software } \\
\text { means extra effort }\end{array}$ & - No doubts & $\begin{array}{l}\text { - No doubts about } \\
\text { the sales force } \\
\text { - Doubts about } \\
\text { implementation } \\
\text { due to special } \\
\text { effort }\end{array}$ & - No doubts & $\begin{array}{l}\text { - Doubts about the } \\
\text { sales force expert } \\
\text { power } \\
\text { - Problem-focused }\end{array}$ \\
\hline
\end{tabular}

Table 51: Category Doubts summary

Source: Developed for this research project

The interviewees found it annoying when the sales force talked a lot about themselves and about things that were not relevant to the buying decision, such as unused products. This was particularly unpleasant for Client J. Unnecessary and too much information leads, according to the interviewees, to excessive demand on the employees and endangers the success of the sale. Even more serious is the mental overload. According to the interviewees, this refers to when the employees see no chance to complete their tasks. The difference from information overload is that, in a mental overload, the employee is afraid that he cannot meet the expectations placed on them because they have to perform too many tasks simultaneously. This perception occurred to employees when the sales force did not pay enough attention to the change that a software implementation entailed. The interviewees wished the sales 
force would have been more sensitive and more restrained. The sales force interviewees were infrequently aware that customers had doubts about them. A direct addressing of the topic helped to solve them. Then, the sales force was aware and adapted their behaviour.

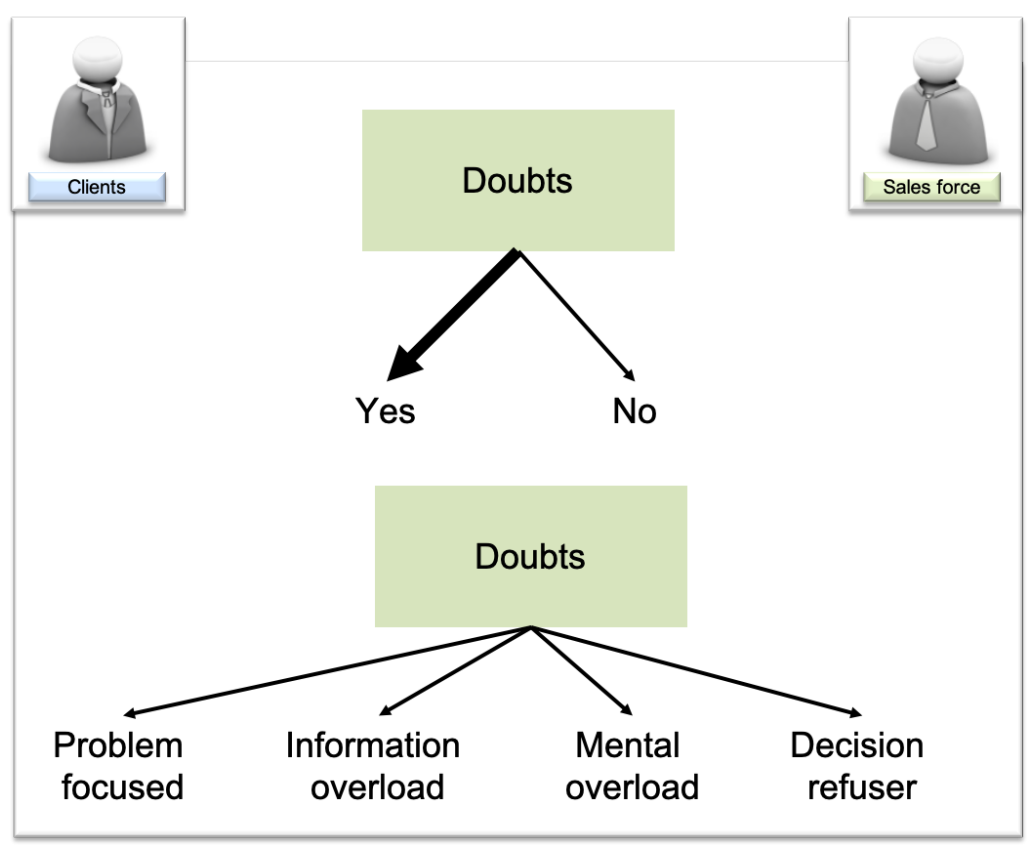

Figure 38: Reasons for doubts

Source: Developed for this research project

\subsubsection{Recommendations}

The results of the category are summarised in Table 52. The interviewees' statements can be grouped into four areas: recommendations about the sales force, recommendations from others, the content of the recommendations, and the impact of the recommendations (Figure 39). The interviewees stated that they did not receive recommendations that directly relate to the sales force. Only Client $\mathrm{C}$ mentioned that that he heard positive remarks about Alpha Software employees. This, however, did not specifically refer to the sales force and is considered to be a general statement. Even if the interviewees had received recommendations about the sales force, it would not have had any influence. Recommendations about Alpha Software that were given by industry peers or friendly companies were especially valuable to interviewees who did not have any personal experience with the company. The substantive recommendations given by the sales force focus on process improvement within the payroll process and the upstream and downstream systems. In addition, there are tips and recommendations for improving the distribution of tasks among employees and 
general organisational changes within the department. Other recommendations that were welcomed by the interviewees related to the state of staff training and various training contents.

\begin{tabular}{|c|c|c|c|c|c|}
\hline $\begin{array}{l}\text { Categories of } \\
\text { Coding Frame }\end{array}$ & Client A & Client B & Client C & Client D & Client E \\
\hline $\begin{array}{l}\text { Recommen- } \\
\text { dations }\end{array}$ & $\begin{array}{l}\text { - From industry } \\
\text { - Process enhance- } \\
\text { ments } \\
\text { - Important }\end{array}$ & $\begin{array}{l}\text { - Recommendation } \\
\text { from friendly } \\
\text { companies } \\
\text { - Organisation of } \\
\text { the department } \\
\text { and individual } \\
\text { processes } \\
\text { - Important }\end{array}$ & $\begin{array}{l}\text { - Recommendation } \\
\text { s from industry } \\
\text { was important } \\
\text { - Suggestions for } \\
\text { process } \\
\text { improvements, } \\
\text { employee } \\
\text { training, } \\
\text { organisational } \\
\text { changes }\end{array}$ & $\begin{array}{l}\text { - Recommen- } \\
\text { dations from } \\
\text { others have } \\
\text { positive influence } \\
\text { - Suggestions for } \\
\text { process } \\
\text { improvements } \\
\text { - Important }\end{array}$ & - Not important \\
\hline $\begin{array}{l}\text { Categories of } \\
\text { Coding Frame }\end{array}$ & Client F & Client G & Client H & Client I & Client J \\
\hline $\begin{array}{l}\text { Recommen- } \\
\text { dations }\end{array}$ & $\begin{array}{l}\text { - From industry } \\
\text { - Recommen- } \\
\text { dations in process } \\
\text { changes } \\
\text { - Important }\end{array}$ & $\begin{array}{l}\text { - From industry } \\
\text { - Recommen- } \\
\text { dations for } \\
\text { process } \\
\text { improvements } \\
\text { - Important }\end{array}$ & $\begin{array}{l}\text { - Recommen- } \\
\text { dations on } \\
\text { process changes, } \\
\text { employee } \\
\text { responsibilities, } \\
\text { employee training } \\
\text { - Important }\end{array}$ & $\begin{array}{l}\text { - From others } \\
\text { - Recommen- } \\
\text { dations regarding } \\
\text { daily tasks had } \\
\text { positive impact on } \\
\text { decision } \\
\text { - Important }\end{array}$ & $\begin{array}{l}\text { - From industry } \\
\text { - Recommen- } \\
\text { dations regarding } \\
\text { process changes } \\
\text { - Important }\end{array}$ \\
\hline
\end{tabular}

Table 52: Category Recommendations summary

Source: Developed for this research project

For the interviewees who chose Alpha Software, the recommendations were quite helpful in the purchase decision process. From their perspective, the recommendations make the expert power of the sales force tangible and suggest that the sales force understands their job, even beyond the products. The sales force is perceived as a source of inspiration and a good partner for day-to-day business. Customers and sales force are on an equal footing. This distinguishes Alpha Software's sales force from its counterparts. For the interviewees who opted for another provider, the recommendations had no influence. Both Client $E$ and Client $G$ decided against Alpha Software for other reasons. 


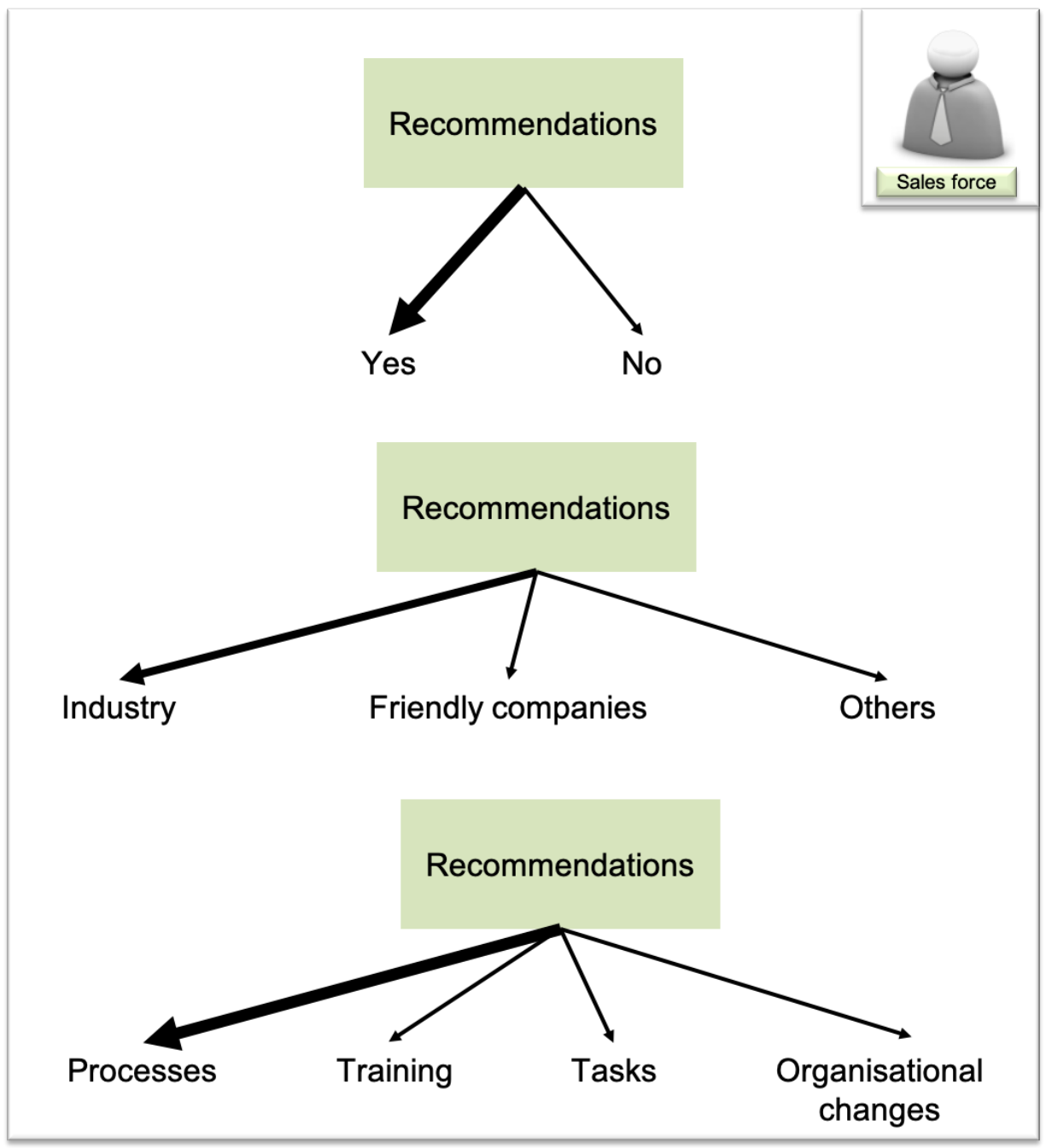

Figure 39: Recommendations

Source: Developed for this research project

\subsubsection{Brand}

The results of the category are summarised in Table 53. In addition to expert power, the brand and what everyone associates with it played an important role in the buying decision for nine out of ten interviewees (Figure 40). Alpha Software is the key player in the industry and has a distinctive position. When selecting new software, Alpha Software was quickly shortlisted among the interviewees due to its market position and industry experience. In addition, Alpha Software has a relatively large number of users, so the experience in terms of the software in practice is comprehensive. The Alpha Software brand has a considerable market reach and embodies decades of experience. The use of Alpha Software in practice has been proven and documented by a wide range of customer testimonials. Even though some of the interviewees (Client B, Client $\mathrm{C}$, Client $\mathrm{D}$, Client $\mathrm{H}$, Client $\mathrm{J}$ ) themselves had not had any personal experience with the brand, the perception of the brand was certainly crucial to their 
purchase decision. The educated clients referred to experiences that industry peers or similar users have gathered with Alpha Software. Client F even went a step further with his remarks and stated that, for him, the sales force not only represents the company but also embodies the brand.

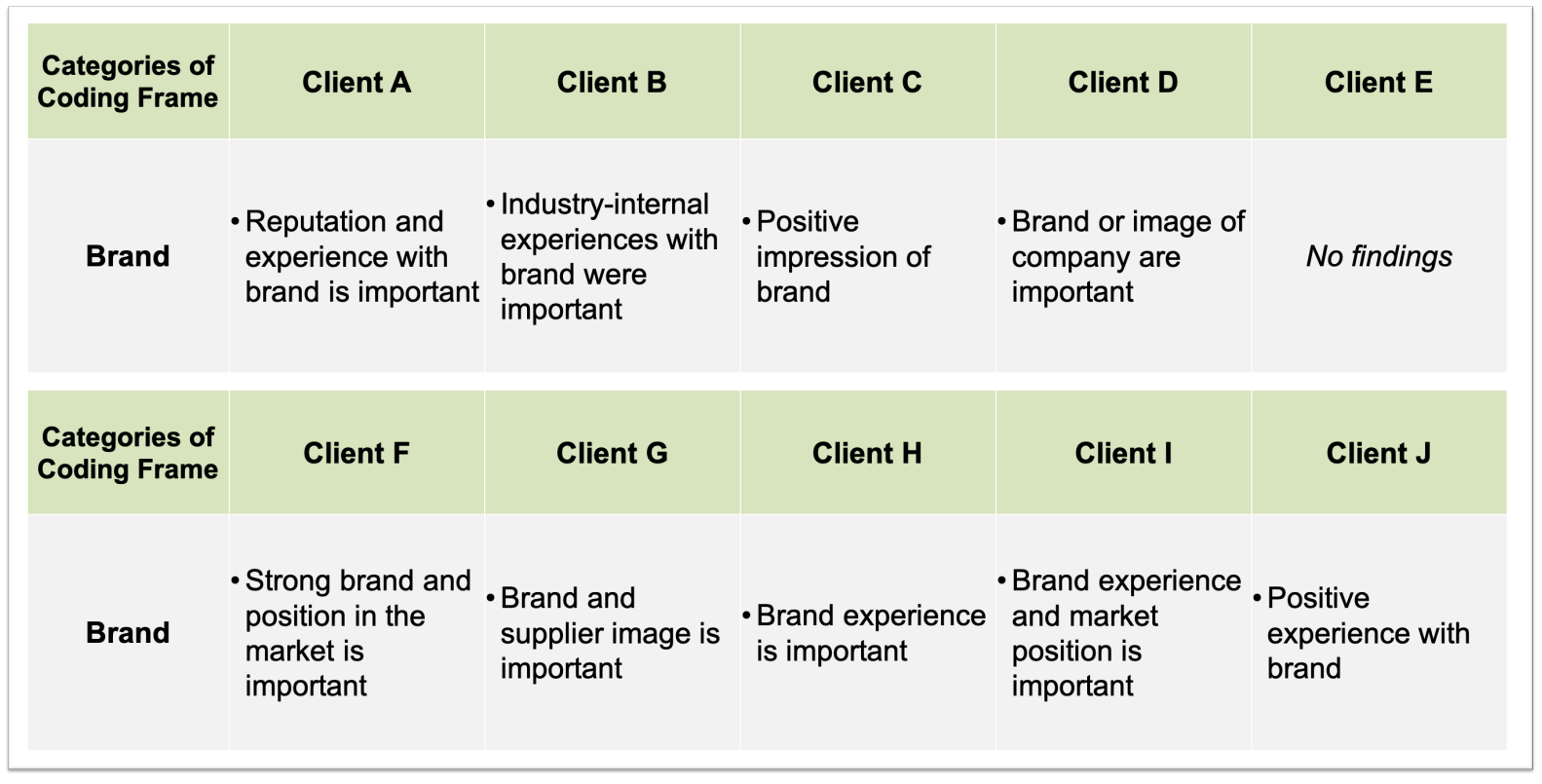

Table 53: Category Brand summary

Source: Developed for this research project

The example given by Client $\mathrm{E}$, however, makes it clear that brand perception certainly has its limits if the software is not shortlisted due to certain KO criteria. Even positive experiences with Alpha Software cannot reverse this situation. The integration into the existing IT landscape has given Client $\mathrm{E}$ a higher rating than the market perception of the brand and the associated advantages. The same applies to Client G. Client G decided to have personal experience with the software due to the usability and overall look of the software against Alpha Software. In the end, it is crucial for the interviewees whether the requirements are fulfilled. 


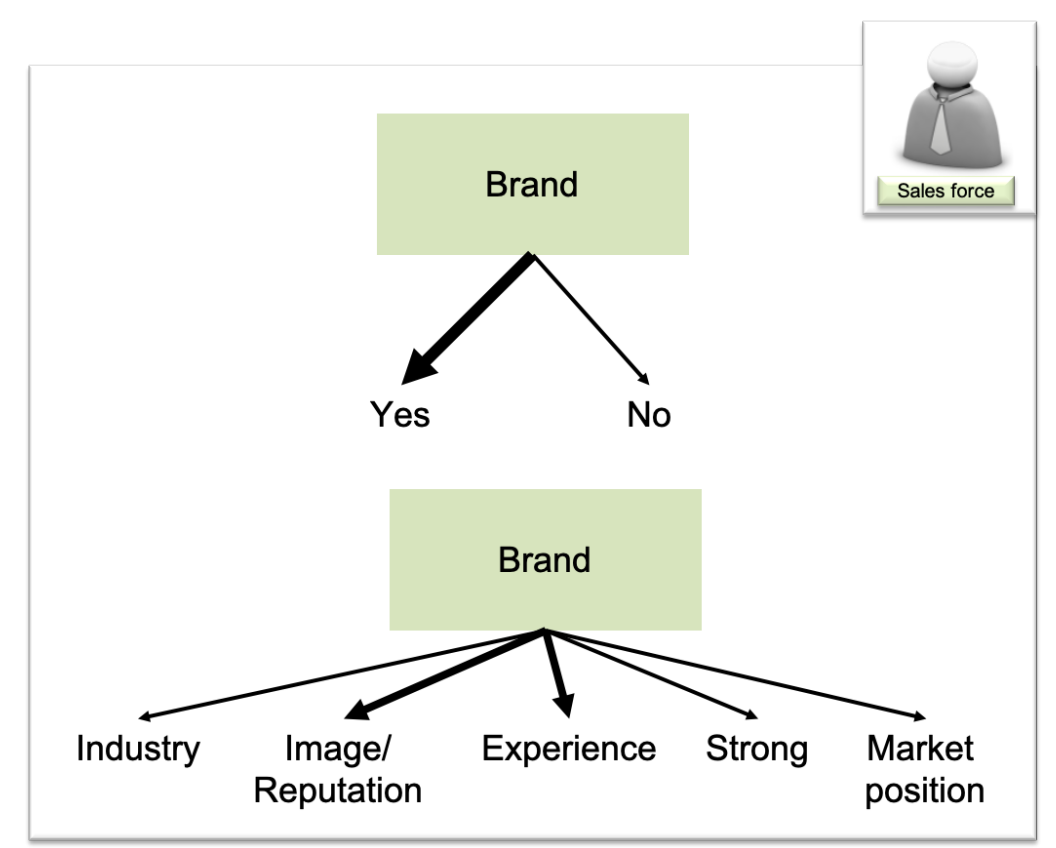

Figure 40: Components of brand awareness

Source: Developed for this research project

\subsubsection{Change}

The results of the category are summarised in Table 54. A software change poses a special challenge for the interviewees. The particular challenge is that the day-to-day business, in addition to the changeover, must commence, and a new, unknown software must be integrated. Content and processes must be defined and maintained. The new software has to be learned. Interfaces to other systems must be built, tested, and released. For the employees, the existing day-to-day business is already timeconsuming, and for the most part, no further resources exist. Additional resources were only approved for interviewees during the conversion period in the form of external consultants. The employees are expected to do the actual work. They all needed to master the transition using their existing resources. Six of the ten interviewees saw such a conversion project as a change project. Based on the interviewees' answers, five components of the change project are visible: chance, mistrust, uncertainty, overextension, and resistance (Figure 41). The reason for a software conversion always depends on the initial situation. This starting situation differs depending on the clients. Several clients currently use obsolete software that no longer meets the legal requirements or modern procedures (Client A, Client B, Client E, Client G). Other clients have had bad experience with audits by public authorities and institutions (Client $\mathrm{C}$, Client $\mathrm{F}$, Client $\mathrm{H}$, Client $\mathrm{J}$ ) or want to change because the existing software is no longer serviced or is poorly serviced (Client D, Client I). All clients agree that the 
software conversion changes the work situation of their employees and their department. They see a chance to improve the existing situation. Despite the existing opportunities, they remain doubtful regarding whether a change is really the desired success. Processes and software features can only be tested conditionally before the conversion. Results and achievements are only visible in live operation. Uncertainty arises right at the beginning of a change project if not all questions and topics are answered in a timely manner. Timely responses are not always possible because they may depend on other decisions made in a different temporal context or lessons that can be learned during the transition. It must be taken into account that the work of the employees who compile the payslips each month requires a highly precise procedure. All open questions and topics must be clarified, if possible, before a payslip is created. Only then is a correct payroll guaranteed. Employees in payroll try to avoid risk. They are far from risky people. Doubts and uncertainty are often common which has become clear in the sales pitches (Client F, Client $\mathrm{H}$ ). According to the interviewees, overworked employees are not able to handle their day-to-day business and a conversion project at the same time. Excessive demand is also visible to employees through resistance, either open or hidden (Client $\mathrm{C}$ ). Not everyone wants to change how they work. These employees use their doubts and uncertainties to attract employees and oppose change. Some of the interviewees have gained experience in other projects (Client $\mathrm{H}$ ). Resistance of employees can massively delay projects or even bring them to failure, according to the interviewees (Client $\mathrm{H}$ ). 


\begin{tabular}{|c|c|c|c|c|c|}
\hline $\begin{array}{l}\text { Categories of } \\
\text { Coding Frame }\end{array}$ & Client A & Client B & Client C & Client D & Client E \\
\hline Change & $\begin{array}{l}\text { - Overwhelmed and } \\
\text { frustrated } \\
\text { employees due to } \\
\text { change issues } \\
\text { - Leads to mistrust } \\
\text { and uncertainty }\end{array}$ & $\begin{array}{l}\text { Choice of } \\
\text { software has far- } \\
\text { reaching } \\
\text { consequences } \\
\text { - Mistrust }\end{array}$ & $\begin{array}{l}\text { - New solution } \\
\text { greater change } \\
\text { for employees } \\
\text { - Increases } \\
\text { resistance, } \\
\text { mistrust, and } \\
\text { uncertainty }\end{array}$ & $\begin{array}{l}\text { - The advantages } \\
\text { of the change } \\
\text { justified the effort } \\
\text { - Leads to mistrust }\end{array}$ & No findings \\
\hline $\begin{array}{l}\text { Categories of } \\
\text { Coding Frame }\end{array}$ & Client F & Client G & Client H & Client I & Client J \\
\hline Change & $\begin{array}{l}\text { - Sales force as } \\
\text { change agents } \\
\text { - Establish } \\
\text { confidence and } \\
\text { trust with change } \\
\text { sensitivity } \\
\text { - Leads to } \\
\text { uncertainty }\end{array}$ & No findings & $\begin{array}{l}\text {-Significant } \\
\text { change for } \\
\text { employees => } \\
\text { Over-extension } \\
\text { - Sales force did } \\
\text { not consider } \\
\text { aspects of change } \\
\text { - Concentration } \\
\text { rather on change } \\
\text { than on sales } \\
\text { - Increases } \\
\text { uncertainty }\end{array}$ & No findings & No findings \\
\hline
\end{tabular}

Table 54: Category Change summary

Source: Developed for this research project

The interviewees expect the sales force to be sensitive to employees and to be aware that a software conversion project is a change project and act accordingly (see also Behaviour in this chapter). If the sales force does not behave accordingly, doubts about the expert power of the sales force are likely to arise (see Doubts in this chapter). To Client $F$, the sales force is more of a change agent than a pure seller. The interviewees who classified the complexity of the project or the intensity of change as medium also see the requirements for a change project (Client $B$, Client $D$ ). 


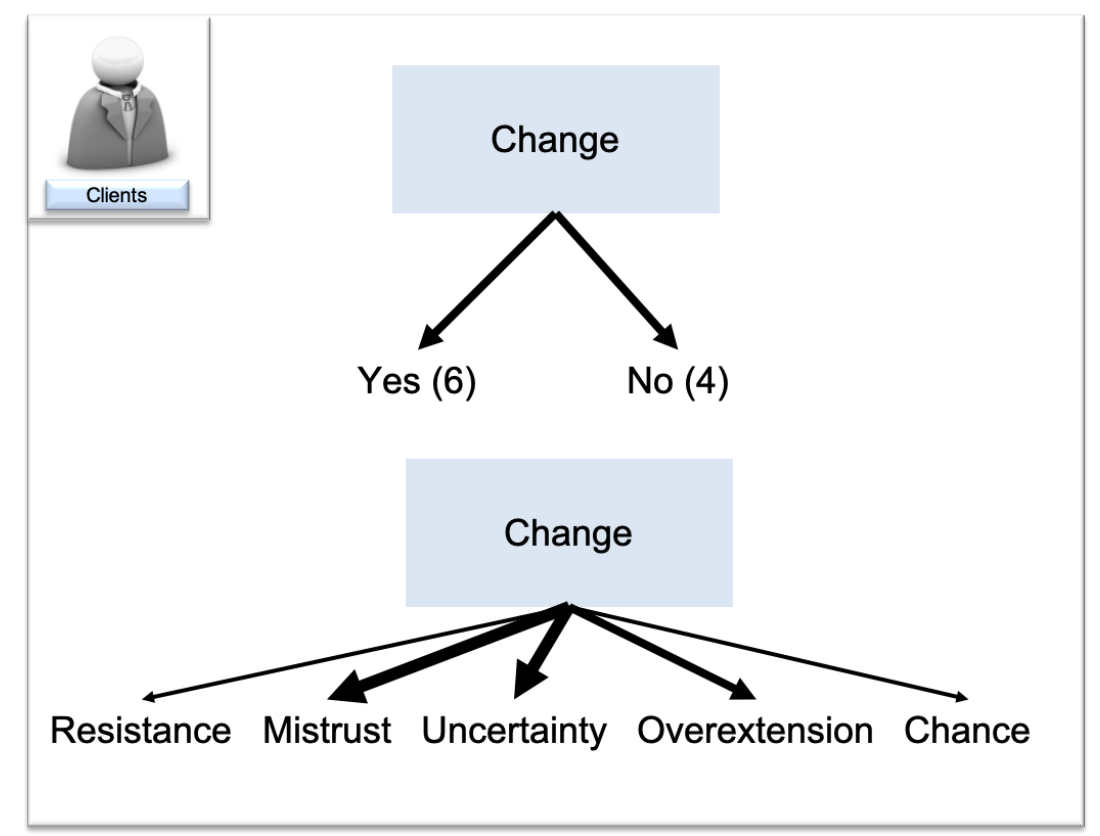

Figure 41: Change project

Source: Developed for this research project

\subsubsection{Strategy}

The results of the category are summarised in Table 55. Seven out of ten interviewees said they were pursuing long-term interests when making a purchase decision (Figure 42). The selection of a new partner is time consuming and binds various internal resources. It can be regarded as an investment in the future. If the selection is wrong, the procedure must be repeated. According to the interviewees, they must be able to rely on the partner. The permanent accompaniment must be ensured. The integration into the IT landscape has to succeed, and the advantage of the new solution must be visible and tangible for all concerned. In the course of a business relationship, requirements change; for example, business areas can grow. It is important to the interviewees that the solution can grow in a modular way and that the software or solution is evolving. The road map for further development must be traceable and transparent. In addition, there are new trends in the market, such as the urge for digitisation. Which future perspectives does the partner offer? For the interviewees, the partners must stay up-to-date and incorporate these new trends into their solutions. They must set new goals only then can they offer the interviewees added value in the long run. 


\begin{tabular}{|c|c|c|c|c|c|}
\hline $\begin{array}{l}\text { Categories of } \\
\text { Coding Frame }\end{array}$ & Client A & Client B & Client C & Client D & Client E \\
\hline Strategy & $\begin{array}{l}\text { - Rely on partner in } \\
\text { the future }\end{array}$ & No findings & $\begin{array}{l}\text { - Long-term } \\
\text { cooperation with } \\
\text { continuous } \\
\text { updates }\end{array}$ & No findings & $\begin{array}{l}\text { - Partner needs to } \\
\text { be fully integrated } \\
\text { in IT environment } \\
\text { - Reliability of } \\
\text { partner }\end{array}$ \\
\hline $\begin{array}{l}\text { Categories of } \\
\text { Coding Frame }\end{array}$ & Client F & Client G & Client H & Client I & Client J \\
\hline Strategy & $\begin{array}{l}\text { - Long-term } \\
\text { partner, further } \\
\text { development } \\
\text { especially } \\
\text { digitisation }\end{array}$ & $\begin{array}{l}\text { - Future } \\
\text { perspectives of } \\
\text { partner }\end{array}$ & $\begin{array}{l}\text { - Long-term } \\
\text { partnership } \\
\text { - Further } \\
\text { development of } \\
\text { solution and } \\
\text { integration of } \\
\text { trends }\end{array}$ & $\begin{array}{l}\text { - Continuous } \\
\text { growth together } \\
\text { with the partner } \\
\text { - Long-term partner }\end{array}$ & No findings \\
\hline
\end{tabular}

Table 55: Category Strategy summary

Source: Developed for this research project

The interviewees (Client B, Client D, Client J), who gave no indication of strategic considerations, said they had neither experience with Alpha Software nor buying experience. Project experiences, however, existed in two cases. The complexity of the solutions and the intensity of the change were rated in the three cases from medium to high. Although the three interviewees did not give any indications of their strategic considerations, it can be assumed that they have a longer-term business relationship. 


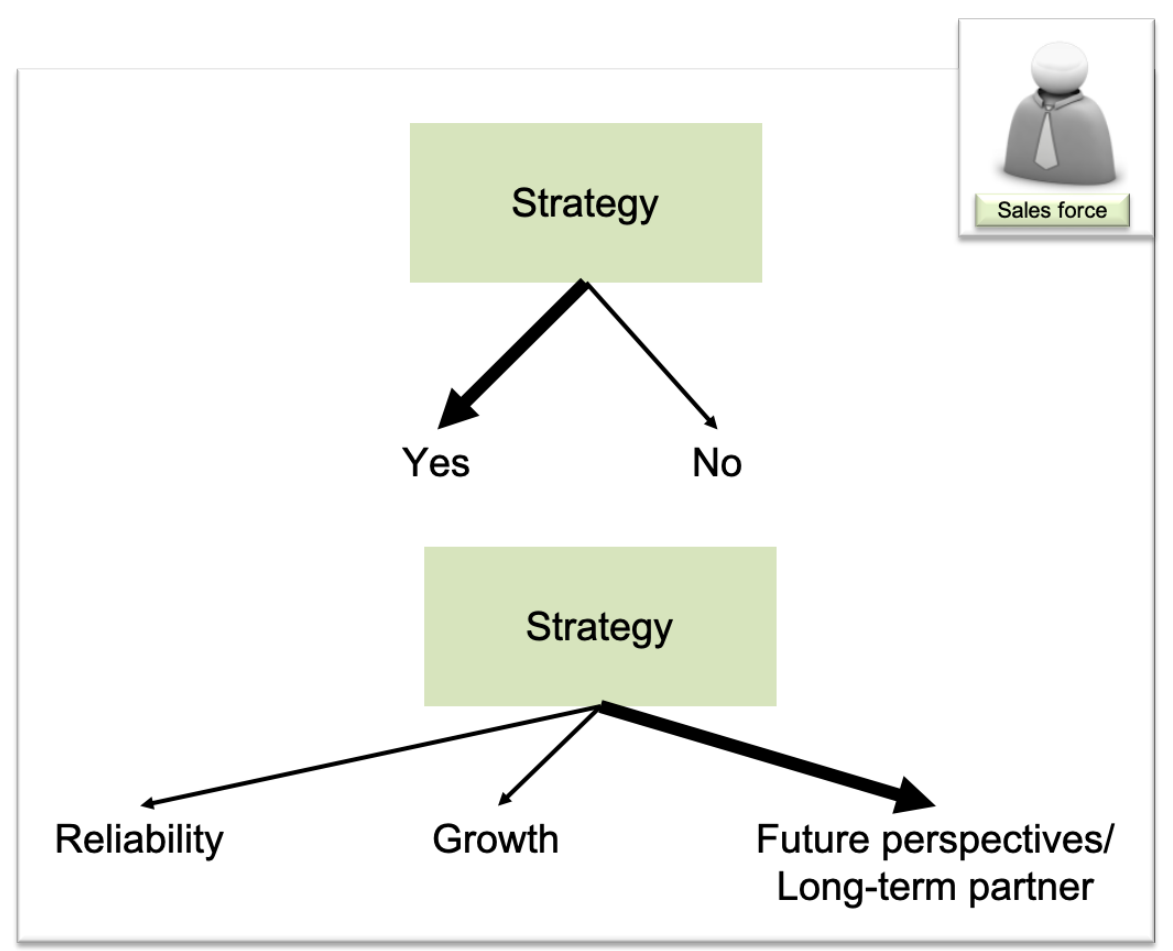

Figure 42: Strategy aspects

Source: Developed for this research project

\subsubsection{Observations}

The results of the category are summarised in Table 56.

\begin{tabular}{|c|c|c|c|c|c|}
\hline $\begin{array}{l}\text { Categories of } \\
\text { Coding Frame }\end{array}$ & Client A & Client B & Client C & Client D & Client E \\
\hline Observations & $\begin{array}{l}\text { Change topic had } \\
\text { special meaning }\end{array}$ & $\begin{array}{l}\text { - Clearly different } \\
\text { expectations } \\
\text { regarding } \\
\text { decision-making }\end{array}$ & $\begin{array}{l}\text { - Upset about the } \\
\text { behaviour of the } \\
\text { sales force }\end{array}$ & $\begin{array}{l}\text { No particular } \\
\text { observations }\end{array}$ & $\begin{array}{l}\text { - Clarification that } \\
\text { sales force was } \\
\text { not responsible } \\
\text { for the sales } \\
\text { failure }\end{array}$ \\
\hline $\begin{array}{l}\text { Categories of } \\
\text { Coding Frame }\end{array}$ & Client F & Client G & Client H & Client I & Client J \\
\hline Observations & $\begin{array}{l}\text { - Experiences with } \\
\text { change }\end{array}$ & $\begin{array}{l}\text { - Clarification that } \\
\text { sales force was } \\
\text { not responsible } \\
\text { for the sales } \\
\text { failure }\end{array}$ & $\begin{array}{l}\text { - Emotional } \\
\text { reaction to } \\
\text { change issues }\end{array}$ & $\begin{array}{l}\text { No particular } \\
\text { observations }\end{array}$ & $\begin{array}{l}\text { - Short and concise } \\
\text { answers, focus on } \\
\text { essentials }\end{array}$ \\
\hline
\end{tabular}

Table 56: Category Observations summary Source: Developed for this research project

The clients who had experience with change and consciously noticed it during the sales process showed this during the interview. It became apparent that the topic of change had a special meaning for them. The behaviour of the sale force and the lack 
of support in choosing the right software could be observed. It was important for the clients who did not choose Alpha Software to expressly point out that the decision was not due to the sales force but to the software or the general conditions. Generally speaking, the observations support the results of the interviews. 


\section{Conclusions and Implications}

\subsection{Objectives of the Chapter}

After having presented the findings of the data analysis in Chapter 4, the aim of this chapter is to discuss the results in the context of the literature review, the research questions, and the research issues. The contribution to knowledge in the form of theoretical implications is articulated. To classify the contributions to knowledge, the findings are divided into two categories. In category one, the findings are classified as Advance in existing knowledge if there is no counterpart in the current literature. In category two, the findings are classified as either Addition to existing knowledge or Confirmation of existing knowledge in relation to the similarities in current literature. Figure 43 displays the summary of the conclusions and the contributions of this research to knowledge on the basis of the research questions and the related research issues. The theoretical implications are the basis for managerial implications, to derive an approach through which the sales force can consciously manage and enhance the client's perception of sales force expert power. 
Research question 1: What are the attributes of clients' perceptions of sales force expert power?

\begin{tabular}{|c|c|c|c|}
\hline Research Issues & Conclusions & $\begin{array}{c}\text { Coding frame } \\
\text { Categories }\end{array}$ & $\begin{array}{c}\text { Contribution of } \\
\text { this Research }\end{array}$ \\
\hline $\begin{array}{c}\text { Product knowledge } \\
\text { Industry knowledge } \\
\text { Process knowledge } \\
\text { Legal knowledge }\end{array}$ & Attributes & $\begin{array}{c}\text { Confirmation of } \\
\text { existing knowledge }\end{array}$ \\
\hline $\begin{array}{c}\text { The understanding of } \\
\text { the attributes of sales } \\
\text { force expert power is not } \\
\text { explicit. }\end{array}$ & $\begin{array}{c}\text { Interface knowledge } \\
\text { Ecosystem knowledge }\end{array}$ & $\begin{array}{c}\text { Attributes } \\
\text { Solutions } \\
\text { Strategy } \\
\text { Doubts } \\
\text { Change } \\
\text { Behaviour }\end{array}$ & $\begin{array}{c}\text { Addition to } \\
\text { existing knowledge }\end{array}$ \\
\hline
\end{tabular}

Research question 2: How do clients form their perceptions of sales force expert power?

\begin{tabular}{|c|c|c|c|}
\hline Research Issues & Conclusions & $\begin{array}{l}\text { Coding frame - } \\
\text { Categories }\end{array}$ & $\begin{array}{l}\text { Contribution of } \\
\text { this Research }\end{array}$ \\
\hline $\begin{array}{l}2 \text {. } \\
\text { The more expert power } \\
\text { the seller employs, the } \\
\text { more trust and certainty } \\
\text { the buyer receives for } \\
\text { his buying decision. }\end{array}$ & $\begin{array}{l}\text { An overload of expert power can } \\
\text { lead to mistrust and uncertainty. }\end{array}$ & $\begin{array}{c}\text { Doubts } \\
\text { Decision } \\
\text { Change }\end{array}$ & $\begin{array}{l}\text { Advance in } \\
\text { existing knowledge }\end{array}$ \\
\hline $\begin{array}{l}5 \text {. } \\
\text { The perception of expert } \\
\text { power in the first buy is } \\
\text { ambivalent. }\end{array}$ & $\begin{array}{l}\text { The perception of expert power is } \\
\text { in the first buy important for the } \\
\text { clients. }\end{array}$ & $\begin{array}{l}\text { Importance } \\
\text { Decision }\end{array}$ & $\begin{array}{l}\text { Addition to } \\
\text { existing knowledge }\end{array}$ \\
\hline $\begin{array}{l}6 . \\
\text { The manner of } \\
\text { behaviour of the sales } \\
\text { force alters the } \\
\text { perception of expert } \\
\text { power and thus the } \\
\text { modes of action. }\end{array}$ & $\begin{array}{l}\text { The manner of behaviour in form } \\
\text { of adaptive selling alters the } \\
\text { perception of sales force expert } \\
\text { power and the position and power } \\
\text { of the sales force is important for } \\
\text { the buyer. }\end{array}$ & $\begin{array}{l}\text { Behaviour } \\
\text { Doubts }\end{array}$ & $\begin{array}{l}\text { Confirmation of } \\
\text { existing knowledge }\end{array}$ \\
\hline $\begin{array}{l}7 . \\
\text { The perception of expert } \\
\text { power is important in } \\
\text { early stages of the } \\
\text { buying process but not } \\
\text { in final stages. }\end{array}$ & $\begin{array}{l}\text { The perception of expert power is } \\
\text { important in all stages. In early } \\
\text { stages product knowledge is } \\
\text { perceived more strongly while the } \\
\text { perception of change knowledge } \\
\text { in final stages predominates. }\end{array}$ & $\begin{array}{l}\text { Importance } \\
\text { Doubts } \\
\text { Attributes } \\
\text { Change }\end{array}$ & $\begin{array}{l}\text { Advance in } \\
\text { existing knowledge }\end{array}$ \\
\hline
\end{tabular}

Research question 3: Which factors affect the formation of clients' perceptions of sales force expert power?

\begin{tabular}{|c|c|c|c|}
\hline Research Issues & Conclusions & $\begin{array}{l}\text { Coding frame - } \\
\text { Categories }\end{array}$ & $\begin{array}{l}\text { Contribution of } \\
\text { this Research }\end{array}$ \\
\hline $\begin{array}{l}3 . \\
\text { The perception of expert } \\
\text { power of supportive and } \\
\text { task-oriented buying } \\
\text { centres is based } \\
\text { primarily on information } \\
\text { exchange and } \\
\text { recommendations. }\end{array}$ & $\begin{array}{l}\text { Information exchange (extended } \\
\text { by strategic issues) and } \\
\text { recommendation are important. }\end{array}$ & $\begin{array}{l}\text { Importance } \\
\text { Recommendations } \\
\text { Strategy } \\
\text { Decision }\end{array}$ & $\begin{array}{c}\text { Addition to } \\
\text { existing knowledge }\end{array}$ \\
\hline $\begin{array}{c}4 . \\
\text { The perception of expert } \\
\text { power is lower when } \\
\text { buyers have high brand } \\
\text { expectations. }\end{array}$ & $\begin{array}{l}\text { The results show that the } \\
\text { perception of expert power is } \\
\text { always high regardless of the } \\
\text { brand expectations. }\end{array}$ & $\begin{array}{c}\text { Brand } \\
\text { Importance }\end{array}$ & $\begin{array}{l}\text { Addition to } \\
\text { existing knowledge }\end{array}$ \\
\hline \multirow{2}{*}{$\begin{array}{l}8 . \\
\text { The perception of expert } \\
\text { power is lower in } \\
\text { extremely important and } \\
\text { highly emotionally } \\
\text { difficult purchases. }\end{array}$} & $\begin{array}{c}\text { The perception of expert power is } \\
\text { lower in highly important } \\
\text { purchases in contrary to the } \\
\text { product and service. }\end{array}$ & $\begin{array}{l}\text { Change } \\
\text { Decision }\end{array}$ & $\begin{array}{c}\text { Confirmation of } \\
\text { existing knowledge }\end{array}$ \\
\hline & $\begin{array}{l}\text { The perception of expert power } \\
\text { alters due to the intensity of } \\
\text { change and how the change is } \\
\text { perceived. Business customers, } \\
\text { unlike consumers, expect a } \\
\text { professional approach to change } \\
\text { rather than benevolence. }\end{array}$ & $\begin{array}{l}\text { Change } \\
\text { Decision } \\
\text { Doubts }\end{array}$ & $\begin{array}{c}\text { Advance in } \\
\text { existing knowledge }\end{array}$ \\
\hline $\begin{array}{c}9 . \\
\text { The intensity of expert } \\
\text { power within the buying } \\
\text { centre has a high impact } \\
\text { on the perception of } \\
\text { sales force expert } \\
\text { power. }\end{array}$ & $\begin{array}{l}\text { The intensity of expert power } \\
\text { within the buying centre has a } \\
\text { high impact on the perception of } \\
\text { sales force expert power. The } \\
\text { perception can be improved by } \\
\text { targeted impact on the } \\
\text { shortcomings in the buying centre. }\end{array}$ & $\begin{array}{l}\text { Change } \\
\text { Recommendations } \\
\text { Strategy }\end{array}$ & $\begin{array}{l}\text { Confirmation of } \\
\text { existing knowledge }\end{array}$ \\
\hline
\end{tabular}


The limitations of this research are presented, and recommendations for further investigations regarding expert power in sales situations are proposed.

\subsection{Conclusions of Research Questions}

\subsubsection{Research Question 1 - Attributes}

Research Issue 1 - The understanding of the attributes of sales force expert power is not explicit.

To the interviewees, sales force expert power is the ability to present and explain a solution in such a way that it is bought by a customer. They follow the views of Kohli (1989), Paesbrugghe et al. (2017), and Sahadev (2005) that the sales force must understand the customer's requirements to develop an individual customer solution and to show how the solution works in practice. The literature supports the mentioned attributes for sales force expert power product knowledge (software features), industry knowledge (e.g. special requirements, important partners within the industry, and terminology), and legal knowledge (e.g. social legislation, tax legislation, and working time legislation) (Boedecker et al., 1991; Crosby et al., 1990; Kohli, 1989; Mallalieu, 2006; Woodside \& Davenport Jr., 1974). The findings are considered to provide confirmation of existing knowledge (Table 57).

\section{Contribution to knowledge - Conclusions}

Research question 1: What are the attributes of clients' perceptions of sales force expert power?

\section{Research Issues}

1.

The understanding of the attributes of sales force expert power is not explicit.
Conclusions

Product knowledge Industry knowledge

Process knowledge Legal knowledge

Interface knowledge

Ecosystem knowledge

Change knowledge
Coding frame Categories

Contribution of this Research

Attributes

Attributes

Solutions

Strategy

Doubts

Change

Behaviour
Confirmation of existing knowledge

Addition to existing knowledge

Advance in existing knowledge

Table 57: Conclusions and contributions to knowledge - Research Question 1

Source: Developed for this research project

In addition, interviewees, according to Palmatier et al. (2006), Sahadev (2005), and Sharma (1990), expect the sales force to have experience and knowledge of how to 
implement a solution and demonstrate how the individual solution will be implemented on the customer's premises. Detailed process knowledge (Kohli, 1989; Lines, 2007; Sahadev, 2005) and software interface knowledge (Houman \& Gadde, 2019) must be present in the sales force. Individual clients use the term ecosystem, which follows the understanding of Tsujimoto, Kajikawa, Tomita, and Matsumoto (2018) that the sales force must understand how to integrate the solution into a comprehensive process landscape (ecosystem) where different systems and stakeholders (internal and external) interact with each other. An ecosystem is a far more complex adaptive system than just integrating upstream and downstream systems, where every actor's performance within the ecosystem affects the performance of the overall system (Galateanu \& Avasilcai, 2014). The sales force needs deep and detailed knowledge of the organisation process and about the systems of competitors and partners existing in the ecosystem to understand the customer's ecosystem and to integrate their own solutions (Tsujimoto et al., 2018). This knowledge extends beyond the process understanding of Kohli (1989) and Sahadev (2005), which reference the processes in companies. Further approaches are provided by Ahlert et al. (2008) and (Woisetschläger et al., 2009), who embed the application of rational interfaces and the wide-ranging service processes into the customer's value chain. Neither them nor Kohli (1989) and (Sahadev, 2005) mention any processes in detail or use the concept of the ecosystem. Barnett White (2005) considers that the sales force should have subjectspecific knowledge. However, she does not explain what this knowledge actually consists of. For Sawhney (2006), a sales force needs intimate knowledge about the customer and the industry to sell a solution. The interviewees have the understanding that their purchase decision does not just refer to a single product. According to their understanding, they buy a solution (see also Section 2.3.3.2). The concept of solution selling is well supported by the literature (Evans et al., 2002; Sawhney, 2006; Schmitz \& Eberhardt, 2009; Tuli et al., 2007). According to the interviewees, the complexity of the solution correlates with the complexity of the requirements. For example, the less different software components are used, the lower the integration into the IT landscape. For the interviewees, the solution essentially consists of six components. The software is a component and contains all software features that meet the customer's requirements. Since the software has a certain complexity, the accompaniment of experienced consultants who control the implementation process, as well as comprehensive training of the later users of the software, is required. Once 
the software has been set up and rolled out, the ongoing support of the customer is taken over by service units, so the customer sends his service requests directly to the appropriate locations. The understanding of the interviewees coincides with the definition of Sawhney (2006) in terms of a solution. He defines a solution as "an integrated combination of products and services customised for a set of customers that allows customers to achieve better outcomes than the sum of the individual components" (p. 369). Due to their size, the companies of the interviewees often have special and individual requirements for a software solution that cannot be served by the standard. Customised and tailor-made solutions are used, also with regard to the integration of the software into the existing IT landscape (Liu \& Leach, 2001). The costs of a solution are not decisive for a purchase decision among the interviewees. As long as the cost-benefit ratio is balanced, the fit of the software is more important, which is distinctive for buying centres in the supportive stage (Paesbrugghe et al., 2017). The focus on a relational process ([1] customer requirements definition, [2] customisation and integration of goods and/or services and [3] their deployment, and [4] postdeployment customer support) gives the supplier chances to offer the solutions more effectively and thus more cost-effectively for the clients (Tuli et al., 2007). The knowledge of a client ecosystem and software interfaces was previously not considered in the literature on sales force expert power. The findings of this research substantiate and explain this specialised knowledge in terms of sales force expert power. Therefore, the findings are considered to add to existing knowledge (Table 57).

The findings of this research reveal parallels to the findings of Barnett White (2005). She found that consumers in emotionally difficult decisions tend to relinquish the expert power of the seller and to favour sellers with benevolence. The aim of consumers in these situations is to minimise the negative emotions that the decision entails, rather than focusing on the accuracy of the facts. Consumers are therefore consciously swapping expert power for benevolence. For less emotional choices, the reverse is true. Barnett White's (2005) remarks refer exclusively to consumers. The remarks can be transferred conditionally to the findings of this research project. When it comes to emotionally difficult decisions, the buying centre loses its confidence in the seller if the seller concentrates too heavily on facts and expert power. However, the buying centre does not expect benevolence from the sales force, according to the findings, but rather are relieved of the fear of change and will be able to handle their operational tasks 
during the software transition. Therefore, in the B2B market, the buyer expects the seller to give him confidence through a professional approach to change other than in the consumer market, where the consumer relies on the benevolence of the seller.

Six of the ten interviewees view such a conversion project as a change project. For one client, the sales force is more of a change agent than a pure seller. The influence of the sales force on the buying centre is comparable with the influence of change agents on a change process. As a consequence of newly acquired products or services, work procedures are frequently dramatically modified, leading to changes in or downsizing of the organisation. Change agents with expert power are more likely to be accepted, and they are rarely the focus of criticism. Less resistance and constructive work cooperation are the consequences. Furthermore, change agents with expert power have a greater influence on the development of good solutions (Lines, 2007). The expert power of change agents involved in implementing strategic change impacts the level of implementation success (Gravenhorst \& Munduate, 2003). Change agents are defined as individuals who have a particular responsibility for the planning, implementation, and outcome of strategic or organisational changes (Lines, 2007). Software conversion projects, as an example of organisational changes, have special requirements for the change agents, such as the consistent integration of all parties involved while maintaining the existing and well-established structures (de Ruyter et al., 2018; Stolle \& Herrmann, 2006; Vering, 2007). The knowledge of the change agent is rare and is considered critical to the performance of organisational tasks (Heijden \& Cramer, 2017; Lines, 2007; Vos \& Rupert, 2018). Its perceived expert power is influenced by known and observable individual characteristics, such as formal education, professional position, and past achievements in relevant process and content areas (Lines, 2007). Highly skilled change agents use more involvement and appreciation than less skilled change agents (Conger, 1998; Jing \& Xie, 2011; Lines, 2007). Since both the use of participation and the sense-giving are positively related to the successful implementation of change, the positive effect of the expert's power on the implementation success is consequentially mediated by an increased use of participation and sense-giving (Grant \& Preston, 2018; Lines, 2007; Pereira, Prada, \& Santos, 2013). To measure expert power, two sets of elements were created, one reflecting the ability based on altering the content of the changes, and the other the process competence (Lines, 2007). An example of elements of the process expert 
scale is that the change agent has extensive experience in managing change. The fact that the change agent is highly competent in the main area of change is an example for the change content expert power scale. The expertise of experts seems to influence the implementation approach chosen by change agents (Gravenhorst \& Munduate, 2003). Lines (2007) has pointed out that proposals made by change agents with perceived expert power and experience are more likely to be accepted and are less likely to produce negative attitudes and behaviours than proposals from change agents with less expert power and related experience. Considering Lines (2007), the intensity of change has a direct impact on the perception of expert power. The higher the intensity of change, the more expert power.

It follows that the sales force should consider the customer's change in the decisionmaking process and should address it separately. The introduction of new software is certainly not a strategic change in the true sense of the word, but the impact and the time dimension of the long-term use of the software have strategic character. Lines (2007) discovered that change agents with a higher proportion of expert power use more participation and sense giving than change agents with less expert power. In addition, suggestions made by change agents with expert power are more likely to be accepted and implemented with less resistance. Change agents with a higher share of expert power are in a better position to implement solutions for organisational change than those with less knowledge. The expert power of a change agent is to be interpreted differently than sales force expert power. Change agents have process knowledge about how to manage change, as well as task knowledge regarding what needs to be addressed and changed concretely. Interestingly, there is a direct link between expert power and implementation success. Expert power had a direct impact on the implementation success without the need for increased participation and sense giving by the change agent. From this, it can be deduced that the sales force can learn from the change agents and adapt the procedure to give the buying centre the necessary confidence to make a purchase decision.

Change knowledge essentially consists of two components: process and task (Figure 44). The process component concentrates on the management of the change. This includes how the people involved are integrated into the change (Vos \& Rupert, 2018), to what extent their worries and hardships are heard, and the individual steps that need to be taken to make the change successful. Ample and intensive communication is 
necessary (Pascale \& Sternin, 2005). The task component focuses on the substantive change that is being made - that is, what is actually being changed. Expertise regarding the topics to be changed plays the decisive role here (Gravenhorst \& Munduate, 2003). Regarding the results of the study, this means that the sales force must understand what and in which phases an employee is involved in the change process and how he can optimally avoid fear of the upcoming changes in these process steps (Vos \& Rupert, 2018). In terms of the task, this means that the sales force must have enough expert power to develop acceptable solutions (Sawhney, 2006; Woisetschläger et al., 2009). The solution knowledge is more pronounced following the research findings. It is important to develop empathy and coaching skills so that the sales force can not only empathise with employees but also remove obstacles to making success visible and repeatedly driving it, so that it does not get stuck in the process of change (Kotter, 2012).

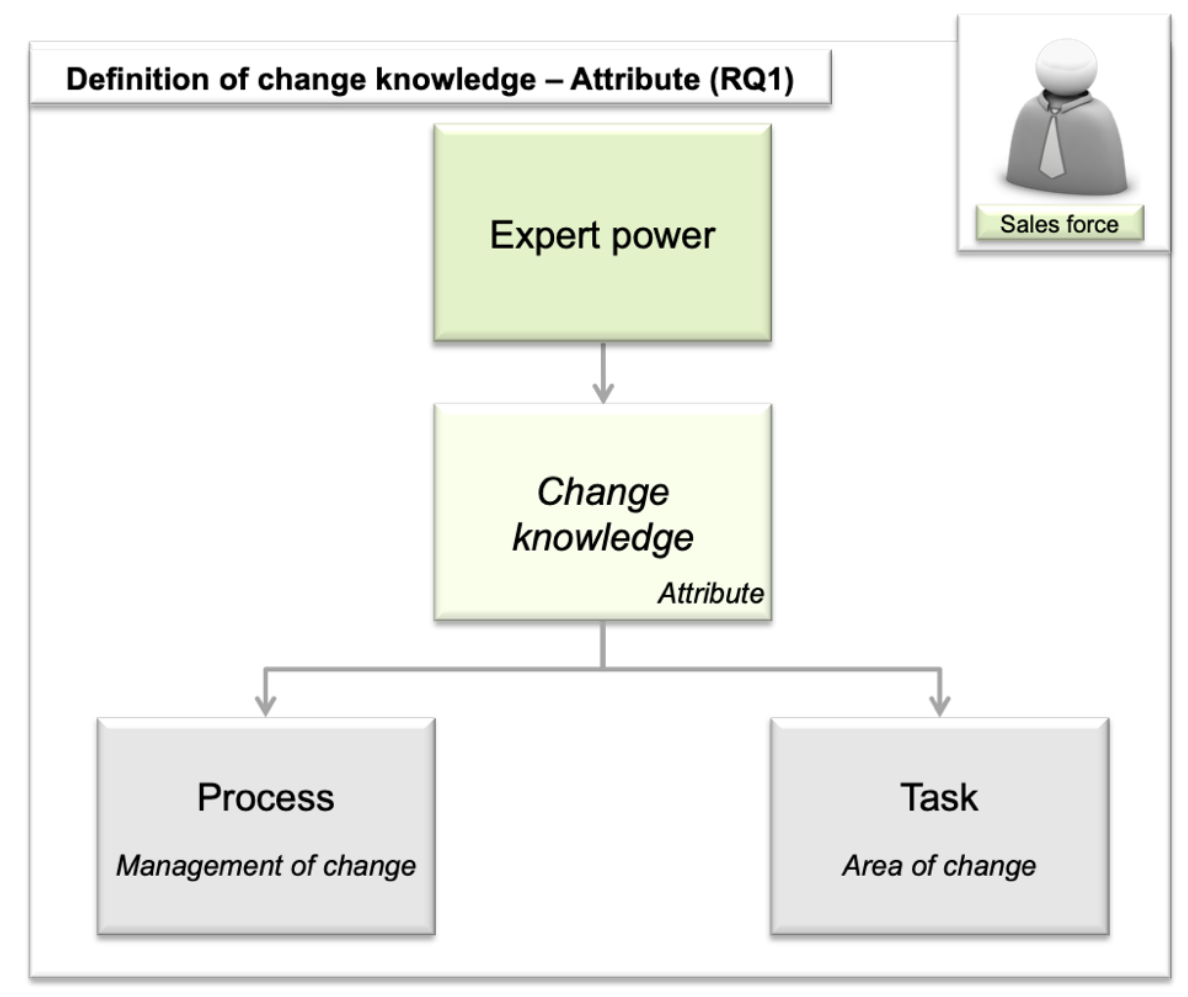

Figure 44: Definition of change knowledge - Attribute (RQ1)

Source: Developed for this research project based on Lines (2007)

Based on the findings of the research project and of Barnett White (2005) and Lines (2007), change knowledge is introduced as an additional attribute to define sales force expert power. Change knowledge is important and necessary for the sales force when the buying centre needs to decide on a complex and organisational solution for a first 
buy and the decision is emotionally difficult for the decision makers. The findings are considered to advance existing knowledge (Table 57).

\subsubsection{Research Question 2 - Formation}

Research Issue 2 - The more expert power the seller employs, the more trust and certainty the buyer receives for his buying decision.

The initial situation for the detailed discussion is the decision of the customer by investment in a new software (in this research project) to change the defined requirements and to improve existing processes. In the consideration is a first buy, which means that the software is newly acquired, and no supplier relationship already exists. The purchase and implementation of the software is subject to a certain complexity, which makes it necessary to set up a buying centre for the purchase decision. In addition, the creation of new software means a major change for the members of the buying centre in terms of work processes and learning new software. Findings have indicated that making such a decision is emotionally difficult for the employees who are directly affected by the implementation. The interviewees perceive the software conversion as an extensive change in their work processes, which can lead to fear of losing their work. Opportunities that come with a software conversion are not seen. A software conversion project thus offers the possibility of a competitive advantage and can be counted among the aforementioned change and improvement initiatives. Since it is a project and it has a defined end with a manageable term, subsequently two payroll programs run in parallel make little sense, it is more of a short-term than a long-term change. A software conversion project can thus be defined as a change project (Appelbaum et al., 2012). The change in size in relation to the scaling may not correlate very strongly with the perception of the change by each of the concerned (see also Figure 21). For example, a minor change in the organisation of work can be considered serious for those affected, for example if work and social relationships are equally affected (Lines, 2005). From a company's perspective, a software conversion project is not a large-scale change. From the HR department's point of view, it is already a drastic change when the payroll program is replaced. Whether it is a large-scale or small-scale change for the members of the buying center is very individual and depends profoundly on experience and previous knowledge. 
Each member has to make the assessment for himself, which of course has an impact on the personal decision frame and the preference (risk-averse vs. risk-taking).

Sales force expert power has a decisive influence on the purchasing decision based on the answers of the interviewees. However, the effect of expert power has its limits. Despite the use of sales force expert power, the buying centres have doubts about the sales force. These doubts arise when the sales force uses less adaptive selling and intensifies its sales orientation, and beyond that, when the sales force overburdens the members of the buying centre with too much information and clarification of details, resulting in an overload of expert power. The dilemma of the sales force is that the customer expects clarification of the open points. However, it is exactly this clarification that unsettles the employees and leads to a loss of confidence, which could end in the total rejection of the conversion project. The overload of sales force expert power leads to mistrust and uncertainty (Figure 45). This contradicts the findings in the literature (Busch \& Wilson, 1976; Taylor \& Woodside, 1982; Woodside \& Davenport Jr., 1974). The overload of expert power can make the members of the buying centre feel overwhelmed because they cannot process the mass of information. Without change knowledge, the conversion project would be considered a danger. Doubts would arise that can trigger anxiety. 


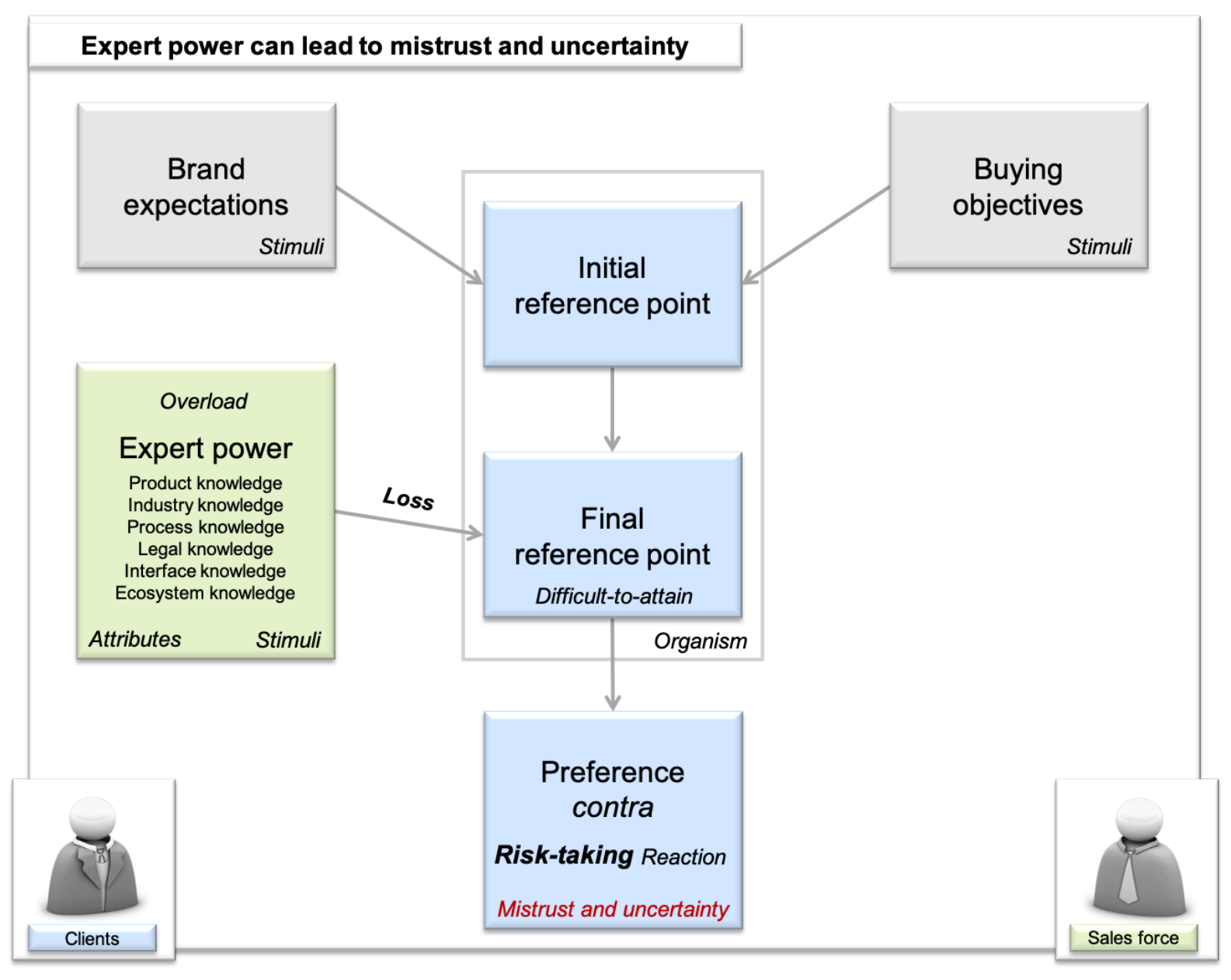

Figure 45: Expert power can lead to mustrust and uncertainty Source: Developed for this research based on (Puto, 1987)

In the definition of Puto (1987), the expert power and the arguments for it are perceived as losses in the sense that the employees can lose their position within the enterprise, as well as their process and application knowledge. This loss causes the final reference point to be perceived as difficult to attain. The reactions on the final reference point will be perceived as risk-taking. According to the employees, there is a risk to avoid. They are generally more risk-averse and will not vote for a project that requires courage and risk-taking. Buying centers, whose reference points indicate a negative decision frame, tend to make a risky purchase decision (Qualls \& Puto, 1989). The employees reject the change and decide against it. Their decision frame is set, and they will do everything based on their relative influence so that the buying centre decides against the solution and the supplier (Choffray \& Lilien, 1978; Corfman \& Lehmann, 1987; Foscht et al., 2017). The selling center will therefore not achieve any sales success, even though it has used sales force expert power. Sales force expert power consequently has a negative impact on the purchase decision and the overload of it leads to mistrust und uncertainty. 
The number of sales pitches was rated by all interviewees as adequate and appropriate for the situation. They felt able to make a purchase decision. If more were needed, more would have occurred. There was no limitation on the part of the sales force. The number of sales pitches varied depending on complexity, buying experiences, and experience with Alpha Software. However, a dependency is not recognisable. The findings do not follow the concept of Taylor and Woodside (1982), which states that the frequency of attempts by the sales force to establish expert power is positively related to purchasing. The frequency of attempts to establish expert power have a negative effect on sales success if expert power creates uncertainty and mistrust.

An overload of expert power can lead to mistrust and uncertainty. The findings are considered to advance existing knowledge (Table 58).

\section{Contribution to knowledge - Conclusions}

Research question 2: How do clients form their perceptions of sales force expert power?

Research Issues

Conclusions

2.

The more expert power the seller employs, the more trust and certainty the buyer receives for his buying decision.

5.

The perception of expert power in the first buy is ambivalent.

6.

The manner of behaviour of the sales

force alters the perception of expert power and thus the modes of action.

7.

The perception of expert power is important in early stages of the buying process but not in final stages.
An overload of expert power can lead to mistrust and uncertainty.

The perception of expert power is in the first buy important for the clients.

The manner of behaviour in form of adaptive selling alters the perception of sales force expert power and the position and power of the sales force is important for the buyer.

The perception of expert power is important in all stages. In early stages product knowledge is perceived more strongly while the perception of change knowledge in final stages predominates.
Coding frame Categories

Doubts

Decision

Change

Advance in existing knowledge

Importance

Decision

Addition to existing knowledge

Behaviour

Confirmation of

Doubts existing knowledge

Importance

Doubts

Attributes

Change
Contribution of this Research

Table 58: Conclusions and contributions to knowledge - Research Question 2

Source: Developed for this research project

Research Issue 5 - The perception of expert power in the first buy is ambivalent. 
Sales force expert power is highly important to the interviewees and thus supports the results of various studies by Crosby et al. (1990); Doney and Cannon (1997), Kohli (1989), and McFarland et al. (2006), among others. Without expert power, meaningful support in the purchase decision is not possible for them, especially in a first buy, which is consistent with Robinson et al. (1967). The interviewees agree with Sawhney (2006) that the customer processes and customer requirements must be understood so that the sales force can offer a solution. General information does not add value and is considered to be a waste of time (Paesbrugghe et al., 2017). The interviewees are interested in facts (Thull, 2012). The results support the findings of Crosby et al. (1990), as expert power is also crucial for the first buy, unlike Doney and Cannon (1997) claim. Delivery performance and a price/cost ratio are important to the clients, but expert power outweighs the crucial factor in the buying decision. The interviewees stated that the more complex the requirement, the more expert power becomes necessary and visible. The same applies to complex products or solutions. The statement sounds realistic and is logically comprehensible, but support for this cannot be located in the literature. The solutions offered by Alpha Software serve complicated issues in the companies due to the tax and social security law issues, and thus offer a good opportunity for the sales force to demonstrate expert power. The solutions are explanation intensive and for long-term use (Backhaus \& Voeth, 2014; Winkelmann, 2012). The interviewees did not provide a consistent picture as to what extent the importance of sales force expert power varies within the purchasing process. Overall, expert power is important throughout the entire purchasing process. Not all interviewed clients saw variations within the purchasing process. For the interviewees who noticed variations, it is clear that sales force expert power increases in importance in the initial phase, as well as towards the end, when the purchase decision is made. In the discovery phase, right at the first contact and initial conversations, according to Thull (2012), it is crucial to build trust in the sales force and the provider (Figure 46). Sales force expert power is essential for this (Weitz \& Bradford, 1999). The interviewees expect that the sales force will pose the right questions and provide satisfactory answers. This is not possible without sales force expert power (Bänsch, 2013). The findings of Mallalieu (2006) are supported, stating that, in the initial stages of a relationship, expert power is significant. One client views sales force expert power to be important even before the actual conversations. Initial information about websites and the way in which appointments are arranged, for example, are clear indicators of 
sales force expert power. The stronger links between marketing and sales as crossfunctional units have become increasingly important in the literature when it comes to managing complex customers and solutions and making the transition from marketing to sales seamless (Johnson et al., 2019). If the sales force and the products are better known, expert power loses its additional importance. The products and the associated features are more in the foreground. The explanation of Belonax et al. (2007) in this context is that the products and services must meet the customer's requirements and therefore have a greater influence on the purchase decision than the sales force expert power. The sales force expert power can certainly vary throughout the process. Not all topics and questions can be answered satisfactorily. However, what must never let up is the reliability of the sales force to clarify the open points in a timely and consistent manner (Stock \& Hoyer, 2005; Weitz \& Bradford, 1999). If the sales force does not act appropriately, the interviewees lose confidence in the sales force (Guenzi, Luca, \& Spiro, 2016). When the solution is designed and the purchase decision is made, sales force expert power seems to regain attention beyond the normal level (Figure 46).

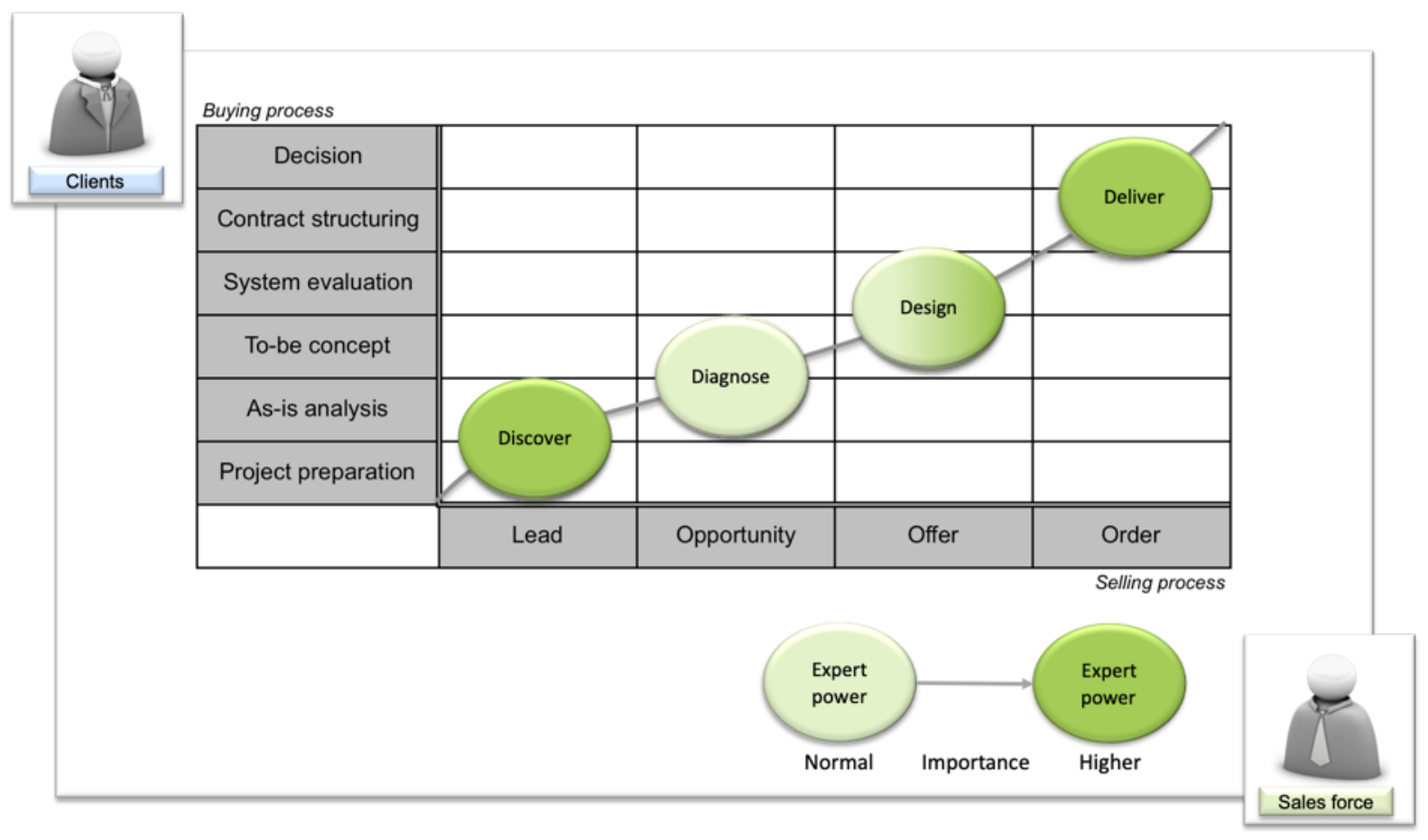

Figure 46: Distribution based on the importance of expert power in a first buy

Source: Developed for the research project based on Hufgard et al. (2005); Rackham (1995); Thull (2012); Vering (2007)

This is a crucial phase for the interviewees and the sales force. Any mistake or faulty behaviour can ruin previous efforts (Guenzi et al., 2016; Román \& lacobucci, 2009). In the design and deliver phases, according to Thull (2012), the interviewees gain process knowledge and knowledge about change when it comes to designing the 
solution according to the requirements and planning the possible implementation. Product knowledge seems to be less important than it was in the beginning of the buying process. The interviewees thus do not support the findings of Mallalieu (2006) in the consumer market, as expert power is also important for final-stage business customers. Figure 46 illustrates that expert power is important throughout the process for the task-oriented buying centres in a first buy. A different distribution of expert power throughout the process was not clearly indicated by the interviewees. As the importance of expert power varies, there is an increase in the beginning and the end of the process. Nevertheless, the perception of expert power is important to the customers in a first buy. Therefore, the present findings are considered to add to existing knowledge (Table 58).

Research Issue 6 - The manner of behaviour of the sales force alters the perception of expert power and thus the modes of action.

To make a purchase decision, according to the interviewees, four feelings are needed: esteem, trust, confidence, and certainty. The interviewees feel valued and appreciated when the sales force understands their problem and requirements and derives an individual solution for them (Conger, 1998; McKay \& Fanning, 2016; Sawhney, 2006). This requires that the sales force deals intensively with their customers (Thull, 2012). The interviewees want to trust that the sales force will act honestly and in their best interest (Mallalieu, 2006; Rotter, 1971). Following Doney and Cannon (1997), the interviewees need confidence that the software will be implemented successfully, and the daily business will not be affected. Moreover, the interviewees need, as described by Ulaga and Kohli (2018) the certainty that the solutions will improve the status quo, that their requirements will be met, and that the solutions will work in practice. In addition to the recommendations and experiences of others and a strong brand perception, sales force expert power is crucial to the purchase decision of the interviewees. Thus, sales force expert power acts directly on the four aforementioned feelings. According to the interviewees, expert power is transported and made visible by the behaviour of the sales force. It is important that the sales force individually addresses each member in a buying centre target group based on their personal knowledge and state of mind (McFarland et al., 2006; Saxe \& Weitz, 1982). The interviewees make decisions as far as possible in the group (Choffray \& Lilien, 1978; Corfman \& Lehmann, 1987). The opinion of the individual counts and, in the case of 
doubt, can not only delay a decision but can overturn it altogether (Neubauer, 1999). To positively influence behaviour, the interviewees follow the well-known concept of adaptive selling (Guenzi et al., 2016; Porter et al., 2003; Spiro \& Weitz, 1990). Regarding the point of criticism of Pettijohn et al. (2011) and Plouffe et al. (2009) that adaptive selling has no influence on the sales results, there are no findings to support this claim in the interviews. According to the interviewees, the sales force needs to have a positive attitude towards the customers and the desired solutions. A positive attitude changes the charisma (Koponen et al., 2019). An open mind enables new and creative solutions. Through empathy, the sales force can empathise with the customer and respond more sensitively to his or her needs (Kaski, Niemi, \& Pullins, 2018). A friendly, modest, and concentrated, but still clean-cut, appearance is perceived by the interviewees as pleasant. Honesty, coupled with helpfulness and sensitivity, demonstrates that the sales force has an interest in the customer and their needs (Borg \& Johnston, 2013; Lacoste, 2018). The interviewees expect the sales force to guide them through the decision-making process in a goal-oriented (Homburg \& Fargel, 2006) and decisive manner (Brown, 1990; Haas, 2009). Moderate pressure and being decisive are positive when it comes to making a decision (Brown, 1990; Haas, 2009). In the decision-making phase, a reasonable use of sales orientation does not negatively affect the perception of trust (Guenzi et al., 2016). They would like to be able to rely on the sales force at any time. According to the interviewees, to display competence, the sales force should ask many questions that focus on the essentials. Rather than simple question and answer sessions, the sales force should be able to lead consecutive conversations designed to create customer value to analyse and understand the objectives of the clients (Rackham, 1995; Shepherd et al., 2011). Listening and giving the client room to address and discuss his issues promotes appreciation and shows that he is the centre of attention. The sales force would do well to sit back in the talks and speak less (Rentz, Shepherd, Tashchian, Dabholkar, \& Ladd, 2002). If the sales force expresses him or herself, the language should be clear and binding (Koponen et al., 2019). The manner of behaviour in the form of adaptive selling alters the perception of sales force expert power. The concepts of Liu and Leach (2001) and Sahadev (2005) are confirmed by the findings.

The interviewees were convinced of Alpha Software's sales force capabilities and found their support to be highly valuable in making a purchase decision. Three of the 
ten interviewees had no doubt about the sales force and found the way they were led to a decision to be appropriate. One client had doubts about the product but not about the sales force. Interviewees who decided against Alpha Software were also positive about the sales force and made it clear that their decision did not depend on the skills of the sales force. Nevertheless, during the purchasing process, doubts arose regarding the sales force's expert power. Two clients expected that the sales force should make the product decision for them. Both products were similar in their designs and differed only minimally. The sales force rejected this and repeatedly encouraged the two clients to make the decision themselves. The claim of the sales force was that they advise the customer until he is in a position to meaningfully make the decision. The sales force, in this case, followed the concepts of Liu and Leach (2001) and Farrell and Schroder (1999), who saw a positive link between consulting activities by the sales force and sales success. This approach was not the right approach for the interviewees and rather led them to question the expert power of the sales force. Doubts arose that were related to the skills of the sales force: strong focus on the problem, being too detailed, information overload, and mental overload. The interviewees complained that the sales force was sometimes too focused on the issues and ignored the solution. The interviewees are primarily solution-oriented people who are more interested in a solution than in the problems. At times, they had the feeling that a solution was impossible because of the various problems. Those interviewed would like a solutionoriented sales force, as described by Sawhney (2006) and Schmitz and Eberhardt (2009). The focus on problems had a rather negative effect on the mood of employees, since the sales force focused too much on the problems and wanted to solve all questions during the sales pitches. However, according to the interviewees, this is not possible and does not make sense. Changing the software can mean a tremendous change for employees. Barnett White's (2005) statements are corroborated by the fact that customers prefer less expert power when making difficult decisions, as their focus on accuracy and detailing tends to create negative emotions and lead to uncertainty. It seems obvious that the sales force wants to eliminate any ambiguity it already sees in the sales process. Based on experience and expert power, the sales force knows how to resolve these ambiguities. It ignores the fact that this is counterproductive at times. The use of expert power is not helpful in these situations and leads rather to uncertainty to the rejection of the sales force. These findings show that more displayed expert power does not mean more confidence is automatically generated. On the 
contrary, the more expert power is used, the less likely a sales success will be. This contradicts the findings in the literature (Busch \& Wilson, 1976; Taylor \& Woodside, 1982; Woodside \& Davenport Jr., 1974). A clarification within the conversion project is sufficient for many topics, as long as they are not exclusion criteria (Neubauer, 1999). Another reason for doubts about the expert power of the sales force is when the sales force pushes itself to the fore and offers information, rather than asking questions to find out what is going on with the customer. The interviewers found it annoying when the sales force talked a lot about themselves and about things that were not relevant to the buying decision, such as unused products. This was highly unpleasant for the clients. Unnecessary and too much information leads, according to the interviewees, to excessive demands of the employees and endangers a sale's success. In these situations, the sales force moves away from customer orientation towards a sales orientation. The sale and distribution of undifferentiated information that has no real customer benefit and serves to put the sales force in a better light is more important. Of course, the sales force is still a long way from hard selling (Guenzi et al., 2016). Nonetheless, sales orientation and the overuse of expert power tends to make customers feel uncomfortable and degrade the perception of expert power. These results contrast with the results of Guenzi et al. (2016) and Mallalieu (2006), who assumed that sales orientation in the final stages of purchases would not have a major impact on the formation of trust. However, the interviewees are responsible for this sales orientation, which reduces trust in the sales force. Even more serious is the mental overload, which, according to the interviewees, is when the employees see no chance to complete their tasks. The difference from information overload is that in a mental overload, the employee is afraid that the expectations placed on him or her cannot be met because too many tasks need to be performed simultaneously (Vos \& Rupert, 2018; Weeks, Roberts, Chonko, \& Jones, 2004). This perception occurred among employees when the sales force did not pay enough attention to the change that a software implementation entailed (Hufgard et al., 2005; Neubauer, 1999; Vering, 2007). The interviewees wished the sales force would have been more sensitive and restrained. The employees in the buying centres have little or no experience with change, nor have they received training in change management. The difference between the expert power and the change between the sales force and the buying centre is high. The sales force interviewees were not often aware that customers had doubts about them. Direct addressing of the topics helped to solve them. The sales 
force then became aware and adapted their behaviour (Koponen et al., 2019). The uneven distribution of expert power in the direction of change between sales force and buying centre was responsible for the fact that the perception of sales force expert power had worsened (Clauss \& Bouncken, 2018; Nyaga et al., 2013). An adaptation of the behaviour of the sales force could, however, quickly improve the perception, for which the different distribution of expert power is also responsible. Therefore, adaptive selling also promotes the perception of sales force expert power in terms of the different distribution of expert power between the sales force and the buying centre.

The interviewees follow the concept of Liu and Leach (2001), as the position and influence and the associated position of power are important. Due to the requirements, the complexity can often not be mapped with standard solutions. Tailored and customised changes must be made in the standard solutions (Liu \& Leach, 2001). The customer is able to improve his position with his customers through customisation (Shepherd et al., 2011; Weitz \& Bradford, 1999). These changes are time consuming for the supplier. The importance that a customer has is not immediately apparent to everyone in the supplier company, according to the interviewees. Here, the interviewees need the influence and power of the sales force to sharpen their meaning in-house and speed up change processes (Homburg et al., 2016). The interviewees' perceptions of sales force expert power are increased by the sales force's position and influence in the supplier firm.

The manner of behaviour in form of adaptive selling alters the perception of sales force expert power and the position and power of the sales force is important for the buyer. The findings are considered to provide confirmation of existing knowledge (Table 58).

Research Issue 7 - The perception of expert power is important in early stages of the buying process but not in final stages.

A buying centre consisting of different functions of the company is set up to make an advantageous purchase decision for the company. This buying centre is characterised by task orientation, which means that the fulfilment of the task is in the foreground to make the most objective and factual decision possible. An attempt to counteract the influence of personal sensitivities and interests of the members of the buying centre is made through intensive communication and by making a group decision. Of course, 
the member of the buying centre cannot decide freely on organisational, commercial, and strategic constraints. The influence of each individual on the purchase decision, however, exists and is desirable. The individual employees of the buying centre have expert power in their respective fields. Expert power related to the new solution and its implementation is, of course, only rudimentary, since the supplier should also be commissioned with the setup and training of the user. An uneven distribution of expert power between the buying centre and the selling centre is therefore mandatory.

The buying centre faces the selling centre. It also consists of different people who perform different functions within the selling centre. The selling centre supports and guides the buying centre so that it can make a decision. The findings have shown that sales force expert power is essential in addition to a strong brand and recommendations from other companies for the buying decision of the buying centre. The prerequisite for this is that the solution offered by the selling centre basically meets the requirements of the buying centre and there are no exclusion criteria that make it impossible to use the solution. If this is the case, the influence of sales force expert power is obsolete, as the customer classifies the solution as more important than sales force expert power. The selling centre has extensive expert power in products, industries, legal, and processes. The findings have shown that today's sales force must also have interface knowledge and an adequate understanding of the customer's ecosystem.

Buying and selling centres interact ideally when they synchronise the buying and selling proces. Expert power works in the four stages (discover, diagnosis, design, deliver) of synchronised processes. To what extent the effect of expert power varies in the stages cannot be clearly explained by the findings. When a variation is recognisable, it is at the beginning and towards the end of the stages, where the perception of expert power increases.

Adaptive selling and solution selling have a positive influence on the perception of sales force expert power. The sales force tries to respond individually to the needs of each member of the buying centre. This is necessary because, as the findings have shown, the purchase decision is made largely as a group, and a single member can block and even overturn a decision. To what extent this really is the case has not been investigated. 

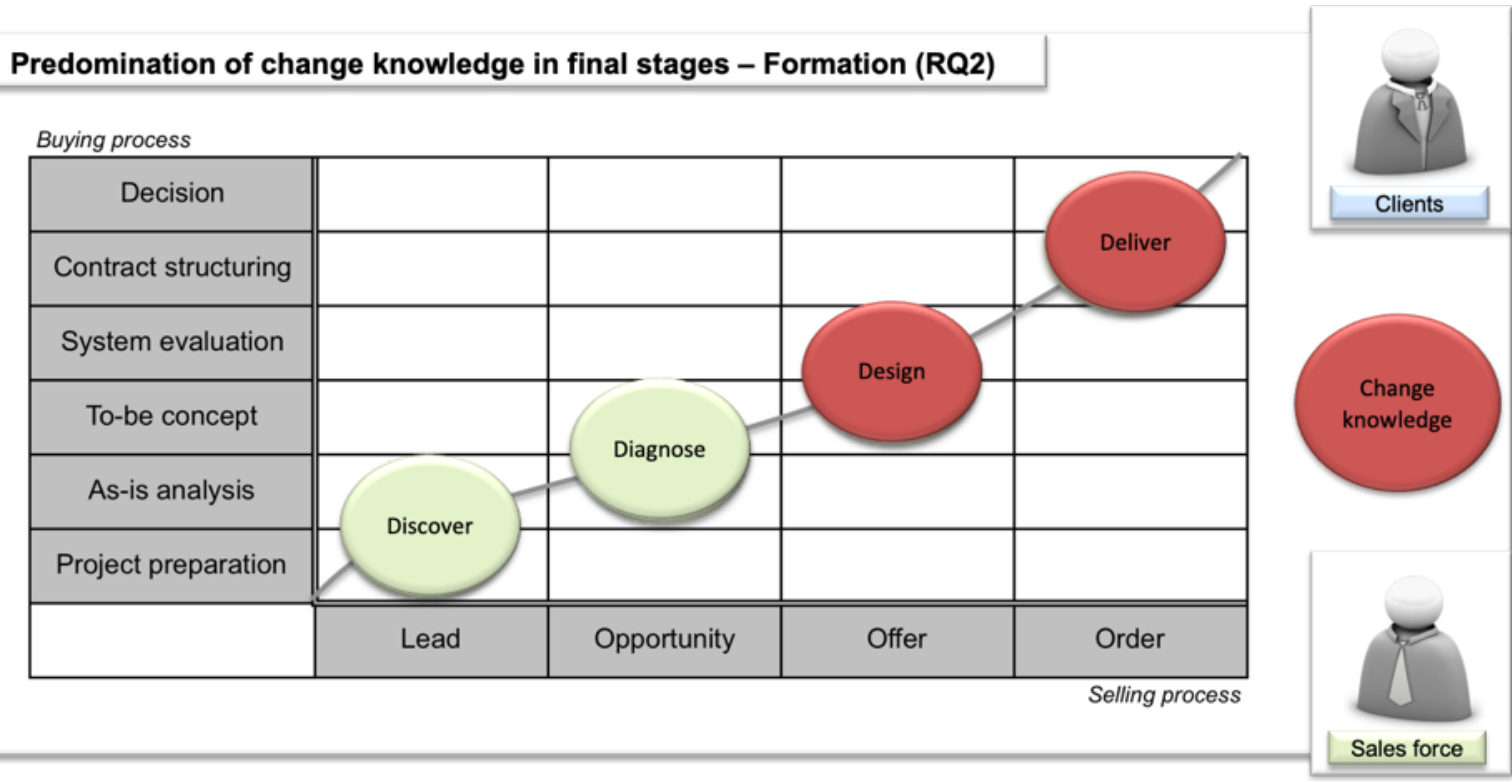

Figure 47: Predomination of change knowledge in final stages - Formation (RQ2)

Source: Developed for the research project based on Hufgard et al. (2005); Rackham (1995); Thull (2012); Vering (2007)

Important to the effectiveness of change knowledge is when the knowledge is used in the synchronised buying and selling process (Figure 47). The findings suggest that change knowledge predominates in the final stages. It works most effectively in the design and delivery process phases (Thull, 2012). In the design phase, the solution is worked out in collaboration with the customer. The design phase defines which components the solution should contain and how they will work together. Product knowledge and process know-how are decisive for this, according to the findings. As the members of the buying centre develop a true understanding of the solution at this stage, the danger of overburdening and uncertainty increases. Now, with sales knowledge, the sales force must influence and assure the customer that the solution is advantageous and that these advantages outweigh the disadvantages (Rackham, 1995; Schmitz \& Eberhardt, 2009). In the subsequent deliver stage, it is agreed upon how the solution will be implemented (Vering, 2007). This implies a certain risk potential for excessive demands and uncertainties. Here, the sales force must behave similarly to the previous stage to appease the customer. According to the findings, process knowledge and change knowledge outweigh product knowledge in the design and deliver stages. Product knowledge is of greater importance in the early stages of the synchronised buying and selling process. The interviewees thus do not support the findings of Mallalieu (2006) in the consumer market, as expert power is also important for final-stage business customers. The perception of expert power is important in all 
stages. In early stages product knowledge is perceived more strongly while the perception of change knowledge in final stages predominates. The findings are considered to advance existing knowledge (Table 58).

\subsubsection{Research Question 3 - Factors}

Research Issue 3 - The perception of expert power of supportive and task-oriented buying centres is based primarily on information exchange and recommendations.

Seven out of ten interviewees stated that they pursue long-term interests when making a purchase decision. The selection of a new partner is time consuming and binds different internal resources (Garrido-Samaniego \& Gutiérrez-Cillán, 2004; Lewin \& Donthu, 2005). It is as an investment in the future. If the selection is wrong, the procedure must be repeated (Ulaga \& Kohli, 2018). From the perspective of the interviewees, they must be able to rely on the partner (Guenzi et al., 2016; Saxe \& Weitz, 1982). A permanent accompaniment must be ensured. The integration into the IT landscape has to succeed, and the advantage of the new solution must be visible and tangible for all concerned (Schmitz \& Eberhardt, 2009; Tuli et al., 2007). In the course of a business relationship, requirements change; for example, business areas can grow. It is important for the interviewees that the solution can grow in a modular way (Ahmad, Mittal, West, \& Wuest, 2018), that the software or solution is evolving (Sawhney, 2006), and that the road map for further development is traceable and transparent. In addition, there are new trends in the market, such as the push for digitisation (Seufert \& Suhren, 2016). According to the interviewees, the partners must stay up-to-date and incorporate new trends into their solutions. They must set new goals only then can they offer added value in the long run (Paesbrugghe et al., 2017). Sale force expert power is important for the decision of a new partner (Kohli, 1989).

Since the interviewees are in the supportive stage with their buying centres, it is clear that strategic issues, i.e. how the supplier's solutions will evolve in perspective and how future trends will be integrated into solutions, are important for the purchasing decision. Paesbrugghe et al. (2017), however, did not integrate the strategic issues into their concept of the buying centre in a supportive stage. The focus is rather on strategy when buying centres are in the integrative stage. The task orientation of the buying centres implies that information exchange and recommendations are used primarily by the sellers. The findings support the approach of McFarland et al. (2006). 
However, they also indicate that the strategic issues are important to the purchase decision, so the exchange of information should be extended by strategic issues.

The interviewees' statements can be grouped into four areas: recommendations about the sales force, recommendations from others, the content of the recommendations, and the impact of the recommendations. The interviewees stated that they did not receive recommendations that directly related to the sales force. Only one client mentioned that he heard positive feedback about Alpha Software employees. This, however, did not specifically refer to the sales force and is considered to be a rather general statement. Even if the interviewees had received recommendations about the sales force, this would not have had any influence. The interviewees either did not receive any recommendations about the sales force or did not consider them to be relevant to their decisions, so the statements of Busch and Wilson (1976) are not supported. Recommendations given by industry peers or friendly companies regarding Alpha Software were especially valuable to interviewees who did not have any personal experience with Alpha Software (Anderson \& Weitz, 1989). The substantive recommendations given by the sales force focused on improvement within the payroll process and the upstream and downstream systems. In addition, there were tips and recommendations for improving the distribution of tasks among employees and for general organisational changes within the department. Other recommendations that were welcomed by the interviewees related to the state of staff training and various training contents (Sirdeshmukh et al., 2002; Szymanski, 1988). For the interviewees who chose Alpha Software, the recommendations were quite helpful in the purchase decision process. Once the decision to replace the existing solution has been made and the requirements for a new solution have been defined, market research begins, in which a limited number of suppliers (up to five suppliers in this case) are shortlisted to enter exploratory talks (Choffray \& Lilien, 1978). Decisive for the shortlisting are existing experiences and the respective brand of the supplier for which they stand and are known. After the exploratory talks, a further restriction is made to one to three alternative suppliers (Choffray \& Lilien, 1978). These remaining suppliers design possible solutions so that a concrete offer can be submitted for a decision. A clear recommendation is prepared for the management by the buying centres so that a final decision can be made based on their relative influence (Corfman \& Lehmann, 1987; Juha \& Pentti, 2008; Lau, Razzaque, \& Ong, 2003). For the interviewees who opted 
for another provider, the recommendations had no influence. Both clients based their decisions on other factors. Recommendations from other companies and the sales force had a positive effect on the purchase decision (McFarland et al., 2006). Recommendations related to the sales force either did not exist or were of no importance to the purchase decision.

Information exchange (extended by strategic issues) and recommendation are important. The findings are considered to add to existing knowledge (Table 59).

\section{Contribution to knowledge - Conclusions}

Research question 3: Which factors affect the formation of clients' perceptions of sales force expert power?

\begin{tabular}{|l|l|c|c|}
\hline Research Issues & Conclusions & $\begin{array}{c}\text { Coding frame - } \\
\text { Categories }\end{array}$ & $\begin{array}{c}\text { Contribution of } \\
\text { this Research }\end{array}$
\end{tabular}

3.

The perception of expert power of supportive and task-oriented buying centres is based primarily on information exchange and recommendations.

4.

The perception of expert power is lower when buyers have high brand expectations.

8.

The perception of expert power is lower in extremely important and highly emotionally difficult purchases.

9.

The intensity of expert power within the buying centre has a high impact on the perception of sales force expert power.
Information exchange (extended by strategic issues) and recommendation are important.

The results show that the perception of expert power is always high regardless of the brand expectations.

The perception of expert power is lower in highly important purchases in contrary to the product and service.

The perception of expert power alters due to the intensity of change and how the change is perceived. Business customers, unlike consumers, expect a professional approach to change rather than benevolence.

The intensity of expert power within the buying centre has a high impact on the perception of sales force expert power. The perception can be improved by targeted impact on the shortcomings in the buying centre.

Importance

Recommendations

Strategy

Decision

Brand

Importance

Change

Decision

Change

Decision

Doubts

Change

Recommendations

Strategy
Addition to existing knowledge

Addition to existing knowledge

Confirmation of existing knowledge

Advance in existing knowledge

Table 59: Conclusions and contributions to knowledge - Research Question 3

Source: Developed for this research project

Research Issue 4 - The perception of expert power is lower when buyers have high brand expectations. 
In addition to expert power, the brand and what everyone associates with it played an important role in the buying decision for nine out of ten interviewees. Alpha Software has a distinctive position as the key player in the industry. When selecting new software, Alpha Software was quickly shortlisted among the interviewees due to its market position and industry experience (Vakratsas \& Ambler, 1999). In addition, Alpha Software has a relatively large number of users, such that the experience in terms of the software in practice is comprehensive. The Alpha Software brand has a considerable market reach, is well known for innovations, and embodies decades of experience. According to Lin (2015), these are innovative brand experiences that have a positive impact on brand equity and brand satisfaction, which in turn means that customers can perceive a brand positively even if they themselves have not had any direct experience with the brand. The use of Alpha Software in practice has been proven and documented by a wide range of customer testimonials (Delvecchio et al., 2004; Marcos Cuevas, 2018). Although some of the interviewees had not themselves had any personal experience with the brand, the perception of the brand was crucial to their purchase decision. Educated clients referred to experiences that industry peers or similar users have gathered (Japutra \& Molinillo, 2019). One client even went a step further with his remarks to states that the sales force not only represents the company but also embodies the brand. Similar to the concepts of Gelb \& Rangarajan (2014) and Xiong, King, and Piehler (2013), in which each employee acts as a brand ambassador to strengthen brand equity, Hughes and Ahearne (2010) have found that there is a positive link between brand identification and sales performance when the installed control systems (e.g. incentive programs, commissions) support brand activities.

Brand perception certainly has its limits if the software is not shortlisted due to certain KO criteria. Even positive experiences with a supplier cannot reverse this situation (Garrido-Samaniego \& Gutiérrez-Cillán, 2004). The integration into the existing IT landscape was given a higher rating by one client than the market perception of the brand and the associated advantages (Schmitz \& Eberhardt, 2009; Tuli et al., 2007). Despite having had personal experience with the software, one client decided against Alpha Software due to the usability and overall appearance of the software. In the end, it is crucial for the interviewees that the requirements are fulfilled on the analogy with Ahlert et al. (2008) and Woisetschläger et al. (2009). 
The findings reveal that expert power is of great importance to those interviewed. At the same time, the brand plays an important role in the purchasing decision, which implies that the sales force interacts with brand perception through its appearance, such that it positively supports the brand and, in turn, colours the brand positively on the sales force and its activities (Brown, Zablah, Bellenger, \& Donthu, 2012). Thus, the concept of Sharma (1990) is not supported. The results indicate that the perception of expert power is always high, regardless of the brand expectations. If the sales force behaves in accordance with the brand, the perception of the brand will be strengthened, which has a positive effect on the perception of sales force expert power when the purchase has a certain complexity and is important to the buyer's organisation (Brown et al., 2012). The results show that the perception of expert power is always high regardless of the brand expectations. The findings are considered to add to existing knowledge (Table 59).

Research Issue 8 - The perception of expert power is lower in extremely important and highly emotionally difficult purchases.

In two cases, the expectation was that the product decision would be made by the sales force. Purchasing or product decisions being made by the sales force in the purchasing process is unusual, and comparable instructions were not found in the literature. To what extent the sales force should make a decision should deviate in individual cases. Both customers who had the expectation that they would make the decision were upset. Thanks to the skills of the sales force and the application of the SPIN method, the customers could be satisfied again (Rackham, 1995). Making a decision for the client carries risks that the client would not be satisfied with the decision, which could jeopardize the implementation of the solution.

It is striking that the interviewees made their purchase decisions as a group within the buying centres. The interviewees created buying centres based on the concepts of Webster and Wind (1972) for selecting the right suppliers. The buying centres are made up of the various people involved, who have different functions within the company and whose skills improve the quality of the decision. Essentially all buying centre members had to stand behind the decision. The reason for this is that the decision to buy new software is far-reaching and it is necessary to consider the personal consequences for each individual. The decision thus has a particular 
importance for the buying centre and requires an intensive exchange to select the most suitable supplier. Thus, the interviewees support the concept of Choffray \& Lilien (1978). The sales force works with their expert power on the decision frame of each member, so that a preference is formed (Puto, 1987). Each member forms his or her own personal preference within the buying centre and brings this into the discussions. One client even went so far as to say that the purchase decision would be postponed or not carried out if not all participants were convinced of the solution. This comes with the risk that the recontinued search for a new supplier binds resources and leads to a double burden in daily work. To what extent each employee can really be motivated by his executives to make a free and, in the case of doubt, contrary decision must certainly be questioned (Comelli \& Rosenstiel, 2009). Organisational constraints and time pressures can lead employees to decide, even when they would not have decided under other circumstances (Webster \& Wind, 1972). Not every employee outlines the scope of his decision and prefers to associate with the organisation, rather than messing with it (Corfman \& Lehmann, 1987; Wiswede, 2007). Software implementation fails if the participating employees are not convinced that the new solution would add value to the organisation (Vering, 2007). The basis for a purchase decision was, for the interviewees, that the solution fit and the requirements were met according to Kohli (1989), Liu and Comer (2007), and Sawhney (2006). The sales force assisted with the purchase decision and provided all necessary information for an informed decision. In addition to the brand and recommendations and experiences of others, sales force expert power most clearly influences the decision of the buying centre when the solution is principally right. This means that the solution does not have obvious exclusion criteria that make a launch impossible or that mean essential functions that are needed by the customers are not covered. If this is the case, neither sales force expert power nor a strong brand or recommendations will help. The interviewees accordingly follow Belonax et al. (2007), who rated the product and service more highly than the expert power of a sales force in important purchases. Therefore, the perception of expert power is lower in highly important purchases in contrary to the product and service. The findings are considered to provide confirmation of existing knowledge (Table 59).

A software change poses a special challenge for the interviewees. The particular challenge is that the day-to-day business, in addition to the changeover, must 
commence, and a new, unknown software has to be integrated. Content and processes must be defined and maintained. The new software has to be learned. Interfaces to other systems must be built, tested, and released. For the employees, the existing day-to-day business is already time consuming, and, for the most part, no further resources exist. Additional resources were only approved during the conversion period for interviewees in the form of external consultants. The employees are expected to do the actual work. They all need to master the transition with their existing resources.

The interviewees follow the approach of Barnett White (2005), as they tend to trust suppliers who are trying to minimise their negative decision-related emotions in an emotionally difficult decision, which is the case here. Barnett White (2005) refers primarily to the consumer behaviour in her statements. However, the results can be transferred to organisational buying behaviour. However, business customers, unlike consumers, do not favour benevolence in the aforementioned situations; they expect a professional approach to change. The perception of sales force expert power is lower in highly emotionally important purchases due to the overload of information and the resulting loss of trust and uncertainty. 


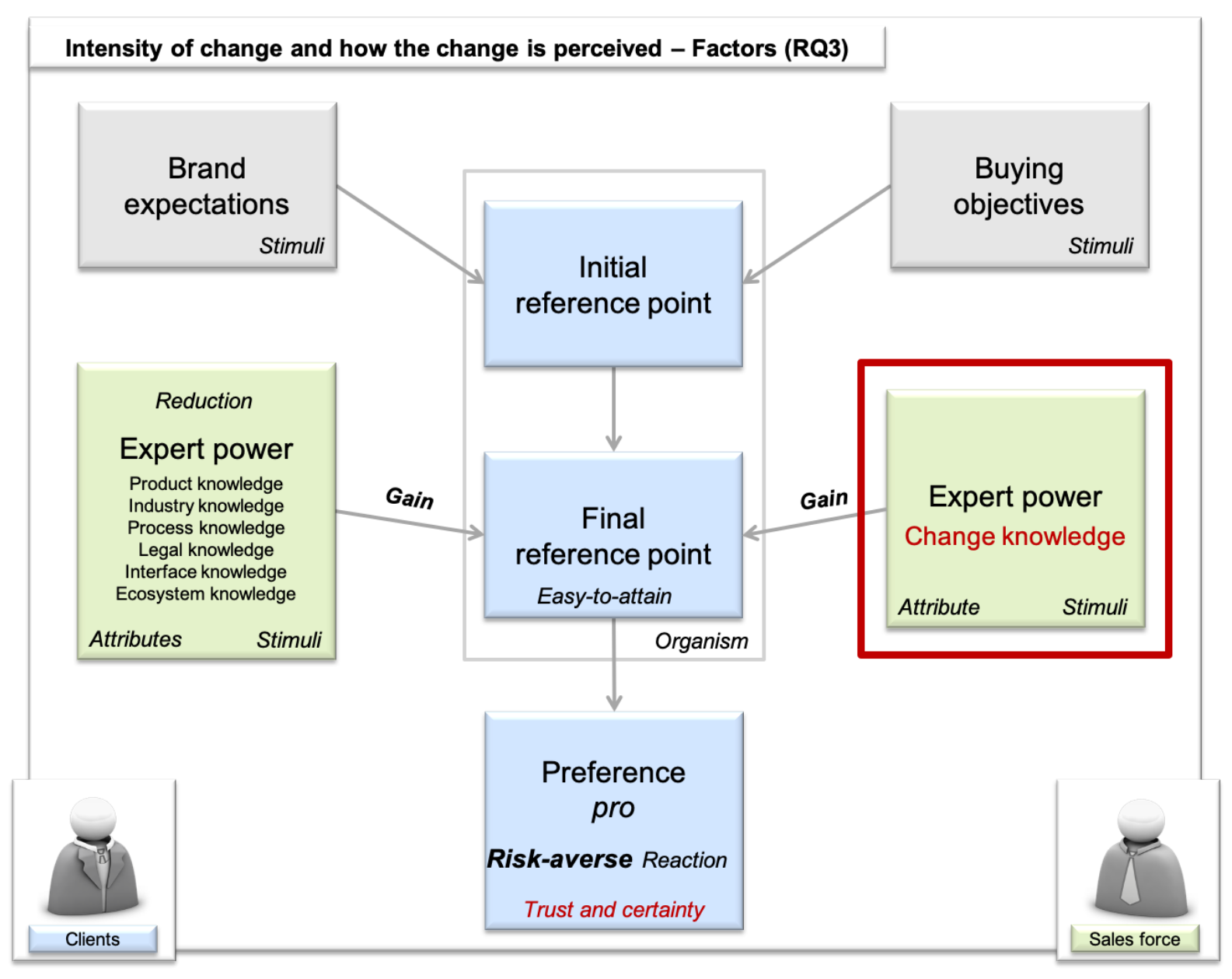

Figure 48: The intensity of change and how the change is perceived - Factors (RQ3) Source: Developed for the research project based on Puto (1987)

The interviewees are far from risky people. Doubts and uncertainty are often common, which are visible in the sales pitches. Overworked employees are not able to handle their day-to-day business and a conversion project at the same time (Weeks et al., 2004). Excessive demand is also visible to employees through resistance, either open or hidden (loannidis, Varsakelis, \& Antoniou, 2019). Not everyone wants to change the way they work (Vos \& Rupert, 2018). Employees use their doubts and uncertainties to attract other employees and oppose change (Wynn, 2019). Resistance of employees can delay projects massively or even lead to their failure (Pascale \& Sternin, 2005).

Figure 47 illustrates in which process steps the change should be discussed by the sales force so that the five components of the change project (chance, doubts, uncertainty, overextension, and resistance) cited by the customers are either intensified (chance) or contained in an early stage. The fact that a sales force, such as a change agent, should act in certain situations to improve the perception of expert power is currently not considered in the literature, so the findings are considered to 
advance existing knowledge. In situations in which buying decisions result in significant change for the buying centre, expert power can lead to mistrust and uncertainty. Therefore, change is an essential factor influencing the formation of sales force expert power. In contrast to Barnett White (2005), business customers expect a salesperson with expert power, also in terms of the issues that a change entails, as compared to consumers, who instead prefer a benevolent salesman.

With change knowledge, the expert power is perceived as a gain. The buying centre realises the advantages that the new solution holds. The working methods and work results will be improved, and there is no reason for them to decide against the solution. From the HR department's point of view, it is already a drastic change when the payroll program is replaced. Whether it is a large-scale or small-scale change for the members of the buying center is very individual and depends profoundly on experience and previous knowledge. Each member has to make the assessment for himself/ herself, which of course has an impact on the personal decision frame and the preference (riskaverse vs. risk-taking). Human behaviour must be considered when dealing with longterm and short-term changes (Al-Haddad \& Kotnour, 2015). The perception and the intensity of the changes have a significant influence on the behaviour of the concerned employees and regarding to this research project on the buying centre and the individual decision frames of each member of the buying centre (Figure 48). Change knowledge as an attribute of sales force expert power creates trust and gives the members of the buying center the certainty that the selected supplier deals most responsibly and purposefully with the expected change. The final reference is perceived as easy to attain. The reaction of the members of the buying centre will turn out to be risk-averse, which is closest to theit personality when considering the interviewees' answers. Their decision frame is also set, this time in the other direction, and the members will do everything based on their relative influence to convince the buying centre to decide on the solution and the supplier (Choffray \& Lilien, 1978; Corfman \& Lehmann, 1987; Foscht et al., 2017). For this consideration, it is irrelevant whether the initial reference point was low or high. Expert power with change knowledge transforms both a low and a high initial reference point into a high final reference point. Expert power without change knowledge does the opposite. Buying centres who frame the alternatives as gains tend to choose the certain (safe) alternative and buying centres who frame the alternatives as losses tend to choose the 
risky (probabilistic) alternative (Qualls \& Puto, 1989). The perception of expert power alters due to the intensity of change and how the change is perceived. Business customers, unlike consumers, expect a professional approach to change rather than benevolence. The second findings of research issue 8 are considered to advance existing knowledge (Table 59).

Research Issue 9 - The intensity of expert power within the buying centre has a high impact on the perception of sales force expert power.

The interviewees thus follow the concept of McFarland et al. (2006), who viewed recommendations as an important aspect when working with task-oriented buying centres. Existing knowledge plays a key role in learning, because learning new knowledge (e.g. about a product or service) is only possible if it is related to the knowledge that is already stored (e.g. recommendations) (Foscht et al., 2017; KroeberRiel et al., 2013). Therefore, the statement of Clauss \& Bouncken (2018) that if buyers lack expert power, then the sales force does not pass on any important information is not supported. There are no indications in the findings of this research. The recommendations make the expert power of the sales force tangible and demonstrate that the sales force understands their job, even beyond the products (Sahadev, 2005). The sales force is perceived as a source of inspiration and a good partner for day-today business (Paesbrugghe et al., 2017). Customers and sales force are on an equal footing (Sirdeshmukh et al., 2002; Szymanski, 1988). This distinguishes Alpha Software's sales force from its competitors. The findings support the concepts of Chinomona and Pretorius (2011) and Nyaga et al. (2013) that customers who have certain shortcomings and resulting power asymmetry with regard to expert power consciously use the expert power of the sales force to improve their processes or compensate for their shortcomings. The result is that the intensity of expert power within the buying centre has a significant impact on the perception of sales force expert power. This perception can be improved through targeted impact on the shortcomings. The intensity of expert power within the buying centre has a high impact on the perception of sales force expert power. The perception can be improved by targeted impact on the shortcomings in the buying centre. The findings are considered to provide confirmation of existing knowledge (Table 59). 


\subsection{Theoretical Implications}

The theoretical implications form the basis for managerial implications to derive an approach by which sales forces can consciously manage and enhance client's perceptions of sales force expert power. The theoretical implications are built on the advances in existing knowledge. For this purpose, the advances of existing knowledge are separated from the other contributions of this research and the results are summarised below.

The results of this study highlight the change issues that a buying centre must tackle and overcome to make a collective buying decision when it comes to an initial purchase characterised by a particular importance and an emotionally difficult decision. Change knowledge as an attribute is added to the attributes of sales force expert power. It additionally shows where in the process the change knowledge finds the most application and how it affects the decision frame of each member in the buying centre. Table 60 summarises the essential contributions which are considered to advance existing knowledge for each research question. The essential contributions are discussed in greater detail below. 
Research question 1: What are the attributes of clients' perceptions of sales force expert power?

\begin{tabular}{|c|c|c|c|}
\hline Research Issues & Conclusions & $\begin{array}{c}\text { Coding frame - } \\
\text { Categories }\end{array}$ & $\begin{array}{c}\text { Contribution of } \\
\text { this Research }\end{array}$ \\
\hline $\begin{array}{c}1 . \\
\begin{array}{c}\text { The understanding of } \\
\text { the attributes of sales } \\
\text { force expert power is not } \\
\text { explicit. }\end{array}\end{array} \quad$ Change knowledge & $\begin{array}{c}\text { Doubts } \\
\text { Change } \\
\text { Behaviour }\end{array}$ & $\begin{array}{c}\text { Advance in } \\
\text { existing knowledge }\end{array}$ \\
\hline
\end{tabular}

Research question 2: How do clients form their perceptions of sales force expert power?

\begin{tabular}{|c|c|c|c|}
\hline Research Issues & Conclusions & $\begin{array}{l}\text { Coding frame - } \\
\text { Categories }\end{array}$ & $\begin{array}{l}\text { Contribution of } \\
\text { this Research }\end{array}$ \\
\hline $\begin{array}{l}2 . \\
\text { The more expert power } \\
\text { the seller employs, the } \\
\text { more trust and certainty } \\
\text { the buyer receives for } \\
\text { his buying decision. }\end{array}$ & $\begin{array}{l}\text { An overload of expert power can } \\
\text { lead to mistrust and uncertainty. }\end{array}$ & $\begin{array}{l}\text { Doubts } \\
\text { Decision } \\
\text { Change }\end{array}$ & $\begin{array}{l}\text { Advance in } \\
\text { existing knowledge }\end{array}$ \\
\hline $\begin{array}{l}7 . \\
\text { The perception of expert } \\
\text { power is important in } \\
\text { early stages of the } \\
\text { buying process but not } \\
\text { in final stages. }\end{array}$ & $\begin{array}{l}\text { The perception of expert power is } \\
\text { important in all stages. In early } \\
\text { stages product knowledge is } \\
\text { perceived more strongly while the } \\
\text { perception of change knowledge } \\
\text { in final stages predominates. }\end{array}$ & $\begin{array}{l}\text { Importance } \\
\text { Doubts } \\
\text { Attributes } \\
\text { Change }\end{array}$ & $\begin{array}{c}\text { Advance in } \\
\text { existing knowledge }\end{array}$ \\
\hline
\end{tabular}

Research question 3: Which factors affect the formation of clients' perceptions of sales force expert power?

\begin{tabular}{|c|c|c|c|}
\hline Research Issues & Conclusions & $\begin{array}{c}\text { Coding frame - } \\
\text { Categories }\end{array}$ & $\begin{array}{c}\text { Contribution of } \\
\text { this Research }\end{array}$ \\
\hline $\begin{array}{c}\text { 8. } \\
\begin{array}{c}\text { The perception of expert } \\
\text { power is lower in } \\
\text { extremely important and } \\
\text { highly emotionally } \\
\text { difficult purchases. }\end{array}\end{array}$ & $\begin{array}{c}\text { The perception of expert power } \\
\text { alters due to the intensity of } \\
\text { change and how the change is } \\
\text { perceived. Business customers, } \\
\text { unlike consumers, expect a } \\
\text { professional approach to change } \\
\text { rather than benevolence. }\end{array}$ & $\begin{array}{c}\text { Change } \\
\text { Decision } \\
\text { Doubts }\end{array}$ & $\begin{array}{c}\text { Advance in } \\
\text { existing knowledge }\end{array}$ \\
\hline
\end{tabular}

Table 60: Contribution to knowledge - Advance in existing knowledge Source: Developed for this research

The initial situation for the detailed discussion is the decision of the customer by investment in a new software (in this research project) to change the defined requirements and to improve existing processes. In the consideration is a first buy, which means that the software is newly acquired, and no supplier relationship already exists. The purchase and implementation of the software is subject to a certain complexity, which makes it necessary to set up a buying centre for the purchase decision. In addition, the creation of new software means a major change for the members of the buying centre in terms of work processes and learning new software. Findings have indicated that making such a decision is emotionally difficult for the employees who are directly affected by the implementation. The interviewees perceive 
the software conversion as an extensive change in their work processes, which can lead to fear of losing their work. Opportunities that come with a software conversion are not seen. A software conversion project thus offers the possibility of a competitive advantage and can be counted among the aforementioned change and improvement initiatives. Since it is a project and it has a defined end with a manageable term, subsequently two payroll programs run in parallel make little sense, it is more of a short-term than a long-term change. A software conversion project can thus be defined as a change project (Appelbaum et al., 2012). The change in size in relation to the scaling may not correlate very strongly with the perception of the change by each of the concerned (see also Figure 21). For example, a minor change in the organisation of work can be considered serious for those affected, for example if work and social relationships are equally affected (Lines, 2005). From a company's perspective, a software conversion project is not a large-scale change. From the HR department's point of view, it is already a drastic change when the payroll program is replaced. Whether it is a large-scale or small-scale change for the members of the buying center is very individual and depends profoundly on experience and previous knowledge. Each member has to make the assessment for himself/herself, which of course has an impact on the personal decision frame and the preference (risk-averse vs. risk-taking). 


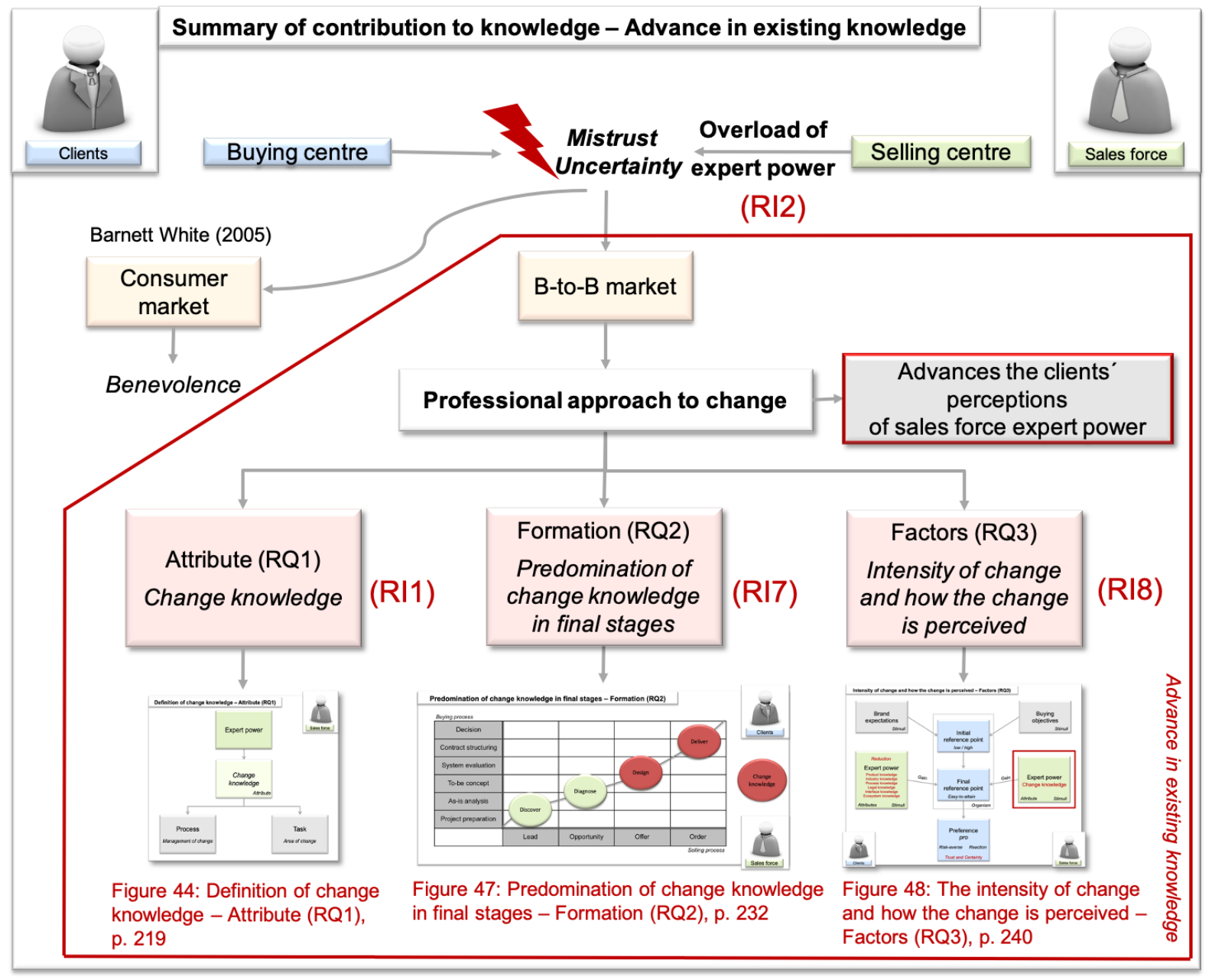

Figure 49: Summary of contribution to knowledge - Advance in existing knowledge Source: Developed for this research project

An overload of sales force expert power can lead to mistrust and uncertainty (Figure 49). The perception of sales force expert power is important in all stages of the buying process. In early stages product knowledge is perceived more strongly while the perception of change knowledge in final stages predominates. Information exchange and recommendations lose their impact due to an unprofessional approach to change which minimises the perception of sales force expert power significantly. Due to the intensity of change and how the change is perceived the perception of sales force expert power alters. Business customers, unlike consumers, expect a professional approach to change rather than benevolence. The interviewed clients perceive the software conversion project as a change project and expect the sales force to be approached and addressed accordingly. Change knowledge is an important attribute for sales force expert power, which can advance the clients'perceptions of sales force expert power. 
The findings reveal that a more intensive examination of sales force expert power has yielded new and meaningful insights for the sales force, which are examined more intensively in the next chapter on practical application.

\subsection{Managerial Implications}

The results indicate that, even today, there are additional methods available for the sales managers, salesmen, and trainers of Alpha Software to improve the sales and training of the sales team. The perception of sales force expert power can be purposefully improved to sustainably secure sales success. Sales force expert power continues to be decisive for sales success, in addition to brand perception and recommendations. The prerequisite for this is that the solutions are suitable for the customer without any exclusion criteria and the buying centre has an interest in longterm and customised solutions. Furthermore, a focus of the sales team training should be on conveying product knowledge, process knowledge, industry knowledge, and legal knowledge. This also applies to solution selling and adaptive selling, as well as the application of the sales methods SPIN and Prime (Rackham, 1995; Thull, 2012). Each member in the buying centre is important and should be addressed individually, as the findings have revealed that the customers are seeking and favouring a group decision. These requirements are the basis for further considerations. Only if these requirements are sufficiently fulfilled are the results of the study to be taken over into leading, control, and training of the sales team. 


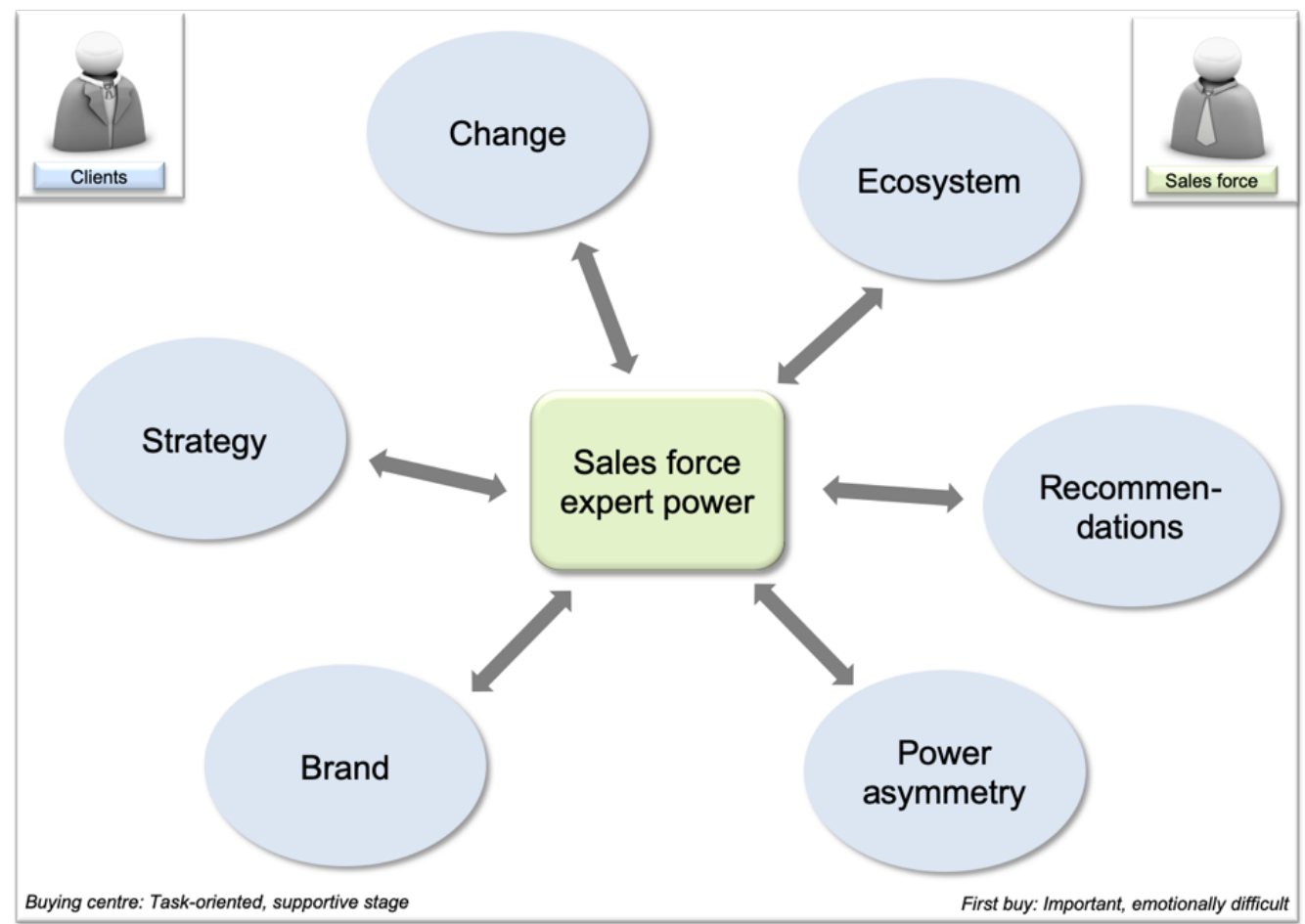

Figure 50: Levers on the perception of sales force expert power

Source: Developed for this research project

Through the application and implementation of the following levers (Figure 50), the members of the sales force are enabled to influence, in a targeted manner, the final reference point of each member in the buying centre through their expert power to achieve a risk-averse and easy-to-attain final reference point to influence the decision in their favour (Puto, 1987).

\section{Power Asymmetry}

The presence of power asymmetry in terms of expert power between buying and selling centres is the basis for subsequent approaches to improve the impact and perception of expert power. The presence of power asymmetry in product knowledge is most likely because no customer will know the product or solution better than the seller itself. Through process knowledge and legal knowledge, the sales force acts on an equal footing with the customer. If this is supplemented by ecosystem knowledge, the sales force is perceived as a cross-solution and balances the power asymmetry in its favour. However, the power asymmetry in the other direction with regard to the project approach and the mentioned change must be compensated actively by the sales force for the purpose of the buying centre. The results have shown that, even if project experience is available, the implementation of a project is not one of the core tasks of the employees in the buying centre. The same applies to the change. 
Certainly, the members of the buying centre have experienced various changes during their working life, but that does not mean that they can handle it professionally. The core tasks of the employees in the buying centre vary, and the sales force must continuously reiterate this.

The belief that the higher the power asymmetry, the better the perception of expert power is not supported by the findings. For clients for which the power asymmetry between buying centre and selling centre is low, because the members of the buying centre are highly competent, the manager of expert power is judged quickly and intensively if the customer has more knowledge than the sales force in areas where it should be the other way around.

The sales force must therefore understand which core tasks the customer perceives on a daily basis and which characteristics and skills are required. Alpha Software customers are payroll executives for which accuracy, punctuality, and conscientiousness are important. They try to avoid any form of risk. Though this applies to the customers of Alpha Software, it may be different for other companies.

\section{Change}

In the field of change knowledge, Alpha Software has the greatest need for action. The sales force needs to be more than sensitised to this topic. In addition to understanding what happens to a client and employees during a complex transition project, personal experience of the sales force would be helpful. Personal experiences can be gathered if the salespeople closely accompany a conversion project by training on the job and experience the needs and fears of the employees first-hand. Regarding which tasks they could take on within the project, it is necessary to discuss this with the project managers in detail. It would be possible to train or carry out the actual analyses. The goal here is not to turn the sales force into a change agent, as this would go too far and take too much time and effort. The understanding of the change will vary. However, understanding what steps each employee goes through as part of a change, how they feel, and how to best help them quickly identify and experience the value of that change is valuable knowledge for sales and can be a substantial advantage over competitors. 
Admittedly, conversion projects require time-consuming training. This training would have multiple benefits in addition to the transformed mindset regarding change. For example, product and process knowledge are deepened. The consultants can be relieved, and if the services of the seller in the project are billed to the customer, this also increases his sales success. In addition, the relationship with the customer can be strengthened, which helps in gaining recommendations.

Even if a regular on-the-job training is not possible, a continuous exchange between consultant and seller regarding the customer and his sensitivities in the change project in the respective project phases would be advantageous to the salesperson in intensifying his or her change knowledge without being directly involved in the project.

\section{Ecosystem}

As previously mentioned, ecosystem knowledge does not just refer to the obvious interfaces of one's own solution (Tsujimoto et al., 2018). Rather, it is about comprehensively understanding the system landscape of the customer, the respective dependencies between the systems, and the different participants. Knowing and understanding, however, does not go so far that the seller could advise the customer. That is the task of the consultants. Rather, it is about acting on equal terms with the customer to better understand what the customer is talking about and the problems he deals with. In the business environment, the performance of the entire unit can be influenced by the role of each unit. From this perspective, business ecosystems could be viewed as complex adaptive systems. Of course, training on the job would also be useful here. However, this is not recommended because of the temporal effort required, in contrast to the topic of change knowledge, which depends on the personal experience.

In an ecosystem, each actor has different qualities, experiences, and beliefs. This path dependence generates lethargy. The different decision-making principles can lead to unintended results at the ecosystem level, even though the decisions and behaviours of each actor at a given time are rational. Knowledge about customer ecosystems is theoretical knowledge that can be conveyed through lectures and discussions with experienced consultants. Personal experiences are not essential to the understanding of the interaction of the participants in the ecosystem. In addition, it would be useful to invite Alpha Software's software partners to the sales meetings so that they can report 
on their solutions and experiences. Of course, a reverse exchange would also be conceivable. This way, the knowledge about the different ecosystems can be continuously improved with comparatively little effort. The perception of sales force expert power would thus be enhanced.

\section{Recommendations}

Recommendations from other companies are important in the decision-making process of the buying centre. Meanwhile, based on the findings, recommendations regarding the sales force have no relevance. The task of the sales force must be to make the existing customers recommenders. Incentives can be given in the context of the target agreement. With each recommender who agrees to provide information, for example, in a phone call with a potential customer, the seller comes closer to achieving his or her goal. The seller will thus actively take care of recruiting. However, the sales force is not responsible for taking care of recommenders permanently. They leave this to marketing, since their task continues to be the acquisition of new customers. If necessary, the sales force can actively rely on existing references as part of an acquisition. It is important that the requirements that a potential customer has are in line with those of the recommender. This requires that the recommender uses the same solutions, comes from the same industry, or is located nearby. In other words, they must have various things in common. This ensures an intensive and successful exchange between customers. For this to be possible, a certain number of recommenders must be available. The goal should be to gain every satisfied customer as a recommender.

Involvement in the target agreements is an initial first step in getting referrals to work. If the sales force sees the success that can be achieved, it has a vested interest in gaining further references. It is also conceivable to give the referrer additional incentives, such as a small appeal when he makes a recommendation or more exclusive access to service units. Thus, the sales force can consciously improve the perception of expert power by providing the right contact persons, therefore providing the customer with important information for his purchase decision from satisfied customers. 


\section{Brand}

The supplier's brand plays an essential role among buying centres in an important purchase decision for a complex solution. A strong brand creates trust and positively distinguishes the supplier from its competitors. Since expert force and brand are important for the purchase decision, they support each other with their effect (Brown et al., 2012; Hughes \& Ahearne, 2010). A brand-conforming appearance enhances the perception of expert power. Meanwhile, sales force expert power transfers to the brand and changes brand perception (Brown et al., 2012; Japutra \& Molinillo, 2019). To improve sales force expert power, it is recommended to train the sales force in the direction of brand understanding and brand-conforming behaviour. The Alpha Software brand, as well as any other brand that is deliberately managed, has a wellcoordinated brand understanding of values, promises, language, imagery, vision statement, and mission statements, among others. Of course, this brand understanding is well known to Alpha Software employees. An interpretation or adaptation for the sales approach, however, has not taken place. The sales management is recommended to do this urgently and train the sales force to become brand ambassadors (Xiong et al., 2013). This means that it is defined which brand promises, brand information, and brand-conforming language is purposefully distributed or used in the sales pitch. Building a unified brand understanding is a learning process that differs according to the tenure of the employees (Flikkema, Castaldi, Man, \& Seip, 2019). Brand understanding has more to do with perceptions of corporate culture, positive examples, and experiences than with any written messages. The brand understanding must be lived. Examples of brand understanding start at the top of the hierarchy and run through the entire company (Lin, 2015). Every employee must have internalised this brand understanding. This applies even more to the units that have direct customer contact. The introduction and support of a control system supports the implementation of the brand understanding (Hughes \& Ahearne, 2010). Through brand-conforming behaviour, the sales force comes closer to achieving its goals and increases the perception of expert power, which in turn has a positive effect on sales success.

\section{Strategy}

Buying centres in the supportive stage want to commit to their suppliers, who deliver innovative and customised solutions, in the long term (Paesbrugghe et al., 2017). The 
selection of suppliers is therefore only partially determined by the solutions currently available. It is equally determined by the strategic direction of the supplier. How does a supplier deal with the digitisation and automation of the industry, which solutions does the supplier strive for in the long term, and which features will come in the near future? How is Alpha Software's strategic direction different from that of its competitors? How do the solutions help customers with future challenges? These are questions that the sales force needs to competently answer. The pure focus on today's product, and perhaps even on the next update, is no longer sufficient based on the findings. Alpha Software, like many other software companies, is agile (Martin, 2013; Wolf \& Bleek, 2011). A five- or ten-year plan is irrelevant. The focus is always on the next sprints, and the road map is outlined for a maximum of the next 3 years. Nevertheless, the company has a long-term strategic focus. The road map and the long-term orientation must be known by the sales force. These topics should be repeatedly addressed in the sales meetings so that the strategic knowledge deepens. Thus, the sales force becomes a competent contact partner without the management of the supplier needing to be integrated into the sales talks. The sales force itself can answer questions, which improves the perception of expert power.

The results of the study provide a useful addition to the existing training of the sales team. It is understandable that the complexity of the requirements for each salesperson and the associated education and training time is increasing, thus posing further challenges. Of course, the question must be asked as to whether a person can fulfil all of the requirements or whether they can be transferred to multiple shoulders. This certainly depends on the solutions offered and the resulting margins to what extent additional sales resources are integrated into the selling centre. In the case of Alpha Software, the future project manager and subject matter expert is always involved alongside the seller in complex topics. The further care of the customer when the project has been implemented is then taken over by a key account manager so that the seller can focus solely on the acquisition of new clients (Wengler, Ehret, \& Saab, 2006). Despite this division of roles, today's sellers must meet all of the requirements to positively distinguish themselves and their company from the competition and to minimise the risk of sales failure.

Ultimately, the seller is no longer perceived as a solution vendor, but also as a change agent and integration manager. The seller's mindset must change to meet the 
requirements. Of course, this also offers sellers many opportunities to develop their own skills. For many sellers, this will be an enrichment of their own work with and on the customer.

Of course, implementing the recommendations costs time and money. In the end, they will pay off and take the quality of sales to a new level. It is not a question of whether the recommendations are implemented for Alpha Software, but rather a question of how they can best and most quickly be implemented. The recommendations are generally transferable to companies in the B2B market with solutions that have to be explained and implemented in projects. Of course, every company needs to review the recommendations on the individual needs and framework conditions before implementation.

\subsection{Limitations and Future Research Directions}

As with all studies, this study has certain limitations. Qualitative research is not concerned with numerical representability, but with deepening the understanding of a particular problem (Miles et al., 2018). In this research project ten customers from a wide variety of industries were interviewed, all but two of whom became customers of Alpha Software. This is therefore only a cross-section of various industries, and thus does not claim to be representative across all industries. In qualitative research, the researcher is both the subject and the subject of his research (Denzin, 1978). The case studies were conducted within one single company. The consideration of one single company is not necessarily regarded as a limitation, since this leads to the possibility of more intensive discussions. This was also supported by the fact that the researcher was employed in a managerial position during the research in the company. The quality of qualitative research strongly depends on the individual skills of the researcher and is more easily influenced by the personal biases and peculiarities of the researcher (Dey, 1993). Thus, not only was exclusive access to customers and potential customers possible, but the discussions could be conducted without delay after completion of the acquisition processes. The confidentiality of the customers and the employees involved was a consistently adhered-to prerequisite for conducting the study. If comments and statements obtained in the interviews made it possible to draw conclusions about customers and employees, these were not taken into account. The resulting impact on the findings is minimal and has in no way affected them. The aim 
of the qualitative methodology is to create detailed and descriptive information in order to understand the different dimensions of the problem to be analysed (Miles et al., 2018). The interviews were conducted with the leading executives from the buying centres. The interview questions were made available in advance with the request to exchange with the persons involved within the buying centre and to compile the answers. To what extent this was consistently implemented is incomprehensible. Consistency is more difficult to maintain, evaluate, and demonstrate in qualitative research (Silverman, 2020). Since qualitative research is a perspective research method, the answers given are not measured (Silverman, 2020). Comparisons can be made that can lead to duplication. Ultimately, each interviewee had the opportunity to contribute his or her individual viewpoints so that objectivity did not necessarily have to exist. The interviewed customers had largely homogeneous characteristics in terms of task orientation and the stage of evolution (supportive stage). In addition, purchase decisions were only taken into account in a first buy, which had a special significance for the customer's organisation and were emotionally difficult for the employees involved. Qualitative research is concerned with aspects of reality that cannot be quantified, with an emphasis on understanding and explaining the dynamics of social relationships (Dey, 1993). A generalisation for all purchase decisions in the B2B market cannot be derived. The selection of the interviewed customers was made objectively and without knowledge about them, so that bias was excluded, and the selection was representative. However, the selection only reflects a very small portion of the entire Alpha Software customer base. The interviewees reported their doubts during the purchasing process, which ultimately had no impact on the sales success, as they could be eliminated by the sales force. When the sale was not successful, the sales force expert power had no influence, as the reason for this failure was related to the products and services. Thus, the question remains unanswered as to what extent sales force expert power could be responsible for sales failures. For the most part, however, quantitative data is required for circumstances that require statistical presentation and are not part of the qualitative research process (Miles et al., 2018).

Approaches for future qualitative and quantitative research result from the mentioned limits of the research project. The products and solutions of the Alpha software require explanation and are essentially intangible goods. To what extent the perception of expert power changes when the products need less explanation and are part of the 
classic, tangible capital goods is a question that was not answered in the research project. Expert power is important when making a purchase in an initial purchase, and even more so when it is highly relevant to a company. How the perception of sales force expert power changes when the relevance of the purchase to the entrepreneur is assessed as low or when it is a repeat purchase is to be examined. The phase in which a buying center is located is also decisive. The buying center involved in the research project were all in a supportive stage. How buying centers, which are in passive and independent stages, react in similar buying situations are issues as well as the role of expert power in a sales failure, for which the sales force expert power was responsible. The approaches outlined could be the starting points for future qualitative research.

In quantitative research data can be quantified. The samples are generally large and are considered representative of the population (Bryman et al., 2018). The results are taken as if they represent a general and sufficiently comprehensive view of the entire population (Saunders et al., 2015). Disciplines such as mathematics and statistics play a fundamental role in analysing and generalising the results obtained (Creswell, 2009). Quantitative research focuses on objectivity and is particularly useful when it is possible to collect quantifiable measures for variables and conclusions from samples of a population (Bryman et al., 2018). But quantitative research can be limited in its quest for concrete statistical relationships, which can lead researchers to overlook broader topics and relationships (Creswell, 2009). If the focus is solely on numbers, there is a risk of missing unexpected or comprehensive information that could benefit the research results (Bryman et al., 2018). Nevertheless, this research project also offers approaches for further quantitative research. The perception of sales force expert power is important in all stages of the buying process. In early stages product knowledge is perceived more strongly while the perception of change knowledge in final stages predominates. Information exchange and recommendations lose their impact due to an unprofessional approach to change which minimises the perception of sales force expert power significantly. An overload of sales force expert power can lead to mistrust and uncertainty. Due to the intensity of change and how the change is perceived the perception of sales force expert power alters. How intensively the change is perceived by customers and how this perception of intensity may change in the course of the purchasing process through the effect of sale force expert could be 
the subject of quantitative research. In addition, it could be examined how intensive the change after implementation of the project actually is compared to the perception of the change at the beginning of the project or in the purchase process. Business customers, unlike consumers, expect a professional approach to change rather than benevolence. The interviewed clients perceive the software conversion project as a change project and expect the sales force to be approached and addressed accordingly. Change knowledge is an important attribute for sales force expert power, which can advance the clients'perceptions of sales force expert power. How intensively it affects the perception of the intensity of the change has not yet been examined.

The extent to which the research results can be transferred to other purchasing situations depends on the respective requirements and general conditions. If they are comparable to those from Alpha Software, the probability of a transfer is higher. A general transfer of the research results to other purchase situations is not recommended. Nevertheless, those responsible and involved in a purchase situation should always know the individual requirements and framework conditions when making recommendations and consciously decide on them.

The research of expert power is established in the literature. However, it is often not clear what exactly is behind expert power. Thus, there is enough room for future research to investigate and describe the attributes of expert power more intensively. This research has helped contribute to a better understanding of the perception of expert power and has provided approaches to consciously improve perception, all with the goal to improve the success of the sales force.

The researcher recognises the value of undertaking qualitative research to gain a deeper understanding of a research topic. However, all qualitative research instruments are limited by sample size, location of study and lack of evidence to corroborate the causality of the findings. Reflecting this, the researcher recommends that future researchers could undertake a quantitative approach to capture a more objective insights into the subject across a range of industries through adopting Likert style questionnaire or statements to test a potential the causality of behaviour. 


\section{Bibliography}

Abdolmohammadi, M. J., \& Shanteau, J. (1992). Personal Attributes of Expert Auditors. Organizational Behavior and Human Decision Processes, 53, 158172.

Aguinis, H., Nesler, M. S., Quigley, B. M., \& Tedeschi, T. (1994). Perception of power: A cognitive perspective. Social Behaviour and Personality, 22(4), 377384.

Ahlert, D., Wangenheim, F. von, \& Kawohl, J. (2008). The concept of solution selling: Theoretical considerations and methods. Transformation. Münster. Retrieved from http://www.innovationskreismarketing.de/transolve/de/content/projektberichte/Transolve_Projektbericht_3.pd f

Ahmad, M., Mittal, S., West, S., \& Wuest, T. (2018). Review on upgradability - A product lifetime extension strategy in the context of product service systems. Journal of Cleaner Production, 204, 1154-1168. https://doi.org/10.1016/j.jclepro.2018.08.329

Al-Haddad, S., \& Kotnour, T. (2015). Integrating the organizational change literature: a model for successful change. Journal of Organizational Change Management, 28(2), 234-262. Retrieved from https://doi.org/10.1108/JOCM-11-2013-0215

Albertazzi, L. (2010). The Ontology of Perception. In R. Poli \& J. Seibt (Eds.), Theory and Applications of Ontology: Philosophical Perspectives (pp. 177-206). Dordrecht Heidelberg London New York: Springer.

Allen, T. J. (1967). Communications in the research and development laboratory. Technology Review (Vol. 70). Technology Review. Retrieved from http://scholar.google.com/scholar?hl=en\&btnG=Search\&q=intitle:Communication $\mathrm{s}+$ in+the+research+and+development+laboratory $\# 0$

Anderson, E., Chu, W., \& Weitz, B. A. (1987). Industrial purchasing: an empirical exploration of the buyclass framework. The Journal of Marketing, 71-86. Retrieved from http://www.jstor.org/stable/10.2307/1251648

Anderson, E., \& Weitz, B. A. (1989). Determinants of continuity in conventional industrial channel dyads. Marketing Science, 8(4), 310-323. Retrieved from http://www.jstor.org/stable/10.2307/183978

Appelbaum, S. H., Habashy, S., Malo, J.-L., \& Shafiq, H. (2012). Back to the future : revisiting Kotter's 1996 change model. Journal of Management Development, 31(8), 764-782. https://doi.org/http://dx.doi.org/10.1108/02621711211253231 Downloaded

Arli, D., Bauer, C., \& Palmatier, R. W. (2018). Relational selling: Past, present and future. Industrial Marketing Management, 69, 169-184. https://doi.org/10.1016/j.indmarman.2017.07.018

Backhaus, K., \& Günter, B. (1976). A Phase-Differential Interaction Approach to 
Industrial Marketing Decisions. Industrial Marketing Management, 5, 255-270.

Backhaus, K., \& Voeth, M. (2014). Industriegütermarketing. (10., Ed.). München: Vahlen.

Bänsch, A. (2013). Verkaufspsychologie und Verkaufstechnik (9.). München: Oldenbourg.

Barnett White, T. (2005). Consumer Trust and Advice Acceptance: The Moderating Roles of Benevolence, Expertise, and Negative Emotions. Journal of Consumer Psychology, 15(2), 141-148. https://doi.org/10.1207/s15327663jcp1502_6

Bazeley, P., \& Jackson, K. (2013). Qualitative Data Analysis with NVivo (2nd ed.). London: SAGE Publications Ltd.

Belonax, J. J., Newell, S. J., \& Plank, R. E. (2007). The Role of Purchase Importance on Buyer Perceptions of the Trust and Expertise Components of Supplier and Salesperson Credibility in Business-to-Business Relationships. Journal of Personal Selling and Sales Management, 27(3), 247-258. https://doi.org/10.2753/PSS0885-3134270304

Berelson, B. (1952). Content Analysis in Communication Research. Glencoe, IL: Free Press.

Bitkom e.V. (2019). Bitkom - About us. Retrieved from https://www.bitkom.org/EN/About-us/index-EN.html

Blake, R. R., \& Mouton, J. S. (1970). The Grid for Sales Excellence. New York, NY: McGraw-Hill.

Blessington, M. (1989). Five Ways to Make Team Selling Work (Really!). Business Month, 134(2), 71-72. Retrieved from

http://scholar.google.com/scholar?hl=en\&btnG=Search\&q=intitle:Five+Ways+to+ Make+Team+Selling+Work+(Really!)\#0

Boedecker, K., Morgan, F. W., Stoltman, J. J., Boedecker, K. A., Morgan, F. W., \& Stoltman, J. J. (1991). Legal Dimensions of Salespersons ' Statements : A Review and Managerial Suggestions Dimensions of Legal Statements: Salespersons ' and Managerial Suggestions. Journal of Marketing, 55(January), 70-80.

Bonoma, T. V. (2006). Major Sales: Who Really Does the Buying? Harvard Business Review, 84(7/8), 172-181. Retrieved from http://www.mendeley.com/research/major-sales-who-really-does-the-buying/

Borg, S. W., \& Johnston, W. J. (2013). The IPS-EQ Model: Interpersonal Skills and Emotional Intelligence in a Sales Process. Journal of Personal Selling \& Sales Management, 33(1), 39-51. Retrieved from https://doi.org/10.2753/PSS08853134330104

Bradford, K. D., Brown, S. P., Ganesan, S., Hunter, G., Onyemah, V., Palmatier, R. W., ... Weitz, B. A. (2010). The embedded sales force: Connecting buying and 
selling organizations. Marketing Letters, 21(3), 239-253.

https://doi.org/10.1007/s11002-010-9106-1

Brady, M. K., \& Cronin, J. J. (2001). Customer Orientation: Effects on Customer Service Perceptions and Outcome Behaviors. Journal of Service Research, 3(3), 241-251. https://doi.org/10.1177/109467050133005

Brand, G. (1972). The industrial buying decision: implications for the sales approach in industrial marketing. London: Wiley. Retrieved from http://books.google.com/books?id=99ygRAAACAAJ\&pgis=1

Brashear Alejandro, T. G., Boles, J. S., \& Yang, J. (2011). The role of social capital and knowledge transfer in selling center performance. Journal of Business \& Industrial Marketing, 26(3), 152-162.

https://doi.org/10.1108/08858621111115877

Brinkmann, J. (2006). Buying Center-Analyse auf der Basis von Vertriebsinformationen. Wiesbaden: DUV.

Brinkmann, J., \& Voeth, M. (2007). An analysis of buying center decisions through the salesforce. Industrial Marketing Management, 36(7), 998-1009. https://doi.org/10.1016/j.indmarman.2007.05.009

Bristor, J. M. (1992). Influence Strategies in Organizational Buying: Journal of Business-to-Business Marketing, 1(1), 63-98.

https://doi.org/10.1300/J033v01n01_04

Brown, B. P., Zablah, A. R., Bellenger, D. N., \& Donthu, N. (2012). What factors influence buying center brand sensitivity? Industrial Marketing Management, 41(3), 508-520. https://doi.org/10.1016/j.indmarman.2011.06.008

Brown, S. P. (1990). Use of Closed Influence Tactics by Salespeople: Incidence and Buyer Attributions. The Journal of Personal Selling and Sales Management, 10(4), 17-29. Retrieved from http://www.jstor.org/stable/10.2307/40471833

Bryman, A., Bell, E., \& Harley, B. (2018). Business Research Methods (5.). New York, NY: Oxford University Press Inc.

Bunderson, J. S. (2003). Recognizing and Utilizing Expertise in Work Groups: A Status Characteristics Perspective. Administrative Science Quarterly, 48(4), 557-591. https://doi.org/10.2307/3556637

Bunn, M. D. (1993). Taxonomy of buying decision approaches. The Journal of Marketing, 57(January), 38-56. Retrieved from http://www.jstor.org/stable/10.2307/1252056

Busch, P., \& Wilson, D. T. (1976). An experimental analysis of a salesman's expert and referent bases of social power in the buyer-seller dyad. Journal of Marketing Research, 13(1), 3-11. Retrieved from http://www.jstor.org/stable/10.2307/3150896

Butler, J. K. (1991). Toward Understanding and Measuring Conditions of Trust: 
Evolution of a Conditions of Trust Inventory. Journal of Management, 17(3), 643-663. Retrieved from http://jom.sagepub.com/content/17/3/643.short

Cannon, J. P., \& Perreault Jr, W. D. (1999). Buyer-Seller Relationships in Markets Business. Journal of Marketing, 36(4), 439-460.

Cartwright, D. (1959). A Field Theoretical Conception of Power. In Studies in Social Power (pp. 183-220).

Chae, S., Choi, T. Y., \& Hur, D. (2017). Buyer Power and Supplier Relationship Commitment: A Cognitive Evaluation Theory Perspective. Journal of Supply Chain Management, 53(2), 39-60. https://doi.org/10.1111/jscm.12138

Chinomona, R., \& Pretorius, M. (2011). SME manufacturers' cooperation and dependence on major dealers' expert power in distribution channels. SOUTH AFRICAN JOURNAL OF ECONOMIC AND MANAGEMENT SCIENCES, 14(2), 170-187.

Choffray, J. M., \& Lilien, G. L. (1976). Models of the multiperson choice process with application to the adoption of industrial products (No. No. 861-76). Cambridge Mass.: MIT Alfred P. Sloan School of Management. Retrieved from http://scholar.google.com/scholar?hl=en\&btnG=Search\&q=intitle:Models+of +the +Multiperson+Choice+Process+with+Application+to+the+Adaption+of+Industrial + Products\#0

Choffray, J. M., \& Lilien, G. L. (1978). Assessing Response to Industrial Marketing Strategy. Journal of Marketing, 42(2), 20. https://doi.org/10.2307/1249882

Clauss, T., \& Bouncken, R. B. (2018). Social power as an antecedence of governance in buyer-supplier alliances. Industrial Marketing Management, (December). https://doi.org/10.1016/j.indmarman.2018.12.005

Coghlan, D. (2001). Insider Action Research Projects: Implications for Practising Managers. Management Learning, 32(1), 49-60.

https://doi.org/10.1177/1350507601321004

Coghlan, D. (2007). Insider action research: opportunities and challenges. Management Research News, 30(5), 335-343. https://doi.org/10.1108/01409170710746337

Comelli, G., \& Rosenstiel, L. von. (2009). Führung durch Motivation (4.). München: Verlag Franz Vahlen.

Conger, J. A. (1998). The Necessary Art of Persuasion. Harvard Business Review, (May-June). Retrieved from

http://www.communicationcache.com/uploads/1/0/8/8/10887248/the_necessary_ art_of_persuasion.pdf

Conrad, D. (2013). Great Leaders are Great Sales People. Journal of Business Studies Quarterly, 4(3), 223-229. Retrieved from http://jbsq.org/wpcontent/uploads/2013/03/March_2013_15.pdf 
Corfman, K. P., \& Lehmann, D. R. (1987). Models of cooperative group decisionmaking and relative influence: An experimental investigation of family purchase decisions. Journal of Consumer Research, 14(1), 1-13. https://doi.org/10.1086/209088

Creswell, J. W. (2009). Research Design. Qualitative, quantitative and mixed methods approaches (3.). Thousands Oaks, CA: SAGE Publications Ltd.

Crosby, L. A., Evans, K. R., \& Cowles, D. (1990). Relationship Quality in Services Selling: An Interpersonal Influence Perspective. Journal of Marketing, 54(July), 68-81.

Curasi, C. F., Boles, J. S., \& Reynolds, R. (2018). Key account buying team members' emotional responses awarding multi-million dollar sales contracts. Industrial Marketing Management, 75(June), 193-205. https://doi.org/10.1016/j.indmarman.2018.05.005

Daft, R. L., \& Marcic, D. (2011). Understanding management (7.). Mason: SouthWestern Cengage Learning.

Dahl, R. A. (1957). The Concept of Power. Behavioral Science, 2(3), 201-215. Retrieved from http://onlinelibrary.wiley.com/doi/10.1002/bs.3830020303/abstract

de Ruyter, K., Keeling, D. I., \& Cox, D. (2018). Customer-supplier relationships in high technology markets 3.0. Industrial Marketing Management, (November). https://doi.org/10.1016/j.indmarman.2018.11.011

Delvecchio, S., Zemanek, J., Mclntyre, R., \& Claxton, R. (2004). Updating the Adaptive Selling Behaviours: Tactics to Keep and Tactics to Discard. Journal of Marketing Management, 20(7-8), 859-875. Retrieved from http://www.tandfonline.com/doi/abs/10.1362/0267257041838791

DeMarco, T. (2002). Structured Analysis: Beginnings of a New Discipline. In M. Broy \& E. Denert (Eds.), Software Pioneers (pp. 520-527). Berlin, Heidelberg: Springer. Retrieved from https://doi.org/10.1007/978-3-642-59412-0_32

Denzin, N. K. (1978). The Research Act: A Theoretical Introduction to Sociological Methods. New York, NY: McGraw-Hill.

Dey, I. (1993). Qualitative Data Analysis: A User Friendly Guide for Social Scientists. London: Routledge.

Donavan, D. T., Brown, T. J., \& Mowen, J. C. (2004). Internal Benefits of ServiceWorker Customer Orientation: Job Satisfaction, Commitment, and Organizational Citizenship Behaviors. Journal of Marketing, 68(January), 128146. Retrieved from http://www.jstor.org/stable/10.2307/30161979

Doney, P. M., \& Cannon, J. P. (1997). An Examination of the Nature of Trust in Buyer-Seller Relationships. Journal of Marketing, 61, 35-51.

Doyle, P., Woodside, A. G., \& Michell, P. (1979). Organizations buying in new task 
and rebuy situations. Industrial Marketing Management, 8(1), 7-11.

https://doi.org/10.1016/0019-8501(79)90012-9

Duncan, D. J. (1940). What motivates business buyers? Harvard Business Review, 18(4), 448-454.

Easterby-Smith, M., Thorpe, R., \& Jackson, P. R. (2008). Management Research: Theory and Research (3.). London: SAGE Publications Ltd.

Easterby-Smith, M., Thorpe, R., \& Lowe, A. (2001). Management Research: An Introduction (2.). London: SAGE Publications Ltd.

Eckert, J. A. (2006). Adaptive selling behavior: adding depth and specificity to the range of adaptive outputs. American Journal of Business, 21(1), 31-39.

Retrieved from

http://www.emeraldinsight.com/journals.htm?articleid=1917857\&amp;show=abst ract

Eisenhardt, K. M. (1989). Building Theories from Case Study Research. The Academy of Management Review, 14(4), 532-550.

Eisenhardt, K. M., \& Graebner, M. E. (2007). Theory Building From Cases: Opportunities and Challenges. Academy of Management Journal, 50(1), 25-32. https://doi.org/10.5465/AMJ.2007.24160888

Elias, S. M. (2008). Fifty years of influence in the workplace: The evolution of the French and Raven power taxonomy. Journal of Management History, 14(3), 267-283. https://doi.org/10.1108/17511340810880634

Elias, S. M. (2009). Restrictive versus promotive control and employee work outcomes: The moderating role of locus of control. Journal of Management, 35(2), 369-392. https://doi.org/10.1177/0149206308318620

Elias, S. M., \& Macdonald, S. R. (2006). Consequences of restrictive and promotive managerial control among American university professors. International Journal of Organizational Analysis, 14(3), 239-250.

https://doi.org/10.1108/19348830610823428

Evans, K. R., McFarland, R. G., Dietz, B., \& Jaramillo, F. (2012). Advancing Sales Performance Research: A Focus on Five Underresearched Topic Areas. Journal of Personal Selling and Sales Management, 32(1), 89-106.

https://doi.org/10.2753/PSS0885-3134320108

Evans, K. R., Schlacter, J. L., Schultz, R. J., Gremler, D. D., Pass, M. W., \& Wolfe, W. G. (2002). Salesperson and sales manager perceptions of salesperson job characteristics and job outcomes: A perceptual congruence approach. Journal of Marketing Theory and Practice, 10(4), 30-44. Retrieved from http://www.gremler.net/personal/research/2002_Saleserson_Perceptual_Congru ence_JMTP.pdf

Farrell, M., \& Schroder, B. (1999). Power and influence in the buying centre.

European Journal of Marketing, 33(11/12), 1161-1170. 
Felser, G. (2007). Werbe- und Konsumentenpsychologie (3.). Berlin, Heidelberg: Springer.

Fischer, P., Jonas, E., Frey, D., \& Kastenmu, A. (2008). Selective exposure and decision framing: The impact of gain and loss framing on confirmatory information search after decisions. Journal of Experimental Social Psychology, 44, 312-320. https://doi.org/10.1016/j.jesp.2007.06.001

Fließ, S. (2000). Industrielles Kaufverhalten. In M. Kleinaltenkamp \& S. Saab (Eds.), Technischer Vertrieb - Grundlagen des Business-to-Business Marketing (pp. 251-370). Berlin: Springer.

Flikkema, M., Castaldi, C., Man, A.-P. de, \& Seip, M. (2019). Trademarks ' relatedness to product and service innovation: A branding strategy approach. Research Policy, 48(6), 1340-1353. https://doi.org/10.1016/j.respol.2019.01.018

Flyvbjerg, B. (2006). Five Misunderstandings About Case-Study Research. Qualitative Inquiry, 12(2), 219-245. Retrieved from http://qix.sagepub.com/content/12/2/219.short

Foscht, T., Swoboda, B., \& Schramm-Klein, H. (2017). Käuferverhalten: Grundlagen Perspektiven - Anwendungen (6.). Wiesbaden: Springer Gabler Verlag.

Franke, G. R., \& Park, J.-E. (2006). Salesperson adaptive selling behavior and customer orientation: A meta-analysis. Journal of Marketing Research, 43(4), 693-702. https://doi.org/10.1509/jmkr.43.4.693

French, J. R. P., \& Raven, B. H. (1959). The bases of social power. In D. Cartwright (Ed.), Studies in social power (pp. 150-167). Oxford, England: University of Michigan. Retrieved from http://psycnet.apa.org/psycinfo/1960-06701-004

Friend, S. B., Ranjan, K. R., \& Johnson, J. S. (2019). Fail fast, sell well: The contingent impact of failing fast on salesperson performance. Industrial Marketing Management, (December 2018). https://doi.org/10.1016/j.indmarman.2019.01.007

Funkhouser, G. R. (1984). A practical theory of persuasion based on behavioral science approaches. The Journal of Personal Selling and Sales Management, (November), 17-25. Retrieved from http://scholar.google.com/scholar?hl=en\&btnG=Search\&q=intitle:A+Practical+Th eory+of+Persuasion+Based+on+Behavioral+Science+Approaches\#2

Galateanu, E., \& Avasilcai, S. (2014). Business ecosystem " reliability ." Procedia Social and Behavioral Sciences, 124, 312-321. https://doi.org/10.1016/j.sbspro.2014.02.491

Garrido-Samaniego, M. J., \& Gutiérrez-Cillán, J. (2004). Determinants of influence and participation in the buying center. An analysis of Spanish industrial companies. Journal of Business \& Industrial Marketing, 19(5), 320-336. https://doi.org/10.1108/08858620410561051

Gelb, B. D., \& Rangarajan, D. (2014). Employee Contributions to Brand Equity. 
California Management Review, 56(2), 95-113. Retrieved from https://doi.org/10.1525\%2Fcmr.2014.56.2.95

Gelfand, M. J., Raver, J. L., Nishii, L., Leslie, L. M., Lun, J., Lim, B. C., ... Yamaguchi, S. (2011). Differences between tight and loose cultures: A 33-nation study. Science, 332(6033), 1100-1104. https://doi.org/10.1126/science.1197754

Ghingold, M., \& Wilson, D. T. (1998). Buying center research and business marketing practice: meeting the challenge of dynamic marketing. Journal of Business \& Industrial Marketing, 13(2), 96-108. Retrieved from http://www.emeraldinsight.com/journals.htm?articleid=856715\&amp;show=abstr act

Giacobbe, R. W., Jackson Jr, D. W., Crosby, L. A., \& Bridges, C. M. (2006). A contingency approach to adaptive selling behavior and sales performance: Selling situations and salesperson characteristics. Journal of Personal Selling and Sales Management, 26(2), 115-142. https://doi.org/10.2753/PSS08853134260202

Gill, J., \& Johnson, P. (2010). Research for Managers (4.). Thousands Oaks, CA: SAGE Publications Inc.

Goff, B. G., Boles, J. S., Bellenger, D. N., \& Stojack, C. (1997). The influence of salesperson selling behaviors on customer satisfaction with products. Journal of Retailing, 73(2), 171-183. https://doi.org/10.1016/S0022-4359(97)90002-6

Goh, M., Lau, G. T., \& Neo, L. (1999). Strategic Role and Contribution of Purchasing in Singapore: A Survey of CEOs. The Journal of Supply Chain Management, 35(4), 12-23. https://doi.org/10.1111/j.1745-493X.1999.tb00240.x

Gonçalves, S. M., da Silva, R. V., \& Teixeira, N. (2018). Individual actors and embeddedness in business-to-business interactions. Industrial Marketing Management, 76(June 2017), 181-191. https://doi.org/10.1016/j.indmarman.2018.08.006

Grant, S. B., \& Preston, T. A. (2018). Using social power and influence to mobilise the supply chain into knowledge sharing: A case in insurance. Information and Management, (October). https://doi.org/10.1016/j.im.2018.10.004

Gravenhorst, K. M. B., \& Munduate, L. (2003). Power dynamics and organisational change: an introduction. Applied Psychology: An International Review, 52(1), 113. Retrieved from http://onlinelibrary.wiley.com/doi/10.1111/14640597.00120/full

Guenzi, P., De Luca, L. M., \& Troilo, G. (2011). Organizational Drivers of Salespeople's Customer Orientation and Selling Orientation. Journal of Personal Selling and Sales Management, 31(3), 269-286. https://doi.org/10.2753/PSS0885-3134310305

Guenzi, P., Luca, L. M. D., \& Spiro, R. (2016). The combined effect of customer perceptions about a salesperson's adaptive selling and selling orientation on customer trust in the salesperson: a contingency perspective. Journal of 
Business and Indu, 31(4). https://doi.org/10.1108/02656710210415703

Haas, A. (2009). Kann zu viel Kundenorientierung nachteilig sein? Eine Analyse der Wirkung der Kundenorientierung von Verkäufern auf die Kaufentscheidung. Zeitschrift Für Betriebswirtschaft, 79(1), 7-30. https://doi.org/10.1007/s11573009-0009-7

Hart, C. (2010). Doing a Literature Review. London: SAGE Publications Ltd.

Hauschildt, J., \& Kirchmann, E. (1997). Zur Existenz und Effizienz von Prozeßpromotoren. Zeitschrift Führung Und Organisation, 66, 68-73.

Heger, G. (1984). Das Rollenverhalten des Akquisiteurs im industriellen Anlagengeschäft. Marketing - Zeitschrift Für Forschung Und Praxis, 6, 235-244. Retrieved from http://scholar.google.com/scholar?hl=en\&btnG=Search\&q=intitle:Das+Rollenver halten+des+Akquisiteurs+im+industriellen+Anlagengeschäft\#0

Heide, J. B., \& Weiss, A. M. (1995). Vendor Consideration and Switching Behavior for Buyers in High-Technology Markets. Journal of Marketing, 59(3), 30-43. Retrieved from http://www.jstor.org/pss/1252117

Heijden, A. V. D., \& Cramer, J. M. (2017). Change agents and sustainable supply chain collaboration: A longitudinal study in the Dutch pig farming sector from a sensemaking perspective. Journal of Cleaner Production, 166, 967-987. https://doi.org/10.1016/j.jclepro.2017.08.074

Hofbauer, G., \& Hellwig, C. (2016). Professionelles Vertriebsmanagement - Der prozessorientierte Ansatz aus Anbieter- und Beschaffersicht (4.). Erlangen: Publicis Publishing.

Hofbauer, G., \& Schöpfel, B. (2010). Professionelles Kundenmanagement Ganzheitliches CRM und seine Rahmenbedingungen. Erlangen: Publicis Publishing.

Hofstede, G. (2011). Dimensionalizing Cultures: The Hofstede Model in Context. Online Readings in Psychology and Culture, 2(1), 1-26. https://doi.org/10.9707/2307-0919.1014

Homburg, C., \& Fargel, T. (2006). Neue Kunden systematisch gewinnen. Harvard Business Manager, (10), 94-110.

Homburg, C., Schäfer, H., \& Schneider, J. (2016). Sales Excellence Vertriebsmanagement mit System (8.). Wiesbaden: Gabler.

Homburg, C., Workman Jr, J. P., \& Jensen, O. (2002). A configurational perspective on key account management. The Journal of Marketing, 66(April), 38-60.

Retrieved from http://www.jstor.org/stable/10.2307/3203414

Hopkinson, G. C., \& Blois, K. (2014). Power-base research in marketing channels: A narrative review. International Journal of Management Reviews, 16(2), 131-149. https://doi.org/10.1111/ijmr.12013 
Houman, P., \& Gadde, L.-E. (2019). Journal of Purchasing and Supply Management Organizational interfaces and innovation: The challenge of integrating supplier knowledge in LEGO systems. Journal of Purchasing and Supply Management, 25(1), 18-29. https://doi.org/10.1016/j.pursup.2018.08.002

Hufgard, A., Hecht, H., Walz, W., Hennermann, F., Brosch, G., Mehlich, S., \& Bätz, C. (2005). Business Integration mit SAP-Lösungen Potenziale,

Geschäftsprozesse, Organisation und Einführung. Berlin, Heidelberg, New York: Springer. Retrieved from

http://books.google.com/books?id=exoDYpe8L6UC\&pgis=1

Hughes, D. E., \& Ahearne, M. (2010). Energizing the Reseller's Sales Force: The Power of Brand Identification. Journal of Marketing, 74, 81-96.

Hunt, J. G. (1984). Leadership and managerial behavior. In J.E. Rosenzweig \& F.E. Caste (Ed.), Modules in Management. Chicago: Science Research Associate. Retrieved from http://www.getcited.org/pub/102295561

Ioannidis, E., Varsakelis, N., \& Antoniou, I. (2019). Change agents and internal communications in organizational networks. Physica A, 528. https://doi.org/10.1016/j.physa.2019.121385

Jackson, W. (2003). Methods: Doing Social Research (3rd.). Toronto: Prentice Hall.

Japutra, A., \& Molinillo, S. (2019). Responsible and active brand personality: On the relationships with brand experience and key relationship constructs. Journal of Business Research, 99, 464-471. https://doi.org/10.1016/j.jbusres.2017.08.027

Järvi, P., \& Munnukka, J. (2009). The Effect of Information Sources on the Success of the Organizational Buying Process. Journal of Business Market Management, 3(4), 209-225. https://doi.org/10.1007/s12087-009-0027-3

Jing, X., \& Xie, J. (2011). Group Buying: A New Mechanism for Selling Through Social Interactions. Management Science, (8), 1354-1372. https://doi.org/10.1287/mnsc.1110.1366

Johnson, J. S., Matthes, J. M., \& Friend, S. B. (2019). Interfacing and customerfacing: Sales and marketing selling centers it. Industrial Marketing Management, 77(September 2017), 41-56.

https://doi.org/10.1016/j.indmarman.2017.08.011

Johnston, W. J., \& Bonoma, T. V. (1981a). Purchase process for capital equipment and services. Industrial Marketing Management, 10(4), 253-264. Retrieved from http://www.sciencedirect.com/science/article/pii/001985018190033X

Johnston, W. J., \& Bonoma, T. V. (1981b). The Buying Center: Structure and Interaction Patterns. Journal of Marketing, 45(3), 143-156. https://doi.org/10.2307/1251549

Johnston, W. J., \& Lewin, J. E. (1996). Organizational buying behavior: Toward an integrative framework. Journal of Business Research, 35(1), 1-15. Retrieved from http://www.sciencedirect.com/science/article/pii/0148296394000778 
Jolson, M. A. (1997). Broadening the scope of relationship selling. Journal of Personal Selling and Sales Management, 17(4), 75-89. Retrieved from http://scholar.google.com/scholar?hl=en\&btnG=Search\&q=intitle:Broadening+th e+Scope+of+Relationship+Selling\#0

Juha, M., \& Pentti, J. (2008). Managing risks in organizational purchasing through adaptation of buying centre structure and the buying process. Journal of Purchasing and Supply Management, 14(4), 253-262.

https://doi.org/10.1016/j.pursup.2008.09.001

Kahn, R., \& Cannell, C. (1957). The Dynamics of Interviewing. New York and Chichester: Wiley.

Kaski, T., Niemi, J., \& Pullins, E. (2018). Rapport building in authentic B2B sales interaction. Industrial Marketing Management, 69(August 2017), 235-252. https://doi.org/10.1016/j.indmarman.2017.08.019

Keshet, S., Kark, R., Pomerantz-Zorin, L., Koslowsky, M., \& Schwarzwald, J. (2006). Gender, status and the use of power strategies. European Journal of Social Psychology, (36), 105-117.

Kipnis, D. (1984). The use of power in organizations and in interpersonal settings. Applied Social Psychology Annual, 5, 179-210. Retrieved from http://psycnet.apa.org/psycinfo/1985-23976-001

Kipnis, D., Schmidt, S. M., \& Wilkinson, I. (1980). Intraorganizational influence tactics: Explorations in getting one's way. Journal of Applied Psychology, 65(4), 440-452. https://doi.org/10.1037/0021-9010.65.4.440

Kleinaltenkamp, Michael, \& Saab, S. (2009). Technischer Vertrieb. Berlin, Heidelberg: Springer. https://doi.org/10.1007/978-3-540-79533-9

Kohli, A. (1988). Measuring multiple buying influences. Industrial Marketing Management, 17(3), 197-204. https://doi.org/10.1016/0019-8501(88)90003-X

Kohli, A. (1989). Determinants of Influence in Organizational Buying: A Contingency Approach. Journal of Marketing, 53(3), 50. https://doi.org/10.2307/1251342

Koponen, J., Julkunen, S., \& Asai, A. (2019). Sales communication competence in international B2B solution selling. Industrial Marketing Management, in Press. https://doi.org/10.1016/j.indmarman.2019.01.009

Koslowsky, M., Baharav, H., \& Schwarzwald, J. (2011). Management style as a mediator of the power distance-influence tactics relationship. International Journal of Conflict Management, 22(3), 264-277. https://doi.org/10.1108/10444061111152964

Koslowsky, M., \& Schwarzwald, J. (2001). The Power Interaction Model: Theory, methodology, and empirical applications. In The use and abuse of power: Multiple perspectives on the causes of corruption. (pp. 195-214). Retrieved from http://ezproxy.library.uvic.ca/login?url=http://search.ebscohost.com/login.aspx?di rect=true\&db=psyh\&AN=2001-06492-011\&site=ehost-live\&scope=site 
Kotler, P., Keller, K. L., \& Opresnik, M. O. (2017). Marketing-Management (15.). Hallbergmoos: Pearson Deutschland $\mathrm{GmbH}$.

Kotter, J. P. (2012). Leading change. Boston, MA: Harvard Business Review Press.

Kroeber-Riel, W., Weinberg, P., \& Gröppel-Klein, A. (2013). Konsumentenverhalten (10.). München: Vahlen.

Kwak, H., Anderson, R. E., Leigh, T. W., \& Bonifield, S. D. (2019). Impact of salesperson macro-adaptive selling strategy on job performance and satisfaction. Journal of Business Research, 94(September 2018), 42-55. https://doi.org/10.1016/j.jbusres.2018.09.015

Lacoste, S. (2018). From selling to managing strategic customers - a competency analysis. Journal of Personal Selling \& Sales Management, 38(1). https://doi.org/10.1080/08853134.2018.1426991

LaForge, M. C., \& Stone, L. H. (1989). An analysis of the industrial buying process by means of buying center communications. Journal of Business \& Industrial Marketing, 4(1), 29-36. https://doi.org/10.1108/EUM0000000002722

Lai, C., Pai, D., Yang, C., \& Lin, H. (2009). Industrial Marketing Management The effects of market orientation on relationship learning and relationship performance in industrial marketing: The dyadic perspectives. Industrial Marketing Management, 38(2), 166-172.

https://doi.org/10.1016/j.indmarman.2008.12.004

Lau, G. T. (1999). Purchase-Related Factors and Buying Center Structure An Empirical Assessment. Industrial Marketing Management, 28(6), 573-587. https://doi.org/10.1016/S0019-8501(98)00031-5

Lau, G. T., Razzaque, M. A., \& Ong, A. (2003). Gatekeeping in organizational purchasing: an empirical investigation. Journal of Business \& Industrial Marketing, 18(1), 82-103. https://doi.org/10.1108/08858620310458651

Lewin, J. E., \& Donthu, N. (2005). The influence of purchase situation on buying center structure and involvement: a select meta-analysis of organizational buying behavior research. Journal of Business Research, 58(10), 1381-1390. https://doi.org/10.1016/j.jbusres.2004.09.004

Lewis, E. S. E. (1903). Catch-Line and Argument. The Book-Keeper, 15, 124.

Lilien, G. L., \& Wong, M. A. (1984). An exploratory investigation of the structure of the buying center in the metalworking industry. Journal of Marketing Research, X(February), 1-11. Retrieved from http://www.jstor.org/stable/10.2307/3151787

Lin, Y. H. (2015). Innovative brand experience' s influence on brand equity and brand satisfaction. Journal of Business Research, 68, 2254-2259.

https://doi.org/10.1016/j.jbusres.2015.06.007

Lincoln, Y. S., \& Guba, E. G. (1985). Naturalistic Inquiry. Newbury Park, CA: SAGE Publications Inc. Retrieved from 
http://books.google.com/books?hl=en\&lr=\&id=2oA9aWINeooC\&oi=fnd\&pg=PA7 \&dq=Naturalistic+Inquiry\&ots=0rnyQgReum\&sig=Oaxc-

frUUdX7hOVec4Fsi3nmc4w

Lines, R. (2005). The Structure and Function of Attitudes Toward Organizational Change. Human Resource Development Review, 4(1), 8-32. https://doi.org/10.1177/1534484304273818

Lines, R. (2007). Using Power to Install Strategy: The Relationships between Expert Power, Position Power, Influence Tactics and Implementation Success. Journal of Change Management, 7(2), 143-170.

https://doi.org/10.1080/14697010701531657

Liu, A. H., \& Leach, M. P. (2001). Developing loyal customers with a value-adding sales force: Examining customer satisfaction and the perceived credibility of consultative salespeople. The Journal of Personal Selling and Sales Management, 21(2), 147-156. Retrieved from http://www.jstor.org/stable/10.2307/20832587

Liu, S. S., \& Comer, L. B. (2007). Salespeople as information gatherers: Associated success factors. Industrial Marketing Management, 36(5), 565-574. https://doi.org/10.1016/j.indmarman.2006.02.006

Lünendonk. (2018). TOP 25 der Standard-Software-Unternehmen in Deutschland 2018. Kaufbeuren: Lünendonk $\mathrm{GmbH}$.

Mallalieu, L. (2006). Consumer perception of salesperson influence strategies : an examination of the influence of consumer goals. Journal of Consumer Behaviour, 268(May-June), 257-268. https://doi.org/10.1002/cb.

Marcos Cuevas, J. (2018). The transformation of professional selling: Implications for leading the modern sales organization. Industrial Marketing Management, 69(January), 198-208. https://doi.org/10.1016/j.indmarman.2017.12.017

Marshall, C., \& Rossman, G. B. (1999). Designing Qualitative Research (3.). Thousands Oaks, CA: SAGE Publications Inc.

Martin, R. (2013). Agile Software Development, Principles, Patterns, and Practices. Harlow: Pearson New International Edition.

Mason, J. (2018). Qualitative Researching (3rd.). London: SAGE Publications Ltd.

Mattson, M. (1988). How to determine the composition and influence of a buying center. Industrial Marketing Management, 17(3), 205-214. https://doi.org/10.1016/0019-8501(88)90004-1

Mayring, P. (2010). Qualitative Inhaltsanalyse. Grundlagen und Techniken (11th.). Weinheim: Beltz.

McFarland, R. G. (2003). Crisis of conscience: The use of coercive sales tactics and resultant felt stress in the salesperson. Journal of Personal Selling and Sales Management, 23(4), 313-326. Retrieved from 
http://mesharpe.metapress.com/index/cudk35khagqqg4d3.pdf

McFarland, R. G., Challagalla, G. N., \& Shervani, T. A. (2006). Influence tactics for effective adaptive selling. Journal of Marketing, 70(4), 103-117.

https://doi.org/10.1509/jmkg.70.4.103

McKay, M., \& Fanning, P. (2016). Self-Esteem (4th.). Oakland, CA: New Harbinger.

McNally, R. (2002). Simulating buying center decision processes: propositions and methodology. Journal of Business Industrial Marketing, 17(2/3), 167-180. https://doi.org/10.1108/08858620210419790

McQuiston, D. H. (1989). Novelty, Complexity, and Importance as Causal Determinants of Industrial Buyer Behavior. Journal of Marketing, 59(2), 66-79. Retrieved from http://www.jstor.org/pss/1251414

McQuiston, D. H., \& Dickson, P. R. (1991). The effect of perceived personal consequences on participation and influence in organizational buying. Journal of Business Research, 23(2), 159-177. Retrieved from http://www.sciencedirect.com/science/article/pii/014829639190026T

Meffert, H., Burmann, C., \& Kirchgeorg, M. (2018). Marketing - Grundlagen marktorientierter Unternehmensführung (13.). Wiesbaden: Gabler.

Miles, M. B., Hubermann, A. M., \& Saldana, J. (2018). Qualitative Data Analysis: A Methods Sourcebook (4th.). London: SAGE Publications Ltd.

Mintzberg, H. (1973). The Nature of Managerial Work. New York, NY: Harper \& Row.

Mintzberg, H. (1979). Patterns in Strategy Formation. International Studies of Management \& Organization, 9(3), 67-86.

Mittal, R., \& Elias, S. M. (2016). Social power and leadership in cross-cultural context. Journal of Management Development, 35(1), 58-74.

https://doi.org/10.1108/JMD-02-2014-0020

Moncrief, W. C., \& Marshall, G. W. (2005). The evolution of the seven steps of selling. Industrial Marketing Management, 34(1), 13-22.

https://doi.org/10.1016/j.indmarman.2004.06.001

Moon, M. A., \& Armstrong, G. M. (1994). Selling teams: A conceptual framework and research agenda. The Journal of Personal Selling and Sales Management, 14(1), 17-30. Retrieved from http://www.jstor.org/stable/10.2307/40471515

Moon, M. A., \& Forquer Gupta, S. (1997). Examining the Formation of Selling Centers: A Conceptual Framework. Journal of Personal Selling \& Sales Management, 17(2), 31-42. Retrieved from doi: 10.1080/08853134.1997.10754088

Müller, M. (2009). Effektives Verhalten von Vertriebsmitarbeitern im Kundenkontakt. Wiesbaden: Gabler. 
Mummalaneni, V. (1984). Group Decision-Making in the Buying Center: A PoliticalCoalitional Perspective. Advances in Consumer Research, 11, 159-164. Retrieved from http://www.acrwebsite.org/volumes/display.asp?id=6235

Murtha, B. R., Bharadwaj, S. S., \& Van den Bulte, C. (2009). Developing and Deploying Effective Customer Solutions: The Role of Networks Within and Between Buying and Selling Teams, 3603(814). Retrieved from http://www.marketingpower.com/ResourceLibrary/Documents/Content Partner Documents/ISBM/2009/Effective_Customer_Solutions.pdf

Murtha, B. R., Shervani, T. A., Challagalla, G. N., \& Kirkman, B. L. (2014). Control system diversity: Implications for selling centers th. Journal of Business Research, 67, 1870-1876. https://doi.org/10.1016/j.jbusres.2013.12.002

Nerdinger, F. (2001). Psychologie des persönlichen Verkaufs. München und Wien: Oldenbourg.

Neu, W. A., \& Brown, S. W. (2005). Forming Successful Business-to-Business Services in Goods-Dominant Firms. Journal of Service Research, 8(1), 3-17. https://doi.org/10.1177/1094670505276619

Neubauer, M. (1999). Krisenmanagement in Projekten (2.). Berlin, Heidelberg, New York: Springer-Verlag.

Neuendorf, K. A. (2002). The Content Analysis Guidebook. Thousands Oaks, CA: Sage Publications.

Nyaga, G. N., Lynch, D. F., Marshall, D., \& Ambrose, E. (2013). Power asymmetry, adaptation and collaboration in dyadic relationships involving a powerful partner. Journal of Supply Chain Management, 49(3), 42-65. https://doi.org/10.1111/jscm.12011

Oliva, R., \& Kallenberg, R. (2003). Managing the transition from products to services. International Journal of Service Industry Management, 14(2), 160-172. https://doi.org/10.1108/09564230310474138

Oliver, R. L., \& Anderson, E. (1995). Behavior- and Outcome-Based Sales Control Systems: Evidence and Consequences of Pure-Form and Hybrid Governance. The Journal of Personal Selling and Sales Management, 15(4), 1-15.

Paesbrugghe, B., Rangarajan, D., Sharma, A., Syam, N., \& Jha, S. (2017). Industrial Marketing Management Purchasing-driven sales : Matching sales strategies to the evolution of the purchasing function. Industrial Marketing Management, 62, 171-184. https://doi.org/10.1016/j.indmarman.2016.09.002

Palmatier, R. W., Dant, R. P., Grewal, D., \& Evans, K. R. (2006). Factors influencing the effectiveness of relationship marketing: a meta-analysis. Journal of Marketing, 70(October), 136-153. Retrieved from http://www.jstor.org/stable/10.2307/30162119

Papenhoff, H., Schultz, C. D., \& Welle, C. (2018). Neue Anforderungen an SellingCenter-Mitglieder. Sales Excellence, 11. 
Pardo del Val, M., \& Fuentes, C. M. (2003). Resistance to change: a literature review and empirical study. Management Decision, 41(2), 148-155.

https://doi.org/https://doi.org/10.1108/00251740310457597

Pascale, T., \& Sternin, J. (2005). Your Company 's Secret Change Agents. Harvard Business Review, 83(5), 72-81.

Patton, M. Q. (2002). Qualitative Research and Evaluation Methods (3.). Thousands Oaks, CA: SAGE Publications Inc. Retrieved from

http://books.google.com/books?hl=en\&lr=\&id=FjBw2oi8El4C\&oi=fnd\&pg=PP23\& $\mathrm{dq}=$ Qualitative+Research+and+Evaluation+and+Methods\&ots=bup3gAMDtL\&si $\mathrm{g}=0 \mathrm{f} \_$HhOL5jNzkkvaWolt1qjHB1r4

Patton, W. E. (1997). Individual and joint decision-making in industrial vendor selection. Journal of Business Research, 38(2), 115-122.

https://doi.org/10.1016/S0148-2963(96)00029-X

Pereira, G., Prada, R., \& Santos, P. A. (2013). Bases of social power for agents. 12th International Conference on Autonomous Agents and Multiagent Systems 2013, AAMAS 2013, 2(May 2013), 1289-1290.

Pesch, J. (2010). Marketing (2.). Konstanz: UVK.

Pettijohn, C. E., Pettijohn, L. S., Keillor, B. D., \& Taylor, A. J. (2011). Adaptive selling and sales performance: An empirical examination. Journal of Applied Business Research (JABR), 16(1), 91-111. Retrieved from http://cluteonline.com/journals/index.php/JABR/article/viewArticle/2031

Plouffe, C. R., Hulland, J., \& Wachner, T. (2009). Customer-directed selling behaviors and performance: a comparison of existing perspectives. Journal of the Academy of Marketing Science, 37(4), 422-439. https://doi.org/10.1007/s11747-009-0142-4

Podsakoff, P. M., \& Schriesheim, C. A. (1985). Field Studies of French and Raven 's Bases of Power: Critique, Reanalysis, and Suggestions for Future Research. Psychological Bulletin, 97(3), 387-411.

Porter, S. S., Wiener, J. L., \& Frankwick, G. L. (2003). The moderating effect of selling situation on the adaptive selling strategy-selling effectiveness relationship. Journal of Business Research, 56(4), 275-281. https://doi.org/10.1016/S0148-2963(02)00440-X

Pruitt, D. G., \& Carnevale, P. J. (2011). Negotiation in social conflict. Maidenhead Eng.: Open University Press. Retrieved from http://www.worldcat.org/title/negotiation-in-socialconflict/oclc/756907034? referer=\&ht=edition

Puto, C. P. (1987). The framing of buying decisions. Journal of Consumer Research, 14(3), 301-315. https://doi.org/10.1086/209115

Qualls, W. J., \& Puto, C. P. (1989). Organizational Climate and Decision Framing: An Integrated Approach to Analyzing Industrial Buying Decisions. Journal of 
Marketing Research, XXVI(May), 179-193.

Rackham, N. (1995). SPIN selling. New York: McGraw-Hill. Retrieved from http://scholar.google.com/scholar?hl=en\&btnG=Search\&q=intitle:SPIN+Selling\#0

Rackham, N., \& DeVincentis, J. (1998). Rethinking the sales force: Refining selling to create and capture customer value. Fortune. New York: McGraw-Hill.

Rapp, A., Agnihotri, R., \& Forbes, L. P. (2008). The Sales Force TechnologyPerformance Chain: The Role of Adaptive Selling and Effort. Journal of Personal Selling and Sales Management, 28(4), 335-350. https://doi.org/10.2753/PSS0885-3134280401

Raven, B. H. (1965). Social influence and power. In I. D. Steiner \& M. Fishbein (Eds.), Current studies in social psychology (pp. 371-382). New York: Holt, Rinehart,Winston. Retrieved from http://oai.dtic.mil/oai/oai?verb=getRecord\&metadataPrefix=html\&identifier=AD06 09111

Raven, B. H. (1992). A power/interaction model of interpersonal influence: French and Raven thirty years later. Journal of Social Behavior and Personality, 7, 217244. https://doi.org/10.1017/CBO9781107415324.004

Raven, B. H. (1993). The Bases of Power: Origins and Recent Developments. Journal of Social Issues, 49(4), 227-251. https://doi.org/10.1111/j.15404560.1993.tb01191.x

Raven, B. H. (2008). The Bases of Power and the Power/Interaction Model of Interpersonal Influence. Analyses of Social Issues and Public Policy, 8(1), 1-22. https://doi.org/10.1111/j.1530-2415.2008.00159.x

Raven, B. H., Schwarzwald, J., \& Koslowsky, M. (1998). Conceptualizing and measuring a power/interaction model of interpersonal influence. Journal of Applied Social Psychology, 28(4), 307-332. https://doi.org/10.1111/j.15591816.1998.tb01708.x

Rentz, J. O., Shepherd, C. D., Tashchian, A., Dabholkar, P. A., \& Ladd, R. T. (2002). A Measure of Selling Skill : Scale Development and Validation. Journal of Personal Selling \& Sales Management, 22(1), 13-21. https://doi.org/10.1080/08853134.2002.10754289

Robinson, P. J., Faris, C. W., \& Wind, Y. (1967). Industrial buying and creative marketing. Boston, MA: Allyn \& Bacon. Retrieved from http://www.getcited.org/pub/101247878

Robson, C. (2002). Real World Research (2.). Oxford: Blackwell.

Rolfes, L. (2007). Die Rolle des Verwenders im Buying-Center: das Beispiel der Beschaffung und Vermarktung biotechnologischer Verbrauchsprodukte. Wiesbaden: DUV. Retrieved from http://books.google.com/books?id=ORdmE8AtNeYC\&pgis=1 
Román, S., \& lacobucci, D. (2009). Antecedents and consequences of adaptive selling confidence and behavior: a dyadic analysis of salespeople and their customers. Journal of the Academy of Marketing Science, 38(3), 363-382. https://doi.org/10.1007/s11747-009-0166-9

Ronchetto Jr, J. R., Hutt, M. D., \& Reingen, P. H. (1989). Embedded influence patterns in organizational buying systems. The Journal of Marketing, 53(4), 5162. https://doi.org/10.2307/1251379

Rotter, J. B. (1971). Generalized expectancies for interpersonal trust. American Psychologist, 26, 443-452. Retrieved from http://psycnet.apa.org/journals/amp/26/5/443/

Rutschmann, M. (2005). Kaufprozesse von Konsumenten erkennen und lenken: Mehr Marktanteil mit neuem Marketing (1.). Heidelberg: mi-Fachverlag.

Sahadev, S. (2005). Exploring the role of expert power in channel management: An empirical study. Industrial Marketing Management, 34(5), 487-494. https://doi.org/10.1016/j.indmarman.2004.11.002

Santos Soares, M., \& Vrancken, J. (2008). Model-Driven User Requirements Specification using SysML. Journal of Software, 3(6), 57-68.

Sarantakos, S. (1998). Social Research (2.). South Yarra: Macmillan Education Autralia PTY Ltd.

Saunders, M., Lewis, P., \& Thornhill, A. (2015). Research Methods for Business Students (7.). Essex: Financial Times Prent.

Sawhney, M. (2006). Going Beyond the Product: Defining, Designing and Delivering Customer Solutions. In R. F. Lusch \& S. L. Vargo (Eds.), The Service-Dominant Logic of Marketing (pp. 365-380). Armonk: M. E. Sharpe.

Saxe, R., \& Weitz, B. A. (1982). The SOCO scale: a measure of the customer orientation of salespeople. Journal of Marketing Research, 19(3), 343-351. Retrieved from http://www.jstor.org/stable/10.2307/3151568

Schlosser, A. E., Barnett White, T., \& Lloyd, S. M. (2006). Converting Web Site Visitors into Buyers: How Web Site Investment Increases Consumer Trusting Beliefs and Online Purchase Intentions. Journal of Marketing, 70(2). Retrieved from https://doi.org/10.1509/jmkg.70.2.133

Schmitz, G. (2008). Der wahrgenommene Wert hybrider Produkte: Konzeptionelle Grundlagen und Komponenten. In Multikonferenz Wirtschaftsinformatik (pp. 665-683). München. Retrieved from http://scholar.google.com/scholar?hl=en\&btnG=Search\&q=intitle:Der+wahrgeno mmene+Wert+hybrider+Produkte+:+Konzeptionelle+Grundlagen+und+Kompone nten\#0

Schmitz, G., \& Dietz, M. (2009). Empowerment als ganzheitliches Managementkonzept zur Steuerung der individuellen Lösungskompetenz bei Lösungsanbietern: Wirkungsmechanismen und Implementierung. Retrieved from 
http://www.msm.uni-

due.de/fileadmin/Dateien/Retailing/Publikationen/Empowerment_als_ganzheitlic hes_Managementkonzept_zur_Steuerung_der_individuellen_Loesungskompete nz_bei_Loesungsanbietern.pdf

Schmitz, G., \& Eberhardt, S. (2009). Die individuelle Lösungskompetenz bei Lösungsanbietern - Konzeptionelle Grundlagen und unternehmensspezifische Diagnose. Retrieved from http://www.msm.unidue.de/fileadmin/Dateien/Retailing/Publikationen/Diskussionsbeitrag_MSM_Nr_ 345.pdf

Scholl, W. (1999). Restrictive control and information pathologies in organizations. Journal of Social Issues, 55(1), 101-118. https://doi.org/10.1111/00224537.00107

Schreier, M. (2012). Qualitative Content Analysis in Practice. London: SAGE Publications Ltd.

Schwarzwald, J., \& Koslowsky, M. (1999). Gender, self-esteem, and focus of interest in the use of power strategies by adolescents in conflict situations. Journal of Social Issues, 55, 15-32.

Schwarzwald, J., Koslowsky, M., \& Agassi, V. (2001). Captain's leadership type and police officers' compliance to power bases. European Journal of Work and Organizational Psychology, 10(3), 273-290. https://doi.org/10.1080/13594320143000672

Schwarzwald, J., Raven, B. H., \& Bui, K. H. (1994). Interpersonal satisfaction and influence tactics in close heterosexual relationships. Journal of Social Behaviour and Personality, (9), 429-442.

Seligman, M. E., \& Schulman, P. (1986). Explanatory style as a predictor of productivity and quitting among life insurance sales agents. Journal of Personality and Social Psychology, 50(4), 832-838.

https://doi.org/10.1037//0022-3514.50.4.832

Seufert, J., \& Suhren, L. (2016). Reach for the cloud - The HR software market looks to 2020. Munich. Retrieved from www.rolandberger.com

Shanteau, J. (1987). Psychological Characteristics of Expert Decision Makers. In J. L. Mumpower, L. D. Phillips, O. Renn, \& V. R. R. Uppuluri (Eds.), Expert Judgement and Expert Systems (pp. 289-304). Berlin: Springer-Verlag. https://doi.org/10.1007/978-3-642-86679-1

Shanteau, J. (1992). Competence in experts: The role of task characteristics. Organizational Behavior and Human Decision, 53(2), 252-266. Retrieved from http://www.sciencedirect.com/science/article/pii/074959789290064E

Shanteau, J., \& Peters, J. M. (1989). The 3 C 's of Expert Audit Judgment : Creativity , Confidence, and Communication The 3 C's. In T. Mock (Ed.), USC Audit Judgment Symposium. University of Southern California School of Accountancy. 
Shanteau, J., \& Stewart, T. R. (1992). Why Study Expert Decision Making? Some Historical Perspectives and Comments. Organizational Behavior and Human Decision Processes, 53, 95-95. Retrieved from http://www.albany.edu/cpr/stewart/Papers/ShanteauStewartExpert-1992.pdf

Shanteau, J., Weiss, D. J., Thomas, R. P., \& Pounds, J. (2003). How Can You Tell If Someone Is an Expert? Performance based assessment of expertise. European Journal Of Operational Research, 136(2), 253-263. https://doi.org/10.1016/S0377-2217(01)00113-8

Sharma, A. (1990). The persuasive effect of salesperson credibility: conceptual and empirical examination. Journal of Personal Selling \& Sales Management, 10, 71-80.

Shepherd, C. D., Miles, M. P., \& Munilla, L. S. (2011). Strategic Sales Conversations As A Foundation For Effective Partnership Selling. Journal of Business \& Economics Research (JBER), 7(2), 1-8. Retrieved from http://journals.cluteonline.com/index.php/JBER/article/viewArticle/2256

Sheth, J. N. (1973). A model of industrial buyer behavior. The Journal of Marketing, 50-56. Retrieved from http://www.jstor.org/stable/10.2307/1250358

Sheth, J. N. (1976). Buyer-seller interaction: A conceptual framework. Advances in Consumer Research, 3(1), 382-386. Retrieved from http://www.acrwebsite.org/volumes/display.asp?id=9295

Sheth, J. N. (1996). Organizational Buying Behavior: Past Performance and Future Expectations. Journal of Business \& Industrial Marketing, 11(3/4), 7-24. Retrieved from http://www.emeraldinsight.com/journals.htm?articleid=856672\&amp;show=abstr act

Shin, H., Collier, D. A., \& Wilson, D. D. (2000). Supply management orientation and supplier/buyer performance. Journal of Operations Management, 18(3), 317333. Retrieved from http://www.sciencedirect.com/science/article/pii/S0272696399000315

Silk, A. J., \& Kalwani, M. U. (1982). Measuring influence in organizational purchase decisions. Journal of Marketing Research, 24, 165-181. Retrieved from http://www.jstor.org/pss/3151617

Silverman, D. (2009). Doing Qualitative Research (3rd.). London: Sage Publications.

Silverman, D. (2020). Interpreting Qualitative Data (6th.). London: SAGE Publications Ltd.

Sirdeshmukh, D., Singh, J., \& Sabol, B. (2002). Consumer Trust, Value, and Loyalty in Relational Exchanges. Journal of Marketing, 66(1), 15-37. https://doi.org/10.1509/jmkg.66.1.15.18449

Smith, J. B., \& Barclay, D. W. (1989). Theoretical perspectives on selling center research. National Centre for Management Research and Development, 


\section{University of Western Ontario.}

Sonnentag, S., \& Lange, I. (2002). The relationship between high performance and knowledge about how to master cooperation situations. Applied Cognitive Psychology, 16(5), 491-508. https://doi.org/10.1002/acp.805

Spiegel-Verlag. (1982). Der Entscheidungsprozess bei Investitionsgütern.

Spiro, R. L., \& Perreault Jr, W. D. (1979). Influence use by industrial salesmen: Influence-strategy mixes and situational determinants. Journal of Business, 52(3), 435-455.

Spiro, R. L., \& Weitz, B. A. (1990). Adaptive selling: Conceptualization, measurement, and nomological validity. Journal of Marketing Research, 27(1), 61-69. Retrieved from http://www.jstor.org/stable/10.2307/3172551

Stafford, T. F., \& Sharma, A. (2000). The Effect of Retail Atmospherics on Customers' Perceptions of Salespeople and Customer Persuasion: An Empirical Investigation. Journal of Business Research, 49(99), 183-191.

Stock, R. M., \& Hoyer, W. D. (2005). An Attitude-Behavior Model of Salespeople's Customer Orientation. Journal of the Academy of Marketing Science, 33(4), 536-552. https://doi.org/10.1177/0092070305276368

Stoddard, J. E., \& Fern, E. F. (2002). Buying group choice: The effect of individual group member's prior decision frame. Psychology and Marketing, 19(1), 59-90. https://doi.org/10.1002/mar.1002

Stolle, R., \& Herrmann, M. (2006). Angebotsmanagement professionell: Erfolgreich vom Angebot bis zum Vertragsschluss. Berlin: Erich Schmidt.

Strauss, A. L., \& Corbin, J. M. (1998). Basics of Qualitative Research: Techniques and Procedures for Developing Grounded Theory (2.). Newbury Park, CA: SAGE Publications Inc.

Stübinger, V., \& Grimm, F. (2018). ITK Märkte.

Sujan, H. (1999). Optimism and Street-Smarts: Identifying and Improving Salesperson Intelligence. The Journal of Personal Selling and Sales, XIX(3), 1733. Retrieved from http://www.jstor.org/stable/10.2307/40471731

Sujan, H., Weitz, B. A., \& Sujan, M. (1988). Increasing Sales Productivity by Getting Salespeople to Work Smarter. Journal of Personal Selling and Sales Management, 8(2), 9-19. Retrieved from http://warrington.ufl.edu/mkt/docs/weitz/Increasing_Sales.pdf

Swan, J. E., Bowers, M. R., \& Richardson, L. D. (1999). Customer Trust in the Salesperson: An Integrative Review and Meta-Analysis of the Empirical Literature. Journal of Business Research, 44(2), 93-107. Retrieved from http://www.sciencedirect.com/science/article/pii/S0148296397002440

Szymanski, D. M. (1988). Determinants of Selling Effectiveness: The Importance of 
Declarative Knowledge to the Personal Selling Concept. Journal of Marketing, 52(January), 64-77.

Tanner, J. F. (1999). Organizational buying theories a bridge to relationships theory. Industrial Marketing Management, 28(3), 245-255. Retrieved from http://www.sciencedirect.com/science/article/pii/S0019850198000522

Taylor, A. (2007). Learning to Become Researching Professionals: The Case of the Doctorate of Education. International Journal of Teaching and Learning in Higher Education, 19, 154-166.

Taylor, J. L., \& Woodside, A. G. (1982). Effects on buying behavior of references to expert and referent power. The Journal of Social Psychology, 117, 25-31. Retrieved from http://www.tandfonline.com/doi/abs/10.1080/00224545.1982.9713403

Thomas, G. (2015). How to do Your Case Study (2.). London: SAGE Publications Ltd.

Thompson, K., Mitchell, H., \& Knox, S. (1998). Organizational Buying Behaviour in Changing Times. European Mmanagement Journal, 16(6), 698-705.

Thull, J. (2012). Mastering the complex sale (2.). Hoboken, NJ: John Wiley and Sons.

Ticehurst, G. W., \& Veal, A. J. (2000). Business research methods : a managerial approach. Retrieved from

http://trove.nla.gov.au/work/9206344?q\&sort=holdings+desc\&_=1509614206984 \&versionld $=45757879+210552413$

Töllner, A., Blut, M., \& Holzmüller, H. H. (2011). Customer solutions in the capital goods industry: Examining the impact of the buying center. Industrial Marketing Management, 40(5), 712-722. https://doi.org/10.1016/j.indmarman.2011.06.001

Trinity College Dublin. (2019). Informed Consent. Retrieved from https://www.tcd.ie/swsp/assets/pdf/Participant consent form template.pdf

Tsujimoto, M., Kajikawa, Y., Tomita, J., \& Matsumoto, Y. (2018). Technological Forecasting \& Social Change A review of the ecosystem concept - Towards coherent ecosystem design. Technological Forecasting \& Social Change, 136(June 2017), 49-58. https://doi.org/10.1016/j.techfore.2017.06.032

Tuli, K. R., Kohli, A., \& Bharadwaj, S. G. (2007). Rethinking customer solutions: From product bundles to relational processes. Journal of Marketing, 71(3), 1-17. Retrieved from http://www.journals.marketingpower.com/doi/abs/10.1509/jmkg.71.3.1

Tversky, A., \& Kahneman, D. (1981). The Framing of Decisions and the Psychology of Choice. Science, 211(4481), 453-458. Retrieved from http://www.sciencemag.org/content/211/4481/453.short

Ulaga, W. (2003). Capturing value creation in business relationships: A customer perspective. Industrial Marketing Management, 32(8), 677-693. 
https://doi.org/10.1016/j.indmarman.2003.06.008

Ulaga, W., \& Eggert, A. (2006). Value-based differentiation in business relationships: Gaining and sustaining key supplier status. Journal of Marketing, 70(January), 119-136. Retrieved from http://www.journals.marketingpower.com/doi/abs/10.1509/jmkg.2006.70.1.119

Ulaga, W., \& Kohli, A. (2018). The role of a solutions salesperson: Reducing uncertainty and fostering adaptiveness. Industrial Marketing Management, 69, 161-168. https://doi.org/10.1016/j.indmarman.2017.11.008

Ulaga, W., \& Sharma, A. (2001). Complex and Strategic Decision Making in Organizations: $1::$ Implications for Personal Selling and Sales Management. Industrial Marketing Management, 30(5), 427-440. Retrieved from http://www.sciencedirect.com/science/article/pii/S0019850199000991

University of Gloucestershire. (2018). Research Ethics : A Handbook of Principles and Procedures. Retrieved from https://www.glos.ac.uk/docs/download/Research/handbook-of-principles-andprocedures.pdf

Vakratsas, D., \& Ambler, T. (1999). How advertising works: what do we really know? The Journal of Marketing, 63(1), 26-43. Retrieved from http://www.jstor.org/stable/10.2307/1251999

Vargo, S. L., \& Lusch, R. F. (2004). Evolving to a New Dominant Logic for Marketing. Journal of Marketing, 68(January), 1-17. Retrieved from http://www.jstor.org/stable/10.2307/30161971

Vering, O. (2007). Systematische Auswahl von Unternehmenssoftware. In J. Becker, O. Vering, \& A. Winkelmann (Eds.), Softwareauswahl und -einführung in Industrie und Handel (pp. 61-108). Berlin, Heidelberg: Springer.

Vos, J. F. J., \& Rupert, J. (2018). Change agent' s contribution to recipients ' resistance to change : A two- sided story. European Management Journal, 36(4), 453-462. https://doi.org/10.1016/j.emj.2017.11.004

Webster, F. E., \& Wind, Y. (1972). A general model for understanding organizational buying behavior. The Journal of Marketing, 12-19. Retrieved from http://www.jstor.org/stable/10.2307/1250972

Weeks, W. A., Roberts, J., Chonko, L. B., \& Jones, E. (2004). Organizational Readiness for Change, Individual Fear of Change, and Sales Manager Performance: An Empirical Investigation. Journal of Personal Selling \& Sales Management, 24(1), 7-17.

Weitz, B. A. (1978). Relationship between salesperson performance and understanding of customer decision making. Journal of Marketing Research, XV, 501-516. Retrieved from http://www.jstor.org/stable/10.2307/3150621

Weitz, B. A., \& Bradford, K. D. (1999). Personal Selling and Sales Management: A Relationship Marketing Perspective. Journal of the Academy of Marketing 
Science, 27(2), 241-254. https://doi.org/10.1177/0092070399272008

Weitz, B. A., Sujan, H., \& Sujan, M. (1986). Knowledge, motivation, and adaptive behavior: A framework for improving selling effectiveness. The Journal of Marketing, 50(4), 174-191. Retrieved from http://www.jstor.org/stable/10.2307/1251294

Wengler, S., Ehret, M., \& Saab, S. (2006). Implementation of Key Account Management: Who, why, and how? An exploratory study on the current implementation of Key Account Management programs. Industrial Marketing Management, 35(1), 103-112. https://doi.org/10.1016/j.indmarman.2005.08.011

Williams, K. C., \& Spiro, R. L. (1985). Communication style in the salespersoncustomer dyad. Journal of Marketing Research, 22(4), 434-442. Retrieved from http://www.jstor.org/stable/10.2307/3151588

Wilson, D. T. (1995). An integrated model of buyer-seller relationships. Journal of the Academy of Marketing Science, 3004(814). Retrieved from http://www.springerlink.com/index/K281456KGNJ13452.pdf

Wilson, E. J., Lilien, G. L., \& Wilson, D. T. (1991). Developing and Testing a Contingency Paradigm of Group Choice in Organizational Buying. Journal of Marketing Research, 28(4), 452. https://doi.org/10.2307/3172785

Wilson, E. J., McMurrian, R. C., \& Woodside, A. G. (2001). How buyers frame problems: revisited. Psychology and Marketing, 18(6), 617-655. https://doi.org/10.1002/mar.1023

Wilson, E. J., \& Vlosky, R. P. (1997). Partnering Relationship Activities : Building Theory from Case Study Research. Journal of Business Research, 39(1), 59-70. Retrieved from http://www.sciencedirect.com/science/article/pii/S014829639600149X

Wilson, E. J., \& Woodside, A. G. (1995). The relative importance of choice criteria in organizational buying: Implications for adaptive selling. Journal of Business to Business Marketing, 2, 33-58.

Winkelmann, P. (2012). Vertriebskonzeption und Vertriebssteuerung - Die Instrumente des integrierten Kundenmanagements (CRM) (5.). München: Vahlen.

Wiswede, G. (2007). Einführung in die Wirtschaftspsychologie (4.). München: Ernst Reinhardt.

Witte, E. (1976). Kraft und Gegenkraft im Entscheidungsprozess. Zeitschrift Für Betriebswirtschaft, 46(4/5), 319-326. Retrieved from http://scholar.google.com/scholar?hl=en\&btnG=Search\&q=intitle:Kraft+und+Geg enkraft+im+Entscheidungsprozess\#0

Witte, E. (1999). Das Promotoren-Modell. In J. Hauschildt \& H. G. Gemünden (Eds.), Promotoren: Champions der Innovation (2., pp. 9-41). Klagenfurt: Gabler. 
Woisetschläger, D., Backhaus, C., \& Michaelis, M. (2009). Solution Selling: Wie der Wandel zum Lösungsanbieter gelingt. In M. Borchert, E. Heinen, \& K. ZühlkeRobinet (Eds.), Systematische Gestaltung von Leistungen und Prozessen in $K M U$ - Voraussetzung für erfolgreiche Internationalisierung von Dienstleistungen (pp. 57-78). Karlsruhe: Verlag Dr. Jochen Heizmann. Retrieved from http://www.dienstleistungsexport.de/data/Systematische_Gestaltung_von_Leistu ngen_und_Prozessen_in_KMU.pdf\#page $=58$

Wolf, H., \& Bleek, W. G. (2011). Agile Softwareentwicklung: Werte, Konzepte und Methoden (2nd.). Heidelberg: dpunkt.verlag.

Woodside, A. G., \& Davenport Jr., W. (1974). The Effect of Salesman Similarity and Expertise on Consumer Purchasing Behavior. Journal of Marketing Research, XI(May), 198-202.

Wotruba, T. R. (1991). The evolution of personal selling. The Journal of Personal Selling and Sales Management, 11(3), 1-12. Retrieved from http://www.jstor.org/stable/10.2307/40471435

Wren, B. M., \& Simpson, J. T. (1996). A dyadic model of relationships in organizational buying: a synthesis of research results. Journal of Business \& Industrial Marketing, 11(3/4), 63-79. https://doi.org/10.1108/08858629610125478

Wynn, A. T. (2019). Change without an agent: What happens when change agents leave? Organizational Dynamics, (May). https://doi.org/10.1016/j.orgdyn.2019.04.009

Xiong, L., King, C., \& Piehler, R. (2013). “That's not my job”: Exploring the employee perspective in the development of brand ambassadors. International Journal of Hospitality Management, 35, 348-359.

Yin, R. K. (2018). Case Study Research and Applications: Design and Methods (6.). Thousands Oaks, CA: SAGE Publications Ltd.

Yukl, G., \& Falbe, C. M. (1990). Influence Tactics and Objectives in Upward, Downward, and Lateral Influence Attempts. Journal of Applied Psychology, 75(2), 132-140. https://doi.org/10.1037/0021-9010.75.2.132

Yukl, G., \& Falbe, C. M. (1991). Importance of Different Power Sources in Downward and Lateral Relations. Journal of Applied Psychology, 76(3), 416-423. https://doi.org/10.1037//0021-9010.76.3.416

Yukl, G., \& Tracey, J. B. (1992). Consequences of Influence Tactics Used With Subordinates, Peers, and the Boss. Journal of Applied Psychology, 77(4), 525535. https://doi.org/10.1037/0021-9010.77.4.525

Zhao, X., Huo, B., Flynn, B. B., \& Yeung, J. H. Y. (2008). The impact of power and relationship commitment on the integration between manufacturers and customers in a supply chain. Journal of Operations Management, 26(3), 368388. https://doi.org/10.1016/j.jom.2007.08.002 


\section{Appendices}

\section{Informed Consent}

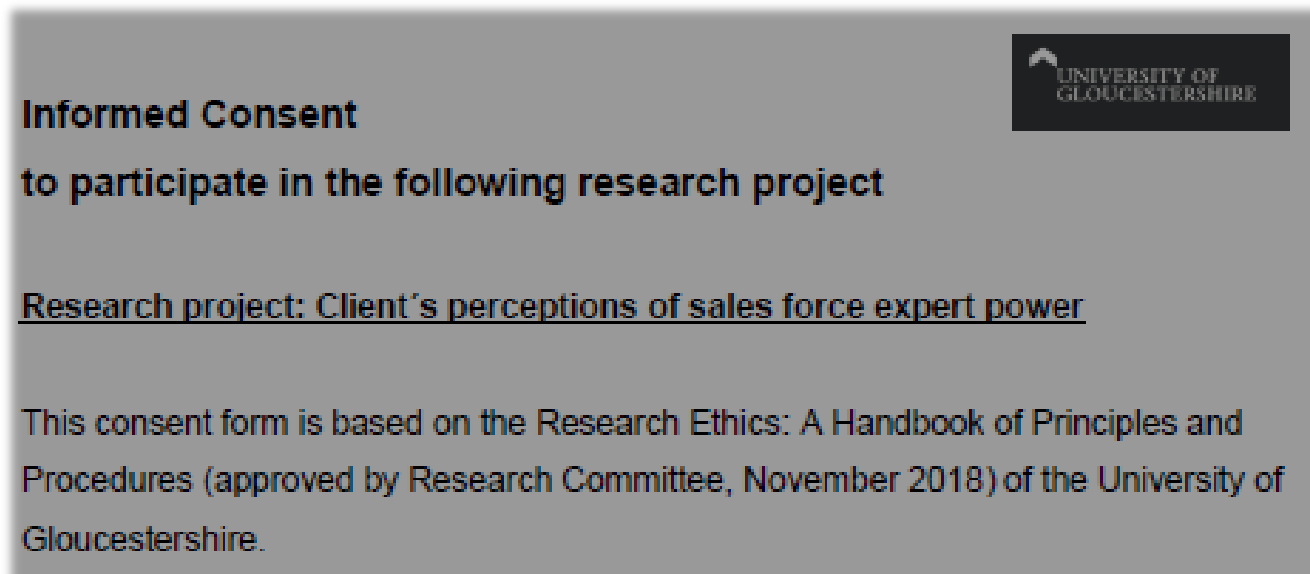

- I. voluntarily agree to participate in this research study.

- I understand that even if I agree to participate now, I can withdraw at any time or refuse to answer.

- any question without any consequences of any kind.

- I understand that I can withdraw permission to use data from my interview within two weeks after the interview, in which case the material will be deleted.

- I have had the purpose and nature of the study explained to me in writing and I have had the opportunity to ask questions about the study.

- I understand that participation involves an interview on the buying interactions with the sales force of Alpha Software.

- I understand that I will not benefit directly from participating in this research.

- I agree to my interview being audio-recorded.

- I understand that all information I provide for this study will be treated confidentially.

- I understand that in any report on the results of this research my identity will remain anonymous. This will be done by changing my name and disguising any details of my interview which may reveal my identity or the identity of people I speak about or the company I am employed.

- I understand that disguised extracts from my interview may be quoted in the dissertation.

- I understand that signed consent forms and original audio recordings will be retained with security arrangements until the exam board confirms the results of the dissertation. 
- I understand that a transcript of my interview in which all identifying information has been removed will be retained for two years from the date of the exam board.

- I understand that under freedom of information legalisation I am entitled to access the information I have provided at any time while it is in storage as specified above.

- I understand that I am free to contact any of the people involved in the research to seek further clarification and information.

Researcher

Stefan Fricke

Email:

\section{Research Ethics Committee}

Dr. Emily Ryall

Telephone: $+44(0) 1242$

Email:

https://orcid.org/0000-0002-6050-4353

Signature of research participant

Signature of participant

Date

Signature of researcher

I believe the participant is giving informed consent to participate in this study.

Signature of researcher

Date

Figure 52: Informed consent - Page two

Source: Developed for this research project based on the Research Ethics (University of Gloucestershire, 2018) and a template of Trinity College Dublin (2019) 


\section{Interview Agenda}

Interview Agenda - Client's perceptions of sales force expert power

1. Introductions (3 mins)

2. Interview Process (2 mins)

- Data collection process (recorded or note-taking)

- Semi-structured interview

- Interview response framework

3. Informed Consent Form (2 mins)

4. Research Topic \& Methodology (3 mins)

- Introduction/background/thesis topic

- Research design

5. Interview (recorded - refer Interview Structure) (100 mins)

6. Closing Comments (10 mins)

Total anticipated time: 120 mins

Figure 53: Interview agenda

Source: Developed for this research project

\section{Interview Structure}

\section{Interview Structure - Client's perceptions of sales force expert power}

Case study book

A. Company facts (completed with client)

B. Participant facts (completed with client)

C. Evaluation of client requirements (completed with client)

I. Attributes of the perceptions of sales force expert power 25 mins

II. Formation of the perceptions of sales force expert power 25 mins

III. Factors affecting the formation of the perception of sales force expert power $\quad 25$ mins

IV. Tips/ Suggestions $10 \mathrm{mins}$

Anticipated total interview time: 100 mins

Figure 54: Interview structure

Source: Developed for this research project 


\section{Interview Guide}

Interview Guide - Clients' perceptions of sales force expert power

\begin{tabular}{|c|c|c|}
\hline \multicolumn{3}{|c|}{ 1. Attributes of the perceptions of sales force expert power } \\
\hline \# & Question & Additional questions/ Comments \\
\hline Q1 & What is your understanding of sales force expert power? & \\
\hline \multicolumn{3}{|l|}{$\mathrm{A} 1$} \\
\hline Q2 & $\begin{array}{l}\text { Which attributes do you use to describe sales force expert } \\
\text { power? }\end{array}$ & Examples? Experiences? \\
\hline \multicolumn{3}{|l|}{ A2 } \\
\hline Q3 & How important is sales force expert power for you? & Why did you choose Alpha Software? \\
\hline \multicolumn{3}{|l|}{ A3 } \\
\hline Q4 & What is the basis for your buying decision? & Could you please describe the structure? \\
\hline \multicolumn{3}{|l|}{ A4 } \\
\hline Q5 & $\begin{array}{l}\text { To what extent is the buying decision based on sales force } \\
\text { expert power? }\end{array}$ & What about the remaining percentages? \\
\hline \multicolumn{3}{|l|}{ A5 } \\
\hline Q6 & $\begin{array}{l}\text { Did you have doubts regarding the sales force expert power } \\
\text { during the buying process? Was there a moment when sales } \\
\text { force expert power was disturbing? }\end{array}$ & $\begin{array}{l}\text { How did you handle the situation? How could this disturbance } \\
\text { be remedied? }\end{array}$ \\
\hline \multicolumn{3}{|l|}{ A6 } \\
\hline Q7 & Has the sales force noticed the disturbance? & How did the sales force adjust their actions? \\
\hline \multicolumn{3}{|l|}{ A7 } \\
\hline Q8 & $\begin{array}{l}\text { Would you make a decision, if you doubt the sales force's } \\
\text { expert power? }\end{array}$ & $\begin{array}{l}\text { What do you expect from the sales force so you are able to } \\
\text { make a decision? }\end{array}$ \\
\hline \multicolumn{3}{|l|}{ A8 } \\
\hline \multicolumn{3}{|c|}{ II. Formation of the perceptions of sales force expert power } \\
\hline \# & Question & Additional questions/ Comments \\
\hline Q9 & Could you please describe your decision process? & $\begin{array}{l}\text { Could you please describe the phases or could you please } \\
\text { describe the several steps until the buying decision is made? }\end{array}$ \\
\hline \multicolumn{3}{|l|}{ A9 } \\
\hline Q10 & $\begin{array}{l}\text { When and how did the perceptions of sales force expert } \\
\text { power arise for the first time? }\end{array}$ & $\begin{array}{l}\text { To what extent did the first contact with the Alpha software differ } \\
\text { with the contacts to the other suppliers? }\end{array}$ \\
\hline \multicolumn{3}{|l|}{ A10 } \\
\hline Q11 & $\begin{array}{l}\text { What intensifies or diminishes the perceptions of sales force } \\
\text { expert power? }\end{array}$ & \\
\hline \multicolumn{3}{|l|}{ A11 } \\
\hline Q12 & $\begin{array}{l}\text { Is sales force expert power equally important in every process } \\
\text { step? }\end{array}$ & $\begin{array}{l}\text { When is sales force expert power more important? When is } \\
\text { sales force expert power less important? Which attributes? Are } \\
\text { they changing in the process? }\end{array}$ \\
\hline \multicolumn{3}{|l|}{ A12 } \\
\hline Q13 & $\begin{array}{l}\text { How did you perceive the sales force in the process and how } \\
\text { satisfied were you with it? }\end{array}$ & Was the number of sales pitches appropriate? \\
\hline A13 & & \\
\hline
\end{tabular}

Table 61: Interview guide - Part one

Source: Developed for this research project 
III. Factors affecting the formation of the perception of sales force expert power

\begin{tabular}{|c|c|c|}
\hline \# & Question & Additional questions/ Comments \\
\hline Q14 & $\begin{array}{l}\text { Which factors affect the formation of sales force expert } \\
\text { power? }\end{array}$ & Could you please give examples? \\
\hline \multicolumn{3}{|l|}{$\mathrm{A} 14$} \\
\hline Q15 & $\begin{array}{l}\text { Is the power and the position of the salesperson in the } \\
\text { supplier company of importance for you? }\end{array}$ & $\begin{array}{l}\text { Which ratings and quotas of the sales force have become known } \\
\text { and have you considered? }\end{array}$ \\
\hline \multicolumn{3}{|l|}{ A15 } \\
\hline Q16 & $\begin{array}{l}\text { How intensively did the sales force address the different } \\
\text { participants of the buying centre? }\end{array}$ & $\begin{array}{l}\text { How well did you feel supported and involved in the buying } \\
\text { process by the sales force? }\end{array}$ \\
\hline \multicolumn{3}{|l|}{ A16 } \\
\hline Q17 & Which sales force recommendations did you accept? & What impact did the recommendations have on your decision? \\
\hline \multicolumn{3}{|l|}{ A17 } \\
\hline Q18 & Which factors are also important for your buying decision? & \\
\hline \multicolumn{3}{|l|}{ A18 } \\
\hline \multicolumn{3}{|c|}{ IV. Tips/ Suggestions } \\
\hline \# & Question & Additional questions/ Comments \\
\hline Q19 & What could the sales force have done better? & Comments? Suggestions? \\
\hline \multicolumn{3}{|l|}{ A19 } \\
\hline Q20 & What tips would you give the sales force along the way? & \\
\hline A20 & & \\
\hline
\end{tabular}

Table 62: Interview guide - Part two

Soure: Developed for this research project 


\section{Case Study Book}

Case Study Book - Clients' perceptions of sales force expert power

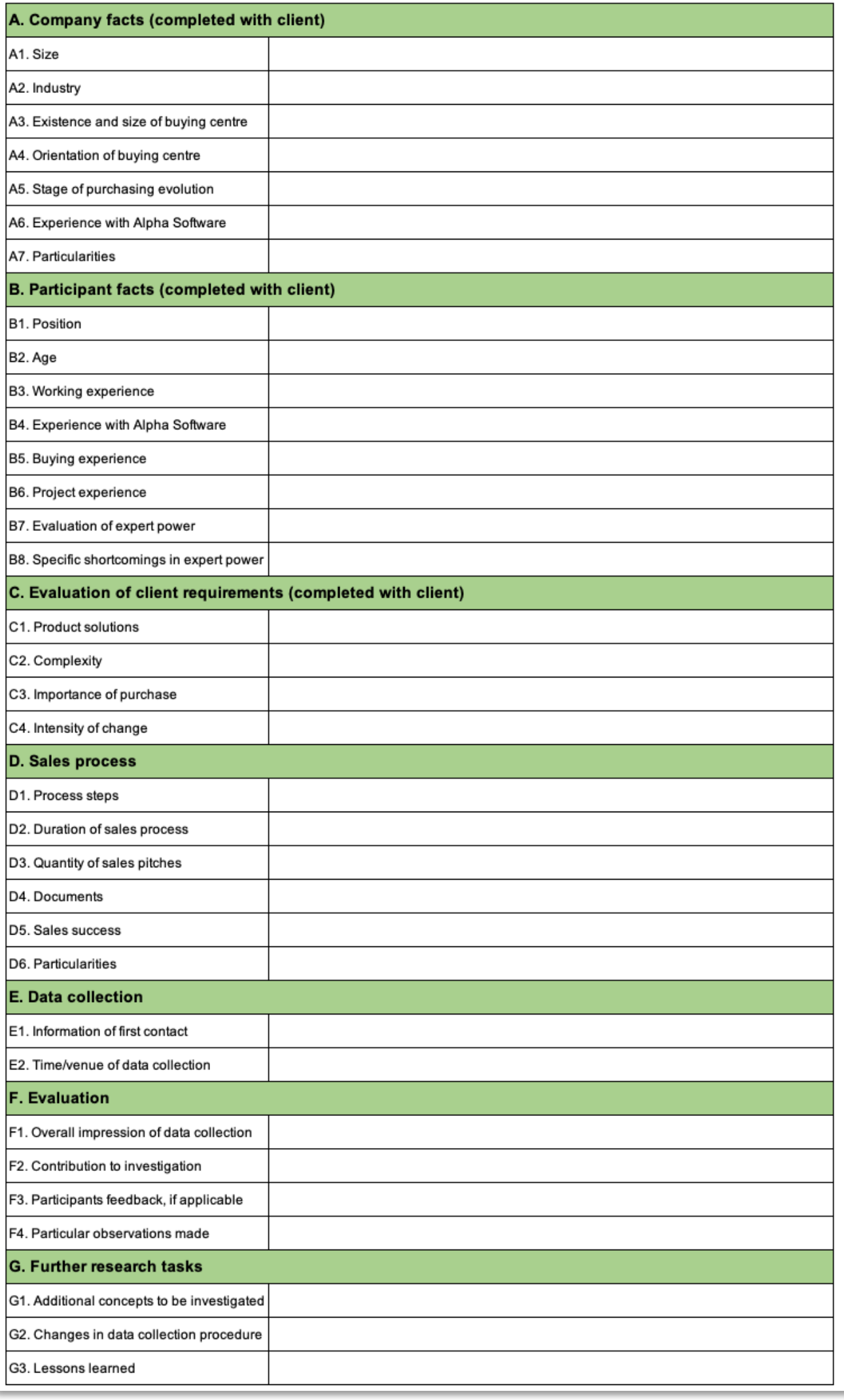

Table 63: Case study book

Source: Developed for this research project 